\title{
Mapa y Cédula Escolar como dispositivos de planificación y gestión de políticas públicas educativas
}

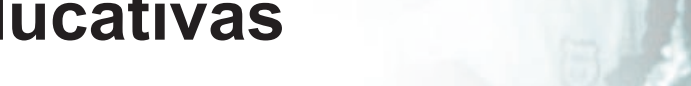



Mapa y Cédula Escolar como dispositivos de planificación y gestión de políticas públicas educativas

Maestría en Planificación y Gestión de Procesos Comunicacionales (PLANGESCO)

UNIVERSIDAD NACIONAL DE LA PLATA

Facultad de Periodismo y Comunicación Social

Tesis de maestría

Aspirante: María Elisa Ghea

Director: Luciano Pedro Sanguinetti 



\section{INDICE}

Prólogo

\section{Presentación}

1.a) El sistema educativo bonaerense en el contexto de la sociedad de la información.

1.b) El recorrido profesional que concluyó en la selección del tema.

2. Planteamiento del problema

2.a) La inscripción de una experiencia de la gestión pública en un proyecto político pedagógico democratizador.

\section{MARCo teórico}

3.a) La importancia del tema.

3.b) La comunicación como alternativa al poder hegemónico.

3.c) Algunas definiciones conceptuales.

3.d) Estado de Situación. El Mapa de la educación desde una perspectiva Latinoamericana.

3.e) La situación de América Latina en el marco de la sociedad de la Información y las TIC: nuevas y viejas fronteras.

3.f) Argentina y el cambio de paradigma. Sociedad del conocimiento y tecnologismo. Estado y políticas educativas.

3.g) Una pequeña digresión: otros dispositivos tecnológicos que pueden enseñarnos algo. 
4.b) La legislación argentina en materia de sociedad de la información.

4.c) La sociedad de la información en el marco de la discusión de la Ley de Servicios de Comunicación Audiovisual. Todas las voces.

5. MAPA Y CÉdula Escolar COMO heRRAMIENTAS DE LA INFORMACIÓN

5.a) La provincia de Buenos Aires y el contexto nacional.

5.b) Las políticas nacionales que impulsan el uso de las herramientas de la sociedad de la información aplicadas al campo educativo.

5.c) El nacimiento de Mapa y Cédula Escolar: prácticas y discursos.

5.d) ¿Qué es el Mapa Escolar?

5.e) Periodo 2001-2005. Crisis y gobernabilidad.

5.f) Reforma administrativa, planeamiento estratégico, prospectiva y difusión de las políticas.

5.g) Una nueva etapa. La inscripción de Cédula y Mapa Escolar en la gestión 2005-2007: Educar en, desde y para la democracia en la formación de sujetos plenos de derechos.

5.h) Números, datos y personas. Nancy y sus hijos.

5.i) Institucionalización del Mapa y la Cédula Escolar.

5.j) ¿Cómo utilizar el Mapa Escolar?

5.k) La aplicación en los cambios de los diseños curriculares.

5.I) La articulación con otros dispositivos de la comunicación

Plan de Trabajo -Dirección de Comunicación y Prensa- Dirección General de Cultura y Educación de la provincia de Buenos Aires e Informe de la gestión en el área.

8. Glosario de Mapa y CÉdula Escolar 


\section{PRÓLOGO}

El trabajo de investigación para la tesis "Mapa y Cédula Escolar como dispositivos de planificación y gestión de políticas públicas educativas" que presenta la periodista, comunicóloga y educadora María Elisa Ghea motiva numerosos intereses abriendo ante el lector los intrincados problemas que atraviesan y vinculan los procesos comunicacionales con la educación en el marco de la Sociedad de la Información y de los procesos políticos actuales.

El objeto de análisis se circunscribe a la provincia de Buenos Aires, pero bien puede tomarse como ejemplo de numerosas experiencias que se realizan en el nivel nacional y en varias jurisdicciones.

Su investigación sobre el Mapa Escolar y la Cédula Escolar, que se implementaran en la provincia de Buenos Aires como herramientas de planificación, gestión y comunicación en instituciones de la administración pública, cumple con la necesidad de investigadores, docentes y políticos de informarse acerca no sólo del avance que se verifica en la digitalización de la información educativa en el país sino, además, de programas existentes a los cuales pueden acceder o que pueden ser modelo para el desarrollo de insumos de información que aportan significativamente a la puesta en marcha de políticas públicas institucionales, provinciales o regionales.

En este particular, la autora se interesa en verificar los efectos de los dispositivos de información y comunicación como herramienta en la toma de decisiones para la planificación y gestión de las políticas educativas, manteniendo su atención, simultáneamente, en tres planos: el empírico, el político y el teórico. Se interesa por las "nuevas categorías y voces que reclaman la necesidad de construir una nueva ciudadanía comunicacional, en la cual la escuela y los dispositivos que pueda crear el Estado tendrán un rol decisivo".

El inteligente enfoque de la autora denuncia cambios acerca del poder en la relación entre comunicación y educación, "en la medida en que el poder se vuelve comunicacional". La relación entre procesos comunicacionales y desigualdad social es una de las preocupaciones que surgen del texto. El uso democrático de instrumentos como el Mapa Escolar y la Cédula Escolar permiten acceder a la situación real de las escuelas, a la marcha de los programas y, en buena medida, a conocer la distribución real de la educación en la población en edad escolar. Los instrumentos que facilitan el acceso a la información sobre el sistema escolar son 
indispensables para transparentar las situaciones reales que este último va atravesando. En la actualidad pueden proporcionarnos una información muy valiosa acerca de los efectos de la Asignación Universal por Hijo, sobre el cumplimiento de la obligatoriedad escolar y colaborar en su aplicación. En un futuro cercano sería deseable que se alcanzara una mayor articulación entre las herramientas comunicacionales provinciales, nacionales y de la región latinoamericana.

María Elisa Ghea aborda también la cuestión de las nuevas fronteras que han surgido más allá de la territorialidad, signadas por el grado de acceso a los medios de comunicación, y puntualiza como un lugar de especial interés su articulación con la educación. Examinar la validez de los instrumentos comunicacionales para hacer luz sobre los procesos de discriminación, los límites institucionales y los resultados de planes educativos de inclusión requiere, efectivamente, de un trabajo de vinculación teórica y política entre información, educación y estudios sobre fronteras sociales y culturales.

Otro aporte importante del trabajo de investigación para esta tesis que realiza la autora, son los interrogantes que plantea. Nos enfrenta a preguntas muy inquietantes, tales como si es posible pensar la transformación pedagógica y política sin tener en cuenta a las tecnologías digitales, el rol que juega la capacitación en ese sentido y el problema ético de la relación entre la demanda de información y la difusión democrática, entre otros. Pero también se pregunta sobre en qué medida intervienen los diferentes actores: las instituciones educativas, los directivos, los docentes, la comunidad en su conjunto y cómo hacer que esta comunidad sea un actor fundamental no sólo para la puesta en práctica en el campo concreto del territorio educativo del proyecto, sino además, un actor que se apropie verdaderamente de éste.

Por último el trabajo de tesis "Mapa y Cédula Escolar como dispositivos de planificación y gestión de políticas públicas educativas", tiene el valor de sintetizar un consistente y elaborado marco teórico que manifiesta reflexiones personales valiosas, con la amplia y exitosa experiencia de la autora en la planificación, dirección y ejecución de políticas comunicacionales en educación. Se trata de un texto de lectura indispensable para quienes trabajan, estudian y enseñan en el espacio sin límites de la educación y la comunicación.

\section{Adriana Puiggrós}

Buenos Aires, junio de 2010 


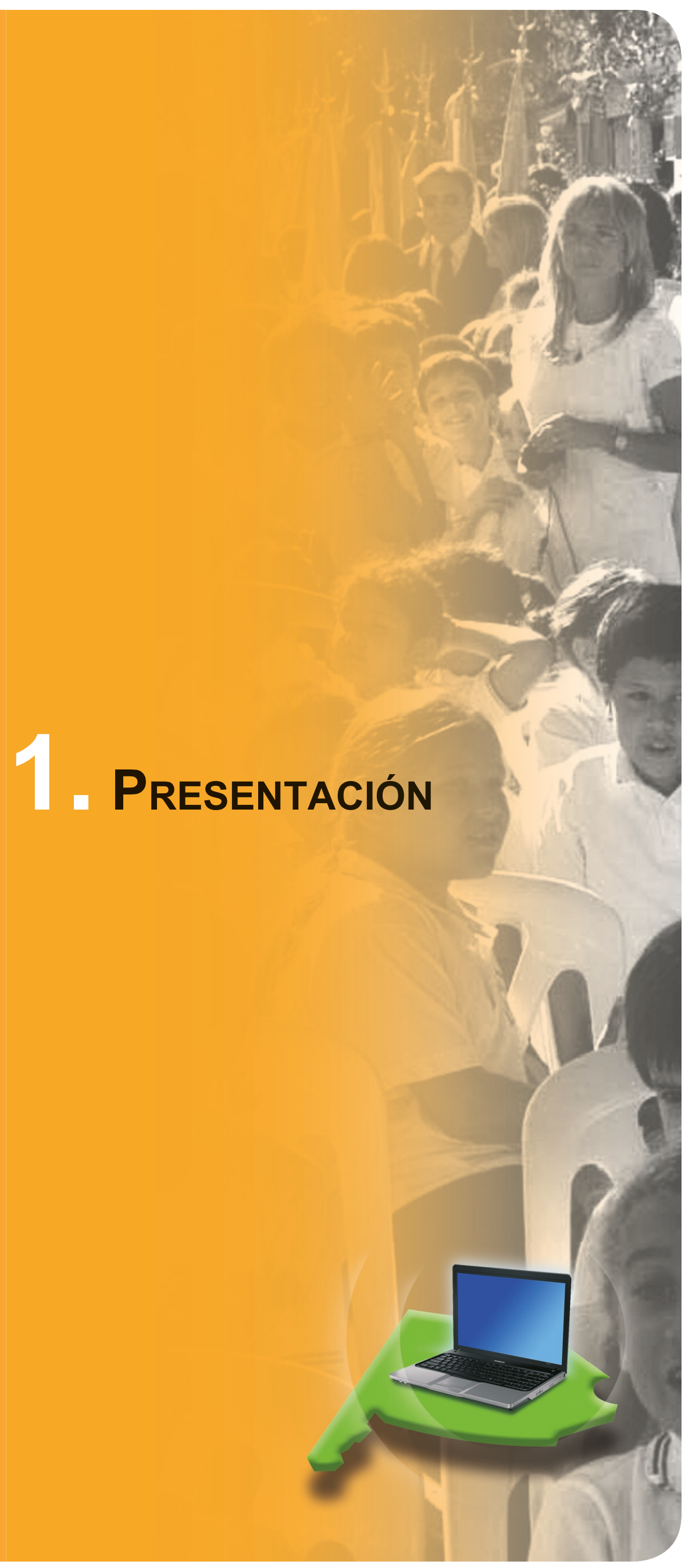





\title{
Presentación
}

\author{
"Ya veremos cómo trató Creso al pobre Gutiérrez, no \\ bien consolidó su reinado, y a qué se redujeron las \\ famosas 'libertades' tan cacareadas por el Hombrecito \\ Económico."(Leopoldo Marechal, Autopsia de Creso, 1965)
}

"Mapa y Cédula Escolar como dispositivos de Planificación y Gestión de políticas públicas educativas", es un trabajo de tesis que propone abordar la conformación de sociedades de la información mediante la selección y análisis de determinadas herramientas informativas particulares como Mapa y Cédula Escolar, dos dispositivos comunicacionales de estadística y relevamiento de datos, elaborados en el año 2000 para conocer, comprender y planificar las políticas en el sistema educativo de la provincia de Buenos Aires. Como veremos en el capítulo 5 , estos dispositivos creados a los efectos de solucionar detrminados problemas coyunturales que había detectado la recién llegada gestión de José Octavio BORDón se pusieron en marcha en 2001 y se convertirían, con el tiempo, en importantes herramientas de información.

Para contextualizar el tema se realizará un análisis de los procesos políticos, sociales, económicos y culturales, en especial a partir de la crisis económica, política e institucional que sufrió la Argentina en 2001 para llegar al contexto actual, que constituyeron los últimos años de la gestión pública en el área educativa, en particular, en la provincia de Buenos Aires, y que de alguna manera signaron los proyectos políticos-pedagógicos del presente.

La propuesta es verificar si estos dispositivos han contribuido, y en tal caso, en qué medida, como insumos informativos para la toma de decisiones en materia de planificación y gestión de políticas educativas desde su puesta en marcha en 2001, tomando como ejes algunos de los principales interrogantes planteados en el transcurso de la elaboración del trabajo referidos a las vinculaciones y tensiones entre la sociedad de la información con los procesos educativos:

- ¿Es posible pensar la transformación pedagógica y política sin considerar "los saberes técnicos" y el uso de las tecnologías digitales? ${ }^{1}$

1 Puiggrós, Adriana y Gagliano, Rafael (Dirección) La fábrica del conocimiento. Los saberes socialmente productivos en América Latina, HomoSapiens, Buenos Aires, 2004, pág. 28. 
- ¿Se puede sostener en el tiempo herramientas tecnológicas que permitan la construcción, acceso, y distribución de esa información sin capacitación?

- ¿Se pueden generar nuevos espacios en ese sentido sin inversión acorde?

- ¿La democracia en la información consiste en darle a los sujetos lo que estos demandan?

- ¿Y acaso es posible demandar algo diferente a lo que se está en condiciones de demandar? En tal sentido, es necesario poner en contexto los supuestos teóricos y político-pedagógicos de los que se parte, así como dar cuenta no sólo del posicionamiento teórico asumido, sino también de la perspectiva histórica y política desde la que se efectúan estos enunciados y de la que surgen los interrogantes.

En primer lugar, para el abordaje analítico de este proyecto político-pedagógico de Mapa y Cédula Escolar — dos dispositivos informativos que relevan información de los sujetos y del sistema, tales como la ubicación de los edificios escolares, la matrícula, la planta docente, etc., están en el contexto de lo que implica la conducción política de uno de los sistemas educativos más grandes y complejos de América Latina-, se debe considerar como primordial realizar un recorrido histórico político, económico y social, desde la asunción de José Octavio Bordón al frente de la Dirección de Cultura y Educación de la provincia de Buenos Aires en el año 2000, ${ }^{2}$ pasando por la gestión de Mario OPORTo, ${ }^{3}$ hasta la culminación de la gestión en el mismo cargo de Adriana PuIGgrós en diciembre de $2007 .{ }^{4}$

En el caso de la gestión de José Octavio Bordón, el país y sin excepción la provincia de Buenos Aires, comenzaba a sentir los fuertes latigazos sobre la estructura social del modelo económico-político implementado en los 90 , con todo lo que significó la reforma educativa que se plasmó en la ley Federal de Educación.

A Mario OpoRto, por su parte, le tocó comenzar el proceso de conducción del sistema educativo provincial en medio de una de las mayores crisis y convulsiones económicas que la Argentina haya sufrido en las dos últimas décadas. Los dos años al frente de la cartera educativa bonaerense a cargo de la doctora PUIGGRós y su equipo de trabajo, estuvieron signados sobre una concepción y una gestión que se fundó en derechos, plasmada, en gran medida, en nuevos corpus jurídicos — tanto en el nivel nacional como en el provincial-y, en particular a los fines de este trabajo, lo referido al derecho a la información y a la educación:

Aun después de décadas de implementación de políticas neoliberales y desinversión, la tradición y la conciencia de la sociedad argentina sobre la necesidad de defender la escuela pública, gratuita y obligatoria, así como la responsabilidad indelegable y principal del Estado

\footnotetext{
2 José Octavio Bordón ocupó el cargo entre diciembre de 1999 y octubre de 2000, siendo Carlos Ruckauf gobernador de la Provincia.

3 Tras la renuncia de Bordón asumió como Director General, en noviembre de 2000, Mario Oporto, quien hasta ese momento había ocupado el cargo de Subsecretario de Educación. Al poco tiempo, en enero de 2002 y tras el estallido de la crisis que terminó con la gestión de Fernando De la Rúa como Presidente, Ruckauf renunció a la gobernación y fue reemplazado por su vicegobernador, Felipe Solá. Luego de la asunción de la Dra. Puiggrós en 2005, Oporto fue designado como Jefe de Gabinete del gobernador Solá y en la actualidad ocupa nuevamente el cargo de Director General de Cultura y Educación.

4 La Doctora Adriana Puiggrós fue designada como Directora General de Cultura y Educación de la provincia de Buenos Aires el 
en esta materia, permiten confiar en que podamos asumir, con un amplio sentido crítico y democrático, la oportunidad para el debate y la intervención soberana sobre nuestro presente y nuestro futuro como Nación, que nos ofrece el proceso de cambio de la Ley Nacional de Educación. ${ }^{5}$

En tal sentido, se comparte el concepto de lo que Verónica Piovani y Analía Elíades entienden como contexto político en lo que se refiere a acceso y uso de nuevas tecnologías y sociedad de la información.

[...] en el escenario del desarrollo capitalista presente, dentro del cual estas tecnologías desempeñan un importante papel. Por supuesto, comprendiendo que el momento actual no representa una ruptura, sino que "[...] el capitalismo cambia constantemente, y que ese proceso de transformación incesante es y ha sido dirigido, desde el principio, por una "lógica del proceso" perfectamente inteligible; lo que se manifiesta tanto en su expansión global como en la constante alteración de las condiciones sociales". ${ }^{6}$

Al mismo tiempo, se funda en la afirmación de la Declaración de Principios de la cumbre Mundial sobre la Sociedad de la Información Ginebra 2003-Túnez 2005 (disponible en Internet), que en su primer punto sostiene

[...] nuestro deseo y compromiso comunes de construir una Sociedad de la Información centrada en la persona, integradora y orientada al desarrollo, en que todos puedan crear, consultar, utilizar y compartir la información y el conocimiento, para que las personas, las comunidades y los pueblos puedan emplear plenamente sus posibilidades en la promoción de su desarrollo sostenible y en la mejora de su calidad de vida, sobre la base de los propósitos y principios de la Carta de las Naciones Unidas y respetando plenamente y defendiendo la Declaración Universal de Derechos Humanos.

Sobre esta base, el presente trabajo procura comprender esos procesos a fin de poner en contexto el proceso de la comunicación en instituciones gubernamentales en el marco de las herramientas que pueden utilizarse - Mapa y Cédula Escolar, en este caso—no sólo con el objetivo de construir sentidos colectivos dentro de una institución y como dispositivos importantes para la planificación y gestión de políticas públicas, sino a su vez como comunicación emancipadora y constitutiva de sociedades de la información más democráticas. ¿Pero a qué nos referimos al hablar de sociedades de la información más democráticas? Este posicionamiento implica una concepción acerca del rol del Estado de signo contrario al que se le había asignado durante la etapa de la hegemonía neoliberal, cuyo punto culminante fue, en el nivel mundial, el Consenso de Washington en el que durante los años 90 los organismos financieros internacionales establecieron un programa de ajustes para los países latinoamericanos en esa ciudad. De tener el talento de Marechal, (citado en el epígrafe del comienzo), quizá se podría hablar del rol que le compete al Estado para controlar y limitar las ambiciones de Creso en beneficio del "pobre Gutiérrez" ${ }^{7}$

5 Puiggrós, Adriana, "Principales cambios curriculares en el sistema educativo provincial", Editorial revista Anales de la educación común, Filosofía política del currículum, Publicación de la Dirección General de Cultura y Educación de la provincia de Buenos Aires, Tercer siglo, año 2, número 4, agosto 2006, en http://abc.gov.ar/lainstitucion/revistacomponents/revista/default.cfm?ldP=5\& page=Editorial\&IdArticulo=193, sitio consultado en octubre 2009.

6 Piovani, Verónica, Eliades, Analía, "Internet y Sociedad de la Información. La concepción política-social y económica de Internet en Argentina y su expresión jurídico institucional", en http://s3.amazonaws.com/lcp/alaic-internet/myfiles/Veronica\%20Piovani\%20 y\%20Aanalia\%20Eliades\%20\%28Argentina\%29.pdf, sitio consultado en octubre 2009.

7 La referencia alude una vez más a la Autopsia de Creso, en la que Marechal realiza una particular crítica filosófica a los sistemas de organización y dominación que el poder ha asumido en distintas etapas históricas, simbolizando Creso (el "hombrecito económico") el prototipo del burgués surgido tras la Revolución francesa y principal impulsor del capitalismo. Creso actúa, como icono del modelo signado por la ambición desmedida de riquezas materiales (lo que hoy llamaríamos el mercado), en detrimento de los derechos del "pobre Gutiérrez", que representa al trabajador oprimido por éste. En el texto de Marechal el límite exterior a la ambición de Creso debe estar marcado y controlado por el Estado. 
En la Argentina, la concepción neoliberal se impuso como producto de un largo proceso que se inició varias décadas atrás y que, con el golpe de 1976, adquirió características de tragedia y vino a legitimar, no sin un amplio consenso de diversos sectores de la sociedad civil (otra vez Creso, para seguir al maestro Marechal), esa larga tradición liberal y privatista fundada en la idea de que el mercado debía avanzar, incluso, en la educación pública. Esta concepción no era nueva, por el contrario, ya estaba presente en los postulados de la llamada Revolución Libertadora de 1955. De este modo se llega a la etapa democrática que se inició en 1983 con la visible tensión entre esta postura que se ha mencionado y aquella que sostenía los principios de una educación democrática, común, laica, popular y universal.

En ése concepto se apoyó la operación de desvalorización de la educación pública o estatal, que había sido tan apreciada por la sociedad argentina durante más de un siglo, para establecer un campo confuso, en el cual se diluyen las responsabilidades. De ese modo los principios contenidos en la Ley Federal de Educación abrieron la posibilidad de penetración del mercado en el campo de la educación pública, perjudicando tanto a la educación estatal como a la educación privada de interés social. ${ }^{8}$

La aplicación de estas políticas ha tenido consecuencias desastrosas en todas las sociedades del mundo globalizado, y aún no es posible estimar el potencial daño de sus más recientes coletazos, manifestados de manera violenta con la crisis financiera internacional originada en los Estados Unidos y que estalló en 2008. A escala mundial se configuraron sociedades fragmentadas que han expulsado a millones de hombres y mujeres de toda posibilidad de subsistencia, afectando de manera particular a los niños, niñas y jóvenes; un ambiente degradado y seriamente dañado por la actividad de un capitalismo de mercado que no reconoce límites; espacios públicos expropiados por corporaciones lucrativas que se convirtieron en monopolios u oligopolios como grandes grupos de poder, así como altísimos niveles de militarización con la excusa de la autodefensa, de la lucha contra el terrorismo y el narcotráfico y con el disfraz de la defensa de liberar a las naciones de las manos de los dictadores.

\section{Estos procesos globales tuvieron amplia repercusión en todaAmérica Latina. Con anterioridad, el colapso} de 2001 configuró a la Argentina como un caso emblemático, analizado por numerosos especialistas internacionales, lo que puso en evidencia el "rotundo fracaso de la hegemonía y dominación del proyecto neoliberal en el mundo." En ese contexto, la sociedad argentina padeció el "incremento de la heterogeneidad y polarización social", ${ }^{10}$ la ruptura de las redes solidarias y de transferencia generacional de saberes en las prácticas laborales,$^{11}$ todo ello en medio de un proceso de quiebre de las identidades políticas colectivas, de pérdida de ciudadanía y de los espacios de participación y de acercamiento de los grandes partidos nacionales con sectores de gran concentración económica. A su vez, esta "conculcación de derechos sociales redefinió de facto los límites de pertenencia a la comunidad, en el sentido amplio del término" y condujo "a la proliferación de luchas en torno al reconocimiento de la existencia, doblemente amenazada por los actuales procesos de globalización."12

8 Cfr. "1er Jornada de Debate Movimiento por la Educación Nacional y popular, 24-8-09”, pág. 110, en http://www.scribd.com/doc/ 21140111/1er-Jornada-de-Debate-MENyP-24-8-09, sitio consultado en octubre 2009.

9 Giroux, Henry, "El neoliberalismo y la crisis de la democracia", revista Anales de la educación común, Tercer siglo, Año 1, números 1-2, septiembre 2005, publicación de la DGcyE de la provincia de Buenos Aires, pág. 75.

10 Svampa, Maristella, La sociedad excluyente. La Argentina bajo el signo del neoliberalismo, Taurus, Buenos Aires, 2005, pág. 25. 11 Ver al respecto: Puiggrós, Adriana y Gagliano, Rafael (Dirección): La fábrica del conocimiento. Los saberes socialmente productivos en América Latina, Ediciones Homo Sapiens, Rosario, año 2004.

12 Svampa, Maristella, Ibídem, pág. 77. 
En paralelo a estas transformaciones nacieron nuevos movimientos sociales de resistencia al modelo hegemónico neoliberal, muchos de los cuales asumieron algunas de las responsabilidades de las que el Estado se había retirado. Un ejemplo de ello fue el surgimiento de las organizaciones "piqueteras", originadas en sectores de desocupados a los que el modelo neoliberal había expulsado del mercado laboral y que llevaron adelante una lucha que no se limitó a hacer visibles sus demandas laborales, sino también se propuso denunciar los profundos niveles de injusticia existentes en la distribución de los bienes materiales y simbólicos y se hizo cargo mediante la organización de sus integrantes, de actividades/roles que le competían al Estado, por ejemplo las escuelas de gestión social.

Todo este proceso económico, social y político, que vino a poner en cuestión los fundamentos mismos del contrato social en las sociedades democráticas contemporáneas tuvo su correlato en materia cultural y educativa, en tanto avanzaba, fundada en la visión del libre mercado, una transformación tecnológica de los medios de comunicación masivos sin precedentes, transformación de la que es imposible soslayar el impacto de la masificación de Internet.

No se pretende desarrollar aquí esta cuestión en profundidad, pero cabe mencionar, sólo como un ejemplo por demás elocuente del impacto cultural y político de las Tecnologías de la Información y la Comunicación (TIC), las implicaciones que en la sociedad de la información ha tenido y tiene, en los últimos años el buscador Google, presentado por sus patrocinadores como "el gran campeón de la democracia" digital, ${ }^{13}$ el paradigma de este nuevo orden hegemónico impuesto en la sociedad global. Esta verdadera operación cultural se funda en la construcción de un sistema informático basado en un algoritmo (celosamente mantenido en secreto por sus desarrolladores) por completo adecuado a la lógica del mercado: la perfecta adaptación de la oferta a la demanda como sinónimo de democracia y, en tal sentido, la voluntad de información deviene siempre en voluntad de más información (como consumo, no como construcción colectiva) "por analogía con la voluntad de poder". ${ }^{14}$

Entre paréntesis, vale la pena mencionar que la palabra "informática" proviene del vocablo francés informatique, como acrónimo de information y automatique (información y automática). De acuerdo a la RAE, se trata de un "Conjunto de conocimientos científicos y técnicas que hacen posible el tratamiento automático de la información por medio de ordenadores", es decir, esta definición en sí problematiza la categoría misma de la sociedad de la información en la que, de manera superficial, podría pretenderse que la información se genera de forma automática y neutra.

Google puede educar su manera de preguntar para que su pedido sea más apropiado a la manera en que funciona el motor y usted encuentre más rápido las respuestas que le interesan, pero no puede ni quiere educar su demanda ni su tipo de interés, sobre los cuales, por el contrario, se apoya para satisfacerlo mejor. ${ }^{15}$

Como para completar la complejidad de esta trama, inscrita en la lógica de las

13 Cassin, Bárbara, Googléame. La segunda misión de los Estados Unidos, Fondo de Cultura Económica, Buenos Aires, 2008. pág. 67.

14 Cassin, Ibídem, pág. 63.

15 Ibidem, pág. 72. 
transformaciones culturales que impone el capitalismo, no cabe duda que el mundo está asistiendo a una serie de luchas y alianzas en el nivel global que modifican las relaciones de poder entre las empresas de comunicación, ya sean de televisión, telefonía, productoras de hardware y de software, que parecen querer reducir el rol del ciudadano en un mero consumidor o usuario, que queda las más de las veces, atrapado en la lógica distributiva empresaria:

Vivimos en un mundo donde nos hacen creer que el usuario es el rey, que es él quien elige lo que quiere. Eso no es cierto porque solo podemos elegir lo que nos ofrecen. La cadena de distribución tiene un poder increíble porque es esta cadena la que decide lo que el usuario final puede ver o no puede ver. ${ }^{16}$

Lógica distributiva que a la vez impacta en la cotidianeidad de los sujetos y las comunidades; en su capacidad de "apropiarse" de la información y los contenidos disponibles; en la percepción del tiempo y del espacio e incluso, en los roles y el discurso legal, tanto dentro como fuera de las instituciones educativas, de los adultos y los niños, niñas y adolescentes, a la vez que desdibuja los límites tradicionales.

Hoy el discurso legal concibe al niño como un ciudadano de pleno derecho que no debe esperar a ser mayor de edad para expresar sus opiniones y participar en las decisiones que lo afectan. La TV y la tecnología lo ponen en contacto más temprano con temas hasta hace poco concebidos como privativos del mundo adulto e ingresan antes en el mercado de consumo, a partir de una oferta para el público infantil que creció en los últimos 20 años. Y la tecnología les permite crear nuevos espacios propios.

No obstante, según las especialistas "la novedad de estos tiempos no es la emergencia de una nueva definición de lo que es ser adulto y ser niño, sino la movilidad y la variabilidad de los atributos que corresponden a una y otra posición. Saber y no saber, autonomía y heteronomía, debilidad y cuidado, son rasgos que ya no definen dicotómicamente la adultez y la niñez, sino que pueden desplazarse y combinarse de maneras diferentes en distintas situaciones y condiciones". ${ }^{17}$

En este mismo escenario han surgido nuevas categorías y voces $-\mathrm{y}$ un claro ejemplo de ello es la masividad en el uso de las redes sociales en Internet- que reclaman la necesidad de construir una nueva ciudadanía comunicacional, en la cual la escuela y los dispositivos que pueda crear el Estado, tendrán un rol decisorio, tal como expresa la Carta de Porto Alegre emitida el último febrero, tras la realización del congreso latinoamericano y caribeño realizado en esas ciudad brasilera entre el 3 y el 7 de febrero de 2010:

[...] una "ciudadanía comunicacional que, en el marco de los procesos políticos y culturales, permita la participación creativa y protagónica de las personas como forma de eliminar la concentración de poder de cualquier tipo para, así, construir y consolidar nuevas democracias". Se trata, afirmaron, "de una nueva ciudadanía comunicativa que contribuya a la plena vigencia de los derechos humanos y de las condiciones de una vida digna.[...] Reclamaron también a los "responsables de la gestión del Estado" para que sean "capaces de llevar adelante políticas públicas y estrategias de comunicación destinadas a asegurar el derecho a la comunicación a través de acciones pertinentes y efectivas que eliminen las diferencias y las desigualdades que hoy existen en materia de producción, acceso y circulación de todo tipo de bienes culturales". ${ }^{18}$

16 Cfr. Febbro, Eduardo, "Guerra real entre gigantes virtuales, diario Página 12", 15 de marzo de 2010, en http:// www.pagina12.com.ar/diario/sociedad/3-142029-2010-03-15.html, sitio consultado en marzo 2010

17 Cfr. "Pequeños ciudadanos que se expresan y consumen", en diario Clarín, 21 de diciembre de 2009, en http://www.clarin.com/ diario/2009/12/21/sociedad/s-02105116.htm, sitio consultado marzo 2010.

18 Cfr. Uranga, Washington, "Ciudadanía comunicacional", diario Página 12", 10 de febrero de 2010, en http://www.pagina12.com.ar/ diario/sociedad/3-142029-2010-03-15.html, sitio consultado en marzo 2010. 


\title{
1.a) El Sistema educativo bonaerense EN EL CONTEXTO DE LA SOCIEDAD DE LA INFORMACIÓN.
}

\author{
“ ¿Cual es la conexión entre estos dos elementos decisivos de \\ la vida social contemporánea, lo global y lo informacional? \\ La comunicación. Esta permite que la información tenga \\ "alcance global [...] La comunicación es el vínculo conector \\ entre lo informacional y lo global. En este sentido, ¿nuestra \\ unidad de análisis acaso deba ser la comunicación y no la \\ información?" (Scott, Lash, Crítica de la Información) ${ }^{19}$
}

En este orden, destacado por Scott LASH en la cita que antecede, es que puede inscribirse la perspectiva del derecho a la información y a la educación en la que se sustenta el modelo comunicacional propuesto, dentro de un proyecto político-pedagógico democratizador como Mapa y Cédula escolar y tomando como base los interrogantes planteados al comienzo para intentar aquí, entonces, un primer recorrido analítico.

Recuperar la visibilidad, en tanto sujetos de derecho, de amplios sectores de la sociedad argentina es recuperar la palabra, la participación política y una distribución democrática de la información. Pero esto no puede reducirse a una consigna discursiva puesto que si no se llevan adelante y se institucionalizan los dispositivos, los medios y las herramientas que hagan posible esta participación, en particular para aquellos que han sido más duramente castigados por las políticas de exclusión, no será posible construir una sociedad más democrática que al mismo tiempo que planifica su futuro pueda recuperar los saberes y las prácticas socialmente productivas.

En este sentido, pensar en procesos que son al mismo tiempo movimientos de desarrollo y de participación en instituciones públicas en las que las prácticas democráticas se han venido desarrollando de manera desigual, supuso principalmente una decisión, en particular de los funcionarios a cargo de la conducción del sistema educativo, que promoviera mecanismos efectivos de participación y protagonismo para todos los actores: de los propios funcionarios de las diferentes áreas, pero, sobre todo, de los docentes, de los auxiliares, los niños, niñas, jóvenes y adultos. ¿Por qué? Porque este es el modo de distribuir el poder en las instituciones de la democracia, ya que

El surgimiento y la multiplicación de representaciones a partir de la superestructura y
hacia la infraestructura también significa la ubicuidad de la comunicación: la ubicuidad
de las comunicaciones. Que los medios están en todos lados significa que también las
comunicaciones están por todos lados. Los medios son, obviamente, los medios masivos
de comunicación. La ontologización de las representaciones nos depara la ubicuidad de las
comunicaciones. Las comunicaciones también son movimientos: movimientos de mensajes
de A a B, de gente de A a B. Los capitalistas también se han escapado de la dominación a
través de la identidad y del ser del objeto fijo (es decir los medios de producción) y están
controlando el movimiento, el devenir de los medios de comunicación. Estamos compelidos
a comunicarnos. Estamos condenados a movernos. Somos propulsados a representar. Hay
una pulsión a la representación, a la representación crónica e incesante.
En la medida en que el poder se vuelve ontológico y escapa del ser al movimiento, el poder
se vuelve comunicacional. Los medios y las comunicaciones (incluyendo el transporte) 
siempre reúnen a los seres desde una distancia. Encontramos sentido al mundo a través de nuestra orientación en el movimiento que atraviesa las representaciones de ayer, que se están transformando en la materia-imagen de hoy. Pero todo el tiempo, en realidad estamos a merced de su movimiento, su cartografía: burlonamente, es la materia-imagen de esas representaciones-devenidas-medios la que nos encuentra sentido a nosotros. ${ }^{20}$

En segundo lugar, y para la delimitación del tema Mapa y Cédula en la Gestión de Adriana PuIGgRós, es importante destacar que este proceso se inscribió en una concepción pedagógica determinada por la vocación de promover la participación en la escuela y de la escuela en la comunidad. Esta situación requiere abrir los ámbitos y los espacios tradicionales en los que transcurren los procesos comunicacionales y de enseñanza-aprendizaje del sistema educativo "formal", a efectos de generar la participación de otros actores de la comunidad: familias, sindicatos, cooperadores, organizaciones sociales, iglesias, empresas, entre otros.

Tal como sostiene LASH, así como en la sociedad industrial-capitalista el poder era controlado por quienes sustentaban la propiedad de los medios de producción, y esto generaba la explotación de los trabajadores (proletariado), en la sociedad de la información el poder es el control simbólico y material de las comunicaciones, lo que genera la exclusión. ${ }^{21}$

Por otra parte, en el caso del campo que abarca el sistema educativo de la provincia de Buenos Aires, como en otros, conviven diferentes sectores, con diferentes necesidades, con múltiples experiencias e identidades culturales muchas veces en contradicción, que no siempre son reconocidas como tales, tal como afirma BAUMAN:

Probablemente, lo que evitó que los pensadores griegos utilizasen la palabra cultura en plural, al margen del contenido que le atribuyesen, fue su postulado incuestionable sobre la naturaleza básicamente innata de los modos de vida, lo que concedía un papel menor a los procesos educativos. El educador era como una comadrona que facilitaba el parto, la aparición de un producto, no su creación. Fueran las que fuesen sus virtudes, el inconformismo y el rechazo de las situaciones establecidas no se encontraban entre ellas. Probablemente se podría interpretar esta aceptación asumida de la unidad armoniosa entre el proceso activo de crecimiento o perfeccionamiento individual y la existencia de parámetros supuestamente inmutables e imposibles de manipular como una reflexión filosófica nacida en el seno de una comunidad culturalmente uniforme y estrechamente entrelazada. Sin embargo, y a pesar de que se detesten esta clase de burdas explicaciones sociológicas, parece haber una base sólida sobre la que defender el rol epistemológicamente restrictivo de una integración social muy desarrollada. Toparse con diferencias culturales no requiere decir forzosamente que se perciban como tales; y percibirlas no implica conferir automáticamente un estatus existencial equivalente a los diversos estilos de vida contradictorios. ${ }^{22}$

En consecuencia, intentando conferirles un estatus-existencia, una política comunicacional democratizadora y centrada en los sujetos de derecho precisa de mecanismos de diálogo con los diferentes actores sociales que son, en definitiva, quienes pueden llevar adelante las transformaciones. Esa transformación a su vez debe traspasar los muros institucionales para crear puentes entre Estado y sociedad y no deberían dejarse de lado las particularidades del

20 Lash, Scott, "De las representaciones a los medios. La contradicción de la representación", conferencia, en http:// www.exargentina.org/ txt/krise slash_representationmedia_es.html, sitio consultado diciembre 2009.

21 Lash, Scott, Ibidem.

22 Bauman, Zygmunt, La cultura como praxis, Ediciones Paidós Ibérica, Barcelona, España, 2002, pág. 119. El subrayado pertenece 
ámbito en el cual se pretende ejecutar la transformación.

En tercer lugar, las decisiones político-educativas que se asumieron en esta etapa estuvieron atravesadas por las tensiones ya mencionadas, pero así también por aquellas especificidades propias del campo de las vinculación entre las prácticas pedagógicas y las Tecnologías de la Información y la Comunicación (TIC), que como ya se ha visto, no están exentas de conflictos de intereses.

Algunas de las que podemos mencionar como más relevantes se vinculan con la profundización de las desigualdades que surgen como consecuencia del inequitativo acceso a estas nuevas variantes de la alfabetización digital, así como a las dificultades que la institución escuela ha demostrado para adaptarse a estas transformaciones. Además, no puede dejar de considerarse la asunción acrítica y, en muchos casos despolitizada por parte de algunos sectores que suscriben el modelo tecnológico impuesto por las grandes corporaciones como Microsoft; la insuficiente regulación en materia legal en nuestro país respecto al uso del software libre;"23 la carencia o limitación de recursos materiales para extender la red en las instituciones educativas y para la capacitación de amplios sectores docentes en el uso de estas TIC, no significaron desafíos menores, al mismo tiempo que la incorporación de estas tecnologías y sus prácticas en las culturas juveniles en ámbitos ajenos a la institución escolar pero que sin lugar a dudas, ${ }^{24}$ tienen profundas implicancias educativas.

Si se reducen los programas a la transmisión de saberes especializados, se condena a los alumnos a usar saberes en circuitos específicos, a depender de otros para realizar operaciones que son básicamente necesarias en la vida actual y difícilmente se les posibilita la instalación de un aprendizaje sustentado en soportes culturales permanentes. La asimilación de nuevos conocimientos requiere del reconocimiento de algunos de los saberes anteriores, heredados, transmitidos por el grupo de pertenencia o por las instituciones educativas tradicionales. ${ }^{25}$

Al mismo tiempo, se rediseñó en consecuencia la política de Prensa y Comunicación de la DGCyE (2005-2007), al entender que ésta debía tener en cuenta la complejidad del sistema educativo bonaerense atravesado por todo tipo de conflictos y sus particularidades locales, sociopolíticas, económicas, sus características culturales no sólo de la institución, sino también, las que hacen a las regiones en las que está inserta. Para ello también es necesario considerar las experiencias de conocimiento no sólo formales, sino informales. A su vez la oportunidad de conducir el sistema educativo bonaerense en ese período debía considerar las características de la sociedad de la información en la Argentina posterior a los 90 y a la crisis del 2001, así como las principales tensiones y conflictos que atravesaban a las instituciones educativas.

En palabras de Adriana Puıggrós, esto supone

23 Existen en tratamiento en la Cámara de Diputados de la Nación diversos proyectos para regular en esta materia, y cabe considerar la Ley de Promoción de la Industria del Software, N 25.922, Cfr. http://www.diputados.gov.arl.

24 Como mero ejemplo, basta con recorrer algunos de los más recientes artículos publicados en diversos medios de comunicación nacionales que abordan de manera recurrente estos fenómenos, entre los que se pueden mencionar: Iglesias, Mariana, "De la calle a Internet: cómo cambió la forma de jugar", diario Clarín, 21 de diciembre de 2009, en http://www.clarin.com/diario/2009/ 12/21/sociedad/s-02105114.htm,; Massoni, Sandra,"Lo que el agua lleva”, diario Página 12, 3 de marzo de 2010, en http:// www.pagina12.com.ar/diario/laventana/26-141286-2010-03-03.html; Haye, Ricardo,"Nuevo paisaje mediático", diario Página 12 , 3 de marzo 2010; "Las mujeres son más activas que los hombres", Clarín, 18 de diciembre de 2009, en http://www.clarin.com/diario/ 2009/12/18/sociedad/s-02103257.htm, sitios consultados marzo 2010.

25 Puiggrós, Adriana y Gagliano, Rafael (Dirección), Ibídem, pág. 27. 
[...] advertir las grietas profundas que se han producido en el interior del sistema, y comprobar que la nueva estructura [propiciada por las reformas educativas de los 90] fue funcional para el estrechamiento de la clase social poderosa, con alta concentración de la riqueza; el de la clase media cuyas expectativas de ascenso social a través de la educación decrecieron tanto como su capacidad adquisitiva, además del enorme ensanchamiento y la fragmentación interna de los pobres. ${ }^{26}$

¿Pero cómo se llegó a este punto y por qué se eligió este abordaje en particular, entre otros muchos posibles? Hasta aquí se ha dado cuenta de manera sintética acerca de cuál es la concepción de la sociedad de la información y, en líneas generales, se ha delineado la propuesta de análisis de esta tesis: abordar y problematizar las categorías de los supuestos teóricos generales mencionados mediante una experiencia concreta de gestión en un organismo del estado provincial bonaerense. Es así que se considera oportuno explicitar la trayectoria profesional previa a esta experiencia, pues por sí misma pone en evidencia cómo influye tanto en la experiencia misma cuanto en las condiciones subjetivas desde las cuales se elige este objeto. Al mismo tiempo, la tarea del comunicador supone una asunción crítica que de cuenta de forma explícita desde dónde se construye su análisis o bien, por decirlo en otros términos, de quién es el que construye este relato.

\section{1.b) El RECORRIDO PROFESIONAL QUE CONCLUYó EN LA SELECCIÓN DEL TEMA}

La decisión de abordar esta temática tiene su origen en mi trayectoria laboral de los últimos 25 años. Por un lado está íntimamente relacionada con la tarea de periodista, primero, y luego con la tarea de comunicadora-planificadora. En este sentido, tuve la oportunidad de diseñar, planificar, gestionar y ejecutar políticas comunicacionales institucionales en diferentes espacios y contextos políticos, económicos y sociales, como lo fueron la Universidad Tecnológica Nacional (UTN), la Honorable Cámara de Diputados de la provincia de Buenos Aires y la Dirección General de Cultura y Educación de la provincia de Buenos Aires (DGCYE), por mencionar los espacios de la administración pública estatal más destacados. Estas oportunidades siempre estuvieron atravesadas por la urgencia de tomar decisiones políticas.

Desde 1988 hasta 1998 trabajé en la gestión y planificación de políticas comunicacionales en el ámbito de la Universidad Tecnológica Nacional (UTN). Esa etapa estuvo atravesada por la impronta dejada por la recuperación de la democracia, luego del proceso de normalización de las universidades nacionales que prosiguió a la Dictadura Militar instaurada en 1976. Las instituciones de educación superior no sólo iniciaron un proceso de organización de sus gobiernos y su administración, sino a su vez, un proceso de diseño de políticas públicas, uno de cuyos ejes más destacado comenzaba a ser la comunicación democrática, entendida ésta como un puente que les permitiera traspasar sus muros, producto del encierro simbólico y material impuesto en las instituciones educativas durante la Dictadura, para relacionarse tanto hacia adentro cuanto hacia afuera con la comunidad educativa y en general. Allí, en la Secretaría de Extensión Universitaria 
de la UTN, a cargo de la Ing. Dora FERNÁNDEZ, junto con dos compañeros, organizamos el Área de Prensa y Comunicación de la Universidad, inexistente hasta aquel momento.

El Área, en los primeros dos años, se dedicó sólo a instalar en el imaginario de los periodistas de las secciones de sociedad y educación, el concepto de que la Universidad Tecnológica Nacional debía ser considerada algo más que la universidad obrera. ${ }^{27}$ Trabajamos para convertirla en una referente de temas no sólo relacionados a la rama de la ingeniería, sino, a su vez, en otras problemáticas que tuvieran estrecha relación con el eje universidad-desarrollo-comunidad y en referente científico-tecnológico, que no sólo era la encargada de formar a más del 50 por ciento de los ingenieros del país, sino, a su vez, mantenía una estrecha relación como referente en las regiones en las que está inserta. Así surgieron otras necesidades comunicacionales, como la importancia de contar con un área dentro de prensa y comunicación que fuera la encargada de la relación universidad y empresa; universidad y medios; universidad y sociedad. Y otra que fuera la encargada de la comunicación interna, teniendo en cuenta que la UTN es la única universidad considerada federal por su conformación, ya que en casi todas las provincias posee una Unidad Académica. ${ }^{28}$

El área de Prensa y Comunicación de la cual fui responsable desde 1988 hasta 1998, creó, a su vez el área de Radios de la utN. Se instauró la red de radios universitarias, y un área editorial que, entre otras tareas, tenía la responsabilidad de editar las revistas Universidad \& Empresas, La Vía y Novedades Tecnológicas. En ese mismo año, el Área de Prensa y Comunicación, se ocupaba también de tres subáreas relacionadas con la comunicación interna y externa: esto es, un Área general y, dentro de ésta, tres subáreas, Radios, Gráfica y Multimedial.

Unos años después, en diciembre de 2000, ingresé como Directora de Prensa y Comunicación de la Honorable Cámara de Diputados de la provincia de Buenos Aires, cuyo Presidente en ese entonces era el diputado Aldo SAN PEDRO. ${ }^{29}$ Aunque la experiencia en esta etapa estuvo atravesada por la alta conflictividad política, económica y social de la época, lo que en un ámbito eminentemente político como la legislatura provincial se vio amplificado, pude desarrollar junto al equipo estable de la Dirección de prensa, diversas herramientas de comunicación institucional, tales como una revista y la reorganización del portal, entre otras.

\footnotetext{
27 Cabe mencionar que la Universidad Tecnológica Nacional tuvo su antecedente en la Universidad Obrera Nacional (uon), creada por el peronismo en 1948. Tras un largo proceso de evolución institucional, en 1959, mediante la Ley 14.855, se constituye como la actual Universidad Tecnológica Nacional (UTN). El comienzo de ese proceso, originado en una etapa de fuertes cambios políticos y a su vez coincidente con el fin de la II Guerra Mundial y con el arranque de la industrialización argentina, estuvo signado por un apasionamiento que iba más allá de lo puramente educativo o académico. La génesis y consolidación de la Universidad Tecnológica Nacional (1948-1959) representa no solo el desafío de una nueva visión sobre la formación de los ingenieros, resistida en un comienzo por el ámbito profesional y universitario y finalmente aceptada y hasta adoptada en el campo académico, sino también el replanteo de la inserción de la universidad en la sociedad y el país. Cfr. Alvarez de Tomassone, Delia Teresita, La génesis de una Universidad (1948 - 1962), Editorial Universitaria de la uTN, 2006, Publicación electrónica, http://www.edutecne.utn.edu.ar/uon-utn/, sitio consultado octubre 2009.

28 La UTN abarca todas las regiones de la Argentina, mediante sus 24 Facultades Regionales y 5 Unidades Académicas que se ubican en la región Noreste: provincias de Chaco, Entre Ríos, Santa Fe; Noroeste: provincias de La Rioja, Tucumán; Centro: Capital Federal y provincias de Buenos Aires, Córdoba, Mendoza y Sur: provincias de Chubut, Neuquén, Santa Cruz y Tierra del Fuego.

29 Aldo San Pedro presidió la legislatura provincial entre el 2000 y 2001. Era uno de los dirigentes de la Alianza (Alianza por el Trabajo, la Justicia y la Educación) que surgió del acuerdo entre la Unión Cívica Radical y el fREPASo, conformada en 1997 y que ganó las elecciones presidenciales de 1999. La Alianza se disolvió tras la crisis que llevó a la renuncia del presidente Fernando de la Rúa el 20 de diciembre de 2001. Luego de ser Senador en la provincia de Buenos Aires entre 2005-2007, fue electo intendente de la localidad de Bragado (2007-2011).
} 
Es así como al hacerme cargo de la Dirección de Comunicación y Prensa de la Dirección General de Cultura y Educación de la provincia de Buenos Aires desde diciembre de 2005 hasta diciembre de 2007, y preservando, aun en ese período, la trayectoria de saberes y prácticas adquiridas al haber estado a cargo de otras dos direcciones de prensa institucionales ya mencionadas, es que intenté, en forma conjunta con los equipos de trabajo de esas instituciones, realizar un plan de comunicación cuyo eje central estuviera puesto en la comunicación como red de integración de la comunidad educativa.

La propuesta final para el área de comunicación surgió luego de hacer un relevamiento acerca de la situación con la que nos encontramos en el sistema educativo en 2005 y, a partir de ese diagnóstico, se construyeron políticas públicas que involucraron a la comunicación como una disciplina esencial a la hora de poder llevarlas al campo concreto de acción que estaba presente, mediante las misiones y funciones propias del área. Fue precisamente para llevar adelante esa tarea que tuvimos que articular con los dispositivos de información existente en la institución y allí resultaron indispensables Mapa y Cédula Escolar. Sobre la consideración de que persisten en esa planificación del trabajo ejes que todavía pueden ser útiles en otras instituciones, incorporamos como Anexo el Proyecto para el área que presentamos en aquella oportunidad. 
2. Planteamiento DEL PROBLEMA 



\section{2.a) La inscripción de una experiencia de la gestión pública en un proyecto político pedagógico democratizador}

¿Qué potencialidades o beneficios brindan hoy las herramientas de la sociedad de la información para la gestión de políticas públicas en el ámbito educativo? Para diseñar la gestión comunicacional de esas políticas públicas, que se va a servir de esas herramientas, se realizó un diagnóstico, que puede resumirse en los siguientes ejes:

- El nivel de acceso a la información del sistema por parte de los funcionarios, entendiéndose desde directores de escuela a directores provinciales de la administración central.

- Estructuras orgánico-institucionales y programas del sistema dedicados a la obtención, procesamiento y distribución de la información.

- El corpus jurídico institucional.

- Las políticas nacionales que impulsan el uso de las herramientas de la sociedad de la información aplicadas al campo educativo.

A lo largo del trabajo, se irán abordando estos ejes en los diferentes contextos históricos que precedieron a la etapa 2005-2007, así como en la especificidad de esa reforma. En lo que refiere al nivel de acceso a la información del sistema por parte de los funcionarios, entendiéndose desde directores de escuela a directores provinciales de la administración central, cabe mencionar que una de las consecuencias, en apariencia de menor jerarquía, del proceso de fragmentación y empobrecimiento social así como el corrimiento del Estado, ha sido la carencia de información sistematizada y confiable, tanto en lo que refiere a su formulación cuanto a su distribución, acerca del propio sistema y sus actores.

Desde ya se alude a los dispositivos de información que permitan, de manera sistemática y organizada, obtener, procesar e interpretar datos del sistema que hagan posible no sólo elaborar diagnósticos, sino también que se constituyan en insumos para la elaboración de estrategias pedagógicas para la toma de decisiones políticas. Entonces, es necesario preguntarse: ¿qué información?, ¿cómo se la elabora y se la distribuye?, ¿para qué?, ¿relevada por quiénes y para quienes?, ¿con qué grado de participación de los diferentes actores del sistema? 
De manera simultánea con estos procesos socio-políticos de gran impacto en nuestras comunidades, el avance tecnológico fue expandiéndose y creando no sólo nuevos dispositivos de comunicación y lenguajes, sino además fuertes transformaciones culturales y pedagógicas, tanto adentro como afuera de las instituciones escolares y los ámbitos gubernamentales.

Es indudable que los jóvenes, adolescentes, niños y niñas fueron ingresando a universos culturales novedosos incluso para los docentes que, por diversas razones que no se desarrollarán aquí, en general han permanecido ajenos a estas transformaciones o las han incorporado de manera inorgánica y desigual. Puede afirmarse algo parecido respecto de los funcionarios y los empleados de la administración del sistema educativo. Si bien hay un aspecto central en lo que refiere a las dificultades para incorporar los equipamientos y las capacitaciones para su adecuado uso, no revisten menor importancia otros factores como la resistencia a la imposición del modelo tecno-burocrático, resistencia justificada por el hecho de que ese modelo estaba asociado con las mismas políticas neoliberales que los organismos multilaterales de crédito impusieron las reformas educativas.

Sin embargo, desde latitudes ideológicas y geográficas distintas, una serie pensadores comenzaron a dudar de los beneficios igualitarios del proceso. Renato Ortiz ${ }^{1}$ distinguió entre globalización económica y mundialización cultural para describir las diferencias entre uniformidad y fragmentación de unos procesos que no correspondían a una misma lógica. Néstor García Canclini² se preguntaba si había una sola forma de globalizarse, en referencia al modelo neoliberal de hacerlo en el que se globalizan los beneficios para los países centrales de la desregulación de las políticas macroeconómicas en los países pobres, mientras ejercen en sus propios países el más frío proteccionismo. ${ }^{3}$

Por otra parte, como sostiene Manuel CASTELLS,

[...] se observa en aquellas personas, sobre todo estudiantes, niños, que están conectadas, es que aparece un segundo elemento de división social mucho más importante que la conectividad técnica, y es la capacidad educativa y cultural de utilizar Internet. Una vez que toda la información está en la red, una vez que el conocimiento está en la red, el conocimiento codificado, pero no el conocimiento que se necesita para lo que se quiere hacer, de lo que se trata es de saber dónde está la información, cómo buscarla, cómo procesarla, cómo transformarla en conocimiento específico para lo que se quiere hacer. Esa capacidad de aprender a aprender, esa capacidad de saber qué hacer con lo que se aprende, esa capacidad es socialmente desigual y está ligada al origen social, al origen familiar, al nivel cultural, al nivel de educación. Es ahí donde está, empíricamente hablando, la divisoria digital en estos momentos. ${ }^{4}$

¿Cómo se llegó a este estado de situación en el sistema educativo bonaerense?

Entre los factores que es posible mencionar, uno es el deterioro de los sistemas comunicativos institucionales gubernamentales — tanto en un sentido horizontal, como vertical y transversal一; otro, la ruptura de las redes interinstitucionales, que llevó no sólo a una desarticulación de las prácticas pedagógicas y de las experiencias educativas, sino también a la ruptura del propio sistema, entendido como construcción y estructura colectiva que dialoga y se alimenta entre sí. Es así que no podemos

1 Ortiz, Renato, Mundialización y Cultura, Alianza Editorial, Buenos Aires, 1997.

2 García Canclini, Néstor, Consumidores y ciudadanos, Conflictos multiculturales de la globalización, Grijalbo, México, 1995.

3 Sanguinetti, Luciano, "Sociedad de la Información: las Políticas Públicas en el ámbito educativo de la provincia de Buenos Aires.", Programa "Comunicación y Sociedad de la Información".FPy CS.,UNLP-Facultad de Periodismo y Comunicación Social.

4 Castells, Manuel, Internet y la Sociedad Red, revista La Factoría, Febrero-Septiembre de 2001, $\mathrm{n}^{\circ}$ 14-15, en http:// www.revistalafactoria.eu/articulo.php?id=185, sitio consultado octubre 2009. 
eludir un enfoque sistémico, que nos permita, en el sentido kantiano, abordar la complejidad de nuestro territorio de análisis, que debe considerar un gran número de variables y factores - políticos, humanos, económicos, tecnológicos, fuertemente interconectados. Es decir, que en diciembre de 2005 al asumir el equipo de trabajo de la Dra. Adriana PuIGGRós, aunque se tenía una perspectiva clara en cuanto a los objetivos generales de la política pedagógica y comunicacional que se pretendía llevar adelante, así como un diagnóstico de la complejidad de problemas que atravesaban a la sociedad argentina y al sistema educativo en particular del distrito más poblado del país, no se contaba con información estadística precisa y sistemática, tanto en el orden cualitativo cuanto en el cuantitativo, respecto de los problemas concretos que se tenían que afrontar.

La falta de datos confiables no sólo fue una problemática a la que tuvo que enfrentarse la gestión de Puiggrós. Cuando asumió José Octavio Bordón, en el año 1999, tampoco se contaba con información concisa, precisa y clara sobre el sistema educativo bonaerense. Esta situación llevó a los equipos del mendocino a plantearse la necesidad de construir dispositivos que fueran las herramientas acordes para contar con información útil para la planificación y gestión de las políticas públicas. Nace en ese entonces la idea de Mapa y Cédula Escolar.

En 2005, cuando ya comenzaba a salir la provincia de Buenos Aires de la crisis económico-financiera surgida en 2001, para la gestión de Felipe SoLÁ estaba claro que el Estado debía recuperar su rol de responsable principal del derecho a la educación, impulsando los dispositivos que habilitaran una mayor participación de los sujetos y revirtieran las consecuencias nefastas de la aplicación de las políticas neoliberales. También lo estaba la importancia estratégica para la emancipación, de una educación inclusiva, capaz de distribuir con justicia social los bienes culturales. Se sostenía la necesidad de garantizar derechos de acceso, permanencia y egreso, así como de los derechos de los trabajadores de la educación a capacitarse, a percibir un salario justo, a recibir una sólida formación de base. Del derecho a educarse en condiciones materiales equitativas, en cuanto a la infraestructura escolar y también en lo que refiere al acceso a los textos, al material didáctico, bibliotecas y conectividad, entre otras. No había dudas acerca de la importancia de recuperar y socializar las experiencias pedagógicas positivas, enriquecedoras alternativas o no, así como la necesidad de jerarquizar a los docentes.

Por último, era necesario inventar nuevos medios y dispositivos de comunicación, a la vez que transformar los existentes, que hicieran posible difundir los conocimientos y saberes de una agenda educativa contemporánea entre el conjunto de la comunidad educativa y, a su vez, ponerlos en diálogo con el resto de la sociedad. En cuanto al segundo eje del diagnóstico referido a las estructuras orgánico-institucionales y programas del sistema dedicados a la obtención, procesamiento y distribución de la información, era indispensable reorganizar la administración del sistema en su conjunto: conectar y conocer los 19.000 establecimientos, organizados en 25 regiones educativas que abarcan los 134 municipios con sus respectivos consejos escolares; conducido — con distintos niveles de responsabilidad — por funcionarios públicos, ya fueran personal jerárquico de la administración central, docentes, directores en las escuelas, inspectores de las distintas áreas (artística, educación física, entre otras) y Niveles educativos (Inicial, Primaria, Secundaria, Superior); inspectores de infraestructura escolar; personal auxiliar (porteros), administrativo y técnico; Secretarios de Inspección. Es decir, un complejo universo con niveles jerárquicos no siempre bien delimitados y distintos grados de responsabilidad en el gobierno y administración del sistema, tal como se puede apreciar en el siguiente mapa. 


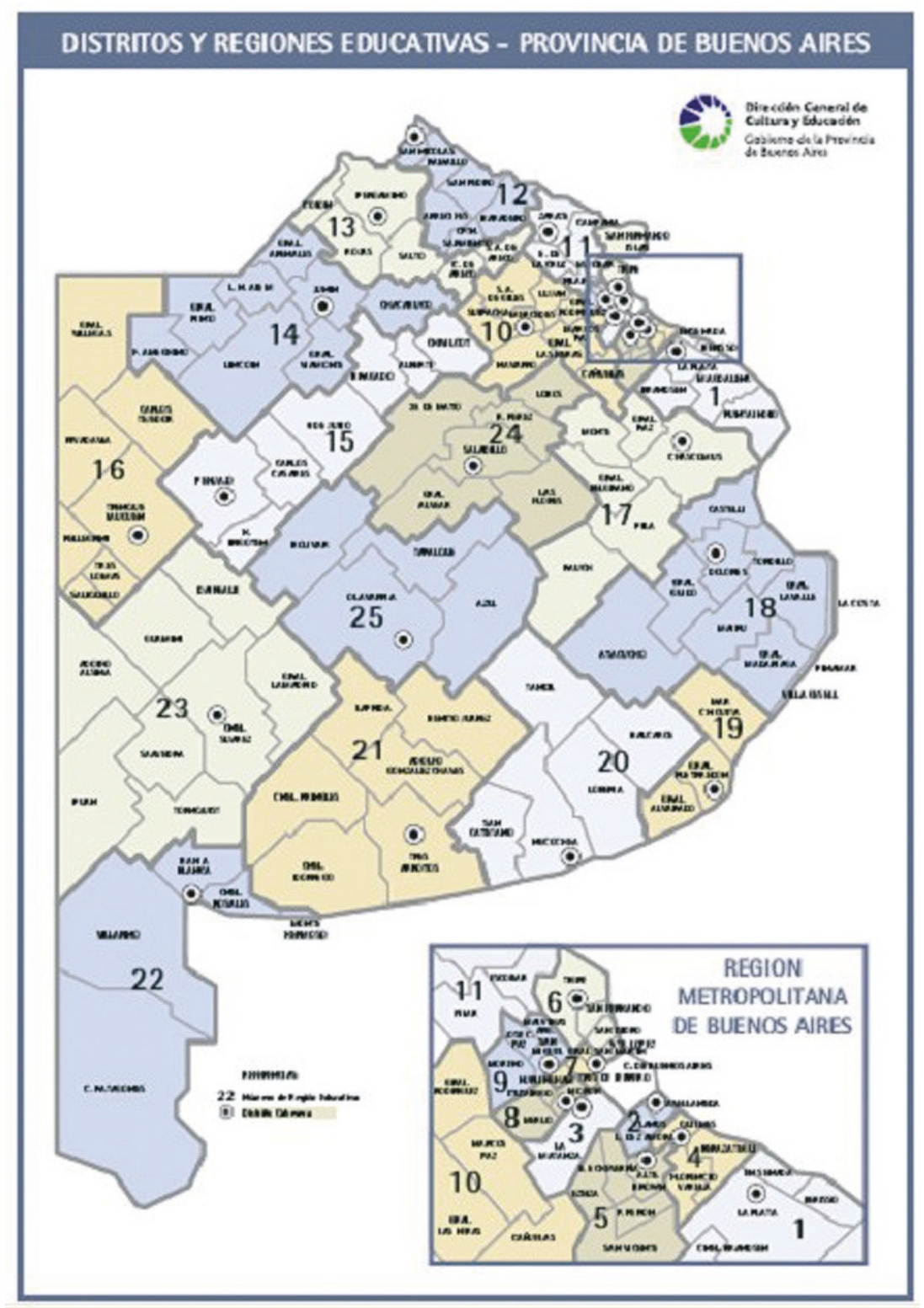

Además, el sistema no sólo debía garantizar el derecho a la educación en un sentido estricto, sino también las políticas sociales complementarias, como el servicio de comedores escolares (Servicio Alimentario Escolar, SAC); las becas; ${ }^{5}$ la provisión de útiles; el transporte (pluvial, terrestre, aéreo) entre otros. Todo eso estaba claro.

También en 2005 había diversas cuestiones que hacían al aspecto educativo que no se conocían con precisión. No había buena información respecto del propio sistema ni respuestas precisas para algunas preguntas básicas: ¿Cuántos alumnos tiene el sistema educativo bonaerense? ¿Dónde están los niños, niñas y jóvenes que no están en las escuelas? ¿Cuáles son los alumnos/as más pobres que necesitan contención social? ¿Cuántos analfabetos adultos hay en la provincia de Buenos Aires? ¿Cuántos chicos y chicas indocumentados, sin derecho a la identidad? ¿Cuántos edificios tenemos?

5 Por ejemplo, cuando en 1999, el entonces gobernador de la provincia de Buenos Aires, Eduardo Duhalde, implementó un programa de becas para alumnos del Polimodal que acababa de crearse, que consistían en un pago de \$100 mensuales a los alumnos del $1^{\circ}$ año del Polimodal, surgieron muchas dificultades para implementar y sostener el sistema y la crisis de 2001 obligó a modificar no sólo la metodología y los requisitos de acceso, sino también la financiación, que, al poco tiempo, quedó a cargo de la Nación. 
¿Cuál es el estado de las medidas de seguridad edilicia? ¿Cuántos alumnos hay en cada escuela? ¿Con qué indicadores de repitencia, abandono, deserción, se elaboran las estrategias de inclusión? ¿Por qué surgen, casi repentinamente, demandas de escuelas en localidades y regiones que hace poco tiempo no las requerían? Desde ya, estos son sólo algunos interrogantes que se pueden formular. Pero es un punto de partida para considerar la elección del objeto de estudio que hemos hecho en este trabajo. En este particular surge, ante la urgencia de gestionar el siguiente interrogante: ¿Cómo planificar y organizar un sistema en constante movilidad sino se lo conoce o no se cuenta con información precisa y actualizada de éste?

Es por ello que es imprescindible un abordaje que se centre sobre una experiencia concreta y tome en consideración aquellos antecedentes que fueron importantes generadores de información al servicio de lograr una reorganización del sistema educativo bonaerense, luego de la desarticulación que provocó la aplicación de las políticas neoliberales de la década del 90. Y para poder dar este paso, era necesario tener un diagnóstico acerca del propio sistema, que, de algún modo, pudiera dar cuenta de algunos de los interrogantes formulados respecto del mismo. Para ello se toman como punto de partida dos programas:

- Mapa escolar.

- Cédula escolar.

No se trata de una elección caprichosa, desde ya. Constituyeron un aspecto esencial para comprender la magnitud del sistema educativo de la provincia de Buenos Aires, uno de los más grandes y complejos de América Latina, no sólo por su dimensión sino también por su diversidad, ya que reúne a más del 40 por ciento de los alumnos/as del país. ${ }^{6}$

Si se observa brevemente la historia del organismo y la estructura institucional del sistema, se destaca que la Dirección General de Cultura y Educación (DGCyE) es, desde 1817, "la organización creada para conducir el sistema educativo en la provincia de Buenos Aires." Con el transcurso de los años y el crecimiento del sistema, amén de los diversos procesos de transformación que atravesó el país en materia educativa, se ha convertido en "una de las instituciones estatales de mayor peso en el país y en la región," ${ }^{8}$ y, en tal sentido, ha tenido enorme influencia en la conformación del espacio público educativo. En cuanto a la evolución, los períodos de mayor significación han sido, según sintetiza Liliana Bevilacqua,

1.- 1810 - 1852: de organización. La conducción de la educación en la provincia tiene su origen en el Cabildo, éste otorga en 1605 la primera licencia para enseñar. Pero recién en 1805, se observa una preocupación más concreta del Estado en materia de educación. Hacia 1810 se registra una población escolar de 500 alumnos en escuelas estatales y 700 en escuelas privadas -el $7 \%$ de la población en edad escolar-.

6 De acuerdo al Relevamiento censal 2005, la matrícula de alumnos en la provincia de Buenos ascendía a 4.444 .957 alumnos de todos los niveles y modalidades y una población total de 14.167.123 hab., mientras que los habitantes de la provincia de Córdoba, la que le sigue en población, era de 3.066.801 habitantes y la de la provincia de Santa Fe, 3.000. 791 habitantes (Censo Nacional de Población, Hogares y Viviendas 2001) Cfr. http://abc.gov.ar/lainstitucion/legislatura20052006/informe_legislatura_2005-2006.pdf, sitio consultado octubre 2009.

7 Bevilacqua, Liliana, Planificación y formulación de políticas educativas, Monografía Acerca del Sistema Educativo de la Provincia de Buenos Aires. Argentina, 2001, en http://abc.gov.ar/lainstitucion/organismos/planeamiento/pdf\%20documentos/ monografia.PDF. 
2.- 1852 - 1916: de consolidación y auge del sistema. [...] Este período de 64 años se caracterizó por intensas luchas en lo que hace a la construcción de un organismo de conducción siguiendo el ideario de Sarmiento (quien en 1856 asume la jefatura del entonces Departamento de escuelas, encargado de la educación primaria, ocupándose de los reglamentos y de los textos escolares. En este año crea la Revista de Educación que funcionaba como órgano de difusión de la conducción educativa) de una educación básica y universal plasmado en la Ley de Educación de 1875, y que fue el antecedente de la Ley 1.420. Este período muestra la unificación definitiva del sistema educativo y altas tasas de crecimiento matricular.

3.- 1916 - 1948: de complejización organizacional y crecimiento estable. Si bien este período se caracteriza por cambios sociales, políticos y económicos, la Dirección General de Escuelas sufre un proceso de complejización y crecimiento en materia de servicios dada la diversidad -en cuanto a cantidad de alumnos y ofertas para los distintos sectores de la sociedad. Un dato destacado fue la implementación de la educación religiosa en el año 1934.

4.- 1945 - 1955: creación como ministerio. Se expande la educación y se amplían las funciones, en 1946 se crea la ley de Jardines de Infantes N 5096, y en 1948 el Instituto de Psicología Educacional. En 1949 pasa a ser Ministerio de Educación. Se masifica la educación primaria. Busca una mayor intervención del estado en la prestación del servicio educativo conforme al proyecto político del período. Se da un crecimiento matricular considerable.

5.- 1955 - 1983: coexistencia de organizaciones. Período de inestabilidad como consecuencia de los cambios políticos en los sucesivos gobiernos civiles y militares de la época. Las variaciones de la matrícula observada tuvieron que ver entre otras cuestiones, con los distintos regímenes políticos mencionados. ${ }^{9}$

En lo relativo al corpus jurídico institucional, es posible establecer diversas etapas:

6.- 1983 - 1992: período democrático previo al actual proceso de reforma. La crisis económica y social del período anterior produce un debilitamiento de la Dirección General de Escuelas. Esta situación redunda en los procesos de privatización y descentralización. ${ }^{10}$

La recuperación de la democracia en 1983, entre otras cuestiones, reinstala la discusión de lo educativo y su relación con la sociedad. El Congreso Pedagógico (Ley 23.114, septiembre de 1984) constituyó uno de los acontecimientos educativos más relevante de esa etapa, ya que, de alguna manera, las conclusiones del Congreso llevado a cabo en 1988 "constituyen el antecedente más inmediato de la Ley Federal de Educación."11 Respecto a la estructura del sistema, la década del 90 estuvo signada por la instauración en gran medida resistida por los sindicatos docentes y otros sectores, de nuevas bases legales para sustentar una reforma nacional y un nuevo programa estatal que se plasmó en el:

\section{Nuevo cuerpo normativo: nivel nacional y de la provincia de Buenos Aires}

- Ley de Transferencia de Servicios Educativos, Nº 24.049 (1991).

- Ley Federal de Educación Nº 24.195 (1993).

- Reforma constitucional (1994).

- Reforma de la Constitución provincial (1994).

- Ley de Educación Superior Nº 24.521 (1995).

- Ley de Educación de la Provincia de Buenos Aires N 11.612 (1995). 
Estos cambios definieron no sólo un nuevo rol del Estado y de la sociedad, sino también una diferente organización y estructura del sistema que no se aplicó de manera orgánica en todo el país, pero que en el caso de la provincia de Buenos Aires se impuso durante la gestión al frente de la Dgcye de la Dra. Graciela GiAnNETtASIo (1992-1999). ${ }^{12}$ De este modo, además de extender los años de obligatoriedad escolar, se efectuaron cambios en la denominación de los niveles educativos y los contenidos de la enseñanza; la institucionalización de un sistema de evaluación y acreditación y de un sistema de capacitación continua y nuevos criterios de inversión pública y privada ligados a los requerimientos de los organismos internacionales de crédito que los impulsaron en casi todos los países de América Latina y una nueva configuración para el ejercicio profesional docente. Todas estas reformas conformaron un escenario de tensiones y contradicciones que se plasmaron no sólo en el ámbito específico de las instituciones escolares sino en todos los niveles del sistema.

Más adelante se desarrollará el cuerpo jurídico y normativo que corresponde a la etapa 2005-2007, que configuró el soporte legal para sostener las reformas introducidas por la gestión de PuIGGRós.

En este contexto de 2001 los dos programas, Mapa y Cédula, comenzaron a implementarse en el 2001 y tenían como objetivo central obtener información del sistema educativo provincial con el fin de planificar las estrategias de la política educativa gubernamental. La Licenciada Mónica GonzÁlez Gaviola, ${ }^{13}$ quien se desempeñaba como Directora de Información y Planeamiento Educativo de la Dirección de Cultura y Educación de la provincia de Buenos Aires (DGCyE), explica que uno de los mayores inconvenientes a los que tuvo que enfrentarse la gestión de José Octavio BORDón fue la falta de información precisa estratégica para la planificación y gestión de las políticas públicas educativas en el contexto de crisis de fines de los 90 .

Cuando asumió Bordón no se podía determinar cuántos alumnos había en la provincia de Buenos Aires. Menos, saber qué cantidad de estudiantes hacía su recorrido en la educación de gestión estatal y cuántos en la gestión privada. Menos aún, sus condiciones socioeconómicas, en qué regiones educativas existían más necesidades edilicias para poder cumplir con la obligatoriedad de la educación. No podía saberse la migración intraprovincial y extra provincial. Es decir, un chico dejaba de ir a la escuela, y no porque abandonara, sino, simplemente porque sus padres, trabajadores quizás golondrinas, se mudaban de provincia y no se sabía si era por esta razón o porque abandonaba el sistema educativo. ${ }^{14}$

Como contrapartida, era necesario pasar de un sistema de información que se sostenía en llenar formularios por parte de los funcionarios de las instituciones escolares provinciales en soporte papel a un sistema informatizado, en red, que pudiera brindar rápidamente datos que permitieran tener un panorama más preciso de la comunidad educativa. Al mismo tiempo, se puso en marcha el portal abc de la DGCYE, al que, entre otras cuestiones, se incorporaba parte de la información del Mapa. ¿Por qué sólo una parte? Según GONZÁLEZ GAVIOLA, tal como lo recoge un artículo publicado en diciembre de 2002,

\footnotetext{
12 Tras asumir como gobernador de la provincia de Buenos Aires en diciembre de 1991, Duhalde designó en la DGCyE a la Dra. Susana Farías de Castro, quien se proponía llevar adelante las reformas que impulsaban los organismos de crédito internacionales y llegó incluso a proponer la derogación del Estatuto del Docente, lo que originó una dura resistencia de los docentes y otros sectores, hasta que renunció en abril de 1992 y fue reemplazada por Giannettasio.

13 Fue la responsable, durante la gestión de Bordón, de conducir el área que tuvo a cargo el diseño y la implementación de los dispositivos Mapa y Cédula escolar y fue entrevistada para esta Tesis. Tras la asunción de Oporto, ocupó el cargo de Directora de Información y Planeamiento Educativo, de la cual siguieron dependiendo ambas herramientas.

14 Entrevista realizada para esta tesis con la Lic. Mónica González Gaviola, Socióloga y Master en Gestión del Conocimiento por
} 
[...] esos datos -índice de repitencia y deserción escolar- podrían "discriminar y marginar" a cierto tipo de escuelas. "Si en el Mapa Escolar publicamos que una escuela tiene un alto índice de deserción o de repitencia estamos condenando al equipo de educadores. Por otro lado, creemos que los padres de los alumnos podrían tomar ese parámetro como un síntoma de mala calidad de enseñanza y de esta manera discriminar una escuela", dijo González Gaviola. Para la funcionaria, "el objetivo del portal es incrementar el acceso a datos que puedan ser utilizados por los docentes y la comprensión de las acciones de gobierno". ${ }^{15}$

Pasaron cinco años desde el comienzo del diseño, planificación y gestión de los programas Mapa y Cédula Escolar hasta la asunción de Adriana PuIGgRós. Sin embargo, estos dispositivos, y su aplicación, formaron parte de la trama comunicacional, tanto en la planificación como en la gestión de los procesos comunicacionales, que se llevaron a cabo en la Dirección de Cultura y Educación durante la gestión 2005-2007. En este sentido, es de interés revisar estos programas desde una visión comunicacional como aporte a futuras estrategias en este particular.

Abordar los objetivos y finalidades de los programas de Mapa Escolar y Cédula Escolar, permite hacer una reflexión y análisis de la sistematización de datos que son de importancia para realizar una propuesta comunicacional factible de ser puesta en práctica. El fin es sistematizar prácticas de la sociedad de la información y su impacto en un ámbito concreto y complejo como lo es el mencionado.

La intención es objetivar procesos, estrategias y experiencias para el desarrollo de la comunicación en el ámbito de la administración estatal, como propuesta alternativa a la que surge del poder hegemónico que plantean los medios masivos de comunicación social agrupados —en su mayoría- en monopolios y oligopolios, no sólo en el sentido estricto del concepto de empresas, sino, además, como uno de los controladores del acceso, circulación, construcción y difusión de la agenda informativa, en este caso educativa.

Por otra parte, se busca verificar si los dispositivos de información como Mapa y Cédula Escolar pueden por sí mismos resolver los problemas de la comunicación en una organización, o bien si su utilidad está condicionada por el marco político general en el que se los inscribe y los fines con que esa información es aprovechada. Además, analizar si la implementación de estos dispositivos tiene continuidad en el tiempo, con los diferentes gobiernos. En este contexto es necesario resignificar los conceptos y estrategias en comunicación y, más específicamente, dentro del campo educativo, si se pretende que sean capaces de vehiculizar las prácticas en modelos alternativos a los impuestos por los grupos dominantes conformados por los medios comerciales y empresariales que pretenden erigirse como los únicos agentes de transmisión de conocimiento e información del quehacer social. En tal sentido, reviste mayor importancia esta decisión cuando se trata de ámbitos de gestión públicos ya que se considera, como se ha dicho, que esta tarea constituye una responsabilidad del Estado que debe asegurar el acceso del derecho a la información a todas y todos los habitantes, además de una manda 
constitucional en nuestro país. ${ }^{16}$

La planificación y la gestión de los procesos comunicacionales que fueron llevadas a la práctica en el período que se aborda son parte esencial del análisis de esta tesis ya que constituyen prácticas concretas de políticas públicas, en este caso provinciales, que se ejecutaron y que, por lo tanto, pueden ser evaluadas no sólo sobre la base de sus supuestos teóricos sino también en cuanto a la aplicación que tuvieron y al impacto positivo o negativo con que afectaron al sistema educativo.

Inscriptas en el contexto actual de sociedades de la información cada vez más complejas y fragmentadas y de las nuevas tecnologías, es indispensable la revisión de las políticas comunicacionales puestas en marcha con el fin de observar si Mapa y Cédula Escolar pueden ser las herramientas adecuadas para entender el Sistema Educativo de la provincia de Buenos Aires y relevar la información adecuada para implementar una política educativa orientada por la justicia social.

I/www.lanacion.com.ar/nota.asp?nota id=459278, sitio consultado marzo 2010.

16 Cabe destacar que la Declaración de Principios de Ginebra 2003 de la Cumbre Mundial de la Sociedad de la Información, declaró la necesidad de "fomentar la diversidad de regímenes de propiedad de los medios de comunicación" y la Convención sobre Diversidad Cultural de la UNESCO (2005) establece que los Estados tienen la obligación y el derecho de "adoptar medidas para promover la diversidad de los medios de comunicación social". [el subrayado es nuestro] A su vez, la Corte Interamericana de Derechos Humanos, en la Opinión Consultiva 5/85, sostiene dicho: 85 “...en principio la libertad de expresión requiere que los medios de comunicación estén virtualmente abiertos a todos sin discriminación o, más exactamente, que no haya individuos o grupos que a priori, estén excluidos del acceso a tales medios, exige igualmente ciertas condiciones respecto de estos, de manera que, en la práctica, sean verdaderos instrumentos de esa libertad y no vehículos para restringirla. Son los medios de comunicación social los que sirven para materializar el ejercicio de la libertad de expresión, de tal modo que sus condiciones de funcionamiento deben adecuarse a los requerimientos de esa libertad. Para ello es indispensable la pluralidad de medios y la prohibición de todo monopolio respecto de ellos, cualquiera fuera la forma que pretenda adoptar...".Cfr. Ley de Servicios de comunicación Audiovisual 26. 522, sancionada el 10 de octubre de 2009. 

3. MARCo Térico

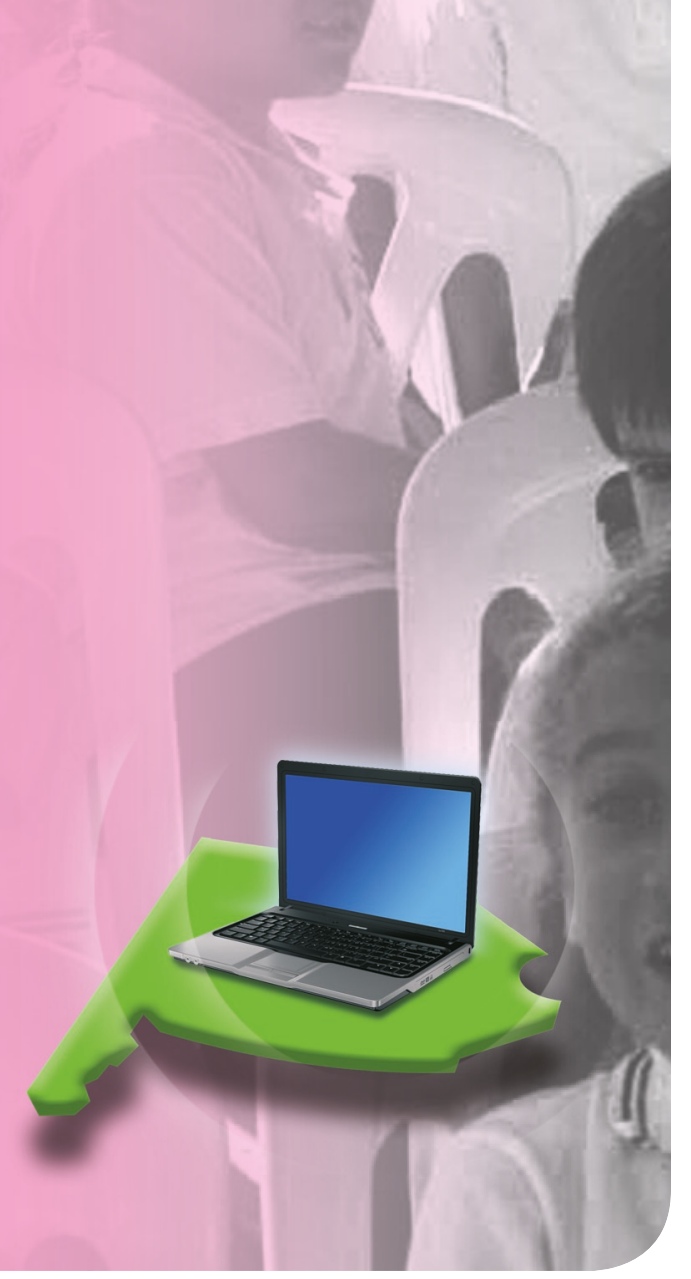





\section{Marco Té́rico}

La presente investigación surge de la gestión misma, puesta en funcionamiento en el período 20052007, como parte de una concepción de las políticas educativas, que consiste en mantener el vínculo comunicacional y la interrelación con los diversos actores de la vida educativa. Aquí juegan un papel preponderante, más allá del diseño de los lineamientos de trabajo en el sector, los actores: docentes, directivos e inspectores de las escuelas de la provincia de Buenos Aires.

Como expresara Adriana Puiggrós, se trabajó "sintiendo el pulso de las expectativas, las esperanzas y la recepción de lo que estaba pensando, diciendo y haciendo", 1 y se tendieron puentes entre las políticas educativas y pedagógicas y la comunidad educativa. Tender puentes y dar voz a los sujetos conlleva a la asunción de la historicidad en la que estos se inscriben, por lo que la política no se limitó a la incorporación de propuestas innovadoras, sino también a recuperar aquellas experiencias, saberes y herramientas existentes que pudieran potenciarse a favor de la planificación-gestión comunicacional.

En esa línea se consideró fundamental reconocer a los sujetos que le dan sentido a la educación. Inmersos en el postulado de la inclusión social y educativa, es de subrayar la concepción de la comunicación entendida como creación colectiva de toda sociedad y de una cultura en la que hay que comprender y percibir a los actores, así como a los desafíos y el impacto, que tanto en los sujetos como en los colectivos, provoca la llegada de cada medio de comunicación que aparece como agente, para ver cuáles son los sentidos construidos alrededor de ellos y re transmitirlos. ${ }^{2}$

Por ello se llevó adelante la tarea desde dos aristas en forma simultánea, lo cual se relaciona con la organización-gestión comunicacional de políticas educativas y la comunicación interna y externa, que dan cuenta del proceso y vincula los diferentes sectores: los de gestión política gubernamental y los del trabajo del aula. ${ }^{3}$

En el plano concreto de la sistematización de la información pública, la importancia del compromiso

\footnotetext{
1 Puiggrós, Adriana, et al, Cartas a los educadores de siglo XXI, Galerna, Buenos Aires, 2007, pág. 9.

2 Saintout, Florencia, "Descubrir una comunicación: En búsqueda de las huellas", en Esteinon, Javier, revista Espacios de comunicación, Nro. 3, 1999, México, pp. 27-49.

3 Cabe destacar que el área de Comunicación y Prensa de la DGcye tuvo un rol importante, ya que actuó como dinamo que puso en funcionamiento la concepción y planificación de las políticas educativas delineadas, dándolas a conocer y poniéndolas a interactuar entre todas las comunidades educativas de la Provincia.
} 
y el rol de los sujetos se pueden verificar en el día a día. ¿Quién carga la información (los datos concretos) acerca de los alumnos? ¿Con qué cuidados y reservas de identidad se realiza? ¿Con qué frecuencia y grado de responsabilidad? ¿Cuáles son los circuitos mediante los que circulan esos datos y para qué? ¿Cómo se procesan y se elaboran políticas sobre esas bases de datos y cómo se socializa la información?

\title{
3.a) La importancia del tema
}

\author{
Porque no se trata de ligar las consecuencias, sino de \\ relacionar y aislar, de analizar, de ajustar y de empalmar \\ contenidos concretos; nada hay más vacilante, nada más \\ empírico (cuando menos en apariencia) que la instauración \\ de un orden de las cosas (Michel Foucault, Las palabras y \\ las cosas, 1966)
}

La importancia del tema radica en construir este relato del proceso de planificación-gestión de la comunicación llevado a cabo en la DGCyE, que sirva como aporte para otras experiencias de comunicación institucional e implementación de políticas públicas. Es decir, dejar un testimonio, construido como relato, lenguaje de la forma que aspira a la precisión de las palabras, aun a riesgo de parecer ambiciosos, del "orden de las cosas" que se construyó mediante la experiencia de la que damos cuenta en este trabajo. Planificación institucional refiere a las herramientas conductoras para el logro de los objetivos organizacionales, mientras que comunicación institucional alude no sólo a lo externo sino que se trata de interpretar la estructura de la entidad como un flujo permanentemente de información, a la vez que a la tarea de gestionar dicha información de un modo eficaz y estratégico.

De este modo, la planificación y la gestión comunicacional se vuelve imprescindible para la comunicación institucional, como nexo para la construcción de la realidad que ampare los diversos actores que la integran no cosifique a los sujetos e incida de forma expansiva y estratégica, con efectos multiplicadores y de locomotora sobre la sociedad y la propia organización. También se puede pensar en el aporte que realiza a partir de la utilización de las TIC en el ámbito gubernamental, desmitificando los preconceptos que suelen emerger respecto a las políticas públicas y del Estado a partir de la experiencia vivida y ya con los resultados plasmados en la gestión. Este enfoque es fundamental en nuestro análisis, ya que

[...] si bien la sociedad no determina la tecnología, sí puede sofocar su desarrollo, sobre todo por medio del estado. 0 , de forma alternativa y sobre todo mediante la intervención estatal, puede embarcarse en un proceso acelerado de modernización tecnológica, capaz de cambiar el destino de las economías, la potencia militar y el bienestar social en unos cuantos años. En efecto, la capacidad o falta de capacidad de las sociedades para dominar la tecnología, y en particular las que son estratégicamente decisivas en cada periodo histórico, define en buena medida su destino, hasta el punto de que podemos decir que aunque por sí misma no determina la evolución histórica y el cambio social, la tecnología (o su carencia) plasma la capacidad de las sociedades para transformarse, así como los usos a los que esas sociedades, siempre en un proceso conflictivo, deciden dedicar su potencial tecnológico. ${ }^{4}$ 
Además puede pensarse otra contribución desde la relación, diferenciación y análisis de la comunicación mediática propiamente dicha, y la comunicación institucional como parte de la planificación de políticas públicas, y que de cuenta del "cómo" de esa tarea en el marco del área de comunicación y prensa institucional.

Partiendo de lo expuesto —de los aportes que puede realizar la gestión—, es que se determina "contar" este trabajo, aplicando lo empírico y lo teórico y, como plantea Georges CouffIGNAL, ${ }^{5}$ se considera al Estado desde la interacción de los particularismos y el entramado global, de manera tal de dejar de actuar como médicos que intervienen sólo en circunstancias excepcionales, para elaborar una transformación que evite la marginalización, y capitalice la globalización de la comunicación que permite el encuentro de los actores sociales con sus gobernantes, re-legitimar su accionar, reivindicar su accionar político y dar soluciones concretas.

Esther DíAz sostiene que el conocimiento es una manera de acercarse a la realidad y de generar nuevas formas de la micro política que ayudan a transformar situaciones de opresión, son verdaderas redes de poder que pueden cambiar la vida de cientos, redes dentro de otras redes, ${ }^{6}$ que, como afirma Focault, ${ }^{7}$ cuando una parte de ella se mueve, se mueve el resto. En términos de Umberto Eco, ${ }^{8}$ la presente investigación versará sobre un objeto reconocible: el proceso comunicacional que se desarrolló durante el período 2005-2007 mediante la utilización de los dispositivos Mapa y Cédula Escolar en la DGCyE, y así se intentará validar las prácticas cotidianas mediante, en este caso, la experiencia misma.

El conocimiento científico no es una entidad abstracta sin anclaje en la realidad, sino que está registrado y relacionado con el resto de la sociedad, de ahí que a partir del momento en que un objeto conocido deviene en objeto de aplicación práctica de ese conocimiento se introduce en la historia y se convierte en objeto histórico, es decir cuya naturaleza es finalizada o sometida al uso humano que la modifica. ${ }^{9}$ Así el objeto histórico cambia y el método científico no puede limitarse a verificar por la experiencia sino por lo histórico, que no es reproducible, y las condiciones de verificación pueden haberse transformado por la influencia de la realidad.

De ahí que ciencia es un término de mayor alcance que conocimiento científico y más abarcativo, y comprende a las instituciones gubernamentales y privadas. Así, se aborda este trabajo desde el paradigma hermenéutico, ya que es el que da mayor relevancia a la interpretación de lo que es. La utilización de este paradigma responde a que el mismo no pretende "llegar a un conocimiento objetivo, sino llegar a un conocimiento consensuado", a la vez que no solo intenta "entender" sino "modificar" aquello que se entiende $y$, de este modo, poder arribar a nuevos conocimientos, más profundos o más amplios, que un primer conocimiento obtenido, según el concepto de Guillermo Orozco Gómez. ${ }^{10}$

\footnotetext{
5 Couffignal, Georges. "El papel del Estado en un mundo globalizado: el caso de América Latina. Democracia y Neoliberalismo." Vol 13. Na 1- Institut des Hautes Études de l'Amérique Latine - Paris. 2002.

6 Díaz, Esther (comp.) Metodología de las Ciencias Sociales, Buenos Aires, Biblos, 1997.

7 Foucault, Michel, Las palabras y las cosas, Siglo XXI, México, 2005.

8 Eco, Umberto. Cómo se hace una tesis, Gedisa, Barcelona, 2002.

9 Piñuel Raigada, José Luís, Teoría de la comunicación y gestión de las organizaciones, Ed. Síntesis, Madrid, 1997.

10 Orozco Gómez, Guillermo, La Investigación en Comunicación desde la Perspectiva Cualitativa, Ediciones de Periodismo y Comunicación. FPyCS.UNLP, La Plata, mayo 1996.
} 
Se utiliza preponderantemente la perspectiva cualitativa, que se "manifiesta en su estrategia para tratar de conocer los hechos, procesos, estructuras y personas en su totalidad, y no sólo a través de la medición de algunos de sus elementos". ${ }^{11}$

Otra característica de esta perspectiva es el uso de procedimientos que hacen menos comparables las observaciones en el tiempo y en diferentes circunstancias culturales, es decir, este método busca menos la generalización y se acerca más al fenómeno y a la interacción simbólica. También ubica al investigador en un trato intensivo con los actores involucrados en el proceso de investigación. De esta manera intentaremos, como propone Eco, decir cosas que aún no fueron dichas a la vez que se conceptualizarán términos pertinentes, y describir, determinar y establecer sobre el estudio. ${ }^{12}$

Por su parte, se incorporó a lo largo de este trabajo la categoría de saberes socialmente productivos con el sentido definido por los investigadores de Alternativas Pedagógicas para América Latina (Appeal), como "aquellos saberes que modifican a los sujetos enseñándoles a transformar la naturaleza y la cultura, a diferencia de los conocimientos redundantes, que sólo tienen un efecto de demostración del acervo material y cultural ya conocido por la sociedad". ${ }^{13}$

\section{3.b) La comunicación como alternativa al poder hegemónico}

La planificación y gestión de procesos comunicacionales en sociedades que deben tender a la solidaridad, a la democratización de la palabra, a la construcción de alternativas que consideren al hombre como un sujeto de derecho, en el cual el derecho al acceso y distribución de la información no deba ser discutido en términos de mezquindad política, sino, como emancipación de los hombres, es primordial para repensar las políticas públicas tendientes al desarrollo humano.

La planificación de estos procesos surge de la síntesis de "saberes socialmente productivos" que están en la matriz cultural de los pueblos, ${ }^{14}$ y que, necesariamente, deben ser tenidas en cuenta a la hora de pensar herramientas que comuniquen a los distintos sectores que son parte de una misma comunidad. Al mismo tiempo, la planificación permite sintetizar los diversos saberes de las distintas disciplinas que pueden aportar a la construcción de herramientas, pensamientos, estrategias para modificar la realidad que en muchas ocasiones es contraria a las necesidades de quienes están oprimidos. Cabe aclarar aquí que entendemos la condición de oprimido en los términos en las que lo define Paulo FREIRE, con toda la complejidad que significa la identificación del individuo oprimido con el modelo cultural que le impone el opresor y la condición de emancipación

11 Cfr. www.crefal.edu.mx/Biblioteca/.../tiv4.htm, sitio consultado en octubre 2009.

12 Borsotti, Carlos A.,Temas de metodología de la investigación en ciencias empíricas, Moño y Dávila Editores, Buenos Aires, 2007. 13 La categoría de saberes socialmente productivos es utilizada como resultado de investigaciones efectuadas por los integrantes de Appeal tanto en México como en Argentina y de allí, a lo largo de las investigaciones, han germinado otras categorías como saberes del trabajo; saberes técnicos, saberes de integración, etcétera. Cfr. Gómez Sollano, Marcela, Hamui Sutton, Liz, "Saberes de integración y educación. Nociones ordenadoras y articulación conceptual”, en Puiggrós, Adriana (Dir.) Rodríguez, Lidia, (coord) et al, Saberes: reflexiones, experiencias y debates, Galerna, Buenos Aires, 2009, pág. 39.

14 El equipo de Appeal comenzó a trabajar en la Universidad Nacional Autónoma de México (UNAM), en la Fundación Barros Sierra para la Prospectiva Educativa y con financiamiento del Consejo Nacional de Investigaciones Científicas y Tecnológicas (CONACYT) de México, en 1981. Cuatro años después, APPeAL inició sus proyectos en la Argentina el Instituto de Sociología de la Universidad de Buenos Aires (UBA) y en su sede privada, con apoyo de la UNAM. En 1985 se estableció una sede en Bolivia, en las Universidades de San Andrés y Cochabamba. Cfr. http://www.appealweb.com.ar/spip.php?article3, sitio consultado en octubre 2009. 
como un proceso que debe surgir de la conciencia del oprimido, ya que es el sujeto quien debe construir su realidad a través de las circunstancias que generan el devenir cotidiano. ${ }^{15}$

Aquí vale pensar en esas herramientas que se pueden convertir en la tecnología aplicada, acorde a cada realidad y particularidad y que aporta a esa transformación. Esta correcta aplicación de tecnología disponible —o por crearse — implica considerar no sólo diferentes técnicas, sino, a su vez, hacer los diagnósticos sociales y de comunicación adecuados. Por su parte la realización de estos diagnósticos no puede, en ese análisis, dejar de lado las huellas propias de la institución. Es imprescindible la exploración de sus proyectos preexistentes y las características propias de los sujetos que componen esa comunidad. Tampoco se puede desconocer, o dejar de lado, los saberes (sabidurías) que ya poseen. Sólo a partir de estas consideraciones será posible construir una estrategia comunicacional transformadora y emancipadora.

Una de las dimensiones de la comunicación alternativa es la dimensión cultural de la acción política. Hacer un anclaje en la dimensión de la cultura propia de las comunidades es esencial para el aporte en la construcción de nuevos modelos políticos, sociales, económicos. La concepción de esa comunicación alternativa fue uno de los ejes de gestión de Adriana Puiggrós y su equipo de trabajo, en la cual se propuso nuevos modelos de política educativa en contraposición con los heredados del proyecto hegemónico neoliberal de los 90 . En consecuencia, a la comunidad educativa en su conjunto se le propusieron desafíos impensados apenas cinco años antes. Impensados, si se considera que, por un lado, el sistema educativo argentino $-\mathrm{y}$, en tal sentido, la provincia de Buenos Aires no es la excepción — se ha caracterizado por una construcción verticalista y muy jerarquizada de las políticas y que, por el otro, la imposición de las reformas que necesitaban aplicar en América Latina los organismos multilaterales de crédito habían impuesto un modelo en el que los lineamientos venían de arriba, ${ }^{16}$ sin mayor protagonismo de los sujetos que conforman el sistema. Asimismo, la salida de la convertibilidad y la crisis del gobierno del Presidente DE LA RúA, habían sumido a la sociedad argentina en un estado de profunda desconfianza y deslegitimación de las instancias de conducción, a la vez que estaban siendo cuestionadas, cuando no rotas, las redes de comunicación hacia adentro y hacia fuera del propio sistema. En este sentido la propuesta de definir a los sujetos como sujetos de plenos derechos, con nuevos valores y percepciones del mundo educativo, implicó una forma distinta de comunicar en ambas direcciones (adentro y afuera) de la institución, cuyo eje fue el de revalorizar las formas y prácticas propias, las matrices del sistema, en definitiva, la cultura de uno de los sistemas de la administración pública más complejo, no sólo en el nivel provincial, sino nacional.

El poder hegemónico de los 90 no sólo tuvo como aliado a los medios de comunicación masiva, que representaron e hicieron lobby por un modelo de Estado al cual se lo debilitaba para que éste tuviera menos injerencia, a fin de dejar en manos del mercado el poder absoluto no sólo de equilibrar entre la oferta y la demanda, sino, también, de monopolizar la cultura. El poder hegemónico también tuvo

15 Freire, Paulo, Pedagogía del oprimido, Siglo xxi, Uruguay, 2005.

16 En el uso coloquial de este tipo de expresiones, como "de arriba"; "de la Plata" —en referencia a la capital provincial—, desnudan hasta qué punto el protagonismo de los funcionarios intermedios y los propios directivos de las instituciones educativas formales del sistema había sido avasallado en muchos casos, para imponer la reforma sostenida por la Ley Federal de Educación de la etapa menemista. 
sus aliados en las mismas estructuras de las organizaciones gubernamentales. Funcionarios que fueron capaces de planificar, gestionar y ejecutar políticas que iban en esa dirección.

\section{3.c) Algunas definiciones conceptuales}

En el caso de la comunicación, y el modo de comunicar los nuevos sentidos y valores, ésta juega un papel importante para la suma de voluntades y en la construcción de que otra realidad es posible. Es así que conviene dar cuenta aquí de algunas definiciones:

Comunicación: Es la creación de toda sociedad y de una cultura y en la cual hay que ver los distintos actores que intervienen y los desafíos ante la llegada de cada medio de comunicación, para ver cuáles son los sentidos construidos alrededor de ellos. ${ }^{17}$ De esta forma, decir comunicación es, como propone BARBero, (BARBERo, 2005, pp. 117 y 118), ${ }^{18}$

[...] hablar de procesos cargados de sentidos, pero también antagónicos, de alguna manera la comunicación como el espacio de punta de la modernización, el motor y las transformaciones culturales que nos hacen contemporáneos del futuro y asociada al desarrollo de las tecnologías de información, la comunicación nos proporciona la posibilidad de alcanzar al fin de la definitiva modernización industrial, de la eficacia administrativa, de las innovaciones educativas y hasta del avance democrático que entrañarían las virtualidades descentralizadoras de la informática, $[\ldots]$

En consecuencia, se trata de unificar algunos conceptos entre los que existe un común denominador y es su apuesta por lo humano y que no tienen un único autor, sino que forman parte de notas recogidas en conferencias y charlas formales e informales propias de los espacios académicos que posibilita la actividad universitaria, y que podríamos consignar de la siguiente manera:

- La comunicación es el proceso simbólico humano por excelencia.

- La comunicación es un proceso activo que permite a las personas, a través de referentes comunes, hacer construcciones colectivas para el desarrollo de la sociedad.

- La comunicación permite la construcción de la cultura, ya que como proceso generador de una serie de relaciones e interacciones, a través del intercambio de mensajes, posibilita la convivencia e intercambiar sentidos.

- La comunicación es co-permitir ver; es un acto de búsqueda de sentidos; es un espacio para la interacción humana; la comunicación es constitución y constitutivo de lo humano.

- La comunicación es una herramienta estratégica para los proceso de desarrollo local. Porque facilita la interacción entre los diferentes actores sociales y las gestiones

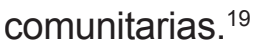

El común denominador de todas estas definiciones se centra en el hecho de que para hablar de

17 Saintout, Florencia, Descubrir una comunicación, en búsqueda de las huellas, en Esteinou Madrid, Javier, Espacios de comunicación, Universidad Iberoamericana, Santa Fe, México.

18 En Botero Montoya, Luis Horacio, "Comunicaciíon política y democracia: un cruce de caminos. Comunicación pública, revista Cuartillas, Publicación del Círculo de Periodistas y Comunicadores Sociales de Antioquia, CIPA, N 15, diciembre 2007, pág. 36.

19 Ceraso, Cecilia, Redes de Desarrollo Local y Colectivos de Comunicación en el Territorio, Tesis de Maestría en Planificación y

Gestión de Procesos Comunicacionales, Dir. Larrañaga, Nancy, La Plata, octubre de 2008. 
comunicación es necesario hablar de ética y de democracia. Si la comunicación no contribuye a formar posiciones de éticas democráticas frente al quehacer del ciudadano, que a su vez contribuyen a la formación y consolidación de la propia institucionalidad democrática, entonces no se puede hablar de comunicación. Desde esta perspectiva, la comunicación, por naturaleza, tiene una función que le es propia: lo político, que es público. ${ }^{20} \mathrm{O}$ bien, siguiendo la definición de Chantal MoufFE, podemos afirmar que la comunicación expresaría, en el registro de las prácticas políticas, la concepción ontológica de lo político. ${ }^{21}$

Institución: Según la RAE es un "Organismo que desempeña una función de interés público, especialmente benéfico o docente o cada una de las organizaciones fundamentales de un Estado, nación o sociedad, a lo que agregaremos que, será siempre entendida como las representaciones sociales del mandato con el cual se crean establecimientos y organizaciones, tal como lo propone Alicia VELAzCo. ${ }^{22}$

Centrándonos en la acción cotidiana, que es donde están presentes los usos y costumbres de una organización; sus creencias, conocimientos, normas y acciones, las dimensiones culturales, históricas, entre otras. Atendiendo estos usos y costumbres que, al interior de los grupos de una organización, son vividos como un modo particular y personal de estar, sentir y trabajar en un establecimiento, y así las instituciones sociales son recreadas por los individuos. Este encuentro o desencuentro entre las instituciones y los individuos se da en el campo de la gestión organizacional. Según Jesús Martín BARBERo la institucionalidad es "una mediación espesa de intereses y poderes contrapuestos" ${ }^{23}$ que afecta la regulación de los discursos que desde el Estado buscan estabilidad y de parte de los ciudadanos, buscan defender sus derechos y el reconocimiento para reconstituir permanentemente lo social.

De esta manera, la comunicación mirada desde la institucionalidad se convierte en cuestión de medios o producción de discursos, que ahora están intentando desplazarse para abrir camino hacia lo cultural y de representación.

Comunicación institucional: Es la construcción vinculada a las necesidades de las personas y los territorios, se da desde el interior de la entidad hacia afuera, lo cual hace imprescindible definir objetivos y metas claras, y generar una comunicación integral, estratégica y eficaz entre los diversos mensajes de la entidad. Ya no se trata de hablar sólo al exterior, sino se trata de interpretar la estructura de la entidad como una interacción permanentemente de información y gestión de esa información de manera eficaz y estratégica. Se ha empleado también como sinónimo de comunicación institucional concepciones como comunicación organizacional, publicidad institucional o relaciones públicas, pero lo cierto es que el fin último es el de trabajar en los procesos de las interrelaciones entre los diferentes actores que confluyen en la institución, de modo que atendiendo las distintas características que

20 Botero Montoya, Luis Horacio. Comunicación política, comunicación pública y democracia, un cruce de caminos. Global Media Journal. http://gmje.mty.itesm.mx/botero.htm

21 Mouffe, Chantal, En torno a lo político, Fondo de cultura económica, Buenos Aires, 2007, pág. 16.

22 Velazco, Alicia, La gestión de las organizaciones educativas. Portal.iteso.mx/portal/page/.../20\%20Alicia\%20Velasco.pdf

23 Martín Barbero, Jesús, De los medios a las mediaciones, Bogotá, Convenio Andrés Bello, 2003, pág 351, pág. 18. 
las atraviesan puedan fomentar el diálogo y la convivencia en pos de innovaciones futuras, la construcción de valores y de referencialidad temática y consensos, generados en el entramado social desde el que se planifica.

Es, por lo tanto, un espacio de intervención y exploración de las posibilidades de cambios sociales y políticos que apoya y moviliza a la democratización de los procesos comunicacionales basada en el reconocimiento de las capacidades de cada persona para expresarse, para describir su respectiva realidad, construir conocimientos y transformar las relaciones sociales en que está inserta. Ser capaces de integrar, hacerse cargo del mayor número de aportes y demandas sociales comunicadas y comunicables, es decir, capaces de ser puestas en común.

Comunicación política: La comunicación política o para los gobiernos no es ajena a la realidad, es decir no puede comunicar la realidad por si sola, sino que es una parte de ella, ${ }^{24}$ y necesita de interlocutores como son los medios masivos de comunicación, los nuevos canales de comunicación como las redes sociales y una persona, equipo o área que planifique la política comunicacional. Esto implica mantener la relación con los ciudadanos durante la gestión misma, mediante un conjunto de recursos técnicos y humanos organizados y destinados a realizar funciones de comunicación que contribuyan a la transparencia, publicidad e interrelación en la ejecución de políticas públicas.

Por su parte, Hannia VEGA sostiene que para acortar la brecha entre sociedad civil y gobiernos, ${ }^{25}$ se debe redimensionar el uso de la comunicación política a partir de situar todos los instrumentos de comunicación como métodos de interrelación adecuados dentro de la dinámica comunicacional. Así, informar adecuadamente implica ofrecer la posibilidad de participar en el proceso de formulación de las políticas públicas a fin de ampliar las oportunidades de escoger.

La comunicación política genera poder y, según Felipe NogueRA, ${ }^{26}$ hay que construirlo día a día, constantemente. A la vez, se puede clasificar la comunicación política en:

- Comunicación reactiva, en la cual se reacciona ante los hechos que se suceden, prevista o imprevistamente, y debe comunicar.

- Comunicación proactiva, como iniciativa que se usa estratégicamente para adelantar la agenda.

- La comunicación contable, por la cual se busca asentar o contabilizar, en la mente de la gente, los logros de la gestión.

- Campaña electoral, que no debe ser ignorada, porque una gestión no debe olvidar nunca el origen ni perder de vista el destino. Es el caso de un gobierno, que viene de una elección y va hacia otra.

- La imperiosa necesidad de escuchar siempre a la gente. Esta es la más importante de todas, y a la que paradójicamente se le suele dar menor importancia. En este caso,

24 Izurieta Cánova, Roberto. "La comunicación política en la era del entretenimiento”, en Izurieta, Arteton, Perina, Estrategias de comunicación para gobiernos, La crujía, Buenos Aires, 2009.

25 Vega, Hannia, "La comunicación de gobierno e Internet”, en Izurieta, Arteton, Perina, Ibídem. 
se debe estar siempre pendiente, estar siempre abierto. Estar en contacto, el hecho de escuchar, según este autor, ya es una buena comunicación.

Planificación: La planificación es una herramienta que presenta una doble dimensión: una científica y otra política al proponer un conjunto de acciones inspiradas en un tipo de pensamiento sistemático y con el propósito de alcanzar determinados objetivos. ${ }^{27}$ Cada una de estas dimensiones está atravesada, a su vez, por perspectivas epistemológicas y científicas que representan la toma de posición y se expresan en el modo de ser y actuar de los protagonistas del proceso. Otro aporte de esta concepción es que la planificación puede ser entendida y utilizada por actores sociales con voluntad de cambio, como una herramienta eficaz para armonizar propósitos que se apoyen en objetivos políticos y sociales de transformación, tomando en cuenta todos los elementos del escenario en el que los mismos deben concretarse y desarrollando la manera de implementarlos de manera eficaz para generar alternativas positivas, como parte integral de un único proceso que comienza con el diagnóstico realizado desde la comunicación o desde una perspectiva comunicacional, sigue con la planificación misma y culmina con el diseño de la gestión.

Otros autores, como Washington URANGA y Daniela BRUNO, señalan los distintos enfoques de la planificación: mientras que para algunos "es un recurso autoritario que se ejerce desde el poder; para otros, es una herramienta capaz de generar espacios de participación que alimenten la concreción de perspectivas de cambio y desarrollo". Planificar implica "organizar los pasos y los medios, partiendo de un diagnóstico de la realidad, de las situaciones que la conforman, buscando respuestas a los problemas y generando alternativas", agregan. ${ }^{28}$ En la misma dirección, Gloria Pérez SeRrAno señala que "la planificación ayuda a conjugar la utopía con la realidad, a armonizar lo que es y lo que debiera ser, a analizar dónde estamos y hacia lo que se tiende". ${ }^{29}$

Por su parte, Prieto CASTILLO expresa que la "planificación de la comunicación institucional es una necesidad de las organizaciones públicas y privadas, aunque muchas no hayan tomado conciencia de ello". Su ausencia provoca "problemas tanto en las relaciones internas como externas"; 30 lo cual incide en el logro de los fines de las grandes mayorías a las que apuntan los organismos. No se trata de un hecho sencillo y su complejidad hace que no siempre sea asumida.

Gestión: Implica poner en marcha un conjunto de acciones y procedimientos mediante los cuales se despliegan una variedad de recursos de comunicación para apoyar la labor de las organizaciones. El modo de planificar puede presentar diversas características con lo que el estilo de gestión es el espacio y modo de hacer. Es ahí donde se cruzan tres componentes fundamentales del cambio: las personas, los recursos y los servicios generados. Así, el estilo de gestión se aprende y desarrolla en la acción profesional directa.

27 Martin, María Victoria, “Planificación en Comunicación: Tres Aproximaciones a su Finalidad en las Organizaciones”, en Razón y Palabra. Revista Electrónica. www.razonypalabra.org.mx/.../n55/mmartin.html.

28 Uranga, W. y Bruno, D., Itinerarios, razones e incertidumbres en la planificación de la comunicación. Aproximaciones a la planificación de procesos comunicacionales, Buenos Aires, Mimeo, abril de 2001.

29 Pérez Serrano, G., Elaboración de proyectos sociales. Casos práticos, Madrid, Ed. Narcea, 1993, pág.9.

citado en Uranga, W. y Bruno, D., Op. cit.

30 Prieto Castillo, D., Planificación de la comunicación institucional, San Salvador, mimeo, Universidad Centroamericana José Simeón Cañas, 1993, pág.4. 
Planificación y gestión educativa: Tal como plantea Alicia VELAZCO, se aborda la gestión educativa desde la concepción de encuentros y desencuentros entre las instituciones y los individuos a partir de lo cual el "encargado de un área comienza a comprender las cercanías o distancias que hay entre el modelo institucional y la manera particular en que cada individuo lo habita. Se trabaja en el reconocimiento de que el cambio en las organizaciones es permanente." 31

También es imprescindible que en la planificación "participativa", como define ANDER-Eggg ${ }^{32}$ se descarten las falsas presunciones, así como acercar a los actores para que asuman el protagonismo de un trabajo colectivo que construya consensos. Esto implica despojarse en diferentes casos de las formas clásicas de trabajo y se trata de un esfuerzo por incluir intereses, motivaciones y convicciones de todos los actores intervinientes en el proceso. Es decir, hay que estar dispuesto a ceder en algún momento, porque cada parte siempre cede algo para llegar a su objetivo. Esto no es más que un requisito del pluralismo y la democracia de toda institución que quiera realizar un trabajo pensado desde la fraternidad y la libertad.

Educación: La RAE, la define como: acción y efecto de educar; crianza, enseñanza y doctrina que se da a los niños y a los jóvenes; o como instrucción por medio de la acción docente. La educación es el proceso de sociabilización de los individuos, a partir del cual, asimila y aprende conocimientos, materializa habilidades y valores, produciendo cambios intelectuales, emocionales y sociales. En el caso de los niños busca fomentar el proceso de estructuración del pensamiento y de las formas de expresión. Así, tal como se refleja en el nuevo cuerpo jurídico que regula en la materia, surgido en los últimos años,

la educación brindará las oportunidades necesarias para desarrollar y fortalecer la formación integral de las personas a lo largo de toda la vida y promover en cada educando/a la capacidad de definir su proyecto de vida, basado en los valores de libertad, paz, solidaridad, igualdad, respeto a la diversidad, justicia, responsabilidad y bien común. ${ }^{33}$

Por su parte, en el artículo $3^{\circ}$ de la norma provincial sancionada en 2007 , se afirma que

La educación es una prioridad provincial y constituye una política de Estado para construir una sociedad justa, reafirmar la soberanía e identidad nacional, profundizar el ejercicio de la ciudadanía democrática y republicana, respetar los derechos humanos y las libertades fundamentales y fortalecer el desarrollo económico-social sustentable de la Provincia en la Nación. ${ }^{34}$

Rol del Estado: En sociedades que presentan altos índices de exclusión social, el papel de los Estados nacionales es fundamental para alcanzar mayores niveles de equidad, de justicia social y de integración de la ciudadanía. Estos objetivos requieren sostener nuevamente la centralidad de lo público y lo político. Se hace necesaria la revalorización del Estado como administrador

\footnotetext{
31 Velazco, Alicia. La gestión de las organizaciones educativas. Universidad Jesuita de Guadalajara. portal.iteso.mx/portal/page/ .../20\%20Alicia\%20Velasco.pdf, sitio consultado octubre 2009.

32 Ander-Egg, Ezequiel, La planificación educativa.Conceptos, métodos, estrategias y técnicas para educadores, Magisterio del Río de La Plata, Argentina.1996.

33 Ley 26.206/06, de Educación Nacional. 
y gestor de políticas públicas democratizadoras. Ello demanda de los funcionarios públicos no sólo la capacidad de liderazgo, sino, además el compromiso ético-político. Los procesos de transformación educativa deben ser entendidos en ese contexto. ${ }^{35}$

Estrategias: Es mucho más que un plan de trabajo, ${ }^{36}$ implica una investigación previa para definir el mensaje, establecer los canales y el público, y define un plan de comunicación, sumamente detallado, con actividades y tácticas con las que se va a trabajar. Se trata de un plan integral en el que cobre sentido todo lo que hace y deja de hacer el gobierno o gestión, todo lo que comunica o deja de comunicar, tal como lo plantea DuRÁn BARBA. ${ }^{37}$ Todo envía mensajes a la población, más aún, cuando esté cargada de políticas ya delineadas.

Por otra parte, la estrategia de comunicación institucional de prensa necesita identificar los inconvenientes, las expectativas, los deseos y las acciones del organismo que cree poder llevar a cabo la tarea. Este análisis previo, permite identificar también las oportunidades reales y los posibles conflictos a futuro tanto externos como internos. No hay que olvidar que toda institución está conformada por personas que poseen distintas ideologías, prioridades y participación en el construir de la institución. Así crear, organizar y poner en marcha "alternativas" que pueden construir, siempre que se cuente con decisión política, el cambio de lo establecido y que requiera ser modificado necesita de la participación de los que integran la institución. Pero aún hay algo más importante. El análisis de situación ayuda a tener una descripción del campo de acción real y evita el divague de aquellos que pretenden poner en marcha soluciones románticas, utópicas y poco efectivas a la hora de recoger los frutos.

En otra instancia, pero en igual sentido, se plantea la necesidad, como en todo organismo público o privado, de coordinar y difundir las distintas actividades que dependen de él y que se llevan a cabo tanto adentro de su ámbito como en sus lugares de influencia. Esto permitirá construir una imagen clara de gobierno y centralizar y descentralizar a la vez la información para su difusión en medios gráficos, radiales, televisivos y digitales. ${ }^{38}$ Para ello, es necesario definir tácticas, como el arte del mejor empleo de los recursos, que se ocupa de los medios para alcanzar los fines estratégicos. Según SCHEINSOHN, ${ }^{39}$ se pueden considerar herramientas tácticas de comunicación: la publicidad, las relaciones públicas, la promoción, la difusión periodística, los actos, etcétera.

\footnotetext{
35 La formación de recursos humanos para la gestión educativa en América Latina. Informe del foro realizado en el IIPE- Instituto Internacional de Planeamiento de la Educación, Unesco, 1999.

36 Izurieta Cánova, Roberto. La comunicación política en la era del entretenimiento, en Izurieta, Arteton, Perina, Estrategias de comunicación para gobiernos, La crujía, Buenos Aires, 2009.

37 Durán Barba, Jaime, Estrategias de comunicación política, en Izurieta, Arteton, Perina, Estrategias de comunicación para gobiernos, La crujía, Buenos Aires, 2009.

38 En este sentido se implementó el Proyecto comunicacional de la Dirección de Prensa de la DGCyE de la provincia de Buenos Aires. La Plata. 2006.

39 Scheinsohn, Daniel, Comunicación estratégica, Granica, Buenos Aires, 2009.
} 


\section{3.d) Estado de Situación. El Mapa de la educación desde una perspectiva latinoamericana}

La rica historia de los acontecimientos sucedidos en América Latina, al menos en lo que fueron sus dos últimos siglos, con sus luchas y resistencias, demuestra que millones de sus habitantes recuperan los saberes y las prácticas populares. Podría decirse que esta es una contra respuesta -y que, como tal, conlleva imperiosamente romper con la imposición de prácticas y teorías que las menospreciaron-al accionar de aquellas políticas, sostenidas en teorías de las corrientes europeas que tendieron a considerarlas atrasadas. Se trata de recuperar la propia mirada sobre las necesidades, los proyectos y la construcción de futuros desde América Latina y para los latinoamericanos. En este sentido, la heterogeneidad de las identidades culturales, sociales, políticas y económicas, obliga a pensar en proyectos de emancipación que las respeten, pero que a su vez, sean integradoras de un sentido común, de una matriz cultural latinoamericana.

Este mirar desde el espacio social e histórico de los pueblos latinoamericanos, fundamenta una filosofía y un conocimiento que necesariamente piensa la historia y el devenir humano "también desde la esclavitud y la servidumbre". Un lugar epistemológico que lleva a evaluar críticamente las corrientes ideológicas del norte que se expresan en los escenarios políticos de nuestros países, preguntando en cada contexto particular, el espacio que ellas le otorgan a las mayorías sociales, conceptual que recupere las resistencias culturales, las manifestaciones políticas de los pueblos, la literatura, el ensayo, las formas de conocimiento y las mentalidades populares, los pequeños y grandes episodios de dignidad, los saberes que están en las "orillas de la ciencia". ${ }^{40}$

Esto implica comprender cuáles son las falencias, las dificultades y los límites de aquellos proyectos concebidos desde el concepto de la Modernidad. Implica redescubrir - o descubrir - aquellos lugares comunes, de conexión, que existen entre los pueblos y que han sido menoscabados por la concepción neoliberal que atravesó la historia de los países americanos, al menos en los 90, como respuesta a que otra historia es posible. Esto requiere concebir al sujeto latinoamericano como protagonista y hacedor en la construcción de su propia historia, recuperando los saberes y las prácticas de los movimientos sociales nacionales y populares, que existen y son cientos. Saber que hay otros territorios que no sólo son los territorios tradicionales, como el que configuran las fronteras cuyos límites determinan que finaliza un país y comienza otro. Existen territorios como los de la salud, la educación, las TIC, la política, la economía, entre otros, que deben recuperarse para el bien común latinoamericano.

Desde esta perspectiva, el tema de la heterogeneidad social de América Latina, no surge como consecuencia de la crisis de los paradigmas occidentales. Si se mira la historia de los otros pensamientos y experiencias latinoamericanas, se hará evidente que desde hace varios siglos, esa problemática aparece como un dato constitutivo. En las Proclamas de Tupac Amaru se reconoce la compleja diferenciación, étnica, social y cultural de las capas populares y Bolívar o Martí remarcan la original composición de nuestros pueblos, el respeto a las identidades y la búsqueda de lineamientos de unidad, la aspiración de alcanzar la fusión de sangre sin "elegidos" genéticos o culturales que permitan encontrar sendas comunes de justicia y libertad. ${ }^{41}$

América Latina sufre aún, a pesar de las políticas aplicadas por los diversos gobiernos actuales 
de tendencia nacional y popular cuyos modelos económicos son de corte social, de inclusión y redistribución de las riquezas, las nefastas consecuencias materiales y simbólicas de los 90.

En materia educativa, Adriana PuIGGRós señala que en las discusiones internacionales se preveía que "para el año 2000 en América Latina no habría analfabetos y se habría llegado a un alto nivel de escolarización", ${ }^{42}$ postura que se apoyaba en una concepción lineal, originada en intereses económicos y políticos internacionales, neoliberales y pseudo-científicas. La consecuencia de estas políticas ha sido la desarticulación y la dispersión de los sistemas públicos, pero no ataca solamente al Estado protector, son directamente al Estado, y en muchos casos los utiliza en beneficio del poder, así es como se conforman los estados clientelares, peligrosa vinculación populista de la más conservadoras de la conformación social.

HoyenAmérica Latina existen dos ejes fundamentales de discusión para sostener las políticas educativas, son dos ejes-problemas — como diría Paulo FREIRE— y son la pobreza y el mercado y que, en términos de PuIGGRós, se la aborda como injusticia social que se multiplica, por lo cual es imprescindible discutir y elaborar estrategias educativas que contribuyan al imperio de la justicia social.

Precisamente con esta metodología de la investigación se analizan estos posicionamientos conceptuales, mediante los datos que se han podido relevar y sistematizar con las herramientas del área de Planeamiento de la Dirección General de Cultura y Educación (DGCYE), Mapa y Cédula Escolar. Asimismo, estas herramientas a la vez que permiten la toma de decisiones políticas estratégicas en materia educativa, tienen que ser puestas a disposición del público y para ello se requiere contar con medios adecuados. Ejemplo de ello es que el informe que se incorpora a continuación de manera parcial, no sólo ha estado disponible desde su elaboración en el portal de la DGCYE (www.abc.gov.ar) sino también en otras publicaciones que se editaron durante el periodo 2005-2007.43

Se considera pertinente incluirlo, por el valor de la información que allí se relevó y que ilustra algunos de los ejes de este trabajo de tesis. Se trata del informe de "Indicadores educativos, comparación de 13 países latinoamericanos y provincia de Buenos Aires", elaborado por la DGCYE en 2005, que muestra un análisis de: Argentina, Bolivia, Brasil, Costa Rica, Chile, El Salvador, Guatemala, Honduras, México, Nicaragua, Paraguay, Perú y Uruguay, y la comparación entre todos los países se centra en la población urbana, que da cuenta de: ${ }^{44}$

Para la población urbana de 5 años se comparan las tasas de escolarización y se analiza qué países cuentan con legislación acerca de la obligatoriedad de la escolaridad en esta edad. La población urbana de 6 a 14 años es analizada a partir de las tasas de escolarización y porcentajes de extraedad en dos o más años para la población de 6 a 14 años por tramos de edad ( 6 a 8, 9 a 11 y 12 a 14 años). Se definen cuatro niveles para cada indicador de la distribución: bajo, medio-bajo, medio-alto y alto. Se presentan diagramas para cada tramo de edad que muestran en qué situación se encuentra cada país, pudiendo distinguir cuatro situaciones: alta tasa de escolarización y bajo porcentaje de extraedad (situación

42 Puiggrós, Adriana, Cartas a los educadores del siglo XXI, Op. cit.

43 Cfr. "Estadística educativa" en Revista Anales de la educación común, publicación de la DGCyE, Tercer siglo, año 1, números 1-2, septiembre 2005, pág. 254.

44 Indicadores educativos: comparación de 13 países latinoamericanos y provincia de Buenos Aires. Dirección de Información y Estadística. Dirección Provincial de Planeamiento. Dirección de Información y Estadística. Dirección General de Cultura y Educación. Provincia de Buenos Aires, en revista Anales de la Educación común, Tercer siglo, año 1, números 1-2 "Adolescencia y juventud". Publicación de la dgcye, septiembre de 2005, pág. 275. 
óptima); alta escolarización y alta extraedad; baja tasa de escolarización y baja extraedad; y, por último, baja tasa de escolarización y alto porcentaje de extraedad (situación más desfavorable).

\section{Población de 5 años}

Los países con una tasa de escolarización superior al $75 \%$ son Argentina, México, Uruguay, Perú y Chile. Hay que tener en cuenta que los países que tienen leyes de obligatoriedad de la sala de 5 años son Argentina, Costa Rica, El Salvador y Uruguay. Por otro lado Perú expresa un compromiso por expedir leyes de obligatoriedad para la educación inicial.

\section{Población de 6 a 14 años}

A partir de las tasas de escolarización y porcentajes de alumnos con extraedad en 2 o más años de 13 países latinoamericanos para la población urbana (Argentina, Bolivia, Brasil, Costa Rica, Chile, El Salvador, Guatemala, Honduras, México, Nicaragua, Paraguay Perú, Uruguay) se comparan los valores y se definen, en cada tramo de edad, cuatro niveles: bajo, medio-bajo, medio-alto y alto.

Argentina tiene la tasa de escolarización más alta para la población urbana y el porcentaje de extraedad está dentro de los niveles más bajos para los tres grupos de edades. México, Uruguay, Perú, Costa Rica y Chile presentan estadísticas similares a la Argentina, aunque disminuye la tasa de escolarización y aumenta la extraedad ${ }^{45}$ excepto Costa Rica que tiene los valores más bajos para la extraedad en dos o más años en la población urbana (sin sufrir grandes variaciones para la población rural).

Guatemala tiene tasas de escolarización con niveles bajos, y la extraedad muy alta. Similar situación se presenta en El Salvador, aunque disminuye la extraedad. Honduras y Nicaragua tienen una tasa de escolarización baja; Nicaragua presenta una tasa de escolarización menor en el grupo de 12 a 14 años respecto a la tasa para las edades de 6 a 11 años. Paraguay, Bolivia y Brasil presentan una tasa de escolarización media con un alto porcentaje de extraedad, principalmente el primero que tiene el porcentaje de extraedad más alto en todos los grupos de edad.

\section{Población de 15 a 17 años}

Argentina, Bolivia, Chile tienen una tasa de escolarización alta. En lo que varían estos países es en el porcentaje de extraedad. Argentina y Chile tienen una extraedad baja; Bolivia alcanza un porcentaje de alumnos con extraedad medio-alto. Brasil, El Salvador y Uruguay muestran una tasa de escolarización media-alta.

Con respecto a la extraedad de estos tres países, El Salvador tiene una extraedad baja; Uruguay, media-baja; mientras que Brasil tiene un alto porcentaje de extraedad. Nicaragua, Paraguay y Perú muestran una tasa de escolarización media-baja. Los porcentajes de extraedad de estos países varían: Nicaragua tiene un nivel medio-alto, mientras que Paraguay y Perú alcanzan los valores más altos.

Los países con las tasas de escolarización más bajas en este grupo de edad son Costa Rica, Honduras, Guatemala y México. Los dos primeros tienen un porcentaje de alumnos con extraedad medio-bajo; México, bajo; mientras que el caso más crítico es el de Guatemala que tiene un nivel de extraedad medio-alto.

\footnotetext{
Tasa de analfabetismo. La tasa de analfabetismo para América Latina y el Caribe La población analfabeta de 15 y más años es $12,7 \%$ en el año 2005. Se comparan las tasas de analfabetismo de 11 países latinoamericanos para la población urbana (Argentina, Bolivia, Brasil, Chile, El Salvador, Guatemala, Honduras, México, Nicaragua, Paraguay y Perú) según tres grupos de edad y se definen en cada tramo de edad, cuatro niveles: bajo, medio-bajo, medio-alto y alto.
} 
TABLA I. TASAS dE ESCOLARIZACIÓN, SECÚN dECILES dE INCRESO FAMILIAR PER CÁPITA

Total Aglomerados Provincia de Buenos Aires. Afios $1995=2004$

\begin{tabular}{|c|c|c|c|c|c|}
\hline \multicolumn{6}{|c|}{ POBLCIÓN DE 12 A 14 AFOSOS } \\
\hline ANO & TOTAL & $\begin{array}{l}\text { SiN } \\
\text { Inckesos } \\
\text { rotal I }\end{array}$ & $\begin{array}{c}\text { Decius } \\
2 \times 3\end{array}$ & $\begin{array}{c}\text { Dialts } \\
4 \times 8\end{array}$ & $\begin{array}{c}\text { OESILES } \\
9 \times 10\end{array}$ \\
\hline 1995 & $90,2 \%$ & $82,9 \%$ & $90,4 \%$ & $94,8 \%$ & $95,2 \%$ \\
\hline 1996 & $89.2 \%$ & $84.9 \%$ & $92,0 \%$ & $92.4 \%$ & $100,0 \%$ \\
\hline 1997 & $95.4 \%$ & $89.9 \%$ & $95.5 \%$ & $98.4 \%$ & $100,0 \%$ \\
\hline 1998 & $98,8 \%$ & $98.4 \%$ & $98,0 \%$ & $99.3 \%$ & $100,0 \%$ \\
\hline 1999 & $97.7 \%$ & $95.4 \%$ & $97,3 \%$ & $98,7 \%$ & $100,0 \%$ \\
\hline 2000 & $98.3 \%$ & $95.4 \%$ & $99.5 \%$ & $100,0 \%$ & $100.0 \%$ \\
\hline 2001 & $97.6 \%$ & $98,2 \%$ & $97.5 \%$ & $97.9 \%$ & $99.1 \%$ \\
\hline 2002 & $98,7 \%$ & $99.1 \%$ & $97.9 \%$ & $98.7 \%$ & $100.0 \%$ \\
\hline $200_{3}$ & $99.5 \%$ & $98,0 \%$ & $99.7 \%$ & $100,0 \%$ & $100,0 \%$ \\
\hline 2004 & $97.2 \%$ & $94.8 \%$ & $97.1 \%$ & $98.7 \%$ & $100,0 \%$ \\
\hline
\end{tabular}

\begin{tabular}{|c|c|c|c|c|c|}
\hline \multicolumn{6}{|c|}{ POBLACION DE 15 A 18 ANOS } \\
\hline ANO & TOTAL & 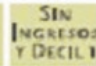 & $\begin{array}{l}\text { Declues } \\
2 \gamma_{3}\end{array}$ & $\begin{array}{c}\text { Diales } \\
4 \wedge 8\end{array}$ & $\begin{array}{c}\text { Deciles } \\
\text { grio }\end{array}$ \\
\hline 1995 & $60,7 \%$ & $40,3 \%$ & $48.5 \%$ & $68.7 \%$ & $97,1 \%$ \\
\hline 1996 & $59.8 \%$ & $37,1 \%$ & $58,2 \%$ & $69.7 \%$ & $97,6 \%$ \\
\hline 1997 & $64.9 \%$ & $43.0 \%$ & $57.9 \%$ & $75.5 \%$ & $85,9 \%$ \\
\hline 1998 & $69.7 \%$ & $61,2 \%$ & $66,3 \%$ & $74.7 \%$ & 91,496 \\
\hline 1999 & $75.7 \%$ & $69,2 \%$ & $72,8 \%$ & $82,3 \%$ & $96,2 \%$ \\
\hline 2000 & $73.8 \%$ & $64.0 \%$ & $75.4 \%$ & 75.296 & $94,1 \%$ \\
\hline 2001 & $74.7 \%$ & $65.6 \%$ & $73.1 \%$ & $76.5 \%$ & $91,6 \%$ \\
\hline 2002 & $80,8 \%$ & $72.5 \%$ & $78,9 \%$ & $84.2 \%$ & $93,8 \%$ \\
\hline 2003 & $80,0 \%$ & $72,0 \%$ & $76.9 \%$ & $82,0 \%$ & $98,6 \%$ \\
\hline 2004 & $79.3 \%$ & $67.6 \%$ & $74.8 \%$ & $86.9 \%$ & $98,0 \%$ \\
\hline
\end{tabular}
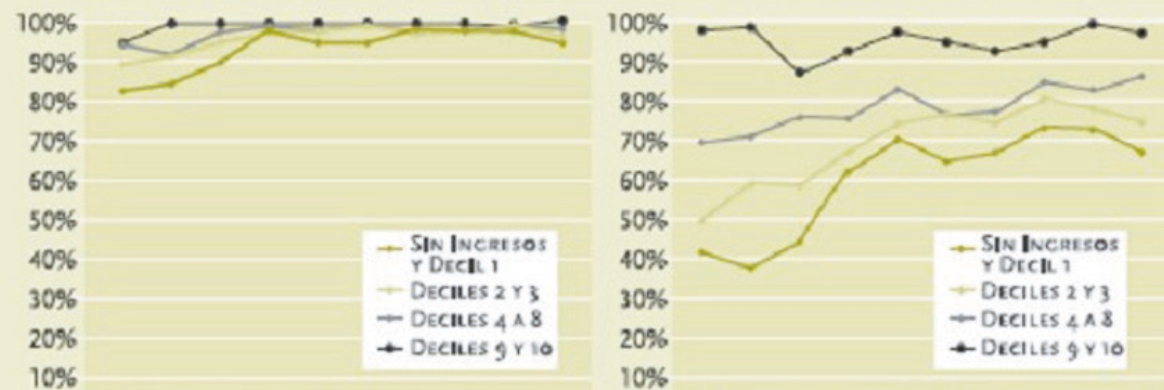

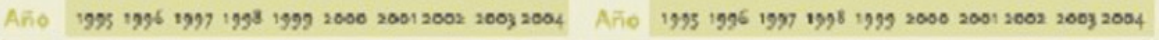

Fuente: Elaberacion propia sobre datos del INDEC; EPH, 1995 - 2004. Incl.ye los aglomerados de Conurbano, Cran La Plata, Bahla Flanca, Mardel Plata

( $\left.{ }^{k}\right)$ Nota: estas tasas de escolarización se obxienen por muestra, por lo tanto, deben leerse den tro de ciertos parámetros. Un grado de error del $3 \%$ es aceptado como válido en el ámbito de las ciencias sociales y es, también, el que permite el Indec en la implement ación de la z $\%$. En consecuencia, una tasa de escolarización del os \% para el grupo de 12 a 14 años de edad indica que entre el $92 \%$ y el $08 \%$ de los ninos de ese grupo cta rio se asisten a al gún establecimiento educa tivo. En este mis mo sentido, una tasa del $100 \%$ refleja que entre el $97 \%$ y el $100 \%$ de los individuos de determinado grupo está inserto en el ámbito educatio.

\title{
Límites de los niveles definidos para la Tasa de analfabetismo:
}

\author{
Alto Medio-alto Medio-bajo Bajo \\ 15 a 24 años $3,5 \%-6,9 \% 2,1 \%-3,4 \% 0,8 \%-2,0 \% 0,6 \%-0,7 \%$ \\ 25 a 34 años $5,7 \%-11,2 \% 3,7 \%-5,6 \% 1,9 \%-3,6 \% 0,3 \%-1,8 \%$ \\ 35 a 49 años $9,0 \%-16,3 \% 5,6 \%-8,9 \% 3,7 \%-5,5 \% 1,3 \%-3,6 \%$
}

\section{Población de 15 a 24 años}

Para el grupo de 15 a 24 años Argentina, Bolivia, Chile y Perú aparecen con las tasas más bajas de analfabetismo para áreas urbanas; México y Paraguay con tasas mediabajas; Brasil y El Salvador, media-altas; mientras que Guatemala, Nicaragua y Honduras presentarían las tasas más altas de analfabetismo. Es importante mencionar que para los casos de Brasil, El Salvador, Guatemala, Honduras y Nicaragua, las tasas de analfabetismo varían considerablemente de las áreas urbanas a las rurales, manifestando diferencias de entre 10 y 19 puntos, presentando las áreas rurales las tasas más altas.

\section{Población de 25 a 34 años}

Para el grupo de 25 a 34 años Argentina, Chile y Perú aparecen con las tasas más bajas de analfabetismo para áreas urbanas; Bolivia, México y Paraguay con tasas mediaaltas; Brasil y El Salvador, media-baja; mientras que Guatemala, Honduras y Nicaragua presentarían las tasas más altas de analfabetismo. Respecto a las diferencias entre áreas urbanas y rurales a los casos señalados en el grupo etáreo de 15 a 24 se agrega 
ahora también Bolivia, con una diferencia considerable entre la tasa de analfabetismo urbano y rural. En todos los casos las diferencias se acrecientan respecto de lo analizado en el grupo etáreo de 15 a 24, señalando como casos que presentan la mayor diferencia a los países de Guatemala y Nicaragua. Como puede notarse, la situación es similar que para la población de 15 a 24 años, exceptuando el caso de Bolivia que aumenta su tasa de analfabetismo para la población de 25 a 34 años.

\section{Población de 35 a 49 años}

Para el grupo de 35 a 49 años nuevamente los países Argentina, Chile y Perú aparecen con las tasas más bajas de analfabetismo para áreas urbanas; Bolivia, México y Paraguay con tasas media-altas; Brasil y Honduras se ubican en el nivel de analfabetismo medio-alto; mientras que en El Salvador, Guatemala y Nicaragua presentan las tasas más altas de analfabetismo. Respecto a las diferencias entre áreas urbanas y rurales se mantienen y aún acrecientan las diferencias con respecto al grupo etáreo de 15 a 24 años.

\section{Análisis de la Población analfabeta de 15 a 49 años}

Como puede observarse la tendencia se mantiene constante en el análisis anterior, pudiendo concluir lo siguiente:

- Argentina, Chile y Perú tienen las tasas de analfabetismo más bajas.

- Bolivia, México y Paraguay, nivel de analfabetismo medio-bajo (en el caso de Bolivia, le corresponde el nivel bajo para la edad de 15 a 24 años)

- Brasil y El Salvador, analfabetismo medio-alto (El Salvador se ubica en el nivel alto para la población de 35 a 49 años)

- Guatemala, Honduras y Nicaragua son los países con las tasas más altas de analfabetismo.

- Todos los países tienen tasas más bajas para las edades tempranas (de 15 a 24 años), aumentando el analfabetismo hacia las edades de 25 a 34 años y 35 a 49 años (excepto Perú que tiene una tasa más alta para la población de 15 a 24 años respecto de la de 25 a 34 años).

- Bolivia, Brasil, El Salvador, Guatemala, Honduras y Nicaragua presentan una brecha pronunciada entre las tasas de analfabetismo en las zonas urbanas y rurales, dejando en condiciones de mayor analfabetismo a ésta última.

\section{3.e) La situación de América Latina en el marco de la sociedad de la Información y las TIC: nuevas y viejas fronteras}

Ya se ha efectuado un recorrido acerca de la información estadística disponible respecto a la situación educativa en nuestro continente. El otro aspecto a considerar aquí se refiere al estado de situación en materia de uso de tecnologías de la información y la comunicación, las tic.

En un documento elaborado en 2003 por la Comisión Económica para América Latina y el Caribe (CEPAL), ${ }^{46}$ cuando los países de la región se preparaban para la primera fase de la Cumbre Mundial sobre la Sociedad de la Información, ${ }^{47}$ y al considerar la creciente presencia de los temas vinculados a las TIC en el discurso político, se plantearon los siguientes interrogantes:

46 "Los caminos hacia una sociedad de la información en América Latina y el Caribe.", CEPAL, documento elaborado en el marco de la Conferencia Ministerial Regional Preparatoria de América Latina y el Caribe (Bávaro, Punta Cana, República Dominicana, 29 al 31 de enero de 2003), 78 páginas.

47 La Cumbre Mundial sobre la Sociedad de la Información (CMSI) se desarrolló en dos fases. La primera fase tuvo lugar en Ginebra acogida por el Gobierno de Suiza, del 10 al 12 de diciembre de 2003 y la segunda en Túnez acogida por el Gobierno de 
¿Qué tipo de sociedad de la información se desea construir? ¿Cuáles son las características básicas y las particularidades del proceso de transición a la sociedad de la información en América Latina y el Caribe? ¿Qué medidas de política se podrían adoptar para impulsar la transición hacia la sociedad de la información $?^{48}$

Estas preguntas siguen vigentes; más aún, cabe agregar una cuestión más fundamental: ¿Se puede observar efectos positivos en la relación entre las TIC y el desarrollo después de casi una década de trabajo?, ¿cuál ha sido y es el esfuerzo, en este sentido, que han desarrollado los gobiernos desde comienzo del siglo XXI?, ¿alcanza sólo con la inversión en compras de computadoras para cada alumno si esta decisión no va acompañada de un proyecto integral que contemple lo educativo, el avance de las nuevas tecnologías y la concepción políticopedagógica que debe acompañar? Por último, ¿qué son las TIc?

\begin{abstract}
Las TIC se definen como sistemas tecnológicos mediante los que se recibe, manipula y procesa información, y que facilitan la comunicación entre dos o más interlocutores. Por lo tanto, las TIC son algo más que informática y computadoras, puesto que no funcionan como sistemas aislados, sino en conexión con otras mediante una red. También son algo más que tecnologías de emisión y difusión (como televisión y radio), puesto que no sólo dan cuenta de la divulgación de la información, sino que además permiten una comunicación interactiva.$^{49}$
\end{abstract}

En el documento "La sociedad de la información en América Latina y el Caribe: Desarrollo de las tecnologías y tecnologías para el desarrollo" (CEPAL, 2008), se afirma que

En los últimos años, los países de América Latina y el Caribe han progresado enormemente en el uso masivo de las TIC en las áreas más diversas del desarrollo económico y social. Esto incluye el despliegue de una infraestructura de información digital, la modernización del Estado, la digitalización de procesos económicos para aumentar la productividad, el mejoramiento de la educación y la salud y la gestión de desastres naturales, entre otras cosas. $^{50}$

En el mismo documento, la CEPAL sostiene que con el avance hacia sociedades de la información en América Latina y el Caribe se han logrado resultados positivos en poco tiempo, lo que ha convertido a las TIC en un recurso tangible para abordar los retos que plantea la agenda de desarrollo. Sin embargo, este progreso tecnológico continúa y se acelera, lo que redunda en nuevos desafíos, a la vez que el proceso de transición hacia sociedades de la información no ocurre en el vacío sino insertado en estructuras regionales preexistentes, lo que implica considerar otros problemas como "el bajo ingreso por habitante y su desigual distribución, la debilidad institucional y los limitados niveles de educación y capacidades."51 Quizá lo más interesante para destacar de este documento es la consideración de que estas tecnologías "son una herramienta y no un fin" y que,$^{52}$ por lo tanto, surge el siguiente interrogante: "¿deben ser las TIC la esencia del enfoque sectorial para el desarrollo de las sociedades de la información o son los diferentes aspectos del desarrollo los que deben ocupar un lugar fundamental en esta

48 CEPAL, Op. cit.

49 "Los caminos hacia una sociedad de la información en América Latina y el Caribe, Conferencia Ministerial Regional Preparatoria de América Latina y el Caribe para la Cumbre Mundial sobre la Sociedad de la Información. Bワaro, Punta Cana, República Dominicana, 29 al 31 de enero de 2003, en http//wnwwituint/wsis/docs/rc/bavaro/eclac-es.pdf, sitio consultado octubre 2009.

50 "La sociedad de la información en América Latina y el Caribe: Desarrollo de las tecnologías y tecnologías para el desarrollo", Santiago de Chile, CEPAL, 2008.

51 Ibidem.

52 CEPAL, 2008, Ibidem. 
revolución tecnológica?"53.

La pregunta adquiere nuevos sentidos al considerar la desigualdad que el acceso a las TIC parece agudizar en la región y el posible impacto de su uso para mejorar los sistemas tradicionales de educación. En tal sentido durante la realización de la primera fase de la Cumbre Mundial sobre la Sociedad de la Información (CMSI), (Ginebra, 2003) se incluyó en la Declaración de Principios la crucial importancia que reviste la educación, tal como lo expresó el Secretario General de las Naciones Unidas, Kofi AnNAn, en conferencia de prensa en abril de 2005.

La alfabetización y la educación primaria universal son factores esenciales para crear una sociedad de la información integrada debemos garantizar que las TIC se utilicen para abrir la puerta a la educación, se trate de muchachas en Afganistán, estudiantes universitarios de Uganda, o trabajadores de Brasil, con el fin de que puedan aprovechar plenamente las posibilidades económicas brindadas y vivan dignamente y al abrigo de la pobreza. ${ }^{54}$

Es por ello que se formuló la recomendación de que los gobiernos deben "Definir políticas nacionales para garantizar la plena integración de las TIC en todos los niveles educativos y de capacitación, incluyendo la elaboración de planes de estudio, la formación de los profesores, la gestión y administración de las instituciones, y el apoyo al concepto del aprendizaje a lo largo de toda la vida." ${ }^{55}$

Al mismo tiempo el capitalismo que ha impuesto el paradigma tecnológico, no es el mismo que el del Siglo XIX que requería de instituciones adecuadas (hospitales, fábricas, escuelas) para el control y disciplinamiento de los sujetos. Para los propios estados, integrarse en la sociedad de la información requiere de recursos económicos capaces de solventar la inversión que conlleva el equipamiento y la capacitación para adaptarse. Es así que en esta etapa de globalización, las fronteras de aquellas instituciones han mutado y, como afirma Deleuze

El marketing es ahora el instrumento del control social, y forma la raza impúdica de nuestros amos. El control es a corto plazo y de rotación rápida, pero también continuo e ilimitado, mientras que la disciplina era de larga duración, infinita y discontinua. El hombre ya no es el hombre encerrado, sino el hombre endeudado. Es cierto que el capitalismo ha guardado como constante la extrema miseria de tres cuartas partes de la humanidad: demasiado pobres para la deuda, demasiado numerosos para el encierro: el control no sólo tendrá que enfrentarse con la disipación de las fronteras, sino también con las explosiones de villasmiseria y guetos. ${ }^{56}$

Tanto los sistemas educativos formales como algunos de los medios masivos de comunicación más extendidos, como la televisión, se diseñaron con una lógica capitalista de oferta/demanda. Tal como sostiene Juan Carlos TeDEsco:

En esta lógica y en este poder se expresaba la voluntad hegemónica de los sectores dominantes. Los nuevos mecanismos culturales de la sociedad y la economía del conocimiento, en cambio, se basan mucho más en la lógica de la demanda. Internet, la TV por cable (y la escuela basada en los mecanismos de responder a las demandas del "alumno-cliente"), invierten el esquema existente en el capitalismo tradicional y, en ese sentido, más que homogeneizar tienden a fragmentar, a diferenciar, a separar. ${ }^{57}$

53 Ídem.

54 Cfr. En http://www.itu.int/wsis/tunis/newsroom/background/ict-education-es.html, sitio consultado octubre 2009.

55 Ibídem.

56 Delleuze, Gilles, "Posdata sobre las sociedades de control", en http://www.uam.es/ra/sin/pensamiento/deleuze/postdata.htm, sitio consultado octubre 2009.

57 Tedesco, Juan Carlos, "Las TICs y la desigualdad educativa en América Latina , en http://www.ritla.net/index.php?option=com 
Este punto de vista nos remonta de nuevo a algunas de las preguntas formuladas en la Presentación de este trabajo, al analizar el impacto en la cultura de la sociedad de la información del buscador más popular en todo el mundo (Google). ¿Es posible pensar la transformación pedagógica y política sin considerar "los saberes técnicos" y el uso de las tecnologías digitales? ${ }^{58}$ ¿La democracia en la información es darle a los sujetos lo que estos demandan? ¿Y acaso es posible demandar algo diferente a lo que se está en condiciones de demandar?

TEDESCO afirma que "una de las modalidades más importantes de la dominación sociocultural consiste, precisamente, en no pedir más que lo que uno ya tiene. La simple adecuación a la demanda, en última instancia, implica reforzar la dominación." 59

Si bien existe un consenso generalizado entre los responsables de los sistemas educativos en cuanto a la importancia de incorporar estas tecnologías, al mismo tiempo "se reconoce que intervenir sobre ellos no modifica automáticamente lo que sucede en la sala de clase, en la relación entre el docente y los alumnos." ${ }^{\circ}$. La literatura corriente acerca de las TIC tiende a presentarlas como un importante y destacado igualador de oportunidades de la población. Silvina GvIRTz ha sintetizado esta potencialidad democratizadora en los siguientes aspectos:

- La oportunidad de acceder a materiales de alta calidad desde sitios remotos.

- De aprender independientemente de la localización física de los sujetos.

- De acceder a un aprendizaje interactivo y a propuestas de aprendizaje flexibles.

- De reducir la presencia física para acceder a situaciones de aprendizaje.

- De desarrollar servicios para el aprendizaje que permitan superar la situación de acceso limitado a la información que tienen principalmente los países pobres.

- De generar mejor información sobre los progresos, preferencias y capacidad de los aprendizajes, posibilidad de evaluar y certificar los aprendizajes on-line y la posibilidad de usar las Nuevas Tecnologías para incrementar la eficiencia, el mejoramiento del servicio y la reducción de costos.

Pero además de democratizadoras, las TICs también incrementarían los niveles educativos debido a: a) cambios en los procesos y estrategias didácticas - pedagógicas implementadas por los docentes; b) la promoción de experiencias de aprendizaje más creativas y diversas y c) la posibilidad de propiciar un aprendizaje independiente y permanente de acuerdo a las necesidades de los sujetos. ${ }^{61}$

Por cierto, la experiencia con el uso de las TIC en los sistemas educativos argentinos, en cualquiera de los niveles, indica que estas promesas fundadas en el enorme potencial de las mismas como factor de justicia social, o, si se prefiere, de reversión de los procesos de exclusión, están muy lejos de la realidad. Aun si se acuerda con la idea de su potencialidad democratizadora, hay que remarcar que esos resultados positivos que se esperan de la tecnología no dependen de las herramientas en sí, sino de los modelos socio-económicos y pedagógicos en los cuales se inscriben.

Esta brecha digital, según algunos diagnósticos, estaría aumentando. La principal conclusión del World Telecommunication Development Report de este año (2002) es que

docman\&task=doc view\&gid=96, sitio consultado octubre 2009.

58 Puiggrós, Adriana y Gagliano, Rafael (Dirección), Op. cit, pág. 28.

59 Tedesco, Ibídem.

60 lbídem.

61 S. Gvirtz. y L. Manolakis. Algunas propuestas para mejorar la calidad y equidad en el Sistema Educativo de América Latina a partir del uso de las NTICs. 
si bien la penetración de la conectividad telefónica está creciendo rápidamente, existe una disparidad muy significativa en la calidad de los accesos a Internet. [...] La capacidad de expansión de las nuevas tecnologías en los países pobres está fuertemente limitada por la concentración del ingreso y por el escaso desarrollo educativo de la población de esos países. Para el caso latinoamericano, las cifras también muestran diferencias significativas según los países. ${ }^{62}$

Una vez más, en el contexto del mundo globalizado y la creciente difusión de las TIC, retorna la pregunta clave acerca de cuánto es el grado de control y participación que pueden ejercer los diversos grupos, incluyendo en esta categoría a los propios estados nacionales, sobre la forma en que estos "procesos de globalización afectan su vida". ${ }^{63}$ El proceso de integración en la sociedad de la información no sólo rompe con algunas fronteras determinadas por la materialidad de los espacios. Conjugado con nuevos procesos migratorios entre países y en el interior de las naciones, así como en el escenario de las desigualdades que acompañan esta nueva configuración del poder, han surgido nuevas fronteras. Ya no determinadas exclusivamente por la noción de territorialidad, sino también por el acceso o su carencia a las nuevas mediaciones e identidades generadas en el mundo globalizado. "Las fronteras tienen significados distintos según de qué lado uno se encuentre y cuán fácilmente pueda cruzarlas", sostiene MoRLEY. ${ }^{64}$

Tabla 1: Indicadores TIC ALADI. Año 2001

\begin{tabular}{|l|l|l|l|l|l|}
\hline \multicolumn{1}{|c|}{ País } & $\begin{array}{c}\text { Población } \\
\mathbf{2 0 0 1} \\
\text { (Millones de } \\
\text { personas) }\end{array}$ & $\begin{array}{c}\text { Penetración } \\
\text { Internet (\%) }\end{array}$ & $\begin{array}{c}\text { Servidores } \\
\text { Web } \\
\text { (cantidad) }\end{array}$ & $\begin{array}{c}\text { Computadoras } \\
\text { (en miles) }\end{array}$ & $\begin{array}{c}\text { Teléfonos (en } \\
\text { miles) }\end{array}$ \\
\hline Argentina & 37,49 & 8,8 & 465.359 & 2.000 & $15.082,9$ \\
\hline Bolivia & 8,52 & 1,8 & 1.522 & 170 & $1.258,8$ \\
\hline Brasil & 172,56 & 4,6 & 1.644 .575 & 10.800 & $66.176,5$ \\
\hline Chile & 15,50 & 20,0 & 122.727 & 1.300 & $8.974,9$ \\
\hline Colombia & 42,80 & 2,7 & 57.419 & 1.800 & $10.460,0$ \\
\hline Cuba & 11,24 & 1,1 & 878 & 220 & 580,7 \\
\hline Ecuador & 12,88 & 2,5 & 3.383 & 300 & $2.194,9$ \\
\hline México & 100,37 & 3,6 & 918.288 & 6.900 & $33.669,0$ \\
\hline Paraguay & 5,64 & 1,1 & 2.704 & 80 & $1.438,8$ \\
\hline Perú & 26,09 & 11,5 & 13.504 & 1.250 & $3.567,3$ \\
\hline Uruguay & 3,36 & 11,9 & 70.892 & 370 & $1.470,9$ \\
\hline Venezuela & 24,63 & 5,1 & 22.614 & 1.300 & $9.248,2$ \\
\hline ALADI & 436,45 & 5,3 & 3.323 .865 & 26.490 & $154.122,9$ \\
\hline
\end{tabular}

Además de la frontera que supone pertenecer a un país en vías de desarrollo, existen otras: fronteras intergeneracionales; las que se configuran por la pertenencia a un determinado género; por origen étnico; por el nivel socio-económico y educativo; el grado de alfabetización; la capacidad de influir en las decisiones políticas; la pertenencia a una comunidad como la latinoamericana. Es decir, todas estas variables deben ser consideradas al momento de analizar el impacto del uso de las TIC, y, en este caso en particular, de la implementación de una herramienta informática y estadística propia de la sociedad de la 
información como lo es Mapa y Cédula Escolar en el contexto del sistema educativo de la provincia de Buenos Aires. Porque si se admite que nuestro presente y nuestro futuro dependen en gran medida de la ciencia y la tecnología, debemos admitir también que la mayor parte de los ciudadanos argentinos, "incluidos los que consideramos cultos, ignoran no sólo la historia de los descubrimientos que nos afectan, sino el propio contenido de tales descubrimientos". 65

La única alternativa verdaderamente democratizadora y que puede influir en el achicamiento de las desigualdades en cuanto al acceso a estas nuevas formas de conocimiento mediatizadas por las TIC es la escuela. "Así, tanto los recursos a invertir como las estrategias de incorporación de su uso, se relacionan estrechamente con los problemas de inclusión-exclusión que plantea la sociedad contemporánea”. ${ }^{66}$

Entonces, ¿qué modelo tecnológico es deseable para un sistema educativo que se proponga formar ciudadanos que puedan ejercer sus derechos en una sociedad con mayor justicia social? ¿Desde qué concepción del conocimiento técnico y científico se sustenta ese modelo? Y, ya abocados al tema específico de esta investigación, ¿sobre qué marco teórico y discursivo se sostuvo la necesidad de crear los dispositivos de información como Mapa y Cédula Escolar?

\section{3.f) Argentina y el cambio de paradigma. Sociedad del conocimiento y tecnologismo. Estado y políticas educativas}

La etapa que comenzó en los 90 configuró una década intensa en cuanto a la producción de nuevas bases legales para el campo de la educación, así como para la configuración de nuevos paradigmas. La Argentina menemista inmersa en estas reformas del Estado y del sistema educativo, se alineó en el clima de época que sostenía la nueva ideología dominante y el pensamiento único, que se podría denominar, en palabras de Héctor SCHMUCLeR, tecnologismo. ${ }^{67}$ Este discurso se sustenta en la convicción de que tanto el conocimiento como la técnica son uno solo. La concepción del conocimiento proviene del modelo de las ciencias naturales, se lo considera objetivo y único. Es decir, que la categoría de "sociedad del conocimiento" es, en realidad, sociedad de determinado conocimiento y modelo tecnológico y no de otros. De este modo,

La ideología de la técnica arrincona el pensamiento en una opción aporética: técnica vs. no técnica, que no sólo prescinde de la voluntad humana sino que se concibe como matriz en la que se gesta la propia naturaleza del hombre. Mencionar los atributos de la voluntad, sin embargo, está muy lejos de suponer que una misma técnica admite usos sustancialmente distintos. El camino es inverso: la técnica lleva en sí la marca de la voluntad, que es anterior

65 Aquilano, Roberto, “Jóvenes, ciencia y tecnología”, en revista Anales de la Educación común, Tercer siglo, año 1, números 1-2 "Adolescencia y juventud”. Publicación de la dgcye, septiembre de 2005, pág. 157.

66 Filmus, Daniel, "Breves reflexiones sobre la escuela del futuro y presentación de la experiencia 'Aulas en red' de la Ciudad de Buenos Aires.", en Filmus et al, Educación y nuevas tecnologías. Experiencias en América latina, IIPE-UNESCO, Buenos Aires, 2003.

67 Schmucler, Héctor, "Apuntes sobre el tecnologismo y la voluntad de no querer, en revista Artefacto. Pensamiento sobre la técnica, Artíulo publicado en Artefacto/1, 1996, www.revista-artefacto.com.ar, sitio consultado en octubre 2009. 
a la técnica y que depende de la percepción que los seres humanos tienen de sí mismos. La técnica construye el mundo pero hay una voluntad humana que previamente le ha dado su nacimiento. Se trata de algo radicalmente opuesto a la doxa que la "naturaliza". Si se desea escapar de la atenazante aporía señalada más arriba, es ineludible indagar en el origen. ${ }^{68}$

¿Qué es, entonces, la técnica? Por supuesto, no es posible hacer aquí un desarrollo exhaustivo de un tema tan complejo. Pero sí intentar una síntesis que puede resultar útil para comprender el clima de época en se originaron los dispositivos que son objeto de análisis en esta tesis y que ha tenido profundas implicancias en los modos de percibir y actuar en el mundo.

Desde ya, es sabido que el vocablo (techné), de origen griego, ha tenido diversas significaciones históricas, incluso entre los propios griegos. Para HEIDEGGER, el concepto de techné encierra en su origen el de poiesis (poesía), y de este modo, privilegia el momento creador por sobre la propia acción que supone la techné (definida por ARISTÓTELES como un tipo de conocimiento que distingue a los hombres de los animales, por su racionalidad). Por el contrario, la reflexión de HeIDEgGER emparenta la techné con la poesía y la entiende "como un renovado y amoroso asombro en la relación del hombre con lo que lo rodea." ${ }^{9}$

La concepción moderna de la técnica es antagónica en este sentido, ya que en ella la técnica y su racionalidad están al servicio, de manera calculada, de dominar la naturaleza para que provea a los seres humanos de determinados recursos (como la energía) vinculados al modelo productivo del capitalismo. Así entendida entonces, desligada de la subjetividad humana que configuran los procesos creativos y críticos, la técnica pasa a ser entendida como un fin en sí misma, que aspira sólo a multiplicarse y extender su dominio. Y si la poiesis instala al hombre en la posibilidad que propone el lenguaje metafórico (metáfora: "ir más allá"), la técnica así entendida, despojada de su vitalidad creativa y poética, no puede darle a los sujetos más que una "artificialización, que indiferencia al hombre."70 El futuro, entonces, aparece signado como un mundo ajeno al devenir histórico - y que no da cuenta, por lo tanto, de la propia historicidad del conocimiento técnico y sus implicancias políticas-y en el que esta visión del tecnologismo impone el proyecto técnico de manera fundamentalista. En el contexto de la globalización, que surge precisamente de la racionalidad tecnologizada, parecería, a priori, que no hay alternativas políticas para los seres humanos más que las de este modelo que modifica la vida cotidiana de millones de personas en todo el mundo, sin que pueda hacerse una apropiación crítica o renunciar a una parte —o al todo- que pretende el paradigma.

Atrapados en este paradigma, implicados en el discurso de Francis FUKUYAMA del fin de la historia que habilitó el supuesto fin de las ideologías, para imponer, paradójicamente, la hegemonía del tecnologismo, "el fin de la historia bien puede ser la consecuencia de la aceptación de la técnica como sustancialidad del mundo. Vivimos un extraño tiempo en el que la derrota del espíritu humano suele ser celebrado como triunfo." ${ }^{11}$ 
Por otra parte, mientras estos postulados se encarnaban en el sentido común, en los años 90 el sistema clientelar se instaló también en la Argentina, sirviéndose así del Estado para fines privados, intereses editoriales de grupos multinacionales e instalación de empresas de comunicación, entre otras tantas. ${ }^{72}$ Es así que, tal como había ocurrido con otras áreas del Estado, el modelo privatizador ejecutado durante las presidencias de Carlos Menem (19891994; 1995-1999) tendía al achicamiento del Estado en beneficio del mercado. Conducida por quien fuera Ministro de Obras y Servicios Públicos entre 1989 y 1991, Roberto Dromı se llevó adelante la primera etapa de las privatizaciones, con la excusa de que eso mejoraría la prestación de los servicios públicos. Este proceso fue acompañado de una enorme operación cultural impulsada por los medios masivos de comunicación para convencer a la ciudadanía de los beneficios y silenciar las protestas de los trabajadores que quedaron sin empleo. El sistema educativo no quedó a salvo de la ola privatizadora, muy por el contrario.

Su trabajo se concentró en realizar el "ajuste" del sistema educativo, transfiriendo la experiencia realizada con anterioridad en las demás áreas del Estado. Utilizaron categorías universalistas que aplicaron a todos los sistemas educativos y que no admiten adaptación alguna a las características nacionales o regionales. ${ }^{73}$

Si bien la imposición de este modelo encontró resistencias, en particular, entre dirigentes sindicales del sector docente como la CTERA, no menos cierto es que el sector empresarial lo apoyó ampliamente. Cabe decir que la educación constituye un "mercado" por demás atractivo para estos sectores, ya que se trata de una vasta clientela "cautiva". Y no se está aludiendo aquí solamente a la educación privada. Más bien la referencia es, en el marco teórico que hemos enunciado, a aquellos aspectos que han surgido al amparo de la revolución tecnológica. La producción de contenidos digitales, la aplicación de las TIC como "oferta" de educación a distancia, son algunos de los aspectos a considerar. Vale la pena aclarar acá que la utilización de la palabra "oferta educativa", como sinónimo de "servicio" conlleva en sí misma, por aquello de la forma y el contenido, la lógica empresarial. Quienes comparten la creencia de la educación es un derecho y es responsabilidad del Estado, tienen que tener especial cuidado con la terminología que se utiliza y que proviene, precisamente, de ese modelo que estamos acá cuestionando. En tal sentido, el papel de los medios masivos de comunicación en esa etapa del menemismo fue decisivo a la hora de instalar este modelo, ya que "Desde su inicio adoptó la definición de lo público del mercado". ${ }^{74}$

Un ejemplo elocuente y doloroso es el del libro. No es un dato menor el que una de las industrias que se vio más afectada es precisamente la industria editorial nacional, que durante décadas había tenido un verdadero liderazgo en el mundo hispano y que, por sus propias características había estado siempre asociada con la tradición de la educación pública argentina.

En nuestro país, hoy no existen (casi) editoriales independientes. Con la compra de Emecé en 2000, el grupo español Planeta controla el $20 \%$ del mercado; ya es propietario de las ediciones de Seix-Barral, Ariel, Espasa-Calpe y otras. El segundo lugar en las ventas lo ocupa Sudamericana, pero ya ha dejado de ser la empresa familiar de los López Llausás; en 1998 fue adquirida por Random House Mondadori, que controla Lumen, Grijalbo y Plaza 
y Janés. El tercer grupo que alcanza una fuerte presencia en los 90 es Prisa-Santillana (Alfaguara, Aguilar y Taurus). En 1991, el grupo colombiano Norma compró la editorial Tesis, y tres años después, Kapelusz (Botto, 2006, 212-213). Estos conglomerados que desembarcan en los 90 controlan cerca del $75 \%$ del mercado (CEP, 2005, 12). ${ }^{75}$

No pocos sectores de la sociedad, en particular de la clase media, "compraron" este modelo que incluía la teoría del derrame, hasta que el impacto del ajuste y la desindustrialización que habían sufrido desde el comienzo los sectores más desfavorecidos y empujó a los trabajadores fuera del sistema laboral y arrasó con sus derechos, los impactó también a ellos. La teoría del derrame hizo aguas en cuanto la clase media pudo comprobar en carne propia hacia adónde se derramaban las riquezas. Fue en este contexto en que se iba configurando, tanto en el imaginario cuanto en las prácticas escolares, un nuevo sujeto pedagógico.

Y la misma operación cultural para imponer en el discurso el modelo hegemónico neoliberal atravesó -y aún atraviesa - el discurso acerca del conocimiento y la sociedad de la información. Como si las dolorosas experiencias de los 90 no hubieran bastado, todavía hoy hay quienes insisten en utilizar estas categorías con el mismo sentido del derrame y pretenden que la mera incorporación de tecnologías en el sistema educativo resolverá mágicamente las desigualdades. Sin embargo,

Aesta altura de los cambios tecnológicos, demográficos y sociales es difícil seguir sosteniendo que la educación de las elites servirá para volcar cultura al conjunto, especialmente cuando una de las condiciones de reproducción de aquellos grupos privilegiados es concentrar la información y la comunicación. ${ }^{76}$

Muchos de los supuestos de aquel discurso hegemónico están aún vigentes e incorporados al sentido común. Afortunadamente, cuando a comienzos de 2009 la Presidenta de la Nación Cristina FERNÁNDEZ DE KIRCHNER impulsó el debate que concluyó con la sanción de la nueva Ley de Servicios de Comunicación Audiovisual, ${ }^{77}$ y si bien la base conceptual sobre la que se formuló el proyecto de ley había sido construido colectivamente y desde hace muchos años por diversos actores de la sociedad, que tuvieron su síntesis en la elaboración de los "21 Puntos" de la Coalición por una Radiodifusión Democrática, ${ }^{78}$ el impulso político dado desde el Poder Ejecutivo Nacional ha permitido poner en la discusión de la agenda política actual muchos de los tópicos que acá abordamos.

En tal sentido, vale la pena insistir en que la experiencia de Mapa y Cédula que elegimos para esta tesis tiene que servirnos, en este análisis, precisamente para verificar si los supuestos teóricos que estamos enunciando se han podido verificar allí. Incluso, si estos programas surgieron en un contexto "invadido" por categorías discursivas propias de la racionalidad tecnocrática de fines de los 90 , puestos en el marco de una lógica democratizadora diferente pueden sostenerse como herramientas estratégicas. Si es cierto que disponer de las herramientas informáticas adecuadas

75 De Diego, José Luis, "Políticas editoriales y políticas de lectura , revista Anales de la educación común, Tercer siglo, año 3, núero 6, Educación y lenguajes, julio de 2007, Publicación de la Dirección General de Cultura y Educación de la Provincia de Buenos Aires, pág. 38.

76 Puiggrós, Adriana, Fuente: Página/12, 09 de setiembre de 2009, http://www.pagina12.com.ar/diario/elpais/subnotas/13146042342-2009-09-09.html, en http://www.adrianapuiggros.com.ar/ver_noticias.php?id=518.

77 La ley 26.522/09 fue sancionada y promulgada el 10 de octubre de 2009 y publicada en el boletín oficial número 31.756 de la misma fecha. Cfr. http://www.coalicion.org.ar/ley26522.pdf, sitio consultado en marzo de 2010. 
para relevar la información son suficientes para modificar la realidad, -y si así fuera, modificarla en qué sentidos y para beneficio de quiénes- en este caso, del sistema educativo en una sociedad democrática, o bien, si por el contrario, como nosotros creemos,

[...] no hay posibilidades de dar respuesta al derecho a la educación de millones de personas de todas las edades sin la incorporación de los servicios de comunicación audiovisual a la enseñanza. Es equivocado considerar que la mera extensión de las nuevas tecnologías mejora la calidad de la educación, dado el complejo de factores que intervienen en ese proceso, pero es indudable que los medios de información y comunicación pueden instalarse convalidando vínculos educativos autoritarios que siempre contienen la peligrosa tendencia de concentrarse, o bien pueden multiplicar los educadores, dar la palabra a los alumnos, poner en el espacio mediático a las instituciones educativas, generando nuevas formas de organización del trabajo pedagógico. ${ }^{79}$

Si miramos hacia atrás, vemos como en nuestra propia historia como nación encontraremos algunas "razones" para este estado de situación. A lo largo de la historia, ${ }^{80}$ la sociedad argentina ha asistido a cambios profundos, vinculados con transformaciones sociales, políticas, económicas y culturales. En la segunda mitad del siglo xx, luego de la crisis del Estado de Bienestar, se fue configurando un orden estatal autoritario, que culminó con el establecimiento del terrorismo de Estado mediante políticas represivas y de desarticulación social que, con violencia material y simbólica, afectaron todos los espacios de lo público, incluido el educativo.

Los gobiernos democráticos que se iniciaron en los años 1973-1976 y 1983, tuvieron como objetivo lograr la democratización y la participación política de los sectores populares. Durante los años 90, el Estado se reconfiguró al profundizar algunas de las políticas que desde la dictadura militar de 1976 se hallaban en génesis. Así, redujo su intervención hasta casi desaparecer de la vida pública y se consolidó como sostén de los sectores empresariales y los capitales extranjeros a los que benefició ampliamente.

Hoy resulta imprescindible intentar reinstaurar el Estado de Bienestar, más allá de que los marcos socio-históricos mundiales que le dieron origen se han transformado. En el contexto del siglo XXI, es necesario volver a pensar el modelo estatal en función de la redistribución de las riquezas, de la inclusión de las mayorías — que han sido marginadas y excluidas - y de la profundización de las prácticas democráticas y participativas. Si bien algunas representaciones describen al Estado como una totalidad homogénea, como una entidad aislada, separada y distante de la sociedad, que lleva adelante un proyecto uniforme. Sin embargo, esta concepción resulta insuficiente para explicar la complejidad del Estado, que en esta perspectiva se considera que se constituye como construcción social y, por lo tanto, contiene la conflictividad y las diferencias presentes en la comunidad. Es conveniente pensar las políticas estatales como posicionamientos que involucran distintos proyectos e intereses que se dan en el marco de procesos sociales más amplios, en lugar de entenderlas como discursos y acciones unívocas. El Estado como modo de organización jurídica de los ciudadanos/as para la consecución de 
sus proyectos de vida, es quien debe garantizar los derechos de todos los sujetos. Con este objetivo, ante las diversas demandas que circulan socialmente, es quien articula los dispositivos vinculados al bien común, de manera que sea posible construir una política pública integral, en la cual se asume como su principal promotor.

La educación constituye uno de los derechos inalienables que el Estado tiene la responsabilidad de garantizar, puesto que no existe otro actor individual o colectivo que cuente con los recursos institucionales, económicos y la capacidad de integración y síntesis político-cultural necesarios para asegurar el acceso, permanencia y egreso de la totalidad de la población al sistema educativo. Mediante la elaboración y prescripción de diseños y propuestas curriculares, por ejemplo, el Estado aporta elementos fundamentales al conjunto de acciones que conforman la política pública referida a educación. Ante la preponderancia de las acciones focalizadas, impulsadas en la década de 1990, los diseños y propuestas curriculares comunes constituyen un componente significativo de las políticas públicas universales en materia educativa, concebidas como herramientas para hacer efectiva la igualdad y la inclusión. En ocasión del debate de la nueva Ley de educación Nacional en 2006, la provincia de Buenos Aires, al igual que las demás jurisdicciones, tuvo su representación en el Consejo Federal de Educación y logró incluir, a pesar de tener que afrontar algunas resistencias, el enunciado de la educación como un "bien público y un derecho personal y social" en la nueva norma. (Ley 26.206, "Artículo $2^{\circ}$.- La educación y el conocimiento son un bien público y un derecho personal y social, garantizados por el Estado.")

En el mismo sentido la presidenta de la Nación, Cristina FERNÁNDEZ dE KIRCHNER, anunció junto al responsable de la cartera educativa, Alberto SILEONI, ${ }^{81}$ una reforma en la educación secundaria, ahora obligatoria, que encuentra su antecedente en la que fuera impulsada en 2007 por la gestión PuIGgrós en la provincia de Buenos Aires, y que deja atrás el modelo del Polimodal de tres años (no obligatorios) de los 90 , recupera los títulos de bachiller y de técnico y extiende a todos los años del secundario la enseñanza de las materias de lengua, matemática e idiomas extranjeros. Además se incorporarán nuevos espacios formativos -como talleres, trabajos prácticos y monografías-, educación sexual, derechos humanos, prevención del consumo de drogas, capacitación laboral, trabajo social y comunitario, artes, deportes y recreación. De este modo se pretende avanzar en el cumplimiento del derecho a la educación, incluyendo a miles de adolescentes y jóvenes que hasta ahora habían sido expulsados del sistema educativo.

\section{3.g) Una pequeña digresión: otros dispositivos tecnológicos que pueden enseñarnos algo}

Cabe aquí una pequeña digresión. En un reciente viaje que tuve oportunidad de realizar a Perú y, más adelante, a México, en calidad de turista, pude ser testigo de algunas de las más extraordinarias obras de la arquitectura azteca e inca, como así también, de las violencias y resignificaciones que sobre estas ejercieron los conquistadores europeos. 
Al observar la catedral Metropolitana de México, ${ }^{82}$ que data del siglo XVı y que está enclavada en el Zócalo del Distrito Federal (DF), es posible descubrir aún los rastros del proceso de colonización, en este caso del modelo arquitectónico, que los españoles impusieron a los vencidos. Las piedras hablan, como lo hacen otros significantes más contemporáneos, pero hay que saber escuchar. Los conquistadores acabaron con los templos aztecas y, después de fundir sus ídolos de oro y mandar el metal a España, utilizaron las piedras de los edificios para erigir, a modo de triunfo, sus propios templos. Es por eso que casi todas las piedras que forman la catedral se extrajeron del Templo Mayor de los aztecas y todavía se distinguen éstas de las "nuevas", como si a pesar del "éxito" de la hegemonía española, los sometidos todavía pudieran darnos cuenta de su derrota, pero también, de quiénes fueron.

La excusa de los conquistadores, al igual que la que utilizaron en Perú, ${ }^{83}$ acompañados de una corriente de la Iglesia católica, era que destruyendo los templos aztecas, mayas o incas y construyendo sobre ese mismo territorio, sobre ese mismo lugar las iglesias, los indígenas serían atraídos a esos sitios para escuchar la palabra de Dios (el dios cristiano y europeo), ya que simbólicamente, para los "salvajes" esos eran los lugares de sus rituales, de sus ofrecimientos a otros dioses. Es así que se puede verificar cómo en el lenguaje antiguo de la piedra, aún podemos leer no sólo lo que se hace evidente a nuestros ojos contemporáneos y nuestra subjetividad occidental, sino también aquello que quedó oculto, escondido detrás de la imposición de los dominadores de entonces. Es decir, al observar el simbolismo impreso en diversos dispositivos de la técnica (arquitectónica, en este caso), me permití reflexionar acerca de otras cuestiones. Hay que intentar poder ver más allá de la materialidad del propio dispositivo, ya sea éste un sofisticado software informático del siglo XXI, ya un antiguo templo maya, azteca o inca construido varios siglos antes de la era cristiana, ya una catedral medieval. Mas aun cuando sabemos que la vertiginosidad de los cambios tecnológicos nos confronta con la frecuente aparición de nuevos dispositivos.

Estamos habituados a leer en el lenguaje y con el pensamiento hegemónico, hemos dicho. Es decir, el lenguaje de los Ayax, los Tiresias y los Cresos de la obra de Marechal. Es dificultoso visualizar las identidades y los mensajes de todos los Gutiérrez que se comunicaron por medio de la tecnología que tenían disponible, ya fuera como esclavos al servicio del antiguo Faraón de Egipto, o del amo español que conquistó América o del señor feudal y el Obispo que promovieron sus templos.

¿Es posible verificar, del mismo modo, ocultos o disimulados en el paradigma neoliberal y tecnocrático, otros registros discursivos en los dispositivos tecnológicos de la actualidad? Piénsese, por ejemplo, en el lenguaje de las catedrales góticas. ¿Qué tendrían para decirnos, si fuéramos capaces de interpretar los simbolismos y arcanos de las corporaciones de artesanos constructores esas "atrevidas bóvedas, la nobleza de las naves, la amplitud

82 La catedral es la sede de la Arquidiócesis Primada de México y se encuentra situada frente a la Plaza de la Constitución, en el centro histórico de la Ciudad de México. Tiene unas medidas aproximadas de de 59 metros de ancho por 128 de largo y una altura de 60 metros hasta la cúpula. Se la considera una de las más destacadas obras del arte mexicano y de todo el arte hispanoamericano. Construida con cantera gris, cuenta con cinco naves y 16 capillas laterales. Está dedicada a la Asunción de la Virgen María.

83 Por ejemplo en el Zócalo (Plaza central) de la ciudad de Cuzco conviven iglesias importantes como la catedral y en diagonal a esta la de los de la Compañía de Jesús y a menos de tres cuadras otra y otra. Todas construidas sobre lugares sagrados o de contemplación de los Incas. 
de proporciones y la belleza de ejecución, hacen de la catedral una obra original, de incomparable armonía, pero que el ejercicio del culto parece no tener que ocupar enteramente."? ${ }^{84}$ Tal vez podríamos encontrar allí la huella de profundas contradicciones entre el mensaje triunfal del cristianismo dominante y la exaltación de su culto y la invitación a la oración, expresado sin duda mediante la verticalidad y el lenguaje de la luz y "la pompa, la estructura y la ornamentación producen y reflejan, con extraordinaria fuerza, sensaciones menos edificantes, un ambiente más laico y, digamos la palabra, casi pagano." ${ }^{85}$ En un lenguaje más contemporáneo, la referencia sería probablemente al contradiscurso oculto dentro del discurso oficial como parte del mismo dispositivo comunicacional que es el edificio arquitectónico.

Se sabe, tanto por FULCANELLI como por otros autores, que así como la racionalidad tecnologizante, por hegemónica en que pretenda erigirse, convive con otras alternativas de interpretación del mundo, también en estas monumentales catedrales tenían lugar otro tipo de ceremonias y rituales populares, característicos de la Edad Media, tales como la Fiesta de los Locos — también llamada Fiesta de los Sabios_ que era una suerte de

Sátira hilarante de un clero ignorante, sometido a la autoridad de la ienciadis frazada, aplastado bajo el peso de una indiscutible superioridad. ¡Ah, la Fiesta de los locos, con su carro del Triunfo de Baco, tirado por un centauro macho y un centauro hembra, desnudos como el propio dios, acompañado del gran Pan; carnaval obsceno que tomaba posesión de las naves ojivales! ¡Ninfas y náyades saliendo del baño; divinidades del Olimpo, sin nubes y sin enaguas: Juno, Diana, Venus y Latona, dándose cita en la catedral para oír misa! ¡Y qué misa! Compuesta por el iniciado Pierre de Corbeil, arzobispo de Sens, según un ritual pagano, y en que las ovejas de 1220 lanzaban el grito de gozo de las bacanales: ¡Evohé! ¡Evohé!, y los hombres del coro respondían, delirantes:

Haec est clara dies clararum clara dierum! Haec est festas dies festarum festa dierum!

(¡Este día es célebre entre los días célebres! ¡Este día es de fiesta entre los días de fiesta!) ${ }^{86}$

Es así que aun si se considera al medioevo europeo, como lo han hecho la mayoría de los historiadores modernos, como una época de predominio del paradigma de la religión cristiana -lo cual, desde ya, es mucho más complejo y heterogéneo-, y aun si se toma como punto de partida un dispositivo de la técnica como es la catedral gótica, que expresa casi como ningún otro aquel paradigma, podemos inferir que este coexistía con otras interpretaciones del mundo, que entraban en tensión y en contradicción incluso, aunque se expresaran en apariencia con el mismo lenguaje de los poderosos.

Interesa, entonces, no perder de vista esta idea a lo largo del análisis, ya que como interpretó Freud en Tótem y tabú, existe una doble "articulación de la historia de los individuos sobre el inconsciente de las culturas y de la historicidad de éstas sobre el inconsciente de los individuos abren, sin duda, los problemas más generales que podrían plantearse con respecto al hombre." ${ }^{87}$

84 Fulcanelli, El misterio de las catedrales, Debolsillo, Barcelona, 2002, pág. 17. 


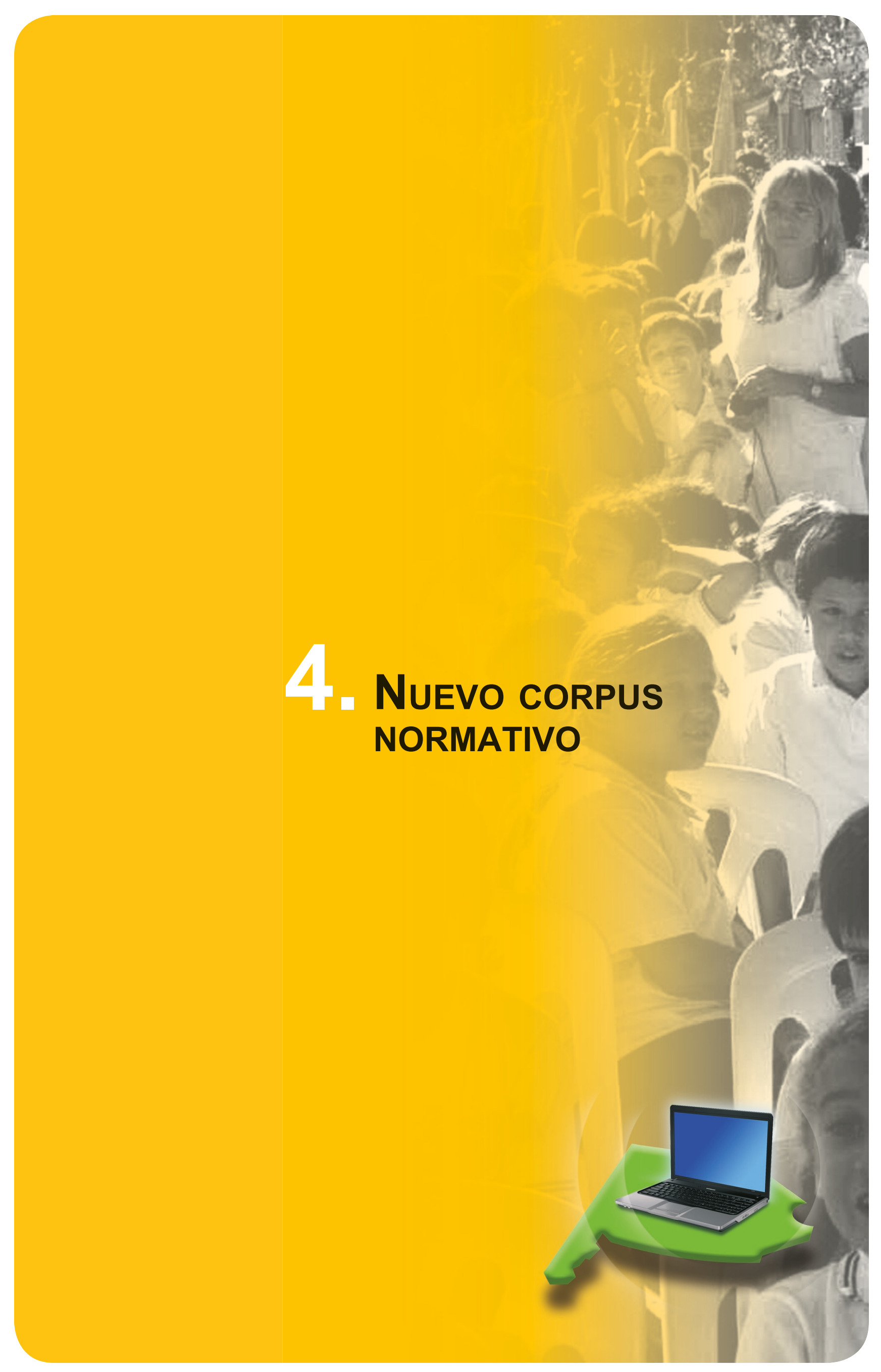





\section{NUEVO CORPUS NORMATIVO}

Cuando se planteó el problema que se aborda en esta tesis se dio cuenta del cuerpo normativo que acompañó el proceso de reformas educativas en la etapa democrática iniciada en 1983 hasta la década menemista. También se ha mencionado la crisis económica, social e institucional que atravesó al país en los últimos meses de 2001, durante el gobierno de la Alianza.

Tras la salida de De LA RúA, el 20 de diciembre asume la conducción del Poder Ejecutivo Nacional el presidente de la Cámara de Senadores, Ramón PUERTA, quién convocó a una asamblea legislativa para elegir un nuevo presidente. El día 23 asumía Adolfo RodRíguez SAÁ, quien renunció el 30 de ese mes, alegando falta de apoyo político, lo que desencadenó una nueva ola de inestabilidad. El entonces presidente de la Cámara de Diputados, Eduardo CAmaño, asumió el Poder Ejecutivo y convocó a una Asamblea Legislativa para nombrar un nuevo presidente. El 2 de enero de 2002 resultó electo por esta asamblea Eduardo DUHALDE como presidente interino.

Durante el gobierno de DUHALDE se tomaron medidas conducentes a salir de la crisis y recuperar la estabilización institucional, económica y social, por efecto del default y la restricción del gasto público. Las consecuencias sociales de la crisis fueron gravísimas y según algunos indicadores, el $54 \%$ de la población se hallaba por debajo del límite de pobreza; la mitad de esta población ( $27 \%$ del total), por debajo de la línea de indigencia. El 26 de junio de 2002, en los alrededores de la estación de trenes de Avellaneda, el gobierno nacional ordenó la represión de una manifestación de grupos piqueteros. Como resultado, fueron asesinados por efectivos de la policía bonaerense los jóvenes activistas Maximiliano KosTEKI y Darío SANTILLÁN, pertenecientes al Movimiento de Trabajadores Desocupados (MTD) Guernica y el MTD Lanús, respectivamente, ${ }^{1}$ y se registró un saldo de 33 heridos por balas de plomo entre los manifestantes. Ante el impacto social y mediático generado, DUHALDE anticipó seis meses el llamado a elecciones presidenciales y anunció que no iba a volver a presentarse.

En las elecciones del 27 de abril de 2003 el Frente para la Victoria (conducido por el ex gobernador de Santa Cruz, Néstor KIRCHNER) obtuvo sólo un 22,0\% de los votos, resultando superado por Carlos MENEM, con una alianza que obtuvo el $24,3 \%$, por lo que debía haber una segunda vuelta (ballotage) que debía llevarse a cabo el 18 de mayo de 2003. Los sondeos indicaban entre un 60 y $70 \%$ de

1 Nucleados en la Coordinadora de Trabajadores Desocupados Aníbal Verón. A ocho años de la masacre los familiares aún reclan que se juzgue a los responsables políticos. 
intención de voto para KIRCHNER, por lo que MENEM renunció a su candidatura, y KIRCHNER asumió como presidente electo el 25 de mayo de 2003.

Con la asunción de Néstor KIRCHNER, comienza una nueva etapa para el país y se produce un importante viraje en materia de política económica y social, orientadas en el marco de un proyecto de reconstrucción y desarrollo nacional, cuyo objetivo es la inclusión y la justicia social (expresada mediante diversas medidas). A su vez, los indicadores económicos comenzaron a modificarse y se inició un proceso de crecimiento y estabilización social e institucional. Es en ese contexto en que se van produciendo las adecuaciones de una nueva base legal para el sistema educativo nacional, que tuvo su correlato también en la provincia de Buenos Aires. En el nivel nacional, se sancionaron las siguientes normas:

\section{Ley de Educación Técnico Profesional $26.058^{2}$}

Referida al ordenamiento y regulación de la educación técnico profesional, su mejora continua, el gobierno y administración de la educación técnico profesional y, en particular, establece los mecanismos para su financiamiento.

\section{Ley de Financiamiento Educativo (LFE) $26.075^{3}$}

Fijó el incremento de la inversión en educación, ciencia y tecnología por parte del Gobierno nacional, los Gobiernos provinciales y el de la Ciudad Autónoma de Buenos Aires, en forma progresiva, hasta alcanzar en el año 2010 una participación del seis por ciento en el Producto Interno Bruto.

\section{Ley de Educación Nacional 26.206/06 ${ }^{4}$}

El 27 de diciembre de 2006 el Gobierno Nacional, presidido por el Dr. Néstor KIRCHNER, promulgó la Ley de Educación Nacional 26.206/06, respondiendo así a la sentida necesidad de adecuar la legislación a los cambios culturales, sociales y tecnológicos del siglo que acaba de comenzar y a la política de instauración de la justicia social, la soberanía política y cultural.

Este nuevo corpus normativo requería de la adecuación de las normas provinciales a la nueva legislación nacional, al mismo tiempo que considerar los antecedentes legales a lo largo de la historia del país, ya que, en diversos periodos, la provincia de Buenos Aires había sido la precursora de las reformas que determinaron las diferentes organizaciones que el sistema educativo nacional se fue dando, como ya se ha mencionado. En tal sentido, PuIGGrós destaca en la Fundamentación del anteproyecto de reforma de la ley provincial, que

Durante el Siglo xx se sucedieron en nuestra Provincia reformas de distinto signo político. La Ley de Reformas a la Educación Común de 1905, efectuada por el gobierno de Marcelino Ugarte (1902-1906) redujo la escolarización obligatoria a cuatro años. El gobierno de Manuel Fresco (1936-1940) reformó la educación según la Constitución Provincial de 1934, la Ley de Escalafón y Estabilidad del Magisterio y la Reforma de 1937. Entre los aspectos

2 Sancionada el 7 de septiembre de 2005 y promulgada al día siguiente, fue publicada en el Boletín Oficial del 9 de septiembre de 2005. 3 Sancionada el 21 de diciembre de 2005, promulgada el 9 de enero de 2006. Publicada en el Boletín Oficial del 12 de enero/06. 4 Sancionada el 7 de septiembre de 2005 y promulgada al día siguiente, publicada en el Boletín Oficial número 31.062 del 28 de 
legales de la profunda obra educativa del gobierno de Domingo Mercante (1946-1951) se destacan la descentralización de la Inspección General de Enseñanza y la creación de las inspecciones distritales por medio de la Ley Orgánica de Ministerios (5694/52), los principios educativos de la Constitución Provincial de 1949, el Estatuto del Docente Provincial (Ley 5651/51), la Ley 5588 que crea los Institutos Superiores de Pedagogía, la puesta en marcha de la educación inicial por la Ley 5096/46 (basada en el proyecto del Diputado Jorge A. Simini) y la reforma diseñada por el Director General de Escuelas y Cultura Julio César Avanza, plasmada en la Ley 5650/51 que reemplazó a la de 1875.

La dictadura de la llamada Revolución Libertadora derogó las principales leyes sancionadas durante el período peronista. El gobierno de Oscar Alende (1958-1962), con la destacada actuación del inspector General Jorge C. Hansen, recompuso la política educativa con una convicción desarrollista y fuerte acento en la integración social. Entre 1966 y 1973 la Reforma Educativa de la dictadura autodenominada "Revolución Argentina" tuvo como cabecera piloto a la provincia de Buenos Aires: en 1970, se redujo de hecho la obligatoriedad a 5 años y se estableció una Escuela Intermedia de 4 años, una secundaria de 3 años y la promoción automática dentro del ciclo elemental, entre otras medidas. La obra comenzada en el período del Gobernador Oscar Bidegain (1973), que recuperaba la tradición peronista, fue destruida por la legislación de facto de la Dictadura durante el denominado "Proceso de Reorganización Nacional" que, entre otras medidas destinadas a desestructurar el sistema nacional de educación pública, transfirió a las provincias las escuelas de nivel inicial, primario y los centros de la Dirección Nacional de Educación de Adultos (DINEA) mediante las Leyes nacionales $21.809 / 78$ y 21.810/78. Los principios educativos democráticos fueron restituidos durante la gestión del gobernador Alejandro Armendáriz (1983/87) en el cual se convocó a la comunidad educativa de la provincia de Buenos Aires a participar activamente en el Congreso Pedagógico Nacional (Ley nacional 23.114/84; Ley provincial 10.367/85) y se sancionó la Ley provincial 10.579 (Estatuto del Docente). Durante el gobierno de Antonio Cafiero (1987/91) se crearon los Consejos de Escuela, mediante el Decreto 4182/88, se convocaron concursos docentes en todos los institutos de la Provincia y se erradicaron los turnos reducidos en el conurbano, en tanto, simultáneamente (1990) nuestro país ratificaba la Convención de Naciones Unidas sobre los Derechos del Niño.

Durante el gobierno de Eduardo A. Duhalde se dictó la Ley de educación provincial 11.612/ 95, actualmente vigente. Siguiendo los lineamientos de la Ley de Transferencia (24.089/91) y la Ley Federal de Educación (24.195/93), ambas de orden nacional, extendió la educación básica a 9 años, estableció la obligatoriedad desde el nivel preescolar llevándola a 10 años, seguida de un nivel polimodal no obligatorio de tres años, que debía combinar la formación general con orientaciones laborales, en las cuales quedaba subsumida la educación técnica. La educación de los adultos, de las personas con capacidades especiales, de adultos y artística salió del tronco central del sistema para integrar regímenes especiales. ${ }^{5}$

En cuanto a las consideraciones doctrinarias, cabe destacar que dicho proceso tuvo lugar en el marco de la política impulsada por el gobierno nacional actual de Cristina Fernández de KIRCHNER y el anterior de Néstor KIRCHNER, que han impulsado una distribución más justa de los bienes materiales y simbólicos, y en ese contexto se sancionó la Ley Nacional de Educación (26.206/06), para lo cual la provincia de Buenos Aires participó activamente

[...] exponiendo y sosteniendo las opiniones mayoritarias surgidas de la Consulta realizada a la comunidad educativa, a los propios efectos, entre junio y septiembre de 2006. Participaron de esa consulta tres millones y medio de personas mediante reuniones sectoriales, encuestas y otras técnicas de opinión, sumadas a tres días de discusión en jornadas de trabajo docente en todos los establecimientos educativos de la Provincia. [...] $]^{6}$

Respecto de los medios de comunicación y las nuevas tecnologías, la Fundamentación destaca que:

Este proyecto de Ley considera que la educación abarca el conjunto de procesos formativos 
que se desarrollan en todos los ámbitos sociales de la provincia de Buenos Aires desde las cuales se produce, intercambia, transmite y adquiere cultura: en las instituciones de enseñanza y aprendizaje, en los movimientos e instituciones de la sociedad civil, en el trabajo, en las actividades productivas y culturales y en los medios de comunicación. [...] Los medios de comunicación no constituyen un elemento anexo más o ajeno al sistema escolar, sino que se conforman como sujetos educadores de máxima importancia, que deben penetrar las instituciones educativas, así como éstas deben apropiarse de las tecnologías de la comunicación y la información. La interioridad que debe tener esa relación requiere que la nueva Ley aborde la educación en el conjunto de procesos sociales que la expresan y no solamente en el sistema escolar. Es indispensable restablecer la responsabilidad del Estado y la comunidad sobre el conjunto de los procesos educativos que se desarrollan en la sociedad, tanto dentro del sistema escolar, cuanto en los medios de comunicación masiva y en los procesos de transmisión de saberes que afectan al conjunto.

Los profundos cambios científico-tecnológicos de nuestro tiempo han abierto espacios de enorme potencia educativa que deben ser tenidos en cuenta en el marco de los principios y regulaciones generales de la Ley Provincial de Educación. Considerando que este cuerpo normativo debe prever su vigencia por lo menos para la próxima década, y que sus efectos tendrán incidencia en el largo plazo, no puede limitarse a regular el funcionamiento escolar sino que debe dejar abiertas posibilidades de transformaciones estratégicas, enmarcando claramente los alcances y limitaciones filosóficas, político educativas, éticas y culturales de la educación en la provincia de Buenos Aires. ${ }^{7}$

Por otra parte, la entonces Directora General de Cultura y Educación subrayó allí el rol del planeamiento, no sólo al considerarlo como un instrumento imprescindible para cada gestión en ejercicio, sino también para la orientación de las políticas hacia el mediano y el largo plazo, integradas al proyecto de desarrollo futuro de la Provincia en la Nación.

Toda la política educativa llevada adelante en la gestión de Adriana PUIGgRós al frente de la DGCyE (2005-2007), se fundó en los principios afirmados en el proyecto de Ley, que, finalmente, quedó sancionada como Ley 13. 688/07, ${ }^{8}$ y son:

- el carácter de derecho personal, bien social y bien público de la educación y el conocimiento;

- la responsabilidad pública de educar a las nuevas generaciones y al conjunto de la sociedad;

- la indelegable responsabilidad del Estado de sostener política, financiera y pedagógicamente el sistema de educación pública, y garantizar que la educación que se realice por diversos medios privados cumpla con los principios de esta Ley;

- la condición de sujetos de derecho de los niños y niñas, los adolescentes, los jóvenes y los adultos;

- los principios de respeto a los derechos humanos y de no discriminación por condición u origen social, de género o étnica, ni por nacionalidad ni orientación cultural, sexual, religiosa o contexto de hábitat, condición física, intelectual o lingüística;

- la in-escindible vinculación entre el sujeto social y la protección del medio ambiente;

- la libertad de enseñar y aprender, en el marco de los principios anteriores;

- el derecho al acceso, permanencia y graduación en todos los Niveles, Modalidades y programas educativos por parte de todos los habitantes de la Provincia, y de aquellos que accedan desde fuera por medio de nuevas opciones tecnológicas;

- la posibilidad de continuidad de los estudios, sin que existan circuitos terminales, garantizando el tránsito vertical y horizontal por el sistema de educación escolar, al cumplir con los requisitos que se fijen para la aprobación de cada segmento formativo, al mismo tiempo que estableciendo estrategias de reconocimiento de los saberes adquiridos en otras prácticas no escolarizadas;

- la calidad de la educación entendida como el cumplimiento de los anteriores enunciados y 
de la transmisión de los principios científicos y tecnológicos y de lenguajes que presiden la producción cultural en el más alto nivel contemporáneo; y

- el irrestricto acceso a la información pública en tanto derecho consagrado constitucionalmente, inalienable y necesario para el libre ejercicio de la ciudadanía, la transmisión social de la cultura y el cumplimiento de los principios anteriores.

Por su parte, tal como se destaca en el acápite de los principales considerandos de este anteproyecto, la norma provincial partió del consenso obtenido en el sentido de inscribir el proyecto provincial en el nacional y concebir "a la Provincia articulada a la Nación y al Sistema Educativo Provincial como parte integrante de un único Sistema Educativo Nacional." 9 Se pensó en términos de un federalismo educativo que dé relevancia a la identidad local, municipal, regional, pero sin por ello perder los lazos articulan "porque necesitamos sumarnos, aumentar la masa crítica de aprendizajes, enseñanzas y conocimientos." Y se subrayó la necesidad de:

- disponer la articulación de todas las leyes de orden nacional y provincial vinculadas para asegurar una integración normativa real e impedir circuitos de educación paralelos o antagónicos;

- establecer los acuerdos necesarios con la Nación y con las demás provincias para regular fluidamente las transferencias de alumnos entre jurisdicciones, la equivalencia de certificaciones y la continuidad de los estudios sin requisitos suplementarios;

- incorporar el Área Metropolitana en tanto zona de confluencia y articulación urbana y social, como objeto del diseño de políticas educativas articuladas, asociadas y complementarias con la Ciudad Autónoma de Buenos Aires;

- asumir que la migración del campo a los conglomerados urbanos, con la consiguiente transformación de identidad y calidad de vida, tendencia creciente especialmente en el último lustro, que es portadora de las culturas de casi todas las provincias argentinas y de los países vecinos, debe significar dentro de nuestras aulas lazos de interculturalidad con lenguas y costumbres diversas, poniendo en evidencia la riqueza que significa la complejidad y diversidad de nuestra población educacional, antes que rechazarla en pos de una uniformidad irreal y excluyente;

- atender las nuevas necesidades que presentan los niños y jóvenes que viven transitoriamente en la provincia de Buenos Aires, o emigran a otras jurisdicciones periódicamente motivados por las características temporales y precarias del empleo propio o de sus familiares; $y$

- establecer acuerdos con los países latinoamericanos, en especial del MERcosur y de otras latitudes así como con otros organismos de integración que los tiempos dicten, de manera coordinada con lo pautado por los convenios internacionales, referidos a las cuestiones educativas vinculadas con las migraciones y los intercambios lingüísticos, culturales y productivos. $^{10}$

Por lo tanto, al sancionarse la Ley de Educación Provincial, si bien se siguió la línea de la Ley de Educación Nacional, la provincia de Buenos Aires efectuó algunas adecuaciones (como extender un año más la obligatoriedad, al incorporar la Sala de 4 del Nivel Inicial, entre otras) y el sistema educativo de la jurisdicción quedó conformado por cuatro niveles y ocho modalidades:

El Nivel Inicial abarca la educación de los niños de 45 días hasta los 5 años inclusive, siendo obligatorias las salas de 4 y 5 años. Tanto la Educación Primaria como la Secundaria contemplan seis años de educación obligatoria, iniciándose la Primaria a los 6 años de edad y la Secundaria al finalizar aquella. Por último, el Nivel Superior, abarca la Formación Técnica y Docente, de grado y continua, y la formación en universidades provinciales. Pueden ingresar, 
al mismo, quienes hayan aprobado la Educación Secundaria.

A su vez, el sistema educativo incluye ocho modalidades, entendiendo por estas "aquellos enfoques educativos, organizativos y/o curriculares, constitutivos o complementarios de la Educación común, de carácter permanente o temporal, que dan respuesta a requerimientos específicos de formación articulando con cada Nivel, con el propósito de garantizar los derechos educativos de igualdad, inclusión, calidad y justicia social de todos los niños, jóvenes, adolescentes, adultos y adultos mayores de la Provincia" (Ley de Educación Provincial N 13.688, Artículo $22^{\circ}$ ). En tal sentido, la provincia de Buenos Aires ha definido como modalidades a: la Educación Artística; la Educación Física; la Educación Intercultural; la Educación Ambiental; la Educación Técnico-Profesional; la Educación Especial; la Educación Permanente de Jóvenes, Adultos, Adultos Mayores y Formación Profesional; y Psicología Comunitaria y Pedagogía Social. La enseñanza de los niveles y modalidades puede desarrollarse en diferentes ámbitos: Rurales continentales y de islas; Urbanos; de Contextos de encierro; Virtuales y Domiciliarios y hospitalarios.

Con anterioridad a la sanción de la Ley de Educación provincial, se había sancionado en 2006 la Ley 13.511 (publicada en el Boletín Oficial N²5.476 del 2006), mediante la cual se creó la Universidad Pedagógica Provincial (UPP), con el objetivo central de lograr una mayor jerarquización académica de los educadores, y disponer de una dinámica de articulación integral con todos los ámbitos del sistema educativo que haga posible la construcción colectiva de la educación a nivel local, regional y provincial. De manera que la Provincia creó la primera universidad pedagógica del país en 2006.

\section{4.a) La estructura orgánico-institucional del sistema y programas del sistema dedicados a la obtención, procesamiento y distribución de datos}

¿Cómo implementar estas reformas cuando la propia estructura interna del sistema está fragmentada? ¿Cómo se vincula una institución en estas condiciones con el conjunto de la comunidad? ¿Cómo recuperar el diálogo entre los diferentes espacios de socialización y acortar distancias entre las tecnologías del aula y las digitales?

Se ha dado cuenta del profundo divorcio que se había producido entre los diversos espacios de socialización y educación en nuestra sociedad, así como del grado de fragmentación que había en la propia estructura institucional del sistema que atravesaba no sólo los niveles de conducción central, sino también los regionales y locales. Incluso, al interior de las propias instituciones escolares. Al mismo tiempo en los años transcurridos entre 1983 y 2005 se había acentuado una tendencia a

[...] la feudalización de la educación en los extremos sociales: barrios privados y clubes de campo con escuelas propias y verdaderas redes escolares construidas por los movimientos sociales y diversas organizaciones de la sociedad, desvinculadas del sistema de educación pública, que fue concebido como un espacio privilegiado para lograr la integración de los 
distintos sectores sociales. ${ }^{11}$

Por lo tanto, era necesario encarar una política tendiente a la reconstrucción de los lazos, tanto al interior de la comunidad educativa cuanto "entre generaciones, entre educadores y educandos y restablecer la transmisión intergeneracional de la cultura". Al mismo tiempo, fundar las bases de estas políticas en un cuerpo jurídico haría posible sus sostenimiento en el tiempo, a la vez que permitiría reforzar la calidad institucional, un reclamo que habían sostenido varios sectores de la sociedad argentina a lo largo de los años del neoliberalismo y la crisis.

En consecuencia se dio inicio a un proceso de reconstrucción de la relación dinámica, educativa y dialógica entre los hijos y sus progenitores; docentes, alumnos (niños, niñas, adolescentes, jóvenes y adultos); maestros, directivos como funcionarios del Estado, desde inspectores hasta consejeros escolares, intendentes y responsables de las distintas áreas del gobierno provincial. Se trataba de la dificultosa tarea de la recuperación del rol del Estado a través de sus instituciones y organismos, distribuidos en todo el territorio bonaerense y, al mismo tiempo, en articulación con los organismos nacionales y federales, en particular en este caso, el Consejo Federal de Educación.

Por otra parte había que reestablecer los canales de diálogo y participación, así como o recuperar la confianza con los trabajadores de la educación (incluyendo a los administrativos, técnicos, auxiliares y profesionales del sistema educativo) y recuperar en su tarea cotidiana el sentido de servidores públicos que, como tales, deben ser reconocidos material y simbólicamente por el Estado. Esto no sólo implica la política salarial y la mejora de las remuneraciones, sino también la implementación de medidas que hacen al mejoramiento de las condiciones de trabajo y el ejercicio profesional, como la capacitación gratuita, en servicio y con puntaje del más alto nivel académico y científico.

Una de las medidas que se tomó en esta materia, con su correspondiente soporte legislativo, fue la ya mencionada creación de la Universidad Pedagógica Provincial (Ley provincial 13.511/06). Asimismo, para reconstruir la trama institucional del sistema, era necesario fortalecer la integración de la educación pública de gestión estatal con la pública de gestión privada y con la educación particular de gestión privada como integrantes de un único sistema educativo provincial.

Inscrito en los procesos nacionales de recuperación de la dignidad y el salario del conjunto de los trabajadores argentinos, la Provincia también avanzó en esta materia en el área educativa. Fue así que se revalorizaron las convenciones colectivas de trabajo, largamente reclamadas por los sindicatos docentes y establecidas por la Ley provincial 13.552/06 "como el espacio legítimo para la discusión sobre el conjunto de temas que vinculan al Estado como empleador y a los docentes como trabajadores." 12

En el mismo sentido, se consideró que un sistema educativo democrático "tiene que establecer un sistema de gobierno de la educación secundaria y la educación superior incorporando a los 
estudiantes, docentes y auxiliares a órganos de dirección y control." ${ }^{13}$ ¿Qué rol debían desempeñar, por lo tanto, los organismos de administración y gestión del sistema en el nivel local y comunitario? En la Fundamentación del proyecto de ley se advierte que

Es indispensable sostener y valorizar los organismos de la comunidad que apoyan y complementan al sistema de educación pública, en particular los consejos escolares y las cooperadoras, así como los organismos asesores de la Dirección General como el Consejo General y el Consejo Provincial de Educación y Trabajo (COPRET). De igual modo estimular las asociaciones civiles de apoyo a la educación pública y otros organismos previstos por las leyes de educación nacional y provincial. En la misma dirección político-educativa resulta indispensable realizar convenios y desarrollar programas conjuntos con otros ámbitos del Estado como con asociaciones representativas del trabajo y la producción, sosteniendo en todos los casos la prioridad pedagógica y formativa de todas las acciones derivadas de los mismos, en consonancia con los objetivos generales de la política educativa provincial prevista en este proyecto de Ley y en los planes estratégicos que se generen en cada gestión.

En cuanto a la administración general, se la concibió sobre la base de garantizar la eficiencia, el control de la gestión y la consolidación de los puestos de trabajo de todo el personal. Para concretar estos objetivos, se requería una modernización del sistema educativo que se llevara adelante con la participación de los trabajadores de la educación, pues los cambios educativos no alcanzan profundidad democrática si no se los acompaña de reformas administrativas y de organización "que conjugan pautas de planeamiento con controles sociales modernos y populares."14

En ese sentido avanzó la aplicación del artículo $65^{\circ}$ de la Ley provincial 11.612 [la norma que regía el sistema educativo provincial en ese momento], referido al nombramiento por concurso de los secretarios técnicos de los Consejos Escolares, la creación de la Dirección de Fondos Descentralizados en la Dirección General de Cultura y Educación, la utilización plena de los organismos de control del gobierno provincial y el sostenimiento y mejora de la política de concursos para el ingreso a la docencia y a los cargos administrativos y técnicos del sistema educativo.

Educar requiere siempre, en cualquier circunstancia, darle crédito al futuro. Pronosticar posibilidades produce inéditas oportunidades de procesos pedagógicos y política educativa. Este proyecto interpela a las personas reales, a todos nosotros. Necesitamos restablecer la confianza entre quienes coincidimos en la democracia, en la constitucionalidad, en los derechos humanos, en la justicia social, en la necesidad de proteger y preservar los sistemas ecológicos, en la soberanía política, en el reconocimiento en la unidad nacional y regional, en la diversidad ambiental y cultural, y en el reconocimiento de la independencia económica, como caminos alternativos transitables en la era de la globalización. ${ }^{15}$

\section{4.b) La legislación argentina en materia de sociedad de la información}

El ingreso del país en la sociedad de la información, del que se ha dado cuenta en los aspectos referidos a tensiones políticas, contenidos y otros, también ha requerido de una adaptación normativa de la legislación general, tal como ocurre en todo el mundo. Ese proceso no ha sido lineal ni sistemático, por lo que el cuerpo jurídico que lo regula, en este como en casi todos los 
aspectos referidos al ordenamiento legal de una sociedad, tampoco lo fue. El recorrido por la normativa es revelador de las diferentes posiciones y tensiones que atraviesan a las sociedades contemporáneas en materia de información y comunicación, a medida que se van introduciendo nuevos avances tecnológicos que afectan aspectos tales como:

\section{Acceso a Internet}

En cuanto al acceso a Internet, se observan las siguientes normas: ${ }^{16}$

\section{Garantía constitucional expresada en los artículos 14 y 32 de la cN}

\section{- Artículo 14}

Todos los habitantes de la Nación gozan de los siguientes derechos conforme a las leyes que reglamenten su ejercicio, a saber: de trabajar y ejercer toda industria lícita; de navegar y comerciar; de peticionar a las autoridades; de entrar, permanecer, transitar y salir del territorio argentino; de publicar sus ideas por la prensa sin censura previa; de usar y disponer de su propiedad; de asociarse con fines útiles; de profesar libremente su culto; de enseñar $y$ aprender. ${ }^{17}$

\section{- Artículo 32}

El Congreso federal no dictará leyes que restrinjan la libertad de imprenta o establezcan sobre ella la jurisdicción federal. [Reinterpretada por toda la doctrina jurídica actual como libertad de expresión].

\section{- Ley 26.032/05 ${ }^{18}$}

Establece que la búsqueda, recepción y difusión de información e ideas por medio del servicio de Internet se considera comprendida dentro de la garantía constitucional que ampara la libertad de expresión.

\section{- Decreto 1279/1997 ${ }^{19}$}

Declara comprendido en la garantía constitucional que ampara la libertad de expresión al servicio de Internet.

\section{- Ley 25.690/03 20}

Establece que las empresas ISP (Internet Service Provider) tendrán la obligación de ofrecer software de protección que impida al acceso a sitios específicos.

16 Cfr. Página de la Comisión de Comunicaciones e Informática, HCDN, en http://www.diputados.gov.ar/, sitio consultado en noviembre 2009.

17 El subrayado pertenece a la autora de esta tesis.

18 Sancionada el 18 de mayo de 2005, Promulgada el 16 de junio y publicada en el Boletín Oficial del 17 de junio de 2005 Boletín Oficial $\mathrm{N}^{\circ}: 30.677$. 


\section{Estándares Tecnológicos}

- Disposición Nº 10/2005 Oficina Nacional de Tecnologías Informáticas

Aprueban los Estándares Tecnológicos para la Administración Pública Nacional, - ETAP

- Versión Invierno 2005, en materia informática y de comunicaciones asociadas.

\section{- Disposición Nº 09/2005 Oficina Nacional de Tecnologías Informáticas}

Autoriza la extensión del período de validez del certificado de la Autoridad Certificante de la Oficina Nacional de Tecnologías de Información por un período de seis años, a partir del 10 de octubre de 2005.

\section{Accesibilidad del Servicio}

- Decreto 252/200021

Programa Nacional para la Sociedad de la Información. Modificación del art. 3 del decreto 1018/98.Modificación del art. 4 del decreto 1293/98

\section{- Decreto 1018/1998}

Crea el programa para el desarrollo de las comunicaciones telemáticas "argentin@in ternet.todos"

\section{- Decreto 554/1997}

Declara de interés Nacional el acceso de los habitantes de la República Argentina a la red mundial Internet. Autoridad de aplicación.

\section{- Decreto 1293/1998 22}

Declara de interés Nacional el proyecto "Internet 2 Argentina", destinado a la implementación, desarrollo y aplicaciones de una red de alta velocidad de telecomunicaciones, con el fin de interconectar centros académicos, científicos y tecnológicos en todo el territorio nacional.

\section{- Resolución 1246/1998 Secretaría de Comunicaciones}

Establece que podrán otorgarse permisos para la prestación del servicio de acceso a Internet a diversas instituciones y organismos gubernamentales y no gubernamentales, cuando dicha prestación se realice sin fines de lucro.

\section{- Resolución 1235/1998 Secretaría de Comunicaciones}

Determina la inscripción que deberán incluir las facturas emitidas por los Internet Provider.

\section{- Resolución 999/1998 Secretaría de Comunicaciones}

Implementa el Programa "Internet 2" en el ámbito de la Secretaría de 
Comunicaciones.

\section{- Resolución 613/1998 Secretaría de Comunicaciones}

Asigna numeración no geográfica para el Servicio de Valor Agregado "Acceso a Internet", con carácter transitorio.

\section{- Resolución 499/1998 Secretaría de Comunicaciones}

Aprueban tarifas promocionales propuestas por las empresas Telecom Argentina Stet France Telecom SA y Telefónica de Argentina SA para los usuarios de los servicios básicos telefónicos a fin de acceder al servicio de valor agregado de acceso a Internet.

\section{- Resolución 2814/1997 Secretaría de Comunicaciones}

Aprueban los precios de acceso de la red telefónica pública, que posibilitarán que los clientes de los prestadores de servicios de valor agregado accedan a los servicios de Internet.

\section{- Resolución 2132/1997 Secretaría de Comunicaciones}

Adopta el procedimiento de audiencia pública, previsto en el reglamento general de audiencias públicas y documentos de consulta, para la presentación de inquietudes sobre aspectos relacionados con Internet.

\section{Dominio en Internet}

\section{- Resolución 203/2009 Ministerio de Relaciones Exteriores, Comercio Internacional y Culto}

Limita el número de nombres registrados que una entidad registrante pueda inscribir en subdominio ".com.ar" u ".org.ar" a doscientos (200).

\section{Correo electrónico}

\section{- Resolución 338/2001 Secretaría de Comunicaciones}

Adopta el procedimiento de documento de consulta previsto en el Reglamento General de Audiencias Públicas y Documentos de Consulta para las Comunicaciones, con la finalidad de tratar el documento que contendrá el "Anteproyecto de Ley de Regulación de las Comunicaciones Publicitarias por Correo Electrónico".

\section{- Resolución 333/2001 Secretaría de Comunicaciones}

Adopta el procedimiento de Documento de Consulta previsto en el Reglamento General de Audiencias Públicas y Documentos de Consulta para las Comunicaciones, con la finalidad de tratar el documento que contendrá el "Anteproyecto de Ley de Protección Jurídica del Correo Electrónico". 


\section{- Resolución 4536/1999 Secretaría de Comunicaciones}

Designa al Correo Oficial de la República Argentina como autoridad oficial de certificación de la firma digital de los poseedores de una Dirección de Correo Electrónico asignada de conformidad con lo establecido por el decreto 1335/99. Mecanismos y procedimientos para que cada habitante disponga de una casilla de Correo Electrónico.

\section{- Decreto 1335/1999}

Declara de interés Nacional, en el marco del Programa "argentin@internet.todos" el proyecto "Una dirección de correo electrónico para cada argentino", destinado a proveer una cuenta de correo electrónico gratuita con una dirección electrónica segura y reconocida a cada habitante de la República Argentina que posea Documento Nacional de Identidad y a cada persona jurídica que posea Clave Única de Identificación Tributaria.

\section{4.c) La sociedad de la información en el marco de la discusión de la Ley de Servicios de Comunicación Audiovisual. Todas las voces}

Mientras se escribía esta tesis, la sociedad argentina asistió a uno de los más amplios y participativos debates en materia de información y comunicaciones del que exista registro, en ocasión de la presentación, por parte del Poder Ejecutivo Nacional, de un proyecto de Ley de Servicios de Comunicación Audiovisual que había sido reclamado, por muchos sectores, desde la recuperación democrática en 1983.

El proyecto enviado al Congreso por el Poder Ejecutivo en 2009 se fundamentó, esencialmente, en el trabajo sistemático, realizado en los últimos cinco años, por la Coalición por una Radiodifusión Democrática, que a su vez, recogía documentos, doctrina y debates anteriores. Por otra parte, se realizaron numerosos foros de debate durante el año 2009, de los que participaron diversas organizaciones, universidades nacionales (con y sin carreras de comunicación, incluyendo a docentes, investigadores, estudiantes, responsables de medios de comunicación universitarios), partidos políticos, redes de radios populares, sindicatos, empresas, cooperativas, entre otros. A su vez, tanto en la Cámara de Diputados de la Nación como en el Senado, se realizaron audiencias públicas para recoger los testimonios de todos los ciudadanos y organizaciones que quisieran participar del debate.

No es materia de este trabajo abordar este tema, pero vale la pena recuperar algunas de las ponencias, fragmentos que ilustran, desde situaciones y prácticas particulares de los sujetos, los enfoques acerca de la sociedad de la información y la necesidad de democratizarla. Los dispositivos como Cédula y Mapa, recogen información acerca de sujetos e instituciones concretas, inscritas en realidades de las que los datos no pueden dar realmente cuenta, pero sí hacer visibles. Lo que se hace con esa información y si esto afecta o no la vida concreta de los ciudadanos, sólo puede ser verificado mediante un análisis de las políticas en las que estos dispositivos se inscriben, se ha dicho aquí. Pero ¿es eso realmente así?, ¿cómo se ve el tema de la sociedad de la información desde 
distintas subjetividades que conforman identidades colectivas heterogéneas? ¿Pueden los medios y las herramientas de la comunicación y la información servir para hacer visibles los problemas, las circunstancias concretas? ¿Debe intervenir el Estado?, ¿cuánto?, ¿cómo?

\section{Visibilidad y reconocimiento}

[...] Estamos aquí presentes los pueblos originarios, para decir una vez más que no se puede seguir con una ley de comunicación de la dictadura, que Invisibiliza a los actores sociales. Invisibiliza a los pueblos originarios, invisibiliza nuestros derechos y sirve para instalar un estereotipo de indígena derrotado. Nosotros decimos que estamos vivos, y que tenemos derechos que exigimos así como los medidas y mecanismos necesarios para el respeto, ejercicio y pleno uso de nuestro derecho indígena a adquirir, operar y administrar servicios de comunicación audiovisual y participación en la sociedad de la información y el conocimiento, para al fortalecimiento de nuestras culturas e idiomas, la afirmación de nuestra identidad y el establecimiento de relaciones interculturales.

Ello implica asumir el reconocimiento de los pueblos indígenas como sujetos de derecho público, así mismo, la obligación del Estado de financiar y desarrollar los servicios de comunicación Indígenas, a fin de que podamos ejercer con plenitud nuestros derechos a la comunicación y a la información. Y en particular, requiere de políticas públicas para que los pueblos originarios tengamos acceso a operar servicios de comunicación audiovisual, dado que los requisitos establecidos actualmente no contemplan a los medios de comunicación Indígena. ${ }^{23}$

\section{Participar en la sociedad de la información}

Justamente, los servicios de comunicación audiovisual y la participación en la sociedad de la información y el conocimiento, constituyen uno de los principales instrumentos mediante los cuales se ejerce el derecho a la identidad y a mantener y desarrollar los propios modelos culturales, el derecho a la autoorganización y el derecho a la participación en todos los asuntos que nos afecten. Estos servicios y esa participación nos permiten a los Pueblos Indígenas dar a conocer nuestra cosmovisión haciendo visible nuestra identidad y establecer vías de interacción con otros Pueblos. ${ }^{24}$

\section{Avance tecnológico, era digital y democracia}

Cuando se habla del avance tecnológico, tiene que estar al servicio de las democracias, de la sociedad, de la educación, de la salud...25

[...] nos parece oportuno transcribir las expresiones del señor Enrique Bustamante, profesor de Comunicación Audiovisual de la Universidad Complutense de Madrid, asesor de la comisión designada por José Luis Zapatero para reformar la Televisión Pública Española vertidas en la pág. 12 del diario Página/12 del día 29 de diciembre de 2008, advirtiendo que "si en los años cuarenta y cincuenta el Servicio Público de Televisión era fundamental para el Estado de bienestar, en la era digital es mucho más importante para aspirar a tener igualdad de oportunidades y el acceso a la sociedad de la información" y las vertidas en el periódico Miradas al Sur, pág. 27, del día 28 de diciembre de 2008 donde el mismo catedrático señala "que las funciones del servicio público de radiodifusión están ligadas a la defensa de la soberanía nacional". ${ }^{26}$

23 Ponencia de Juan Chico. Organización indígena Napalp. Autor del libro Napalpi. En Cámara de Diputados de la Nación sesiones ordinarias 2009, proyecto de Ley de Servicios de Comunicación Audiovisual, audiencias públicas. Comisiones de Comunicaciones e Informática, de Presupuesto y Hacienda y de Libertad de Expresión, apartado "Reproducción textual de los documentos presentados".

24 Ponencia de Matías Melillan, comunicador indígena. Confederación Mapuche de Neuquén Encuentro Nacional de Organizaciones de Pueblos Originarios En Cámara de Diputados de la Nación sesiones ordinarias 2009, proyecto de Ley de Servicios de Comunicación Audiovisual, audiencias públicas. Comisiones de Comunicaciones e Informática, de Presupuesto y Hacienda y de Libertad de Expresión, apartado I, "reproducción textual de los documentos presentados".

25 Lucas Molinari, Radio Gráfica FM 89.3, Ciudad de Buenos Aires, en Ibídem.

26 Felipe Boccoli. Presidente de la Federación de Cooperativas de telecomunicaciones de la República Argentina FECOTEL, en Ibídem. 


\section{Pluralidad, igualdad de oportunidades, discriminación}

Por su parte, la Convención Interamericana para la Eliminación de Todas las Formas de discriminación contra las Personas con Discapacidad, aprobada por la OEA e incorporada al derecho interno por la ley 25.280, establece y obliga a los Estados adherentes a "tomar medidas para eliminar, los obstáculos arquitectónicos, de transporte y comunicaciones que existan, con la fi nalidad de facilitar el acceso y uso para las personas con discapacidad" (artículo III, punto $1 \mathrm{c}$ )". Desde hace casi 26 años anhelamos una legislación en servicios de comunicación audiovisual democrática, plural, participativa y federal. Este es el momento para que, de una vez por todas, incluyamos a las personas con discapacidad en la sociedad de la información, permitiéndoles así ejercer su derecho de ciudadanas/os, garantizándoles la igualdad real de oportunidades y de trato en los medios de comunicación audiovisual. ${ }^{27}$

La ponencia de la Lic. Analía Elíades en las audiencias públicas, "Hacia una Ley de Servicios de Comunicación Audiovisual. Una batalla Política y Cultural", destaca que:

La norma de la dictadura militar y sus reformas durante los 90 conciben a la radiodifusión como una actividad mercantil, comercial, que debe ejercerse prioritariamente por el sector privado y subsidiariamente por el Estado.

El punto de partida de la propuesta de ley de servicios de comunicación audiovisual, puesto a debate público a partir de su anuncio oficial en marzo de 2009 parte de una consideración totalmente distinta: la actividad radiodifusora es parte integrante del derecho a la comunicación. Y reconoce tres actores fundamentales para su ejercicio: el sector público, el privado con fines de lucro y de gestión privada sin fines de lucro (artículo 21 de la Propuesta de proyecto de ley). [...] En este sentido, cabe considerar los aportes de los 21 Puntos de la Iniciativa Ciudadana por una Ley de Radiodifusión de la Democracia, receptado por el Poder Ejecutivo nacional para la elaboración de la propuesta de ley establece que para la elaboración de la propuesta de ley establece que investigar, buscar, recibir y difundir informaciones, opiniones e ideas, sin censura previa, a través de la radio y la televisión, en el marco del respeto al Estado de derecho democrático y los derechos humanos". [...] A su vez, el Punto 2 determina: "La radiodifusión es una forma de ejercicio del derecho a la información y la cultura y no un simple negocio comercial. La radiodifusión es un servicio de carácter esencial para el desarrollo social, cultural y educativo de la población, por el que se ejerce el derecho a la informaciónde la población, por el que se ejerce el derecho a la información. 
5. Mapa y Cédula
Escolar como HERRAMIENTAS DE LA INFORMACIÓN 

El trabajo se propone verificar si dispositivos de la sociedad de la información, como lo es Cédula y Mapa Escolar, han contribuido, y en tal caso, en qué medida, como insumos informativos para la toma de decisiones en materia de política educativa desde su creación en 2001. Asimismo, si esto ha sido así, es ineludible la pregunta siguiente: ¿al servicio de qué políticas? En tal sentido, pueden distinguirse tres etapas desde la implementación de Cédula y Mapa.

La primera etapa, durante la gestión de José Octavio BoRDón como Director General de Cultura y Educación (diciembre 1999-noviembre 2001), tuvo como principal objetivo conocer y reconstruir el sistema educativo; una segunda etapa, durante la primera gestión de Mario OPORTo en ese cargo, ${ }^{1}$ se orientó en hacer frente a la crisis de 2001 y sus consecuencias inmediatas y, por último, una tercera etapa conducida por Adriana PUIGGrós, se propuso la construcción de un sistema educativo para los siguientes años.

\section{5.a) La provincia de Buenos Aires y el contexto nacional}

En la provincia de Buenos Aires luego de la década menemista comenzó a superarse el momento más agudo de la crisis del sistema educativo, denominado por Puiggrós como "una fuerte inundación", ${ }^{2}$ que había destruido los subsistemas de lo educativo, entre los cuales se encontraban los sistemas de comunicación interna. Se dispersó a las escuelas en nombre de la "autonomía escolar", lo que en otros países causó la desaparición de sectores de la educación pública.

En los 90, en la Provincia se trabajó para que cada escuela tuviera sus proyectos institucionales, pero sin sostener lazos distritales, entre organizaciones sociales, con el Estado provincial, en definitiva no había políticas de integración social, comunitarias que articularan las demandas y necesidades. Al mismo tiempo, la Ley de Transferencia de los Servicios Educativos 24.049 había tenido como efecto la atomización de diversos subsistemas (modelos y formatos escolares

1 Mario Oporto, quien fuera Director General de Cultura y Educación durante el último tramo de la gobernación de Carlos Ruckauf (2001) y, luego, durante la gobernación de Felipe Solá (2001-2006) volvió a ocupar la cartera educativa bonaerense al asumir Daniel Scioli en diciembre de 2007.

2 Puiggrós, Cartas a los educadores del siglo xxi, Ibídem. 
en los distintos niveles) en las 24 jurisdicciones e incluso, al interior de cada una de ellas, por lo que resultaba muy difícil la reconstrucción de los lazos institucionales tanto al interior de cada provincia como en la relación con el conjunto del sistema en el nivel nacional. En consecuencia el gobierno y administración de un sistema educativo atomizado y heterogéneo que requería ser reconstruido constituyó una de las prioridades para conducir la nueva etapa, que se inicia al finalizar 1999.

Durante la gobernación de Carlos Ruckauf, en el año 2001, ${ }^{3}$ José Octavio BoRdón ocupó el cargo de Director General de Cultura y Educación fue sucedido, en el mes de noviembre de ese mismo año, por quien fuera hasta entonces Subsecretario de Educación, Mario OpORTo.

La designación de BORDón generó fuertes expectativas de un cambio sustancial en la dirección de la política educativa que se había sostenido en la Provincia durante la gobernación de DUHALDE, no sólo por su procedencia sino también por las ideas que sustentaban al espacio político al que este pertenecía. De algún modo su nombramiento implicó, en el imaginario de vastos sectores críticos de la reforma encabezada por la gestión de Graciela GIANNETTASIO, una apuesta hacia la construcción de un futuro que permitiría recomponer el sistema educativo. Es necesario considerar que cuando fue designado a fines de 1999, todavía estaban frescos los recuerdos de los acontecimientos de 1995, cuando BORDón había enfrentado en las elecciones a Carlos Menem y obtuvo 4.993.360 de votos.

BoRdón se había abierto del PJ y había formado el Frepaso junto con Chacho ÁlvarEZ, a quien derrotó en una interna abierta y fue candidato a presidente. Tras ser batido por el "voto cuota" y por el riojano a prueba de balas, la alianza se resquebrajó con velocidad: BoRDón intentó acercar a BELIz al Frepaso, lo que fue resistido por Chacho. El quiebre definitivo fue en 1996, cuando Bordón renunció a su banca en el Senado y también abandonó su partido PAIS. El resultado para su capital político fue catastrófico. ${ }^{4}$

Una de las preocupaciones del entonces Director General, quien compartía muchos de los fundamentos teóricos acerca de la sociedad de la información que conformaban por entonces el marco conceptual que proporcionaban algunos organismos internacionales, consistía en introducir al sistema educativo provincial en la sociedad del conocimiento y la información, como se la denominaba por entonces. Por otra parte BoRdón consideraba que las herramientas de la sociedad de la información eran imprescindibles para iniciar el proceso de reconstrucción del sistema educativo y, en particular, para gobernarlo y administrarlo.

Es precisamente por esos años en los que las TIC y las redes aparecen en el discurso educativo en el ámbito internacional como las herramientas clave para motivar a los niños, poner en comunicación a los estudiantes de diversos países, reintegrar a los sectores y grupos

3 En medio de la crisis del 2001 y con la Provincia atravesada no sólo por un tremendo déficit financiero sino también por innumerables conflictos sociales, Ruckauf renunció a su cargo de Gobernador, para el que había sido electo en 1999, tras derrotar a la fórmula de la Alianza y asumió como Ministro de Relaciones Exteriores y culto de Eduardo Duhalde. Lo reemplazó su Vicegobernador, Felipe Solá. 4 Véase "Qué es de la vida de...José Octavio Bordón, diario Página 12, 5 de agosto de 2008, http://www.pagina12.com.ar/diario/elpais/1- 
excluidos a los diálogos productores de riqueza, sentido y pertenencia social. ${ }^{5}$ Como se analiza en el punto 3.e. "La situación de América Latina en el marco de la sociedad de la Información y las TIC: nuevas y viejas fronteras" de este trabajo, la integración de las TIC, el acceso a Internet y el trabajo en red parecen haberse constituido en una medicina universalmente útil para todos los malestares de la educación y casi todas las disfunciones del nuevo ordenamiento social.

La producción de investigaciones, artículos, libros, textos, sitios, revistas, congresos, conferencias, recomendaciones, declaraciones, soluciones sobre estos tópicos a nivel internacional se presenta inagotable. Los países centrales producen una abundante literatura dedicada a promover la adopción de TIC y del trabajo en redes en la educación, y a la investigación sobre los cambios que esta integración produce. ${ }^{6}$

Coviene repetir que las TIC no son artificios neutrales, sino tramas de dispositivos, técnicas, conocimientos y saberes que se articulan con las prácticas concretas de las sociedades, así como con los sistemas de interpretación de las personas y los grupos que las utilizan, por lo que la forma en la que "las tecnologías se imbrican en la producción de prácticas sociales depende de la capacidad que los sujetos, las instituciones y las sociedades tengan para construir y recrear conocimientos y sentidos en torno de sus potencialidades y sus usos."7

Se iba configurando, en consecuencia, un nuevo marco para la educación escolar en la sociedad de la información, que, como señalan algunos investigadores "sitúa la educación en una posición central, como base para el acceso al conocimiento, y la convierte en una prioridad estratégica para el desarrollo económico y social." ${ }^{\text {D }}$ Debido a ello el papel central de la educación en la configuración del nuevo paradigma económico y social impulsa la transformación radical de los planteamientos educativos heredados de la sociedad industrial, con argumentos de distinto orden.

Por otra parte, en el aspecto de la administración del sistema, la orientación de la gestión de BORDón consideraba la descentralización y la autonomía escolar como medio para desburocratizar un sistema que por entonces comprendía 4.200.000 alumnos, 250.000 docentes, 17.000 escuelas y un presupuesto anual de 3.500 millones de dólares, para lo cual era indispensable disponer de un sistema de información y comunicación moderno y ágil. Sin embargo esto originó numerosos conflictos con sectores políticos y docentes que veían esas posturas como la antesala de la municipalización de la educación y que, por lo tanto, emprendieron acciones de resistencia al modelo de esa gestión.

En una entrevista concedida en 2000 al diario La Nación, Bordón reveló que su propósito era "avanzar en el proceso de autonomía escolar sin la necesidad de impulsar cambios en la legislación ni en los estatutos docentes, un tema que encendería un cortocircuito en la relación con los gremios docentes."

\footnotetext{
5 Palamidessi, Mariano (comp.) Galarza, Daniel, Landau, Mariana, Schneider, Débora La escuela en la sociedad de Redes. una introducción a las TIC en la educación, s/d. Se puede cosultar en Internet.

6 Ibídem, pág. 2.

7 Ibídem.

8 “La escuela en la sociedad en red, Internet en el ámbito educativo no universitario", investigación de la Universidad Abierta de Cataluña, pág. 18, en http://www.uoc.edu/in3/pic/esp/pdf/PIC_Escoles_esp.pdf, sitio consultado octubre 2009.

9 Cfr. http://www.lanacion.com.ar/nota.asp?nota_id=25345, sitio consultado en octubre 2009.
} 
Pese a lo cual y tras casi una década durante la cual el sistema educativo bonaerense había estado orientado a la reforma educativa que introdujo la Ley Federal ${ }^{10}$ soplaban nuevos vientos y BORDón impulsó diversas acciones y programas en este sentido, para sistematizar la información, como la realización de un análisis de situación que permitiera, con criterio estadístico, caracterizar globalmente el sistema educativo provincial. ${ }^{11}$ La introducción de estos dispositivos requería, por supuesto, de la capacitación de los diversos funcionarios que tenían distintos niveles de responsabilidad.

Mónica González Gaviola, ${ }^{12}$ quien ideó y estuvo a cargo de la puesta en marcha de Mapa y Cédula escolar explica que

Teníamos una dificultad. Más allá de las resistencias propias que implica intentar cambiar un orden establecido que lleva años en una institución, que ya era parte del sistema, de su matriz, por un lado la inmensidad del sistema educativo de la provincia que es muy diferente de una región a otra. Por otro un atraso en lo que refería a la incorporación de nuevas tecnologías. Se hablaba de la necesidad de conectividad de las escuelas pero parecía un desafío enorme, casi imposible tanto en lo económico como en la posibilidad concreta y cierta de que las escuelas contaran con conexión a la red de redes. Casi 17 mil establecimientos distribuidos a lo largo y ancho de la provincia no son poca cosa, y el otro desafío, que era una prioridad más que desafío, fue el de la capacitación de los actores principales que eran los encargados de cargar los datos.

Planificar unos de los sistemas educativos más complejos de la Argentina, como lo es el de la provincia de Buenos Aires, implica tener en cuenta diversas cuestiones. No es sólo un tema de recursos económicos, sino, a su vez implica comprender, tener un diagnóstico real, de lo que la comunidad educativa y sus administradores consideran prioridades. Estas tensiones no fueron menores en un momento histórico en el cual la Provincia estaba sumergida en una crisis económica más que importante. Se recordará que en el año 2001, a los empleados de la administración provincial se les pagaba, a destiempo y con reducción salarial, con los bonos llamados Patacones. En otro orden de cuestiones, había existido una desinversión importante en infraestructura escolar y los salarios de los docentes y auxiliares provinciales estaban en niveles magros, y las escuelas se habían convertido en grandes comedores escolares en los cuales se le brindaba asistencia alimenticia a miles de niños.

Además de las resistencias existentes por las cuestiones macro y micro económicas, y más allá de cuestiones de ideología y política pedagógica por las que el sistema educativo bonaerense atravesaba en ese entonces, los cambios profundos siempre -o casi siempregeneran incertidumbres y crisis entre los miembros de la comunidad que acostumbrados a una metodología laboral consideran que los cambios que no son consensuados internamente carecen de aplicabilidad en la práctica concreta o en su campo específico. En el caso de la

10 Durante la gobernación de Eduardo Duhalde (1991-1999, incluyendo la reforma constitucional que posibilitó su reelección) ocuparon el frente de la cartera educativa la Dra. Farías de Castro (diciembre 1991-abril 1992), —cuya gestión estuvo definida no sólo por los intentos reformistas sino por un fuerte enfrentamiento con los docentes cuando intentó la reforma del Estatuto del Docente- y luego por la Dra. Graciela Giannettasio, quien ocupó el cargo hasta 1999, período en el caul se consolidó la reforma.

11 Sistema Educativo bonaerense. Los números en la comparación Nacional. 1983-2000. Dirección Provincial de Planeamiento. Dirección de Información y Estadística. Dirección General de Cultura y Educación. Provincia de Buenos Aires. Cfr. http://abc.gov.ar/ lainstitucion/organismos/planeamiento/pdfdocumentos/sistemaeducativo.pdf, sitio consultado en octubre 2009.

12 Mónica González Gaviola es Lic. en Sociología y Master en Gestión del Conocimiento por la Universidad Complutense de Madrid. 
implementación del sistema de carga de la información para Mapa y Cédula Escolar, éstos no fueron la excepción. Mónica González Gaviola recuerda que

A los primeros que les dimos computadoras fue a los actores que tenían que trabajar con nosotros de manera directa. Luego a los inspectores, a los consejeros escolares e inspectores, y después a las escuelas. Esto fue así porque en los primeros años trabajamos en armar el software. La decisión de hacer un software específico fue una cuestión muy importante por lo complejo que es el sistema de la Provincia. No se podía aplicar cualquier dispositivo de recolección de datos, por las características socio-económicas y territoriales en general de la Provincia, la cual tiene una diversidad socio-cultural y problemáticas inconmensurables entre si. No es lo mismo las escuelas en el contexto de islas, que las rurales o las urbanas, sólo por mencionar algunas variables.

Dentro de la concepción de aplicabilidad del programa Mapa y Cédula Escolar, los equipos técnicos encargados de su puesta en funcionamiento consideraron que era estratégicamente adecuado no comenzar por etapas con el programa.

Una de las dudas que teníamos era si comenzábamos con la aplicación de Mapa y Cédula por etapas. Esto implicaba comenzar por el nivel primario y luego hacerlo en el nivel medio y superior. Decidimos abarcar todo, comenzar por todos los niveles, porque considerábamos que íbamos a tener menos resistencias. Las resistencias te aparecen antes que llegue. Fue una cosa terrible, miles de personas para capacitar a ellos mismos y a todos. Había mucho descreimiento de que la Provincia pudiera implementar un dispositivo de sociedad de la información que implicaba, por un lado, adquisición de equipamiento tecnológico, por el otro, capacitación de recursos humanos y por sobre todas las cosas, decisión política para llevarlo a la práctica y sostenerlo en el tiempo..$^{13}$

En tal sentido, es ilustrativo observar los considerandos de la Resolución 1098/01, mediante la cual el Director General aprobó la organización académica del Curso "Capacitación en herramientas informáticas-Cédula escolar" para los secretarios de escuelas, una ampliación del Relevamiento de Matrícula Escolar que se había puesto en marcha a los fines de conocer la situación de la población escolar en la Provincia. Como se desprende del propio texto, no sólo considera allí el aspecto de la capacitación en sí mismo, sino cuestiones relativas a la situación laboral de los docentes y la difusión de esta normativa no sólo a las Direcciones implicadas en su implementación sino también mediante el área de Prensa:

La Plata, 28 de Marzo de 2001.

\section{[...] CONSIDERANDO:}

Que la Resolución Ministerial 4611/00 aprueba el Programa de Relevamiento de Matrícula;

Que la Disposición 45/01 aprobada por la Subsecretaría de Educación instrumenta el Operativo de Cédula Escolar 2001;

Que el Plan Provincial de Formación Continua contempla el desarrollo de diferentes itinerarios y estrategias de capacitación, entre otros, las instancias virtuales;

Que la Resolución № 6113/00 ha aprobado el Proyecto Marco de Capacitación Virtual y los problemas y contenidos estratégicos de la enseñanza de la informática educativa;

Que es prioritario establecer un procedimiento eficiente y confiable de recolección y procesamiento de datos de matrícula en todos los niveles y servicios del sistema educativo provincial que sirva de base al planeamiento educativo central, regional, distrital y local; 
Que es necesario contar en los establecimientos educativos con secretarios capacitados para gestionar información confiable a través del uso de herramientas informáticas;

Que es necesario desarrollar un sistema de gestión administrativa que permita generar información que alimente una base de datos común a todos los establecimientos;

Que cada escuela cuente con información clara y organizada respecto a su matrícula;

Que el Consejo General de Cultura y Educación se ha expedido favorablemente respecto al proyecto;

Que en virtud del inciso ii) del Artículo 33 de la Ley Provincial de Educación es atribución del Director General de Cultura y Educación autorizar la creación y funcionamiento de unidades educativas siendo los cursos de capacitación unidades de formación continua de los secretarios del Sistema Educativo;

Que la presente se encuadra en las facultades conferidas por el artículo 33, inciso u) y x), de la Ley Provincial de Educación N¹1.612;

Por ello, EL DIRECTOR DE CULTURA Y EDUCACION

RESUELVE:

ARTICULO $1^{\circ}$.- Aprobar la organización académica del Curso "Capacitación en herramientas informáticas- Cédula Escolar", para secretarios de escuelas, que como Anexo pasa a formar parte de la presente Resolución.

ARTICULO $2^{\circ}$.- Declarar actividad de Interés Educativo, la ejecución del Curso "Capacitación en herramientas informáticas- Cédula Escolar", para secretarios de escuelas, coordinado por la Dirección Provincial de Educación Superior y de Formación y Capacitación Docente Continua.

ARTICULO $3^{\circ}$.- Aprobar la localización y la carga horaria del trabajo tutorial para el curso "Capacitación en herramientas informáticas - Cédula Escolar", para secretarios de escuelas, que como Anexo II pasa a formar parte de la presente Resolución. [...]

ARTICULO $7^{\circ}$.- Registrar esta Resolución que será desglosada para su archivo en la Dirección de Coordinación Administrativa, la que en su lugar agregará copia autenticada de la misma; notificar al Consejo General de Cultura y Educación, la Dirección Provincial de Educación Superior y de Formación y Capacitación Docente Continua, la Dirección Provincial de Planeamiento y Evaluación de la Calidad Educativa, a todas las Direcciones Docentes y a la Dirección de Relaciones Públicas y Prensa para su correspondiente difusión.

Cumplido, archivar.

RESOLUCIÓN N 1098

José Octavio Bordón. Director General de Cultura y Educación de la Provincia de Buenos Aires

Otro aspecto por cierto novedoso de esta etapa fue el intento de implementar una planificación por áreas de los presupuestos, para lo cual era imprescindible también contar con información completa y actualizada acerca del sistema. En una nota dirigida a la Directora del Instituto Superior de Formación Docente N 92 de Laprida, Gladys Elena Mariñas, el Director General de Cultura y Educación destaca lo brindado en el año 2000 con las respuestas dadas a algunos de los problemas que se habían abordado: ${ }^{14}$

Nos propusimos fortalecer el lugar de la escuela en la comunidad y jerarquizar la 
responsabilidad y autoridad del directivo, que es el eje de la transmisión de valores y conocimientos", expresa el funcionario. [...]

Bordón destaca que, "conscientes de la necesidad de salvar la histórica deuda contraída con la educación y con la convicción de que es necesario trabajar juntos para superar los problemas que tenemos y asumir los nuevos desafíos, hemos concretado diversas acciones".

Puntualmente, cita la puesta en marcha de las unidades de planificación distrital, que permiten configurar un presupuesto, con la participación de los consejos escolares, los intendentes, los representantes de la comunidad, los inspectores, los directivos y los docentes, "para priorizar demandas a partir de un diagnóstico realista". [...]

Siguiendo la misma línea de trabajo -agrega-, "le comunicamos que se pondrá en marcha, durante el mes de marzo el Operativo de Relevamiento de Matrícula para Cédula Escolar.

Este programa se propone mejorar y optimizar del uso del tiempo en tareas administrativas de la escuela para permitir mayor dedicación al trabajo pedagógico, así como evitar la superposición de demandas de información provenientes de diferentes organismos".

Los establecimientos escolares recibirán un instrumento informático especialmente diseñado, que le permitirá sistematizar el registro de matrícula con edad, sexo, nivel, rama y otra información social relevante a la gestión escolar. Esto permitirá simplificar todos los procedimientos administrativos que tengan que ver con los alumnos. En una primera etapa se distribuirán, siguiendo un esquema de prioridades, 2.500 computadoras para uso administrativo.

Se prevé el entrenamiento de 500 capacitadores que transmitirán conocimientos de informática a 15.000 secretarios de establecimientos durante el mes de marzo. "Un operativo de esta envergadura -afirma Bordón- sólo será posible con el esfuerzo conjunto de todos los actores del sistema educativo provincial".

"Si bien, inicialmente, el compromiso de tiempo será significativo, creemos que se traducirá pronto en el mejoramiento de la calidad y las condiciones de trabajo en los establecimientos educativos. Les solicito especial colaboración para que se logren con éxito las metas previstas".

Por otra parte, se acaba de concretar la Red Privada Virtual (RPB), con la integración de todos los servicios telefónicos básicos existentes a la fecha más telefonía inalámbrica para escuelas rurales. Dicha red trata a cada miembro (cada teléfono que la integra) como un interno y engloba todas las comunicaciones de voz o fax en una sola estructura. Se incluye también la instalación de otra línea telefónica en las escuelas dedicada al acceso a la intranet y al e-mail de la DGCYE. Esto hará posible que las escuelas no paguen más los servicios telefónicos al hacerse cargo de ellos la DGCYE.

Bordón afirma que "así se facilitará el acceso al portal educativo abc.gov.ar lanzado a fin de mes. "Será un espacio virtual abierto y dinámico, dirigido especialmente a la comunidad educativa de nuestra provincia que permitirá la entrada de los docentes a la intranet sin necesidad de estar abonados a un prestador de servicios de Internet. Brindará, entre otras cosas, información y espacios de debate y capacitación".

"Le comunicamos que, a través de la cooperadora, el/la director/a de cada escuela tendrá asignado un monto mensual permanente destinado a solventar gastos menores, habituales del funcionamiento de cada institución. [... $]^{15}$

Es así que durante su gestión, además de crearse el Portal www.abc.gov.ar, se incorporaron equipos de técnicos y equipamiento informático con el objetivo de lograr mayores niveles de 
conectividad y redes de comunicación intrasistema, y se realizaron algunos acuerdos con empresas informáticas para la provisión del servicio de Internet en escuelas rurales, tarea que quedó inconclusa, o más bien, asumió otra orientación, cuando BoRdón renunció a su cargo en 2001 y los efectos de la crisis y la emergencia económica ocuparon la totalidad de la agenda educativa de su sucesor.

\section{5.b) Las políticas nacionales que impulsan el uso de las herramientas de la sociedad de la información aplicadas al campo educativo}

Cabe mencionar que esta orientación que impulsaba la gestión de BORDón se inscribe en el contexto nacional de la época. Ocupaba la presidencia DE LA RúA, y algunos de sus equipos técnicos propiciaban la multiplicación de la conectividad y la inserción de las Tic en el ámbito de la educación. El modelo es el proyecto del portal Educ.ar, que en sus estatutos propone:

la fijación de la política de contenidos de dicho Portal Educativo, mediante la calificación y evaluación de contenidos propios y de terceros que sean incluidos en el mismo" y: "establecer una red de comunicación (intranet) a fin de otorgar conectividad a los establecimientos educativos, los docentes y los alumnos con el 'Portal Educativo'; asesorar al Ministerio de Educación en todo lo relacionado al equipamiento del conjunto de dichos establecimientos, incluyendo cuestiones tales como su infraestructura y la correspondiente programación asegurando su mantenimiento y permanente renovación tecnológica, a fin de permitir el mejor uso posible del "Portal Educativo" en la educación Argentina. ${ }^{16}$

Impulsado por Martín VARSAVSKY, el programa Educ.ar no logró su principal meta que consistía en implementar un plan de conectividad para 52.000 escuelas, aunque sí tuvo éxito en cuanto a la incorporación del sitio punto Ar. Además de otros problemas, como los relativos al financiamiento, uno de los errores de este enfoque, a la luz de la perspectiva actual, fue considerar a la capacitación de los docentes (los principales usuarios) como una instancia posterior a la implementación de la tecnología, desde un modelo conceptual muy diferente al que se sostiene en esta investigación y al que propuso la Lic. BORDón.

Por otra parte, el Estado no asumió la responsabilidad completa de conducir el proceso de conectividad en el sistema educativo, sino que recurrió a los aportes de numerosas empresas y particulares, cuyos intereses no son, como lo hemos afirmado en diversas oportunidades, otros que los lucrativos.

En el orden nacional ya en 1996 comenzaron a sistematizarse datos e información estadística educativa surgida de los Relevamientos Anuales (RA). Con esta información, comenzaron a elaborarse diversas herramientas y dispositivos con insumos que, en muchos casos, son provistos por las administraciones provinciales, y se plasman en los Anuarios Estadísticos, como se explica en las siguientes páginas. Cabe consignar que después de la Ley de Transferencia la Nación no tiene bajo su jurisdicción a las instituciones educativas, por lo tanto en materia de estadística, como 
en casi todos los aspectos estratégicos de la política educativa, es fundamental la articulación entre el Estado nacional y las distintas jurisdicciones tanto provinciales como municipales.

Los Anuarios Estadísticos, coordinados por la Dirección Nacional de Información y Evaluación de la Calidad Educativa (DINIECE) sistematizan la información surgida de los Relevamientos Anuales que surgen de los censos que permiten obtener información de establecimientos estatales y privados de las 24 jurisdicciones del país desde el año 1996 y son publicaciones que "contienen información referida a la oferta educativa, la organización y magnitud de la matrícula y las designaciones docentes en los niveles nacional, provincial y de la Ciudad Autónoma de Buenos Aires, desglosada por tipo de educación, nivel de enseñanza y sector de gestión." ${ }^{17}$ Los operativos de relevamiento son planificados, coordinados e implementados por el Área de Información de la DINIECE en el marco de la Red Federal de Información Educativa que conforman las Unidades de Estadística de cada una de las jurisdicciones.

El Relevamiento Anual homologa conceptos, criterios y procedimientos que aseguran la comparabilidad de los datos educativos de todo el país en adecuadas condiciones de cobertura y calidad educativa. Cada año la DINIECE acuerda con las jurisdicciones las definiciones conceptuales y operativas del Relevamiento y elabora los cuadernillos que las Unidades de Estadística Educativa distribuyen y procesan a partir de los datos brindados por los establecimientos educativos de todo el país. ${ }^{18}$

En el caso de los docentes se llevan adelante los Censos Docentes cada 10 años en las 24 jurisdicciones del país desde el año 1994. Relevan información sobre personas que tienen designaciones docentes y trabajan en establecimientos de gestión estatal y de gestión privada de todos los niveles educativos (excepto el universitario) y tipos de educación. Las dimensiones del relevamiento son:

- La inserción institucional del docente en el establecimiento educativo o unidades de gestión escolar.

- Las características socio-económicas y demográficas.

- La situación laboral.

- La formación.

- Las actividades de capacitación y desarrollo profesional realizadas.

- La trayectoria profesional.

- Las percepciones del docente acerca de las condiciones en las que desarrolla su tarea.

Los instrumentos utilizados fueron:

- En 1994, Cédula Censal Docente con 30 preguntas.

- En 2004, Cédula Censal Docente con 47 preguntas.

El Censo Docente del 2004 es comparable con el del 1994 y además agrega variables no relevadas entonces. Están disponibles las bases de datos con información seleccionada de 
los Censos Docentes correspondientes a los años 1994 y $2004 .^{19}$

En el caso de la provincia de Buenos Aires, ya en el Informe del Sistema Educativo bonaerense 1983-2000 producido por la Dirección General de Cultura y Educación (DGCYE) se ponía de manifiesto la preocupación por elevar los valores de los indicadores de promoción, repitencia y deserción, lo que ha sido una constante en los últimos años tanto en el ámbito de la gestión gubernamental como desde los distintos sectores de la sociedad. No obstante, las dimensiones de éstos generan nuevos desafíos en relación con la planificación del sistema educativo y de la institución escolar.

A su vez, al considerar la situación general de la provincia de Buenos Aires y las urgentes necesidades de financiamiento, un Informe del periodo 2001-2003 de la Secretaría de Relaciones Económicas, Internacionales y Cooperación que funcionaba durante la gobernación de RUCKAUF, denominado "Oportunidades de cooperación internacional en la provincia de Buenos Aires", daba cuenta de algunos puntos destacados como potencial:

- 14.300.000 habitantes;

- 38\% de la población nacional;

- $307.000 \mathrm{~km}^{2}$;

- 40\% del PBI Nacional;

- Índice de Desarrollo Humano alto, comparable a Chile y República Checa;

- $98 \%$ de alfabetismo;

- Índice de Desarrollo Educativo alto, comparable a Israel y Grecia;

-134 municipios;

- 13 Universidades Nacionales;

- 4.500.000 alumnos en 16.000 escuelas 40.000 médicos 4.000 establecimientos asistenciales;

- 20.000 organizaciones comunitarias;

- 900 periódicos y 6.600 revistas.

En el mismo informe, se consigna un ítem de Modernización de la gestión educativa

- interconectividad del sistema educativo provincial y portales educativos;

- programas de cédula escolar;

- programas de legajo único;

- presupuesto participativo por objetivos;

- descentralización administrativa y fortalecimiento escolar;

- planificación estratégica para el desarrollo educativo: unidades de planificación distrital.

En los datos de este mismo Informe referidos al año 1996, se encuentra información acerca del estado de situación de la gestión educativa de la Provincia que en función de las tasas seleccionadas, revela el más alto índice del nivel primario en la mayoría de las provincias del país, 
y la nueva estructura del sistema educativo se tradujo en un aumento de la cobertura escolar.

En la provincia de Buenos Aires, específicamente, los indicadores mantenían la misma tendencia observada en el Total País y en relación con la promoción efectiva en el nivel primario/EGB, Buenos Aires y Capital Federal (hoy Ciudad Autónoma de Buenos Aires) presentaban valores superiores a la media nacional, manteniendo también los porcentajes más altos de la Región Centro y de las otras provincias. Por el contrario, en el nivel medio el valor de la variable muestra el porcentaje más bajo de la Región y por debajo de la tasa media nacional.

La tasa de repitencia en la provincia de Buenos Aires se presenta, en ambos niveles educativos, con valores inferiores a la media nacional y muestra con Capital Federal, los porcentajes más bajos de la Región y del resto del país.

En cuanto a la deserción, el comportamiento del indicador es opuesto en los niveles estudiados: primaria presenta uno de los valores más bajos y educación media el valor más alto de la Región y del país; y revela, en consecuencia, una amplitud de 20 puntos en los valores de la variable en los niveles de referencia. Además, la deserción en la Provincia en el nivel medio estaba a cuatro puntos por encima de la media nacional. En función de la expansión del sistema educativo —nivel de enseñanza primaria/EGB y media/ Polimodal- entre los años 83 y 2000 se dio una evolución sostenida y un significativo aumento de la matrícula del sistema provincial en más de un millón de alumnos, que se refleja en los valores de los indicadores.

Esto pone en evidencia dos procesos de crecimiento matricular que se pueden asociar, hasta los años 90 al crecimiento poblacional básicamente, y a partir de estos años a un proceso de expansión fuertemente influido por el impacto de la transferencia de escuelas del ámbito nacional y la implementación de la transformación educativa a partir de 1996. No obstante los datos concretos este Informe concluye con una serie de interrogantes, que dejan abierta la investigación:

El análisis de los indicadores provoca y moviliza diferentes posturas en la comunidad educativa. Las respuestas a pensar se relacionan, entonces a las siguientes preguntas: ¿Qué esta pasando fuera del aula y de la escuela?, ¿Qué está ocurriendo dentro de las escuelas y de las aulas?, ¿Cómo podemos vincular estos dos planos de análisis?

Ahora bien, en el 2003, desde la DGCYE, en pleno desarrollo de una reforma que involucraba desde lo administrativo hasta la gestión misma, se buscaba mejorar la eficiencia, la equidad y la calidad de la educación. Discusión aún vigente y que ha llevado a tomar medidas en forma conjunta con el Consejo Federal de Educación para la implementación de programas acordes que tiendan a mejorar esta situación.

Así planteaba dicho organismo que para realizar buenos diagnósticos y evaluar el alcance de las transformaciones debían mejorarse los sistemas de información educativa. Preveía el aprovechamiento de las nuevas tecnologías informáticas para reestructurar fundamentalmente la interacción con los datos y con los modelos que se esconden tras esos datos. Con dichos propósitos se trabajó a partir de octubre de 2000 en los proyectos de Cédula Escolar y Mapa Escolar, con el fin de "incrementar el acceso a 
mejores datos e incorporar distintos escenarios a la toma de decisiones, aumentar la participación y reducir el conflicto en la toma de decisiones y aumentar la confianza en las decisiones tomadas." 20

En síntesis, se desarrollaron procedimientos tendientes "a cambiar la cultura institucional promoviendo el uso de información en todas las instancias de toma de decisiones." ¿Cómo surgieron estos programas de Mapa y Cédula Escolar?

\section{5.c) El nacimiento de Mapa y Cédula Escolar: prácticas y discursos}

Se toma como fuente principal para este acápite el propio Informe Final que en 2002, tras un año de implementación de estos programas, se elaboraron para dar cuenta de su razón de ser y los resultados de su implementación, ${ }^{22}$ así como las entrevistas realizadas a la Lic. Mónica GonzÁLEZ GAVIOLA y a la Lic. Jorgelina SEMINARIO, quienes fueron responsables de conducir estos programas en el período abordado para esta investigación. ${ }^{23}$

Al frente de la por entonces (2002) Dirección de información y Estadística se encontraba la Lic. Mónica GonzÁlez Gaviola, quien, junto con su equipo técnico, fue la responsable de diseñar e implementar el programa de Cédula Escolar que se inició durante la gestión de José O. Bordón, programa que continúa en la actualidad. Se considera importante esta metodología, ya que no siempre es posible contar con la posibilidad de observar nuestro "objeto" de estudio desde sus orígenes, casi con una lupa que da cuenta no sólo de la información que en sí misma contiene sino también del discurso técnico y político sobre el cual se sostuvo a lo largo del tiempo. Por otra parte, la perspectiva cronológica permite ir observando si el discurso en torno al propio programa se fue modificando con los cambios de gestiones que se sucedieron durante su implementación, así como si cambiaron, o no, sus objetivos y el uso que de la información producida se hizo para la toma de las decisiones políticas.

También permitirá evaluar cómo uno de los objetivos centrales de este trabajo, en qué medida estos dispositivos han sido utilizados, si es que realmente se los ha aprovechado en todo su potencial, hasta qué punto las dificultades intrínsecas en la conducción política de un sistema tan complejo hacen posible la viabilidad y continuidad de programas como este, que no pueden responder a las necesidades de la coyuntura sino que han sido diseñados como herramientas para la planificación y la gestión prospectiva.

En este, como en muchos otros aspectos de los dispositivos para planificar políticas de Estado, nuestro país nos ha ido acostumbrando a los vaivenes que imponen las urgencias, que muchas veces tiene como consecuencia el abandono parcial o total de aquellos aspectos que requieren,

20 Informe Ejecutivo de la Institucionalización de los Programas Cédula / Mapa Escolar. Dirección de Información y Planeamiento Educativo. Dirección General de Cultura y Educación. Provincia de Buenos Aires.

21 Ibídem.

22 González Gaviola Mónica, (Directora), "Informe Final 2001. Programa De Relevamiento de Matrícula para La Cédula Escolar" Dirección de Información y Estadística Enero 2002, en http://abc.gov.ar/escuelas/consultas/cedulaescolar/informes/i_final.PDF, sitio consultado octubre 2009. 
para su buen funcionamiento, una constancia no sólo en su financiamiento sino también en lo que refiere a la capacitación de los docentes y los equipos técnicos en el caso educativo.

En los primeros considerandos, el Informe Final daba cuenta de la capacidad de los nuevos dispositivos tecnológicos para penetrar en "todas las esferas de la actividad humana ya sea individual y colectiva", así como de darse una "relación particularmente fuerte entre los aspectos culturales, espirituales y los materiales." 24

El recorrido histórico aludía al crecimiento exponencial del uso de la tecnología de la información, desde la invención de la computadora (1950) hasta el estadio actual en el que la tecnología "penetra la estructura y la mayoría de las prácticas sociales." ${ }^{25}$ En tal sentido, en la etapa de la revolución industrial

[...] los dispositivos tecnológicos estaban centrados en la introducción de nuevas fuentes de energía y en la capacidad de descentralizar su uso durante la producción y los procesos de circulación. En la sociedad informacional los dispositivos tecnológicos se centran en la generación de conocimiento, el procesamiento de información y la comunicación de símbolos. Si bien el conocimiento y la información siempre fueron elementos fundamentales de todo desarrollo tecnológico, lo que es específico de la tecnología de la información es la acción del conocimiento sobre sí mismo como fuente principal de productividad y poder. Esta etapa de cambios profundos se caracteriza a nivel institucional por amplios procesos de deslegitimación y desestructuración (que incluye muchas veces hasta la desaparición) de instituciones y organizaciones. ${ }^{26}$

Es necesario, a los fines de este trabajo, contrastar los supuestos teóricos sobre los que se fundó el programa y su aplicación, así como reproducir textualmente algunos de los argumentos de dicho Informe. En tal sentido, es posible revisar el siguiente Extracto del Informe Final 2001. Programa de Relevamiento de Matrícula para La Cédula Escolar": ${ }^{27}$

Una de las principales dimensiones en los procesos de cambio en una organización es la información y el conocimiento. Si bien la información se conforma por datos que han sido categorizados, organizados, analizados, contextualizados y comunicados, ${ }^{28}$ puede darse la paradoja de que existan muchos datos y poca información..$^{29}$ La información se compone de datos relevantes y se convierte en conocimiento cuando es usada para hacer comparaciones, evaluar consecuencias y establecer conexiones y tomar decisiones. ${ }^{30}$ Se impone hoy el aprovechamiento de las nuevas tecnologías informáticas para definir, capturar, almacenar, analizar, mantener, mejorar y difundir el conocimiento de una organización.

La introducción, el desarrollo y la gestión de Tecnologías de la Información conforman, hoy, un recurso estratégico para cualquier organización no sólo porque se han complejizado y enriquecido sus usos tradicionales sino que se han transformado en herramienta fundamental para cambiar actitudes y procesos que colaboren en la mejora en la obtención de metas y objetivos de estas organizaciones. Los avances en tecnología tienen la potencialidad de reestructurar fundamentalmente la manera en que los planificadores interactúan no sólo con las computadoras sino con los datos y con los modelos que se esconden tras esos datos. ${ }^{31}$

24 González Gaviola, Ibídem, pág. 2.

25 Ibídem.

26 Ibídem. pág.2-3.

27 Los subrayados en las siguientes citas pertenecen a la autora de esta tesis.

28 Porat, Marc, The Information Economy: Definition and Measurement, Washington. DC, Departamento de Comercio de Estados Unidos, Oficina de Telecomunicaciones, 1977.

29 Shiefelbein, Ernesto: En Busca del Eslabón más Débil: Mejorar la Estadística Educativa, en: Boletín 46, OREALC, Santiago, 1998.

30 Empson, L. (1999, October 8). The challenge of managing knowledge. The Financial Times Mastering Series:

Mastering Strategy, 8-10.

31 Hiekkila, Eric J.: GIS is dead, Long live GIS, APA journal, Summer 1998. 
Muchos países de la Región se encuentran en pleno desarrollo de reformas que implican cambios en la administración y gestión de los sistemas educativos con el objeto de mejorar la eficiencia, la equidad y la calidad de la educación. Para medir y evaluar el alcance de estos objetivos deben destinarse recursos técnicos y financieros a mejorar los sistemas de estadística educativa así como la calidad de la información que estos recogen y el conocimiento que producen.

Como se observa hasta aquí, el dispositivo de Cédula ha surgido en un contexto como el que se ha descrito en el que la utilización de terminología como "eficiencia" y "calidad", muy en boga por entonces, merece ser interpretada. Otra vez "Las palabras y las cosas", en el marco del paradigma tecnologizado. En ese contexto el discurso de la calidad funciona en un registro "moral", que apela a la "responsabilidad de los actores del funcionamiento de las organizaciones, culpabilizándolos de su crisis o fracaso e induciéndolos a que sean más productivos." $32 \mathrm{Al}$ mismo tiempo, este discurso encubre y/o desplaza los problemas centrales de la educación, en particular los que se refieren al financiamiento, colocando en el centro de la escena los problemas de eficacia y eficiencia del propio sistema educativo.

Este desplazamiento de la responsabilidad del Estado hacia otros actores (directivos, institución escolar, sindicatos docentes, pedagogos, dispositivos tecnológicos) atraviesa la época en que surgieron los programas que analizamos.

Sin embargo, esto no implica que sean los dispositivos per se los portadores de esos significados, pero sí que es relevante dar cuenta no sólo del contexto histórico en que surgieron sino también del contexto discursivo que los habilitó y legitimó, es decir, el clima de época. Lo mismo ocurre con el concepto de "calidad educativa", acerca del cual existe una gran cantidad de literatura crítica, en particular, la que refiere a la concepción de calidad como aquella que es determinada por ciertas evaluaciones que llevan adelante organismos internacionales o consultoras y que no dan cuenta de las características locales, de la interculturalidad ni de una concepción de calidad que se vincule con una escuela que forme sujetos de derecho y ciudadanos críticos del sistema y no meros consumidores.

Pese a lo cual, tanto para elaborar políticas públicas de uno como de otro modelo, se necesita disponer de información para la toma de decisiones. Al mismo tiempo, la experiencia posterior en la gestión educativa nos permite suponer que a pesar de estas reservas que se efectúan respecto de las categorías utilizadas en la fundamentación teórica del programa, también se encontrarán allí las huellas de una génesis diferente, orientada en un sentido participativo y de apropiación de un modelo alternativo en cuanto al uso de las TIC.

Al retomar el Informe Final, ${ }^{33}$ este continúa describiendo que:

Es sumamente importante tener en cuenta el nuevo paradigma, muchas veces ignorado, acerca del rol que juegan las metodologías de desarrollo de los sistemas de información. 
Hirschein y Klein ${ }^{34}$ describen la evolución de la concepción del desarrollo de los sistemas de información desde la idea de "expertos" al nuevo rol de "catalizadores", "emancipadores" o "liberadores".

En este sentido, tanto la Lic. Seminario como la Lic. GonzÁlez Gaviola, destacan que este paradigma no sólo modifica la imagen del planificador, sino también la relación entre los planificadores y las tecnologías de información y entre éstos y los distintos actores de la organización para la que se planifica. Para elaborar un diseño propio, autónomo, se tuvieron en cuenta cuatro componentes considerados por ambas como fundamentales en cualquier proceso que pretenda instalar nuevas tecnologías de información y gestión: ${ }^{35}$

1) Qué: identificación del tipo de conocimiento y prácticas a ser transferidos, que éstos sean realmente importantes, relevantes para la organización.

2) Quién: identificación de actores, participantes y usuarios.

3) Por Qué: identificación de las motivaciones de los participantes. La gente comparte su conocimiento y acepta nuevos conocimientos y prácticas sólo cuando espera recibir algo a cambio, aunque los beneficios que se esperan suelen no ser materiales.

4) Cómo: la metodología con que se desarrollen los procesos de innovación tecnológica para mejorar la capacidad de administrar o gestionar prefiguran el éxito o fracaso de los programas y su nivel de consistencia con valores democráticos.

Al recuperar el mencionado Informe Final 2001 del Programa de Relevamiento de Matrícula para la Cédula Escolar, se observa en el punto de "Relevamiento de Matrícula para la Cédula Escolar en la Provincia de Buenos Aires: Programa Cédula Escolar-Construcción de un sistema de información de alumnos" una descripción general de las características provinciales y, ${ }^{36}$ en ese marco, se subraya la importancia de asegurar procedimientos que al aprovechar las TIC "hagan cada vez más eficiente y confiable los procesos de recolección, procesamiento y administración de datos y que enriquezcan su exploración y análisis."

En esta línea, se tuvieron en cuenta tres dimensiones fundamentales del sistema educativo provincial: los alumnos y su contexto familiar; los docentes y la infraestructura escolar, para lo cual se resolvió desarrollar un Sistema de Información de Alumnos que en el futuro articulara con las otras dos dimensiones en un Sistema Global de Información para la Gestión Educativa y la Toma de Decisiones. Al integrar la información de alumnos a un Sistema de Información Geográfico Socio-educativo, resultaría combinarla con datos geográficos, demográficos, socio-

35 González Gaviola Mónica, (Directora), “Informe Final 2001. Programa de Relevamiento de Matrícula para la Cédula Escolar”, Op. cit. 36 El Informe señala que La provincia de Buenos Aires es la más extensa de la Repúlica Argentina, cuenta con una población de 13.818.677 habitantes que representan $38.15 \%$ de la población total del país. Su sistema educativo cuenta con alrededor de 16.000 establecimientos que imparten distintos tipos de servicios (educación inicial, general básica, polimodal, superior, adultos, especial, formación profesional, educación complementaria, educación física y artística) mediante gestión estatal o privada. Los mismos están distribuidos en toda su extensión territorial (norte-sur: $892 \mathrm{Km}$., este-oeste: $600 \mathrm{Km}$. y superficie: $307.387 \mathrm{~km} 2$ ) e incluyen actores de diferentes edades y condiciones sociales y educativas. En este complejo sistema la información es una herramienta esencial para la gestión y la toma de decisiones. 
económicos, entre otros, obtenidos de distintas fuentes tales como censos y encuestas de hogares. Tal como comenta la Lic. Gaviola, muchas veces una escuela sólo tenía el registro de una baja en la matrícula, pero desconocía si ese alumno había abandonado su educación o si se había mudado a otra escuela de la misma provincia, por ejemplo.

Respecto a la descripción del Programa, Mónica GonZÁLEZ GaVIOLA, afirmaba en el Informe Final 2001, que el objetivo era "[...] ayudar a gestar una nueva cultura de la información, resultó fundamental una buena identificación de actores, participantes y usuarios del sistema de información y gestión."37

En tal sentido, tanto el Gabinete del Ministro como los Directores de distintos niveles de enseñanza, los Supervisores y los Directores y/o secretarios de las escuelas fueron identificados como los principales actores y en consecuencia, trabajaron en distintas etapas en relación directa con el equipo encargado del diseño e implementación del programa. También se contó con la participación de otros actores, como los capacitadores en herramientas básicas informáticas y los alumnos pasantes que lo hicieron sólo en algunos momentos. Durante la entrevista efectuada en diciembre de 2009, la Lic. GonzÁlez Gaviola destaca la importancia que tuvo el protagonismo de los alumnos - así como de otros capacitadotes muy jóvenes-, ya que en este punto quedó en relevancia la brecha generacional existente entre los docentes y otros funcionarios del mundo adulto, con dificultades para incorporar los lenguajes y las prácticas de las TIC con las que los jóvenes se vinculan con mucha facilidad. Este acento puesto aquí permite hacer un paréntesis respecto de la importancia de la circulación y elaboración colectiva de los saberes y del intercambio generacional, ya sea que estén al servicio, como en este caso, de un dispositivo como Cédula Escolar, ya que lo estén para otros objetivos, lo cual sin duda es materia de investigación para los especialistas en didáctica y pedagogos de otras orientaciones.

El primer eje organizador del sistema de Cédula es la identificación única de cada persona (alumnos) a partir de su número de documento de identidad. El segundo es la fecha de nacimiento que permite obtener la edad de los alumnos y a partir de la misma, indicadores como el de sobreedad, en el marco de las heterogeneidades ya señaladas del sistema educativo provincial, que tiene:

[...] servicios educativos que están organizados en forma secuencial, por niveles, de acuerdo a requerimientos y logros pedagógicos posibles en cada una de las edades. Este segundo eje organizador permite obtener indicadores de repitencia.

La mayoría de los niveles tienen una estructura pedagógica con un número determinado de años de estudio que completan ciclos y que están previstos como regulares (Inicial, EGB, Polimodal, Adultos) y existen otros que, por adaptarse a requerimientos particulares, tienen una estructura y una duración más flexibles.

\section{Los alumnos y las personas}

Una misma persona (niño, joven o adulto) no debería estar inscripta en más de un establecimiento correspondiente a servicios educativos básicos. (Educación inicial, EGB, educación polimodal). Pero una misma persona puede recibir un servicio educativo básico y otros servicios complementarios (educación física, educación artística, apoyo escolar complementario, etc). Esta complejidad en la posibilidad de combinaciones de inscripciones 
de una misma persona hace que sea muy difícil cuantificar la matrícula del sistema educativo provincial sin distinguir entre alumnos y personas.

El hecho de que puedan existir varios alumnos en una misma persona merece un tipo de análisis particular y es, al mismo tiempo, de mucha relevancia pedagógica y social, especialmente en un sistema educativo en el que no está generalizada la doble escolaridad.

El procesamiento informático de la información nominal de matrícula, adonde cada persona tiene un código de identificación personal (Documento Nacional de Identidad) permite distintos tipos de análisis que hasta este momento no habían sido posibles. ${ }^{38}$

Vale la pena acá hacer un pequeño paréntesis reflexivo. Se ha visto que este dispositivo se propone "ayudar a gestar una nueva cultura de la información" que al parecer, se inscribía en el paradigma tecnologizado del que hemos realizado una crítica. Se observa en la propia terminología del informe las huellas de ese discurso, que apela a la construcción de un "Sistema Global de Información para la Gestión Educativa y la Toma de Decisiones."

Inscrito en la lógica neoliberal que dominaba en esa etapa, y puesto al servicio de las reformas educativas previstas en ese proyecto, es posible en principio afirmar que aun así, recogía y comenzaba a sistematizar una serie de datos que permitirían conocer el mapa del sistema educativo bonaerense incluso para inscribirlo en un proyecto de signo contrario al entonces imperante. Por su parte, la metodología de implementación jugó un rol decisivo, como se ha señalado, al incorporar la lógica de la producción colectiva del conocimiento técnico necesario para implementar este nuevo dispositivo y capacitar a los actores.

Al mismo tiempo, este trabajo se propone observar si al implementarse en la compleja trama del propio sistema, en la que la acción subjetiva de los diferentes actores que se hacían responsables de la provisión de la información, su circulación y procesamiento (directivos de escuelas, personal técnico y administrativo de la DGCYE, entre otros) no era homogénea ni, necesariamente, estaba de acuerdo con los principios ideológicos sobre los cuales se sostenía el programa, este programa se fue modificando.

E incluso, dar cuenta de qué ocurrió al darles continuidad, durante la gestión de Adriana PUIGGRós (2005-2007), que cuestionaba el sentido común neoliberal a la vez que se proponía "expandir los actuales compromisos políticos y pedagógicos a lo largo de una amplia variedad de esferas públicas que permanecen centrales en cualquier noción viable de políticas democráticas." ${ }^{39}$

A priori, nuestra premisa parece cobrar validez y permite reafirmar que no son los dispositivos técnicos, en tanto herramientas de la información, los que posibilitan las transformaciones.

\section{Aspectos metodológicos de Cédula Escolar. "Con el trabajo conjunto información para todos."}

En cuanto al plano metodológico, el programa introducía algunos procedimientos novedosos en 
lo que refiere a la participación de los distintos actores del sistema, a partir de un eslogan que refería "Con el trabajo conjunto, información para todos". "Es por esto" — se sostenía en el Informe Final 2001—“que la metodología y el nivel de participación de los distintos actores prefigurarán su éxito o fracaso."

Es decir, se consideraba como sustento filosófico del programa la necesidad de democratizar los procesos relacionados con la información y la necesidad de involucrar a la mayor cantidad de actores del sistema, como condición para su éxito, "con metodologías participativas en cada una de las etapas." 40

Si seguimos el Informe, veremos que

Las tareas principales se concentraron alrededor del consenso de datos a relevar, definiciones e indicadores, la unificación de la forma y los pedidos de información a las escuelas y la forma de digitalización de piezas y procesos administrativos. Se trabajó sobre la importancia de completar los datos administrativos con información que contemple las dimensiones sociales y pedagógicas.

Con cada uno de los grupos se definieron distintos niveles de uso de la información de manera de ajustar la estructura y la cantidad de los datos a las distintas necesidades ya que es tan peligrosa la escasez de datos como la superabundancia de los mismos. También se discutió y se llegó a consensos en cuanto a un diseño de base de datos que permita la ampliación permanente del modelo, adaptándose a las futuras funcionalidades del sistema.

Este último punto se subraya, porque allí radica quizá uno de los mayores hallazgos del programa, en cuanto a la visión prospectiva que implicaba y de abrir la puerta a futuras modificaciones de su diseño. Interesa también destacar el aspecto de capacitación y formación de los actores del sistema, en especial, de aquellos funcionarios que ocupan niveles jerárquicos en la estructura de conducción, no condicionados a las coyunturas políticas, como los secretarios y los inspectores. Por lo tanto, resultaba fundamental, para el sostenimiento en el tiempo, que estos actores se apropiaran de la herramienta e incluso, pudieran intervenir en sus posibles mejoras.

2. Capacitar a los secretarios fue una de las líneas de acción fundamentales para el éxito del programa. Para lograr los objetivos propuestos es imprescindible contar con secretarios capacitados en la producción y administración de información confiable a través del uso de herramientas informáticas. El personal administrativo debe transformarse, paulatinamente, en el gestor de los datos de matrícula de cada establecimiento que, a su vez, alimentan la base de datos y el sistema de información común a todos los servicios educativos.

Se realizaron 550 cursos de 70 horas cada uno para capacitar en herramientas básicas de informática a 16.000 secretarios (o quien cumple ese rol en el establecimiento) con el objetivo de que logren operar eficazmente la PC, experimentando su utilidad para la gestión administrativa escolar. Sin esta capacitación la apropiación de una nueva metodología de trabajo hubiera sido imposible.

3. Implementar una estrategia sencilla y amigable, de "tecnología convivial", que permita la recolección descentralizada de datos válidos y confiables y el posterior uso de los mismos por la escuela. Se trabajó en el desarrollo de un software propio, realizado en etapas, con la participación de los distintos actores. Se partió de un prototipo muy sencillo que respetó la cultura tradicional de la escuela en cuanto al registro de los datos de los alumnos. Se trasladó el registro escolar tradicional a un formato digital. El desarrollo del 
software partió de un simple software de registro de alumnos para evolucionar hasta un software de gestión de alumnos en el establecimiento. En la etapa de diseño detallado se tomaron en cuenta las diversidades de cada uno de los niveles, y se diseñaron pantallas con funcionalidades y validaciones adecuadas a cada uno de ellos.

El diseño de un software propio y específico es otro aspecto del programa que interesa destacar por su valor en cuanto a la generación y adaptación de la tecnología en función de las necesidades propias, dejando de lado la reproducción de diseños elaborados en otras latitudes y con otros fines, tan habitual en la época en que surgió.

La etapa de relevamiento para la elaboración de la herramienta, que también contó con la colaboración de los distintos niveles institucionales, implicó el análisis de la organización del sistema educativo provincial para permitir la clasificación de los alumnos matriculados según parámetros pertinentes. El alto nivel de participación de los usuarios, el interés demostrado por ellos en brindar sugerencias y proponer mejoras durante toda la implementación del programa hizo que el software se fuera ajustando a sus necesidades y facilitó los procesos de apropiación de la nueva tecnología. La implementación de una mesa de ayuda y el soporte operativo permanente vía telefónica, correo electrónico o página web permiten la "traducción" casi inmediata de las necesidades detectadas por los usuarios y la solución a sus problemas y es complementaria a la capacitación. Resulta un termómetro permanente del desarrollo del programa. Se recibieron 11.000 llamadas telefónicas durante el primer año de implementación acercándose al promedio de una llamada por establecimiento.

4. Descentralizar la carga de información otorgándole más poder a la escuela en lo que respecta al manejo de datos de alumnos; considerándola como el lugar central del proceso pedagógico, ésta se transforma en la principal fuente y gestora de datos. Tradicionalmente la escuela viene percibiendo las demandas de información como tareas meramente burocráticas, sintiendo que se recargan sus horarios y se le quita tiempo a tareas pedagógicas. Estas demandas se superponen, con diferentes definiciones, muchas veces incomprensibles. Los resultados de los distintos relevamientos nunca vuelven a la escuela lo que impide que se comprenda la importancia del uso de sus propios datos. Al descentralizar las tareas relacionadas con la información de alumnos y transformar a cada secretario o director en un gestor de información se comienza a generar una nueva cultura. La herramienta informática utilizada para la carga de los datos les provee al mismo tiempo de una herramienta administrativa de ahorro y ordenamiento de tiempo. A cambio del tiempo invertido en la digitalización de los datos (que muchas veces significó hasta un mes de trabajo en establecimientos muy grandes) el programa los provee de la base de datos de los alumnos para la administración interna del establecimiento con la posibilidad de realizar e imprimir listados de alumnos por sexo, edad, nacionalidad, etc., listados de secciones y listados del total de alumnos del servicio educativo. También les ofrece la posibilidad de realizar movimientos y promoción de alumnos sin repetir la carga de datos, disponer del Legajo digital de cada alumno, etcétera.

El protagonismo que el programa Cédula Escolar pretendía otorgarle a la escuela es un aspecto que hay que desarrollar. La validez de este principio es imprescindible en cualquier enfoque democratizador de la educación, así como el reconocimiento de la propia institución escolar como portadora del "lugar central del proceso pedagógico". Esta premisa implicaba en sí un riesgo, que bien vale la pena correr si se pretende abrir el juego de la participación en las decisiones.

La escuela argentina, y la bonaerense en particular, venía de sufrir las transformaciones impuestas por la transferencia y luego la reforma. Muchos de los docentes todavía no habían podido asimilar la nueva organización del sistema y sus nuevos roles. Todavía convivían formatos diferentes que no terminaban de integrarse al sistema (por ejemplo, en las escuelas Normales transferidas de la 
Nación a la Provincia) y reconversiones de tareas que no se habían asentado, junto con prácticas tradicionales de circulación de la información que no se ajustaban a las nuevas propuestas. A la vez, durante todo el proceso de la reforma (con la creación de la EGB y el Polimodal, por ejemplo), la escuela había sido demandada desde diversas áreas gubernamentales, para proveer todo tipo de información: condiciones edilicias, características socio-demográficas de la matrícula, de cuyos resultados muchas veces permanecía al margen. En consecuencia, se habían roto los canales de confianza para brindar datos que muchas veces habían sido utilizados en perjuicio de las instituciones.

Esta sobrecarga de demanda de información desde distintos ámbitos de la conducción (inspectores areales, regionales, área de infraestructura escolar, Planeamiento, Evaluación o desde el propio gabinete del Director General) convivía con un déficit en cuanto al equipamiento informático, la capacitación de los responsables de generar los datos y las propias dificultades para unificar la información en la DGCYE. Esto se hacía más que evidente cuando, frente a la necesidad de informar a la prensa o a los propios funcionarios del gobierno de una situación de conflicto en cualquier establecimiento, surgían claras discrepancias (en cuanto al número de alumnos e incluso, aunque parezca asombroso, en algunos casos, respecto al propio emplazamiento del edificio) si la información era provista por el área de infraestructura escolar, la Dirección de Educación Primaria, el Inspector Regional o la propia Directora/or de la escuela.

Además, la convivencia en un mismo edificio de diferentes "servicios" (por ejemplo, una escuela primaria con los tres ciclos de EGB, Polimodal, un bachillerato de adultos o bien un Instituto Superior de Formación Docente), difuminaba las responsabilidades de cuál de los directores de estos servicios debía hacerse responsable de la información relativa a las condiciones edilicias, por ejemplo. O bien si el equipamiento informático que se proveía debía ser utilizado por todos los niveles que compartían un mismo edificio.

Por otra parte, en ese año de 2001 todavía era reducida la red de conectividad, incluso, muchas escuelas carecían de línea telefónica y, en el medio rural, las distancias y las dificultades de acceso no facilitaban la circulación de información de manera sistemática. De modo que para implementar Cédula, era necesario además de considerar todos estos aspectos y sortear diversos obstáculos y resistencias (algunas justificadas y otras arbitrarias, si se quiere), brindar los soportes digitales para la transmisión de los datos, tal como se evidencia en el propio informe

5. Centralizar el procesamiento de la información. Las bases de datos de alumnos de los distintos establecimiento fueron enviadas en discos flexibles por las escuelas a la administración central que se ocupa del procesamiento y análisis de la información. La identificación única de cada alumno y su trasmisión en formato digital hizo trasparente la información que en formato papel permanecía absolutamente compartimentada: se pudo conectar personas y alumnos, haciendo posible saber cuántos alumnos hay en cada persona. También permitió conectar distintos relevamientos tales como los de evaluación de la calidad de la educación, solicitudes de becas, etc. con las fichas familiares y de salud de los alumnos. Estas operaciones hacen posible la elaboración de complejos perfiles y modelos de análisis que resultan de interés tanto pedagógico como social. La identificación única de cada alumno permite realizar estudios que toman en cuenta particularidades y permite analizar trayectorias escolares. La posibilidad de incluir complejos datos sociales y pedagógicos en el análisis permite romper con explicaciones simplistas del complejo proceso pedagógico. 
confiabilidad de los datos de origen. A su vez ya comenzó a generar múltiples impactos en los distintos actores y niveles del sistema educativo mediante la implementación de nuevos procedimientos de recolección, procesamiento y uso de la información permitiendo un ahorro significativo en los gastos de recolección de datos.

En la etapa de consistencia y sistematización de los datos se desarrolló un software para la auditoría e integración de los datos recibidos en el servidor, lo que automatiza las consultas de control de la calidad de la información y la elaboración de reportes para la corrección o control de errores detectados por parte de los establecimientos educativos. Estos reportes vuelven a las escuelas que, al consultarlos, toman conciencia de lo que significa la inconsistencia de datos y comienzan a valorar el rigor en los mismos. En esta etapa también se apeló permanentemente a los distintos actores institucionales del sistema educativo provincial. Los procedimientos de validación de datos que el software tiene, el procedimiento de consolidación de datos que se llevó a cabo en el momento de recepción de las bases, los procedimientos para la búsqueda de errores en el acopio de bases nunca podrán reemplazar la importancia fundamental que tienen los responsables de la administración de las escuelas por su conocimiento personal y compromiso con los destinatarios principales del sistema educativo: los alumnos. Son ellos quienes, en última instancia, garantizan la calidad de los datos relevados en cada establecimiento.

6. Usar apropiadamente la tecnología informática existente y proveer de equipamiento a aquellos servicios que no dispongan, teniendo presente la optimización del aprovechamiento de los recursos humanos, tecnológicos e informáticos disponibles en las escuelas y en las distintas instancias del sistema. Se partió de un relevamiento del equipamiento disponible que permitió elaborar criterios para la distribución eficiente y equitativa del equipamiento nuevo.

\begin{abstract}
¿Pero cómo lograr que un programa tan novedoso, implementado en un momento de gran inestabilidad política y social se institucionalice y se sostenga en el tiempo? Más adelante, en el informe realizado en 2003, referido a la "Institucionalización del Programa Cédula Escolar en el sistema de información de la Dirección de Información y Planeamiento", ${ }^{41}$ se da cuenta del grado de avance en este sentido, de los aspectos que queremos destacar.
\end{abstract}

\title{
Relevamientos tradicionales y Cédula escolar
}

- INICIAL: Releva datos de matrícula según año de estudio y sexo; secciones por establecimiento educativo de gestión estatal y privada. Se refiere al 15 de abril de cada año. Se realiza en planillas de papel especialmente diseñadas para cada tipo de educación por la DIPE [Dirección de Información y Planeamiento].

- CENSAL: Releva datos relacionados con alumnos matriculados, planta funcional y personal docente y no docente. Aporta datos de los alumnos por edad, sexo, año de estudio, nacionalidad, turno y sección, repitencia y servicios alimentarios. Permite la elaboración de un amplio repertorio de indicadores y su comparación a nivel nacional.

Se efectúa a mediados del ciclo lectivo. Se realiza en cuadernillos en papel diseñados por el Ministerio de Cultura y Educación de la Nación.

- FINAL: Releva datos de matrícula con referencia al último día de clase. Permite elaborar información sobre los movimientos intra-anuales de alumnos. Se realiza en planillas de papel. Se realiza en planillas de papel especialmente diseñadas para cada tipo de educación por la DIPE.

Se observa que partir del año 2002 estos distintos relevamientos se sincronizaron en Cédula Escolar y se conformó la base de datos de cada establecimiento que "contiene los legajos 
de alumnos con su identificación a través del DNI y que permite seguir trayectorias escolares individuales se entrega a la DIPE en soporte disquete por medio de las Secretarías de Inspección o a través del correo electrónico." De este modo, se obtuvo un Modelo Conceptual Único y la base de datos correspondiente, lo que permitió, además, "integrar todos los datos en un solo sistema."

Por su importancia, esta tarea involucró a toda la Dirección e integró a las tareas de análisis a informáticos con especialistas en educación y en estadística. Se utilizó una herramienta específica de análisis de sistemas denominada CASE (ingeniería de software asistido por computadora).

Luego de haber logrado un único diseño conceptual robusto se construyó la base de datos correspondiente. El diseño físico de la base de datos se realizó en Microsoft SQLServer 2000 como Sistema Gestor de Base de Datos (SGBD). En el desarrollo de la misma se contempló lo siguiente:

- La migración de toda la información histórica de la DIPE.

- Que el sistema de base de datos no sufra anomalías de almacenamiento.

- Que el modelo lógico pueda modificarse fácilmente ante nuevos requerimientos.

- Que no se corran riesgos de redundancia de información ni inconsistencias de datos.

- Que la estructura de datos permita realizar todas las relaciones pertinentes entre los mismos y las consultas correspondientes.

- Que la recuperación de información, ante diferentes demandas y consultas, sea sencilla.

- Que el mantenimiento de los datos (altas, bajas y modificaciones) sea muy simple.

Otro de los logros fue la renovación de los programas de carga, clasificación, consistencia y anexado de datos provenientes de distintos relevamientos y el diseño de un sistema "Clasificador de Bases de Datos de Cédula Escolar", lo que generó un sistema que permitía realizar las operaciones básicas de mantenimiento y actualización del listado provincial de establecimientos, denominado "maestro establecimientos" (que en el año 2002 consignaba 15.869 establecimientos activos) con su correspondiente clave de identificación de cada establecimiento, además de su nombre, número, domicilio, teléfono, etcétera. Se utiliza para digitalizar los datos de los relevamientos Inicial y Final y permite realizar la carga masiva de los datos asegurando la consistencia e integridad de los mismos. También se afianzó un aspecto fundamental en la implementación de TIC en áreas gubernamentales, para garantizar el control y el uso adecuado, ya que "Cada operación realizada por un usuario queda registrada permitiendo una auditoría tanto de calidad de procedimientos como de tiempos empleados." 42

\section{5.d) ¿Qué es el Mapa Escolar?}

Por la misma época que comenzaba a implementarse Cédula Escolar, surgió el programa de Mapa Escolar, que se proponía como "un Sistema de Información Georeferenciada, que permite capturar, guardar, desplegar y analizar información espacial integrada con información educativa, social, económica, demográfica, etcétera"43.

De acuerdo a lo que se ha podido investigar, el Sistema de Información Geográfico (herramienta, 
comúnmente conocida como GIS $)^{44}$ se propone como herramienta estratégica para el planeamiento educativo. En el diseño de este software habían intervenido varias áreas del gobierno provincial y sus objetivos eran "incrementar el acceso a mejores datos del sistema educativo, mejorar la comprensión de acciones de gobierno, aumentar la participación, incorporar distintos escenarios, reducir el conflicto en el proceso de toma de decisiones y aumentar la confianza en las acciones emprendidas." ${ }^{45}$

Aunque pretendía configurar la información estadística con la representación gráfica espacial de ésta, en apariencia no llegó a completarse, para cumplir con los objetivos referidos a la posibilidad de consultar información sobre oferta educativa distrital; analizar comparativamente los datos de cada escuela en relación con su distrito y su región, imprimir y guardar la información consultada en forma de tablas y mapas. Sin embargo, aun de manera parcial, este dispositivo pudo recuperar gran parte de la información del sistema educativo, al menos, en algunas variables como tipo de establecimiento por distrito y localidad; diferenciación entre instituciones de gestión estatal y gestión privada y otros, como:

- Acceder a la información estadística con la representación gráfica espacial de la misma.

- Trabajar con información de distintos niveles de educación y tipos de gestión, y en distintos niveles de agregación (escuela, distrito, región y provincia).

- Acceder a distintos mapas temáticos de datos e indicadores.

- Consultar información sobre oferta educativa distrital.

- Imprimir y guardar la información consultada en forma de tablas y mapas.

- Identificar las escuelas en ámbito urbano (U) y rural (R). Estas últimas se clasifican a su vez en rural agrupado (RA) y rural disperso (RD).

Consultada respecto de la síntesis de la significación de Mapa y Cédula Escolar y sus implicancias para el planeamiento educativo del sistema escolar en su conjunto, Mónica GonZÁLEZ GaVIOLA explica que

Los objetivos eran tener un diagnóstico social de las escuelas y su entorno. Nosotros preguntábamos no sólo cuántos alumnos tiene tal o cual establecimiento, sino, también, por ejemplo, si tienen Documento Nacional de Identidad, si tenían mamá y papá, el nivel educativo de esos los padres, si tenían trabajo y en qué trabajaban. Esta información, que es absolutamente privada, sirve para la planificación en diversas áreas educativas. Por ejemplo para la elaboración de distintos programas; para la planificación de la infraestructura escolar, para planificar los cuerpos docentes que deben tener las instituciones, para planificar la entrega de materiales pedagógicos, entre otras cuestiones. ${ }^{46}$

En ese momento, según explica GonzÁlez Gaviola, fue difícil que los ministros y funcionarios del sistema educativo comprendieran la lógica de Mapa y Cédula. Sin embargo, a través de este sistema pudo detectarse por ejemplo, que cientos de niños y niñas no tenían el Documento Nacional de Identidad (DNI), lo que significó poder hacer campañas en este sentido en forma conjunta con otros ministerios provinciales para el otorgamiento de documentación, como así también, determinar que ningún niño/niña quedara fuera del sistema educativo por la falta del

44 Slagle, Mike: GIS in Community based School Planning: A Tool to Enhace Decision Making Cooperation, and Democratization in the Planning Processs en: Stein \& Schools Lecture Series, Policy, Planning and Design for a 21 st Public education System, Ithaca, NY, March 2, 2000. 
DNI. También la información obtenida sirvió para detectar en el área de salud los niveles de salud escolar e hizo posibles las campañas en este sentido, como pueden serlo las de vacunación. Es importante destacar que todas las etapas del proyecto fueron acompañadas por normativa que ordenó las diferentes acciones, entre las que se destacan: ${ }^{47}$

- Dar valor documental al registro digital de matrícula en reemplazo del tradicional registro de matrícula en papel.

- La Resolución 1430 del 16 de abril del 2003, que incorpora el uso de Mapa Escolar a la decisión de creación y ubicación de cualquier nuevo establecimiento.

- La estructura orgánico funcional de la Dirección de Información y Planeamiento Educativo (DIPE) fue reorganizada a partir de la institucionalización de los programas Cédula / Mapa definiendo nuevas tareas y procedimientos. (Ver la Resolución Ministerial 4747/02 "Acciones de la Dirección de Información y Planeamiento").48

\section{8.e) Periodo 2001-2005: crisis y gobernabilidad}

Tras la renuncia de BORDón, comienza la que se ha denominado aquí como la segunda etapa a analizar en la implementación de Cédula y Mapa Escolar.

El estallido de la crisis de 2001 tuvo un fuerte impacto en el sistema educativo bonaerense. Esa etapa se caracterizó, entre otras cuestiones, por la emergencia económica, que dificultaba el funcionamiento de los comedores escolares, la provisión de útiles y material didáctico, el pago de los salarios docentes y del personal administrativo, el incumplimiento en el sostenimiento de las becas para alumnos de Polimodal que se habían creado durante el último año de la gobernación de Eduardo DUHALDE (1999); un clima político inestable y el surgimiento de movimientos sociales que, como reacción a las consecuencias nefastas de los 90 , comenzaron en la provincia de Buenos Aires y en todo el país, a efectuar demandas vinculadas con el acceso y la permanencia en el sistema educativo para amplios sectores de la población que había quedado afuera, a la vez que fueron creando nuevas instituciones educativas gestionadas por las propias organizaciones sociales.

Por otro lado, debido al déficit en las finanzas provinciales y a la declaración de la emergencia económica (Ley 12.727/01), la gestión de Mario OPORTo—quien había reemplazado a BorDón en noviembre de 2001 - realizó un fuerte ajuste salarial y un reordenamiento del sistema orientado a reducir la inversión, por ejemplo, en lo que refiere al tema de la desfavorabilidad, ${ }^{49}$ que originó una alta conflictividad con los sindicatos docentes debido al deterioro salarial y una gran pérdida de días de clases debido a los paros del sector. En tal sentido, la Ley de Emergencia económica promulgada por Carlos RucKAUf, establecía:

47 Detalle del marco legal en el Anexo y en http://abc.gov.ar/Docentes/RecursosPedagogicos/cedula/resolucion.htm, sitio consultado marzo 2010.

48 Cfr. "Banco de Proyectos Exitosos de la Gestión Pública de la provincia de Buenos Aires, pág. 6, en http://abc.gov.ar/escuelas/ consultas/cedulaescolar/informes/Pres_Bco\%20_Exitosos.PDF, sitio consultado marzo 2010.

49 La desfavorabilidad es una clasificación que, con determinados criterios, determinan distinto grado de compensaciones salariales de acuerdo a los establecimientos en los que se desempeñan los docentes. En 2002, durante la gestión de Oporto, se modificaron estos criterios y se reclasificaron todos los establecimientos, lo que originó fuertes reclamos por parte de los sindicatos docentes. La nueva clasificación elimin criterios de desfavorabilidad de las escuelas en función de la composición de su matrícula y la distancia con el centro 


\section{CAPITULO V-DE LA RELACION DE EMPLEO PÚBLICO Y REGIMEN SALARIAL}

Artículo 15: Redúcense las retribuciones brutas totales, mensuales, normales, habituales, regulares y permanentes, y el sueldo anual complementario, excluyendo las asignaciones familiares del personal de la totalidad de los organismos provinciales, incluido el comprendido en convenciones colectivas de trabajo, sea que pertenezcan a la Administración Central o Descentralizada, organismos autónomos, autárquicos, de la Constitución, de Previsión y Asistencia Social o empresas públicas, sociedades del Estado, sociedades en que la Provincia tenga participación accionaria y el correspondiente al régimen jerarquizado superior del Banco de la Provincia de Buenos Aires, de conformidad a lo establecido en la Planilla Anexa, que forma parte integrante de la presente Ley. Del mismo modo quedarán alcanzados los legisladores y los agentes de ambas Cámaras de la Honorable Legislatura. Todos los beneficiarios del sistema previsional, tanto del Instituto de Previsión Social como de la Caja de Retiros, Jubilaciones y Pensiones de la Policía de la Provincia, estarán alcanzados por la escala de reducciones que surge de la Planilla Anexa, a la presente. Asimismo, está alcanzado por lo dispuesto en el presente artículo, el personal que presta servicios en escuelas privadas subvencionadas por la Provincia, en la medida en que su remuneración sea pagada a partir del subsidio provincial [...]

Incluso para efectuar este ajuste en el tópico salarial de la desfavorabilidad, era necesario contar con la información precisa acerca de los establecimientos y los docentes que se desempeñaban en estos, ya que se consideraba para ese plus salarial la distancia con los medios de transporte y los centros urbanos, la accesibilidad, entre otros. Es decir, aquí se observa cómo estos dispositivos pueden ser utilizados con objetivos incluso contrarios a los que los originaron.

Si bien los programas de Cédula y Mapa Escolar continuaron vigentes, el equipamiento y la conectividad necesaria para su óptimo funcionamiento no pudo completarse debido a la crisis y, probablemente, debido también a las tensiones que atravesaban distintas instancias del gobierno provincial vinculadas no sólo con el conflicto salarial sino también con intereses empresarios en materia comunicacional (provisión de Internet, telefonía, etcétera).

Asimismo, la gestión de OpORTo se propuso continuar con el proceso de descentralización del sistema educativo bonaerense, a los efectos de reducir el "gasto público" (lo que debería denominarse inversión educativa) y desburocratizar algunas cuestiones del funcionamiento y la administración, lo que generaba ciertas sospechas y resistencias en los municipios, en el sentido de que se aplicaría una política similar a la de la Ley de Transferencia, derivando la responsabilidad del sistema educativo a los intendentes, tal como el propio OPORTO explicaba en un reportaje concedido al diario El Día el 12 de noviembre de 2001:

P: El proceso de descentralización, ¿cómo se va a hacer para que no salten los intendentes y digan que en realidad lo que quiere hacer el gobierno es tirarles el problema a ellos sin darles un peso? ¿La provincia contempla dentro de este proceso girar plata para este fin a los municipios?

M.O.: Aun en los momentos de mayor crisis todos los intendentes de cualquier partido, han sido aliados de la educación. Ellos ponen recursos para la educación. Destapan pozos, pintan escuelas, arreglan emergencias. Son muchísimos los intendentes que vienen aquí junto con su consejo escolar a reclamar pero también a proponer y a trabajar por la educación de su distrito. El primer concepto es un concepto, yo diría de mentalidad. El tema educativo es una responsabilidad de la provincia pero es un tema que abordamos en conjunto con los municipios bonaerenses. Cuando yo hablo de municipios hablo también de las instituciones provinciales que trabajan con el municipio como el consejo escolar o la secretaría de inspección. Pero el primer punto es ese, es un tema en conjunto. No podemos hoy estar tironeando, tenemos que trabajar en conjunto. Segundo, no hay descentralización sin transferencia de recursos. 
P: La reducción del gasto con el proceso de descentralización sería que al desburocratizar el sistema se evitan gastos que se tienen que hacer sí o sí.

M.O: El concepto sería, lo que yo hago, vos lo podés hacer más barato y mejor. Sería mantenimiento de escuelas, contratación de transporte escolar, servicios como agua potable, destape de pozos. Para eso tenés que darle poder de decisión al consejo escolar y al municipio porque si no es desconcentrar y decir yo te doy la plata a vos pero tenés que hacer lo que yo te digo. En cambio, nuestra propuesta es: ustedes marquen las prioridades y hagan, con el presupuesto que yo les puedo transferir, lo que el distrito más necesita. Después creo que esa experiencia la podemos también transferir al control del ausentismo médico. El control es mejor hacerlo a nivel local que provincial porque en cuanto las decisiones se bajan más y los controles se bajan más, todo es más eficiente.

En cuanto al panorama general del conjunto del sistema y el impacto que la crisis de 2001 causó en éste, es interesante recorrer parte de la versión taquigráfica del Informe que el Director General de Cultura y Educación presentó ante la Legislatura provincial en 2003.50

[...] El 2002 comenzó con una ley que nos dio la posibilidad de tomar medidas de ahorro y de ajuste. [Ley de Emergencia Económica 12. 727/01] También existió la incertidumbre con respecto a la posibilidad del pago de los salarios en tiempo y en forma. Esto fue mejorando a lo largo del año.

Por lo tanto, los objetivos del 2002, mirando y repasando lo que hablamos con todos ustedes el año pasado, eran muy limitados. Por un lado, comenzaban las clases ordenadamente y, por otra parte, manteníamos la continuidad de las mismas cumpliendo con el dictado de los 180 días de clase, volviendo a los pagos salariales en tiempo y en forma y, de esta manera, terminando con la incertidumbre. De esta forma se terminó el año pasado. [...]

¿Cómo podemos hacer para mantener un sistema en crecimiento que incluya la matrícula, la extensión de la escolaridad y de la obligatoriedad de la misma con el aprendizaje, es decir, con exigencia académica? [...]

El año que cerró hemos tenido un presupuesto estimado en aproximadamente 3.500 millones de pesos, que es el presupuesto de este año. He hablado hace pocos meses en la Comisión de Presupuesto, y estamos abiertos a toda esa discusión, pero no me quería extender en demasía sobre este punto. No hay que dejar de señalar, cuando uno habla de la realidad del 2002, del inmenso desafío que teníamos, que era el de acomodar nuestras medidas educativas a una realidad presupuestaria que se achicaba. En este mismo recinto dijimos que de acuerdo a las medidas que tomáramos, también íbamos a ver las características reales de un sistema educativo que todos, en hipótesis, veíamos que crecía desmesuradamente en algunos aspectos y que era insuficiente en otros.

En este marco, se dio la Ley del 28 de febrero del año pasado, que fue muy difícil de llevar adelante y que generó conflictos durante todo el año, en un marco de conflicto social que sin duda rebalsaba al tema educativo. [...]

Con todo ello, y con un gran esfuerzo, se realizó un ahorro de 230 millones de pesos. En educación, cuando uno habla de ahorro, no es un orgullo sino que es un esfuerzo y, en algunos casos, es un retroceso. De este dinero, 190 millones fueron hechos en gastos de personal, en donde, por supuesto, la gran medida fue el achicamiento presupuestario en desfavorabilidad y también lo que marcaba la Ley 12.727, de Emergencia, que se venía aplicando desde antes. Hemos logrado ahorrar 40 millones de pesos en la racionalización de las ramas, en la eliminación de las horas cátedra y en el control del presentismo. Esto es simplemente un panorama de lo que fue el año 2002 y que nos llevó a tener un gasto real ejecutado similar o casi idéntico al del presupuesto de este año, que es comparable con el de 1999, aunque para atender mayores servicios.

Como se observa en el propio informe del Director General, implementar este ajuste requería de los datos precisos de todo el sistema, en particular para el aspecto salarial. Se hizo imperativo controlar y reducir la superposición de cargos o aquel crecimiento que se consideraba injustificado. 
Hemos aumentado de 1999 hasta hoy de 4.200 .000 alumnos a 4.500.000; de 15.700 servicios a 15.989, y de 290 mil cargos a alrededor de 300 mil cargos. Un dato que merece ser destacable es que pudimos frenar el deslizamiento de cargos, que anualmente era de entre 10.000 y 11.000 , y este año lo pudimos controlar, de acuerdo a los datos que ha dado el Ministerio de Economía. [... ${ }^{51}$

Por otra parte, aquí se daba cuenta de la complejidad y diversidad del sistema, las diferentes instituciones que lo conforman y las cuestiones a atender en tal sentido para disponer de datos confiables. Sobre este particular OpORTo agrega en el informe:

\begin{abstract}
Voy a dar algunos datos de las características de nuestro año educativo 2002. En el mismo trabajamos con alrededor de 15.900 establecimientos -casi 16.000 establecimientos- entre escuelas estatales, privadas y municipales, concentrándose, por supuesto, en el Nivel Inicial, EGB y Polimodal. Vuelvo a aclarar que vamos a redondear lo referente a la diversidad de los servicios educativos que brinda la Provincia. En Educación Inicial, tenemos 2.064 jardines de infantes estatales que, sumados a los privados y municipales, llegan a los 3.500. Pero, aparte de los jardines de infantes comunes que nosotros conocíamos, también están los jardines maternales, los SEIM, ${ }^{52}$ más algunas ofertas, fundamentalmente privadas, de jardines hogares.

En el EGB tenemos 6.000 escuelas, que se suman a las escuelas hogares y las escuelas albergues. En el Polimodal tenemos -entre estatales, privadas y municipales- 2.500 escuelas, aproximadamente. Con respecto a toda esta información, después se la vamos a dejar en manos de ustedes. Hay escuelas que tienen su sede con anexo y con hogares y extensiones en pueblos más chicos. También están las escuelas agrícolas, para la producción, los CEPT, ${ }^{53}$ las agrarias también con hogar, con unidades rurales, con extensión y anexos.

La Educación Superior con su complejidad y la diversidad de ofertas educativas, y podemos mencionar la Artística: la estética, música popular, conservatorio, escuela de danzas clásicas y tradicionales, teatro, artes visuales, cerámica, y polivalente de arte.

Hay escuelas que también tienen sus anexos; de la misma manera existe la complejidad de ofertas en Escuelas Especiales y en las Escuelas de Adultos. Asimismo, hay que hacer mención a los Centros de Educación Física y a los Centros de Educación Complementaria. Todo esto hace que estemos atendiendo a una matrícula de 4.500 .000 chicos. La cifra inicial del 2001 era de 3.160 .000 alumnos y la cifra inicial del 2002 era de 3.200 .000 alumnos. La conclusión es que casi no hubo crecimiento, pero aquí es muy importante aclarar algunas cosas. Todavía no tenemos las cifras iniciales del 2003, que se va a cerrar después de Semana Santa, a fines de abril, aclarando, entre paréntesis, que es una decisión política. Estamos dando orden de no tomar ninguna medida hasta fines de abril, cuando tengamos las cifras definitivas. Este fue un debate a lo largo de todo el año: el tema del número de matrícula. Se vieron los números, no bajó la matrícula, tenemos incluso un leve crecimiento en el sector estatal y un leve crecimiento en el sector privado en este año. Cuando analizamos las cifras y cuando venimos a hablar con los representantes del pueblo bonaerense, tenemos que decir la verdad. Hay un crecimiento en los Centros de Educación Física (CEF) y un crecimiento en [el nivel] Adultos que hacen la suma total. [...]

Lo que también se ha estabilizado, como una meseta, es hasta el año pasado el reparto entre oferta privada y estatal: 72 por ciento la estatal y 28 por ciento la privada, que viene desde la década del 90 . En la década del 80 , el porcentaje era de 77 a 23 y, actualmente, ha disminuido la oferta estatal o ha aumentado la privada, depende cómo lo veamos.
\end{abstract}

Cabe acá una aclaración. Entre las diversas consecuencias que el impacto de la crisis de 2001 ha tenido sobre el sistema educativo, en los últimos años se ha ido modificando la conformación de este porcentaje. Por diversas razones que no es posible desarrollar aquí, si bien tradicionalmente la educación de gestión privada había sido elegida por grupos minoritarios de la sociedad argentina, en general, de sectores de alto poder adquisitivo o por razones vinculadas a cuestiones religiosas

51 Los subrayados pertenecen a la autora de la tesis. 
y/o de elección de proyectos pedagógicos alternativos o con orientaciones curriculares específicas (en la formación de más de una lengua, por ejemplo), eso ha ido cambiando. En la actualidad la matrícula de la gestión privada tiende a crecer, al incorporarse en ésta a sectores de clase media y clase media baja, o bien sectores de los más desfavorecidos que eligen esta alternativa. ${ }^{54}$

Al continuar con el informe de OpORTo se puede observar que la utilización de los dispositivos de la información fue funcional a la política aplicada, al considerar, por ejemplo, los indicadores de promoción, repitencia y deserción:

Otro dato importante es el que se refiere a la promoción, repitencia y deserción. Lo que he planteado todo el año pasado y los primeros meses de éste con mucho énfasis, es que las cifras deben servir para solucionar problemas y no para entrar en debates inútiles, ya que un chico constituye todos los chicos. Igualmente, las cifras deben servir para brindar alarmas y ver dónde tenemos mayores dificultades.

En Educación General Básica, sumadas las dependencias privadas y estatales en el período 2001-2002, tuvimos una promoción de 92,5 por ciento, repitencia de 5,1 por ciento y deserción de 2,4 por ciento. Existe como un levísimo aumento de deserción, ya que el año anterior era de 2,35 y ahora es de 2,38 y un aumento importante con respecto al año 2000, que era de 1,8 por ciento. Además, ha bajado la repitencia levemente de 5,6 por ciento a 5,1 por ciento, con lo que la promoción se ha mantenido estable en 92,5 por ciento en la EGB. Cuando nos referimos al área estatal y privada, nos encontraremos con otras cifras. En el Polimodal la cifra ha sido de 85 de promoción, 1,5 de repitencia y 10 de deserción. Fue menor la deserción que el año anterior y más arriba que el año 2000 , que era de 7,1 ; en el 2001, 10,6 , y este año, 9,9. La repitencia bajó levemente; igualmente, está por encima de lo que fue el período 1999-2000.

El segundo problema del que debemos ocuparnos es de la deserción y el abandono. De acuerdo a las estadísticas hay una importante porción de alumnos que dejan el sistema. Esta no es una noticia novedosa, porque si miramos para atrás, veremos que esto ya había ocurrido, pero no por eso debemos dejar de prestarle atención. Respecto a la gestión estatal, observamos que en la Educación General Básica se mantienen las cifras aproximadas de deserción y repitencia. En Polimodal, las cifras de deserción aumentan en 2 puntos y en 1,5 las cifras de repitencia.[...]

Pero me interesaba que viéramos algo de estudio, porque aquí es donde nosotros marcamos las principales dificultades, dónde hay que fortalecer. $Y$ si se observa el período 2001-2002, las cifras no varían demasiado. El punto más flojo es octavo año. Allí es donde hay que trabajar. Son cifras muy fuertes, muy diferentes. Por ejemplo, en promoción, en un promedio que va desde el mejor, el sexto año, en el que promociona el 95,5 por ciento, al que tiene más dificultades, que puede ser el séptimo año, con un porcentaje de 91,3, noveno, con 91 y octavo con 83,5. Allí tenemos las cifras de promoción más alarmantes, o las peores; no quiero usar palabras muy grandilocuentes.

Lo cierto es que tenemos cifras de repitencia mayores de un promedio de 5 por ciento y en octavo se pasa al 8; y de deserción, de un promedio que va del más bajo en segundo año, con 0,8 -varios con cero o con 1-, levantando a 2,5 y 3 , hasta llegar a 8 , en octavo. Entonces, octavo año es un desafío muy grande, un problema muy grande. Lo más sólido es segundo ciclo de EGB. Tenemos las mejores cifras de promoción; por lo tanto, las más bajas de deserción y repetición. [...] educación pública de nuestro país, pero no debe desconectarse de la decisión política que se tomó en el Congreso Pedagógico de 1985. [...] Muy poco tiempo después, la hiperinflación provocó una disparada de chicos hacia la escuela estatal; a continuación, en los primeros años del menemismo, una buena parte de la clase media aumentó sus ingresos- aunque no así su situación económica estructural-, fundó escuelas privadas que se pusieron de moda y, desprendida del viejo mandato, mandó a sus hijos a las escuelas privadas. Creció el mercado de la educación en el cual, por supuesto, rigen las reglas del libre mercado, es decir, salvo excepciones heroicas, cada uno de acuerdo a su origen social. Y se produjo una diferenciación entre las escuelas privadas, de modo que no sólo las hay muy buenas, buenas, regulares y malas, sino que las hay para distintos sectores sociales. Hay escuelas privadas que atienden a los más pobres de todos." Véase Puiggrós, Adriana, "Educación, ¿estatal o privada?", diario Diagonales, 8/9/08, en http://www.adrianapuiggros.com.ar/ ver recomendados.php?id=270 
Desde luego que no lo tenemos discriminado por escuelas por distrito, y mucho menos por barrios, pero las cifras, a medida que se le van cruzando indicadores sociales, se van afirmando para bien o para mal. [...]

Nuestras cifras sobre las tasas de escolaridad son similares a las del INDEC. En general, la población de entre 6 y 11 años está cubierta en un 99,7 por ciento. Es decir, tiene una alta cobertura. Si uno le agrega a esto la Sala de 5 , se ve que de 5 a 11 años la cobertura es del 99 por ciento, y todas las diferencias se las lleva la Sala de 5.

Si se toma la franja de 11 a 14 años, estamos en una cobertura de casi 99 por ciento, teniendo en cuenta las alarmas que ya señalé, ya que éstas son cifras de inicio, pero son auspiciosas con respecto a ocho años atrás. En 1995 y 1996 estábamos entre el 88 y 89 por ciento, y también hubo un gran incremento en la franja de 5 a 18 años, en la que estamos cubriendo un 81 por ciento; mientras que en 1995 y 1996 se cubría el 58 por ciento.

El tercer problema que estoy planteando es que hay que ver una señal de alarma entre los más pobres de 5 a 18 años, porque es un sector en que hay que trabajar mucho. Son los chicos que aparecen en octavo y noveno, y es una franja que hay que atender especialmente. Esa atención especial está vinculada a un montón de estrategias, entre ellas la oferta de secciones. [...]

Seguimos avanzando en el programa de Cédula Escolar y Mapa Escolar, con algunos resultados. Por ejemplo, el Atlas Escolar que como todo proyecto de localización de instituciones, se trata de un mapa para saber dónde tenemos ofertas educativas y dónde aparecen los problemas. Entonces uno ve dónde hay oferta y dónde no. Uno sabe dónde comienzan los desiertos de ofertas y esto es como las estadísticas; toda información tiene que servir para detectar los principales problemas para ir atacándolos. [...]

Con la asunción de Néstor KIRCHner como Presidente de la Nación en 2003 y el viraje dado en materia de política económica, así como la puesta en marcha de una política nacional orientada hacia la inclusión y la justicia social (expresada mediante diversas medidas), el país comenzó a estabilizarse.

La "Ronda de Consulta por el futuro de la educación", realizada en 2004 con diversos sectores de la sociedad, se configuró como un aporte importante para elaborar los lineamientos educativos que se presentaron en 2003 como "Bases para el plan de educación 2004-2007". ${ }^{55}$ A su vez, gran parte de la sistematización de la información, aun en medio de las dificultades ya mencionadas, relevadas por los programas de Cédula y Mapa Escolar se constituyeron en valiosos insumos para planificar esas políticas, cuyos ejes principales fueron:

1. La escuela del proyecto nacional;

2. Cultura, ciencia y tecnología para un nuevo modelo de país;

3. Educar para el trabajo y la producción;

4. Todos en la escuela aprendiendo;

5. Escuela exigente;

6. Mejores maestros y profesores;

7. Programas para adolescentes;

8. Administración eficiente del sistema educativo provincial;

9. Educación ambiental para un desarrollo sustentable.

55 Cfr. En http://abc.gov.ar/lainstitucion/sistemaeducativo/planeducativo/default.cfm. En la sistematzación de gran parte de la información obtenida en esta consulta fue efectuada por equipos técnicos de la DGCyE en conjunto con investigadores de Appeal, quienes bajo la dirección de Adriana Puiggrós, asesoraban al Prof. Oporto en esa etapa. 
En particular, en lo que refiere a la administración del sistema (Punto 8), se aspiraba a continuar el proceso de descentralización administrativa y a "desburocratizar en beneficio de la escuela y de las necesidades educativas de la población" así como a realizar "una austera y eficaz utilización de los recursos." ${ }^{66}$ Como se observa en los objetivos desagregados de este punto, los dispositivos de Mapa y Cédula adquieren, en este contexto, un valor estratégico:

- Reorganización y simplificación del organismo administrativo central de la Dirección General de Cultura y Educación.

- Implementación de la nueva regionalización del Sistema Educativo Provincial.

- Previsión de las necesidades de construcción y ampliación de la infraestructura escolar, con un plan de obras anual que permita el normal desarrollo de los ciclos lectivos.

- Uso intensivo de la información de los Programas de Cédula Escolar y Mapa Escolar desde todos los niveles de decisión: organismo central, Regiones, Distritos, escuelas.

- Puesta en marcha del Tablero de Control de las políticas públicas en educación. ${ }^{57}$

Si bien este Tablero de Control era un objetivo compartido con otras áreas del gobierno provincial que nunca llegó a consolidarse, el modelo de los Programas que analizamos era fundamental para su desarrollo. Las Bases, en materia administrativa, se proponían, además:

- Participación activa de los organismos locales en las decisiones distritales (Consejos Escolares, Secretarías de Inspección, escuelas, Cooperadoras): mantenimiento (Fondo Único Descentralizado de Infraestructura Escolar) y refacción de los edificios escolares, contratación de transporte escolar, contratación de alquileres de edificios escolares, gestión logística escolar, distribución de equipamiento escolar, gestión del Programa de Becas, Comedores Escolares, provisión de útiles escolares.

- Capacitación e incorporación de equipamiento informático a los Consejos Escolares para los programas de Gestión Administrativa, Administración Financiera Contable y Sistemas de Información.

- Control estricto y auditorias de licencias médicas y tareas pasivas.

- Normalización del trámite jubilatorio. Agilización de los trámites de jubilación para enfermedades de largo tratamiento y tareas pasivas permanentes.

- Trabajo conjunto entre la Dirección General, la Legislatura y los gremios para acordar las reformas necesarias al Estatuto del Docente.

- Generación de mecanismos para ampliar la participación de la Comunidad Educativa. Nueva Ley de Cooperadoras Escolares.

\section{5.f) Reforma administrativa, planeamiento estratégico, prospectiva y difusión de las políticas}

La gestión de Adriana PuIgGrós dispuso una nueva organización para el área del planeamiento, en el marco de la reorganización del sistema educativo, que estuvo a cargo del Lic. Carlos GIORDANO. En tal sentido, se propuso jerarquizar el área, convirtiéndola en una Dirección Provincial con dependencia directa de la Directora General, que incluía áreas ya existentes, como la de Información y Estadística y la de Evaluación —que continuó encabezada por la Lic. Jorgelina Seminario y su equipo- y otras que se incorporaron, como la de Investigación, la de Producción Editorial y de Contenidos, entre otras.

Esta Dirección provincial tuvo la misión de elaborar y difundir las líneas de planeamiento de corto, 
mediano y largo plazo, así como de relevar y analizar información estadística básica; coordinar y sistematizar información georreferenciada; desarrollar proyectos de investigación en temas estratégicos; evaluar aprendizajes; elaborar propuestas de mejora; resguardar información y documentación y poner todo esto a disposición de autoridades, docentes y usuarios en general.

Para entender la importancia del tema, es necesario recorrer brevemente la historia del planeamiento educativo en el país. En tal sentido, el planeamiento educativo se instala como una función de la gestión educativa hacia fines de la década de 1950 en varios países de América Latina, en el marco de la carrera por el desarrollo tecnológico y económico, que requería que los Estados nacionales planificaran su intervención en las diferentes áreas de la actividad social a fin de potenciar el desarrollo y los factores de incidencia en éste. En nuestro país, los Planes Quinquenales impulsados durante los gobiernos de Juan PERÓn y, más adelante, la creación del Consejo Nacional de Desarrollo (CONADE) a comienzos de la década de 1960 (uno de los diversos organismos creados en el marco de las ideas desarrollistas para garantizar el impulso e integración de sectores claves de la economía), marcaron el inicio sistemático de las tareas de planeamiento estatal. En esta etapa se consideraba al planeamiento como una función tan específica y especializada que se concentraba en un área independiente de cada ministerio.

Por su parte, el planeamiento educativo se introdujo en el país fuertemente asociado a las corrientes economicistas que sostenían la teoría del capital humano. Esta teoría concebía a la educación como una inversión productiva, a la vez que postulaba la necesidad de un crecimiento planificado basado en metas y objetivos de los planes globales de desarrollo. En tal sentido, se le asignaba a la educación una tarea básica de formar recursos humanos para desenvolverse en la transición de una sociedad tradicional a una sociedad moderna. Los trabajos de la coNADE consideraban que la planificación del sector educativo, junto con la disponibilidad de factores tecnológicos y recursos energéticos, era una condición para el desarrollo económico.

En los primeros años de la década del 70, esta concepción se fue complejizando al enfrentar fuertes críticas a la estructura administrativa del Estado y comenzó a considerarse el planeamiento no como una actividad especializada de un área del Estado, sino como una actividad que debía formar parte de las funciones corrientes de todos los agentes estatales. De acuerdo a la información suministrada en la página web oficial de la Dirección de Planeamiento

En 1972/1973, se incorporan al Ministerio de Educación nacional una serie de organismos que asumen la función de planificación. Como resultado de estos cambios estructurales, se formula en 1974 un Plan Trienal, que se proponía descentralizar para aliviar la concentración del aparato burocrático en el orden nacional. En rigor, el plan formulado preveía una desconcentración de las actividades administrativas desde el orden nacional hacia las provincias, que no se operacionalizó en acciones concretas.

\section{La dictadura}

Durante la última dictadura militar, las capacidades de planeamiento construidas desde la década de 1960 fueron fuertemente minadas, tanto por la persecución de investigadores, académicos y especialistas (muchos de los cuales debieron exiliarse), como por la desinversión en las áreas de investigación, estadística, currículum, etc. El Ministerio de Planeamiento sostenido por el Proceso se encargó fundamentalmente de tareas de propaganda, y no desempeñó ninguna de las funciones clásicas del planeamiento. Durante 
la dictadura, se interrumpieron las series estadísticas y el proceso de transferencia de servicios educativos de 1978 no fue seguido con relevamientos de información sobre matrícula, planteles docentes, etcétera.

\section{La recuperación democrática}

La década de 1980 estuvo marcada por intentos trabajosos por recuperar esas capacidades estatales. Desde el punto de vista de la estadística educativa, no se logró una recuperación plena de la actividad estatal. Los diagnósticos que se impusieron hacia el final de la década (sobre todo tras el Congreso Pedagógico) acerca del "vaciamiento de contenidos" hablaban, más en general, de este empobrecimiento del debate en una de las funciones sensibles del planeamiento que consistía en la formulación del currículum.

Estos debates se reconstruyeron y se continuaron en el campo académico, de manera dispar en distintas universidades y centros de investigación, y se reintrodujeron en el ámbito de la gestión educativa en el contexto de la reforma de 1993. La transferencia de servicios educativos nacionales a las provincias de 1992, terminó por "especializar" las funciones de gestión y de planeamiento en el nivel nacional. Un "Ministerio sin escuelas" encontraba su sentido en el ejercicio de las funciones de planeamiento (estadística, evaluación, capacitación, etc.). El contexto de transferencia y reforma, que las provincias debieron gestionar, exigió al límite las capacidades de planeamiento de los ministerios provinciales.

En ese marco, se impuso una modalidad del diseño e implementación de políticas que fueron los "programas". La estructura de programas (con gestión, evaluación y recursos propios) se fundamentaba en una suerte de desconfianza de quienes diseñaban las políticas hacia quienes debían implementarlas (v.g. las gestiones provinciales, las direcciones de niveles educativos, las ramas, los inspectores, etcétera.)

La provincia de Buenos Aires definió ya en la ley provincial de 1994 (artículo 45) una función de planeamiento en el ámbito de la Dirección General de Escuelas. Esta función era definida, más allá del planeamiento de las políticas educativas, como la previsión de la expansión racional del sistema. Es decir, el planeamiento era entendido en clave del establecimiento de prioridades para la creación de escuelas, la dotación de recursos, etcétera. ${ }^{58}$

En este contexto, la gestión Puiggrós se propuso una reforma administrativa ligada a planificar el sistema, que tuvo en cuenta que históricamente la DGCYE destina más del $94 \%$ del presupuesto a la administración de recursos humanos y queda un $6 \%$ que se distribuye para infraestructura escolar, equipamiento, transporte, pago de servicios, entre otros, lo que en el periodo $2006 / 2007$

[...] implica un gasto corriente cercano a los 10 mil millones de pesos al año (8.500 en cargos estables y 1.500 en suplencias); involucrando a 300 mil personas (247 mil docentes y 53 mil auxiliares), con un ritmo de crecimiento anual de 20 mil agentes. La reforma planificada tiene varias etapas, en distinto estado de avance. El primer grupo de reformas se concentró en:

- Reforma del proceso de determinación y reestructura de plantas orgánicas funcionales (POF).

- Fortalecimiento y promoción de la salud laboral docente.

Ambas medidas se complementaron también con:

- El fortalecimiento del control administrativo, financiero y contable.

- La designación de secretarios técnicos en los consejos escolares, y la instrumentación de un nuevo proceso de control de rendiciones de fondos descentralizados.

- La conexión de más de mil escuelas a Internet con banda ancha.

- La telegestión de trámites desde las escuelas.

- La instrumentación de la posibilidad de comunicar novedades laborales por esta vía. ${ }^{59}$ 


\section{5.g) Una nueva etapa. La inscripción de Cédula y Mapa Escolar en la gestión 2005-2007: educar en, desde y para la democracia en la formación de sujetos plenos de derechos}

Otro aspecto que consideró la gestión que comenzó a fines de 2005, además de su definición de entender a la educación como "un bien y un derecho social" de cuya provisión el Estado es responsable principal, fue el objetivo de educar en, desde y para la democracia en la formación de sujetos plenos de derechos, como la estrategia más eficaz para combatir la pobreza y lograr la inclusión con justicia social." ${ }^{60}$

A su vez y a partir de estas premisas, recuperaba algunos de los postulados que se habían formulado en el Plan 2004-2007, pero efectuando "las actualizaciones y modificaciones que la sociedad demandara." No es el tema específico de esta tesis abordar la complejidad de la propuesta político-pedagógica que se llevó adelante, pero si destacar que una de las preocupaciones principales era implementar medidas de justicia social que permitieran aumentar la matriculación para que todos los niños, niñas y jóvenes accedieran a la escuela y, en tal sentido, una vez más, los datos proporcionados por los dispositivos de Cédula Escolar eran fundamentales para evaluar estos resultados mediante los indicadores de matriculación, promoción, abandono, entre otros.

Durante la presentación efectuada a comienzos de 2006 por la Directora General de Cultura y Educación ante la Legislatura provincial, se presentaron algunos datos representados mediante gráficos del sistema educativo para ilustrar sus dimensiones, y, al mismo tiempo, establecer comparaciones con otras provincias y otros países de América Latina, que se reproducen más adelante. ${ }^{61}$

Por su parte, la gestión Puiggrós, reorganizó el área de Planeamiento incluyendo dentro de esa órbita, convertida en Dirección Provincial a la Dirección de Información y Estadística Educativa dentro de la cual funcionaban Mapa y Cédula Escolar, y habilitando la continuidad de los equipos técnicos y administrativos responsables de ambos programas. Esta decisión estaba orientada a no perder los saberes adquiridos por estos equipos ya no sólo por su formación científica de base, sino enriquecidos por la experiencia que venían realizando desde el año 2001. Es justamente la capitalización de esa experiencia la que posibilita que un determinado dispositivo técnico, como los del caso que nos ocupa, que ha ido atravesando diversas contingencias a lo largo de los años, adquiera mayores fortalezas.

Precisamente con los datos proporcionados por esos relevamientos, se elabora la información que, en este caso mediante el informe ante los legisladores, se hace pública.

Por otra parte, se propició que los datos obtenidos y debidamente elaborados mediante los rigurosos sistemas que se habían desarrollado no sólo pudieran utilizarse hacia el interior de 
La complejidad en el gobierno y administración del sistema educativo provincial, tanto por su magnitud como por su heterogeneidad, puede ilustrarse con algunas comparaciones estadísticas que lo contextualizan:

Población provincia de Buenos Aires y otros países de América Latina

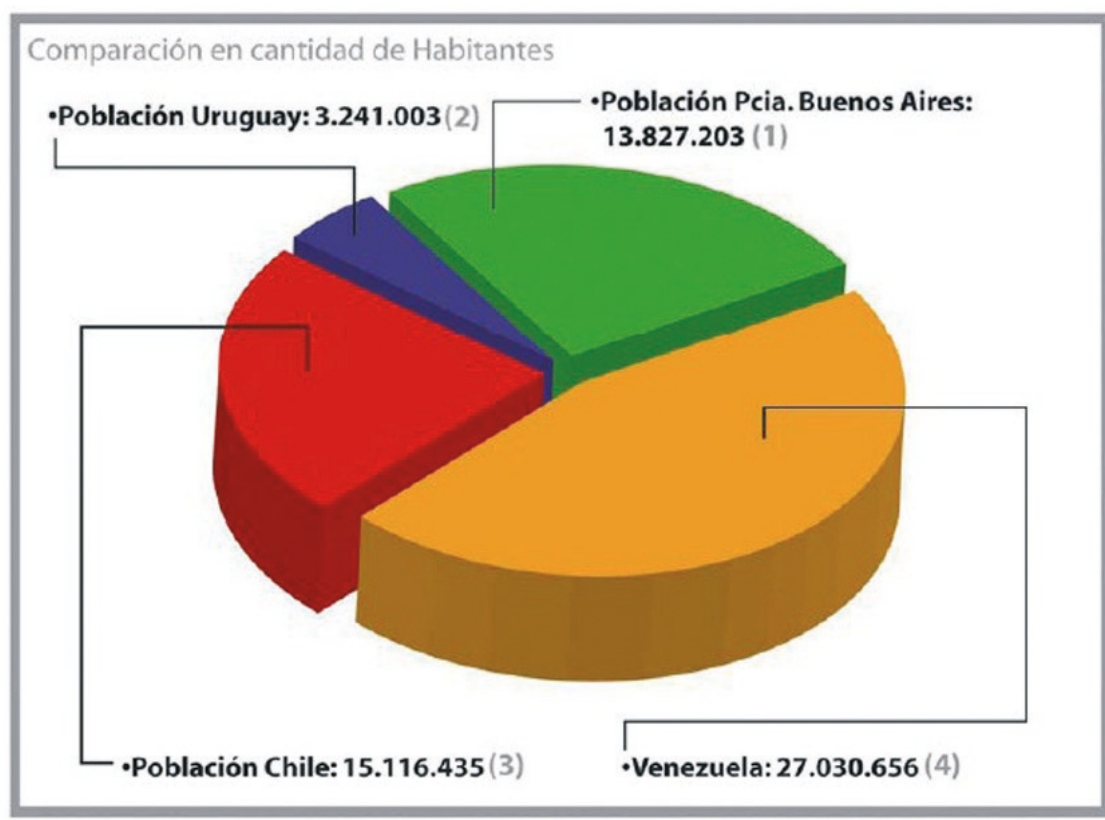

(1) Fuente: INDEC, Censo Nacional de Población, Hogares y Viviendas 2001

(2) Fuente: Instituto Nacional de Estadística Censos de Población años 2004-Fase 1

(3) Fuente: Instituto nacional de estadistica Chile, Censo 2002

(4) 27,030,656 hab (Fuente: Instituto Nacional de estadística, Gobierno Bolivariano de Venezuela)

Población total del país y de la provincia de Buenos Aires

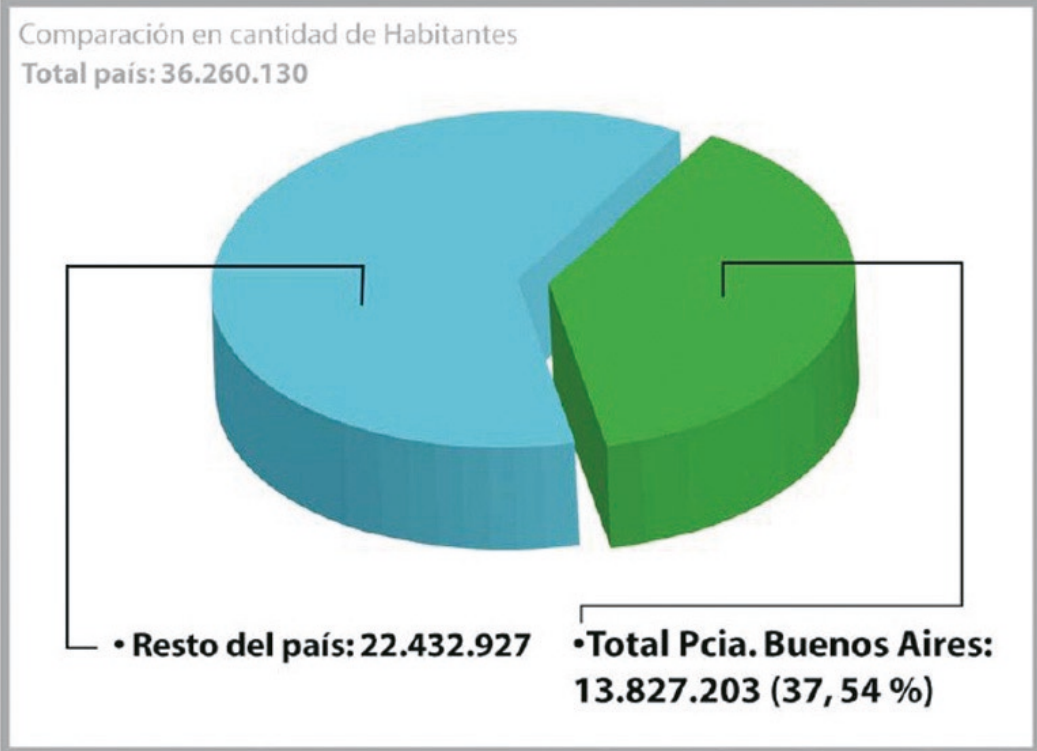

Fuente: INDEC, Censo Nacional de Población, Hogares y Viviendas 2001. 
Comparación de la matrícula de alumnos de la provincia de Buenos Aires y la población total de otras provincias argentinas

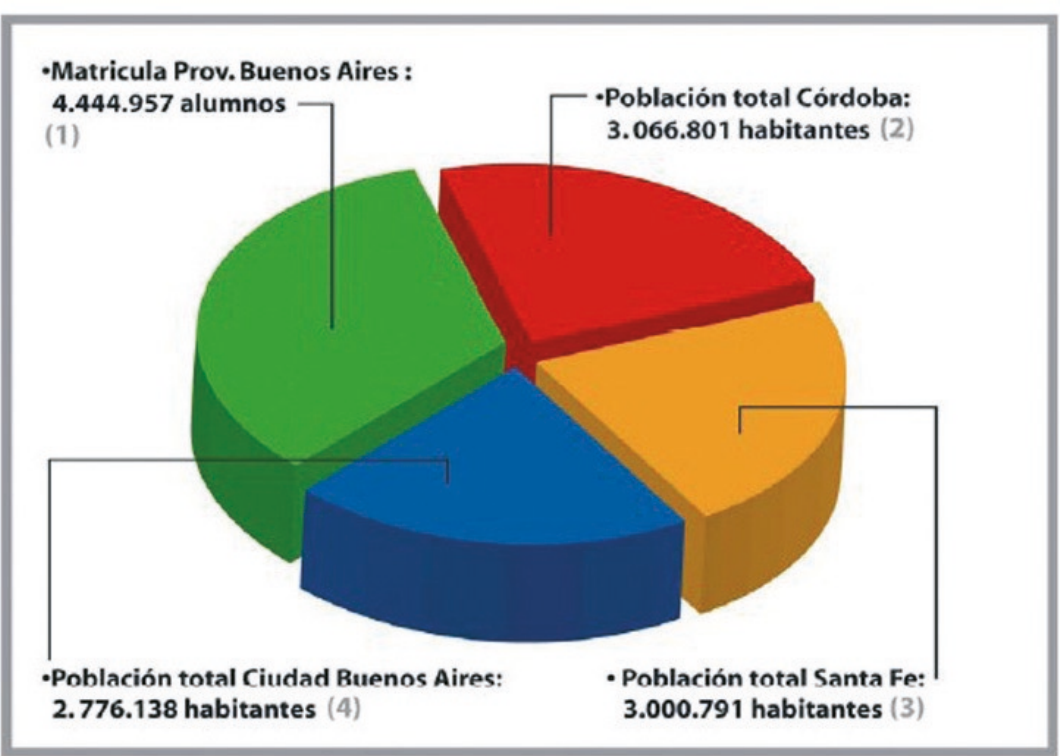

(1) Relevamiento censal 2005 No incluye la matrícula atendida en los Servicios de Apoyo-Incluye gestión Municipal y DIPREGEPFuente: Dirección Provincial de Planeamiento. Dirección de Información y Estadistica.

(2) Fuente: Censo 2001, INDEC

(3) Fuente: Censo 2001, INDEC

(4) Fuente: Censo 2001, INDEC

\section{Docentes jurisdicción provincia de Buenos Aires y otras}

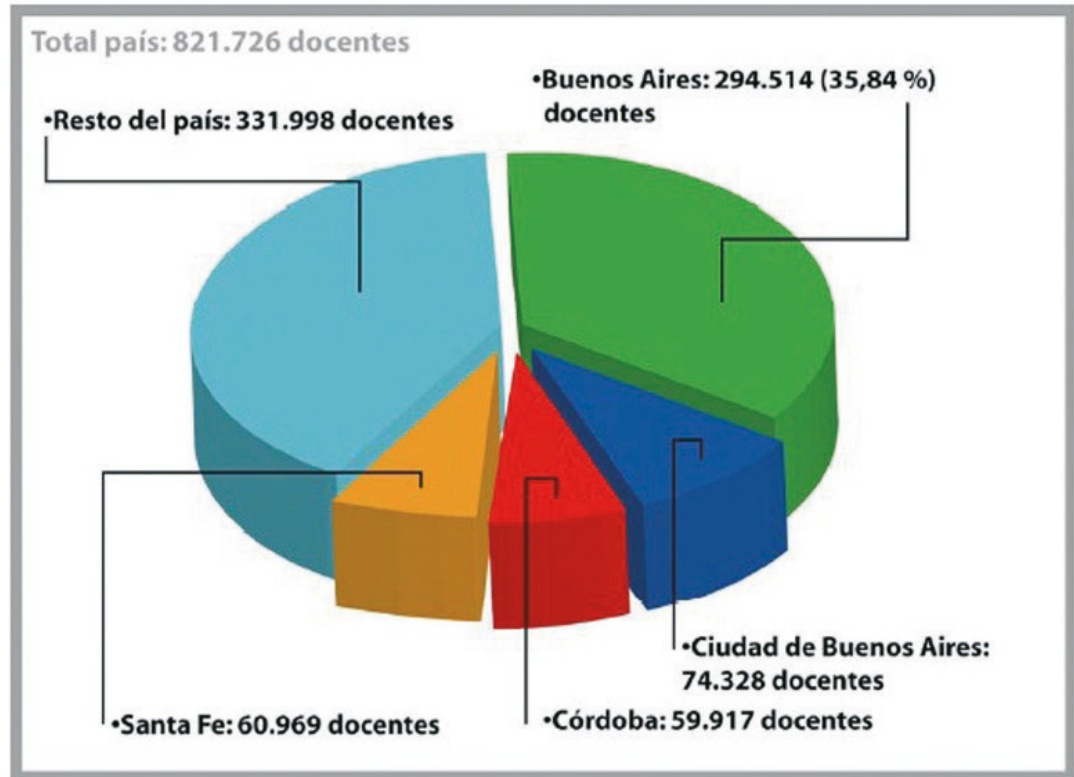

Fuente: INDEC, Dirección Nacional de Estadisticas Sociales y de Población. Dirección de Estadisticas Sectoriales en base a datos del Censo Nacional Docente 2004, del Ministerio de Educación, Ciencia y Tecnología de la Nación. 


\section{SISTEMA EDUCATIVO PROVINCIA DE BUENOS AIRES}

\section{DATOS GENERALES}

\begin{tabular}{|c|c|c|c|c|c|c|}
\hline Gestión & \multicolumn{2}{|c|}{ Servicios' } & \multicolumn{2}{|c|}{ Matrículal } & \multicolumn{2}{|c|}{$\begin{array}{c}\text { Docentes"l } \\
\text { (Noviembre 2005) }\end{array}$} \\
\hline Estatal & $10.443:$ & $65,59 \%$ & 3.108 .747 & $69,94 \%$ & 223.674 & $76,23 \%$ \\
\hline Privada ${ }^{*}$ & 5.478 & $34,41 \%$ & 1.336 .210 & $30,06 \%$ & $69.751:$ & $23,77 \%$ \\
\hline Total & 15.921 : & $100 \%$ & 4.444 .957 & $100 \%$ & 293.425 : & $100 \%$ \\
\hline
\end{tabular}

1 Fuente: Dirección Provincial de Información y Planeamiento Educativo

" Fuente: Dirección de Tecnología de la Información-Departamento Información de Gestión

* Incluye Municipal

\section{SERVICIOS EDUCATIVOS 2005}

\section{Total Provincia}

15.921

\section{Servicios Educativos / TOTAL PROVINCIA POR TIPO DE GESTIÓN}

\begin{tabular}{|c|c|c|}
\hline \multicolumn{3}{|c|}{ Servicios Educativos } \\
\hline Estatal & Privada & Municipal \\
\hline 10.443 & 5.171 & 307 \\
\hline $65,59 \%$ & $32,48 \%$ & $1,93 \%$ \\
\hline
\end{tabular}

Servicios Educativos - Matrícula / TOTAL PROVINCIA POR NIVELES Y TIPO DE GESTIÓN

\begin{tabular}{|c|c|c|c|c|c|c|}
\hline \multirow{2}{*}{ Nivel y Tipo de Educación } & \multicolumn{2}{|c|}{ TOTAL } & \multicolumn{2}{|c|}{ Estatal } & \multicolumn{2}{|c|}{ Privada $\left({ }^{* *}\right)$} \\
\hline & Matrícula & Serv. & Matrícula & Serv. & Matrícula & Serv. \\
\hline Educación Inicial & 614.498 & 4.671 & 348.893 & 2.558 & 265.605 & 2.113 \\
\hline Educación General Básica & 2.429 .151 & 5.951 & 1.681 .752 & 4.370 & 747.399 & 1.581 \\
\hline $\begin{array}{l}\text { Educación Primaria Básica } \\
\left(1^{\circ} \text { Y } 2^{\circ} \text { ciclo }\right)\end{array}$ & 1.658 .770 & 5.944 & 1.136 .986 & 4.366 & 521.784 & 1.578 \\
\hline $\begin{array}{l}\text { Educación Secundaria Básica } \\
\left(3^{\circ} \mathrm{ciclo}\right)\end{array}$ & 770.381 & 5.376 & 544.766 & 3.850 & 225.615 & 1.526 \\
\hline Educación Polimodal y TTP & 766.284 & 2.370 & 545.673 & 1.112 & 220.611 & 1.258 \\
\hline Educación Superior & 148.458 & 485 & 81.857 & 198 & 66.601 & 287 \\
\hline $\begin{array}{l}\text { Adultos y Formación } \\
\text { Profesional }\end{array}$ & 215.686 & 1.461 & 199.575 & 1.403 & 16.111 & 58 \\
\hline Educación Especial & 72.025 & 590 & 61.245 & 436 & 10.780 & 154 \\
\hline Educación Artística (*) & 51.514 & 105 & 44.522 & 87 & 6.992 & 18 \\
\hline Psicología y Asistencia S. E. & 30.142 & 156 & 28.439 & 148 & 1.703 & 8 \\
\hline Educación Física & 117.199 & 132 & 116.791 & 131 & 408 & 1 \\
\hline TOTAL GENERAL & 4.444.957 & 15.921 & 3.108 .747 & 10.443 & 1.336 .210 & 5.478 \\
\hline
\end{tabular}

Fuente: Dirección Provincial de Información y Planeamiento Educativo. Dirección de Información y Estadística.

${ }^{*}$ ) No incluye matrícula atendida en los Servicios de Apoyo - $\left({ }^{* *}\right)$ Incluye gestión municipal

Servicios Educativos 2005 / SEGÚN UBICACIÓN

\begin{tabular}{|c|c|}
\hline Urbanos & Rurales \\
\hline $78,7 \%$ & $21,3 \%$ \\
\hline
\end{tabular}

Servicios Educativos con Ubicación Urbana por Nivel Educativo y Tipo de Gestión.

\begin{tabular}{|l|r|r|}
\hline \multicolumn{1}{|c|}{ Nivel educativo } & \multicolumn{1}{c|}{ Estatal } & \multicolumn{1}{c|}{ Privada } \\
\hline Inicial & $45,2 \%$ & $54,8 \%$ \\
\hline EGB & $62,7 \%$ & $37,3 \%$ \\
\hline Polimodal & $43,3 \%$ & $56,7 \%$ \\
\hline Especial & $73,3 \%$ & $26,7 \%$ \\
\hline CEC & $94,4 \%$ & $5,6 \%$ \\
\hline Artística & $82,9 \%$ & $17,1 \%$ \\
\hline CEF & $99,2 \%$ & $0,8 \%$ \\
\hline Adultos & $95,6 \%$ & $4,4 \%$ \\
\hline Superior & $40,7 \%$ & $59,3 \%$ \\
\hline
\end{tabular}


Cantidad de docentes en establecimientos de educación formal y variación relativa del período. Total del país según provincia. Años 1994 y 2004

\begin{tabular}{|c|c|c|c|}
\hline \multirow{2}{*}{ Provincia } & \multicolumn{2}{|c|}{ Cantidad de docentes } & \multirow{2}{*}{$\begin{array}{l}\text { Variación } \\
\text { porcentual }\end{array}$} \\
\hline & 1994 & 2004 & \\
\hline Total del país & 655.750 & 821.726 & 25,3 \\
\hline Ciudad de Buenos Aires & 69.569 & 74.328 & 6,8 \\
\hline Buenos Aires & 215.956 & 294.514 & 36,4 \\
\hline Catamarca & 8.274 & 10.711 & 29,5 \\
\hline Chaco & 18.339 & 23.589 & 28,6 \\
\hline Chubut & 8.391 & 10.940 & 30,4 \\
\hline Córdoba & 55.616 & 59.917 & 7,7 \\
\hline Corrientes & 15.777 & 18.825 & 19,3 \\
\hline Entre Ríos & 25.009 & 30.415 & 21,6 \\
\hline Formosa & 9.805 & 11.751 & 19,8 \\
\hline Jujuy & 12.352 & 16.722 & 35,4 \\
\hline La Pampa & 7.258 & 8.303 & 14,4 \\
\hline La Rioja & 6.214 & 9.080 & 46,1 \\
\hline Mendoza & 27.777 & 39.010 & 40,4 \\
\hline Misiones & 14.744 & 20.148 & 36,7 \\
\hline Neuquén & 10.388 & 16.372 & 57,6 \\
\hline Río Negro & 12.976 & 16.962 & 30,7 \\
\hline Salta & 17.981 & 21.528 & 19,7 \\
\hline San Juan & 12.400 & 14.395 & 16,1 \\
\hline San Luis & 7.044 & 8.121 & 15,3 \\
\hline Santa Cruz & 5.217 & 7.242 & 38,8 \\
\hline Santa Fe & 54.829 & 60.969 & 11,2 \\
\hline Santiago del Estero & 13.769 & 17.353 & 26,0 \\
\hline Tierra del Fuego & 2.452 & 3.827 & 56,1 \\
\hline Tucumán & 23.613 & 26.704 & 13,1 \\
\hline
\end{tabular}

Fuente: INDEC, Dirección Nacional de Estadísticas Sociales y de Población. Dirección de Estadísticas Sectoriales en base a datos del Censo Nacional Docente 2004, del Ministerio de Educación, Ciencia y Tecnología de la Nación.

Servicios Educativos con Ubicación Rural por Nivel Educativo y Tipo de Gestión

\begin{tabular}{|l|c|c|}
\hline \multicolumn{1}{|c|}{ Nivel educativo } & Estatal & Privada \\
\hline Inicial & $89,5 \%$ & $10,5 \%$ \\
\hline EGB & $96,2 \%$ & $3,8 \%$ \\
\hline Polimodal & $77,0 \%$ & $23,0 \%$ \\
\hline Especial & $87,5 \%$ & $12,5 \%$ \\
\hline CEC & $100,0 \%$ & $0,0 \%$ \\
\hline Artística & $0,0 \%$ & $0,0 \%$ \\
\hline CEF & $100,0 \%$ & $0,0 \%$ \\
\hline Adultos & $99,4 \%$ & $0,6 \%$ \\
\hline Superior & $66,7 \%$ & $33,3 \%$ \\
\hline
\end{tabular}

Fuente: Dirección Provincial de Información y Planeamiento Educativo - Dirección de Información y Estadistica 
MATRÍCULA 2005

Matrícula / TOTAL PROVINCIA POR TIPO DE GESTIÓN

\begin{tabular}{|c|c|c|c|}
\hline \multicolumn{2}{|c|}{ Estatal } & \multicolumn{2}{c|}{$\begin{array}{c}\text { Privada } \\
\text { (incluye Municipal }\end{array}$} \\
\hline Relev. anual 2004 & Relev. anual 2005 & Relev. anual 2004 & Relev. anual 2005 \\
\hline 3.150 .029 & 3.108 .747 & 1.297 .504 & 1.336 .210 \\
\hline $71 \%$ & $70 \%$ & $29 \%$ & $30 \%$ \\
\hline
\end{tabular}

Matrícula / TOTAL PROVINCIA según tipo de gestión y Nivel de Enseñanza

\begin{tabular}{|c|c|c|c|c|c|c|}
\hline \multirow{2}{*}{ Nivel de Enseñanza } & \multicolumn{3}{|c|}{ Matrícula relev. anual 2005} & \multicolumn{3}{|c|}{ Matrícula relev. anual 2004} \\
\hline & Total & Estatal & Privada* & Total & Estatal & Privada* \\
\hline Dirección de Educación Inicial & 614.498 & 348.893 & 265.605 & 594.757 & 347.581 & 247.176 \\
\hline $\begin{array}{l}\text { Dirección de Educación } \\
\text { General Básica }\end{array}$ & 2.429 .151 & 1.681 .752 & 747.399 & 2.441 .033 & 1.717 .957 & 723.076 \\
\hline $\begin{array}{l}\text { Educación Primaria Básica }\left(1^{\circ}\right. \\
\text { Y } 2^{\circ} \text { ciclo) }\end{array}$ & 1.658 .770 & 1.136 .986 & 521.784 & 1.653 .935 & 1.153 .617 & 500.318 \\
\hline $\begin{array}{l}\text { Educación Secundaria Básica } \\
\left(3^{\circ} \text { ciclo }\right)\end{array}$ & 770.381 & 544.766 & 225.615 & 787.098 & 564.340 & 222.758 \\
\hline $\begin{array}{l}\text { Dirección de Educación } \\
\text { Polimodal y ПTP }\end{array}$ & 766.284 & 545.673 & 220.611 & 767.247 & 547.110 & 220.137 \\
\hline $\begin{array}{l}\text { Dirección de Educación } \\
\text { Superior }\end{array}$ & 148.458 & 81.857 & 66.601 & 155.043 & 86.730 & 68.313 \\
\hline $\begin{array}{l}\text { Dirección de Adultos y } \\
\text { Formación Profesional }\end{array}$ & 215.686 & 199.575 & 16.111 & 221.855 & 202.015 & 19.840 \\
\hline $\begin{array}{l}\text { Dirección de Educación } \\
\text { Especial }\end{array}$ & 72.025 & 61.245 & 10.780 & 68.946 & 58.812 & 10.134 \\
\hline $\begin{array}{l}\text { Dirección de Educación } \\
\text { Artística** }\end{array}$ & 51.514 & 44.522 & 6.992 & 50.476 & 43.630 & 6.846 \\
\hline $\begin{array}{l}\text { Dirección de Psicología y } \\
\text { Asistencia S. E. }\end{array}$ & 30.142 & 28.439 & 1.703 & 30.599 & 29.044 & 1.555 \\
\hline Dirección de Educación Física & 117.199 & 116.791 & 408 & 117.577 & 117.150 & 427 \\
\hline Total general & 4.444.957 & 3.108 .747 & 1.336 .210 & 4.447 .533 & 3.150 .029 & 1.297 .504 \\
\hline
\end{tabular}

Fuente: Dirección Provincial de Información y Planeamiento Educativo. Dirección de Información

y Estadística

* Incluye Gestión Municipal

** No incluye la matrícula atendida en los Servicios de Apoyo

\section{Matrícula / PROMEDIO DE ALUMNOS POR SERVICIO EDUCATIVO}

\begin{tabular}{|l|c|c|c|}
\hline Tipo/Nivel de Educación & Total & Estatal & Privada \\
\hline Inicial & $\mathbf{1 3 1 , 2 3}$ & 136,92 & 124,41 \\
\hline EGB & $\mathbf{4 1 3 , 0 0}$ & 391,87 & 471,05 \\
\hline Polimodal & $\mathbf{3 1 2 , 2 8}$ & 470,21 & 174,68 \\
\hline Superior & $\mathbf{2 9 7 , 9 6}$ & 409,12 & 223,21 \\
\hline Adultos y FP & $\mathbf{1 4 2 , 2 7}$ & 136,07 & 298,36 \\
\hline Especial & $\mathbf{1 1 9 , 2 3}$ & 137,82 & 67,83 \\
\hline Artística & $\mathbf{4 9 0 , 8 3}$ & 518,07 & 359,17 \\
\hline CEC & $\mathbf{1 8 9 , 6 5}$ & 188,41 & 212,65 \\
\hline CEF & $\mathbf{8 6 4 , 0 5}$ & 868,15 & 327,00 \\
\hline
\end{tabular}

Matrícula / PROMEDIO DE ALUMNOS POR SECCIÓN

\begin{tabular}{|l|c|c|c|}
\hline Tipo/Nivel de Educación & Total & Estatal & Privada \\
\hline Inicial & $\mathbf{2 5 , 9 8}$ & 27,28 & 24,45 \\
\hline EGB & $\mathbf{2 7 , 5 9}$ & 27,08 & 28,83 \\
\hline Polimodal & $\mathbf{2 8 , 8 6}$ & 28,54 & 29,63 \\
\hline Superior & $\mathbf{2 8 , 1 3}$ & 29,97 & 26,14 \\
\hline Adultos (EGB) & $\mathbf{2 1 , 3 6}$ & 21,37 & 19,82 \\
\hline Artística & $\mathbf{2 7 , 3 7}$ & 27,98 & 23,77 \\
\hline CEC & $\mathbf{2 5 , 8 4}$ & 25,82 & 26,17 \\
\hline CEF & $\mathbf{2 5 , 3 5}$ & 25,32 & 23,36 \\
\hline
\end{tabular}

Fuente: Dirección Provincial de Información y Planeamiento Educativo. Dirección de Información y Estadística. Relevamiento Inicial 2005 
Promoción, repitencia y abandono interanual / TODOS LOS TIPOS DE GESTIÓN

\section{Educación General Básica}

\begin{tabular}{|l|c|c|c|c|}
\hline \multicolumn{1}{|c|}{ Período } & Promoción & Repitencia & $\begin{array}{c}\text { Abandono } \\
\text { interanual }\end{array}$ & Reinscripción \\
\hline $1999 / 2000$ & $92,60 \%$ & $5,60 \%$ & $1,80 \%$ & - \\
\hline $2000 / 2001$ & $92,20 \%$ & $5,44 \%$ & $2,35 \%$ & - \\
\hline $2001 / 2002$ & $92,50 \%$ & $5,12 \%$ & $2,38 \%$ & - \\
\hline $2002 / 2003$ & $91,90 \%$ & $6,10 \%$ & $2,00 \%$ & - \\
\hline $2003 / 2004$ & $91,40 \%$ & $6,35 \%$ & $1,90 \%$ & $0,35 \%$ \\
\hline $2004 / 2005$ & $90,20 \%$ & $6,80 \%$ & $2,6 \%$ & $0,40 \%$ \\
\hline
\end{tabular}

Polimodal

\begin{tabular}{|l|c|c|c|c|}
\hline \multicolumn{1}{|c|}{ Período } & Promoción & Repitencia & $\begin{array}{c}\text { Abandono } \\
\text { interanual }\end{array}$ & Reinscripción \\
\hline $1999 / 2000$ & $88,70 \%$ & $4,20 \%$ & $7,10 \%$ & - \\
\hline $2000 / 2001$ & $84,14 \%$ & $5,24 \%$ & $10,62 \%$ & - \\
\hline $2001 / 2002$ & $85,00 \%$ & $5,03 \%$ & $9,97 \%$ & - \\
\hline $2002 / 2003$ & $81,30 \%$ & $7,50 \%$ & $11,20 \%$ & - \\
\hline $2003 / 2004$ & $76,18 \%$ & $8,45 \%$ & $13,83 \%$ & $1,54 \%$ \\
\hline $2004 / 2005$ & $74,2 \%$ & $9,00 \%$ & $15,30 \%$ & $1,50 \%$ \\
\hline
\end{tabular}

Fuente: Dirección Provincial de Información y Planeamiento Educativo. Dirección de Información y Estadística.

Promoción, repiłencia y abandono interanual / GESTIÓN ESTATAL Educación General Básica

\begin{tabular}{|c|c|c|c|c|}
\hline \multicolumn{1}{|c|}{ Período } & Promoción & Repitencia & $\begin{array}{c}\text { Abandono } \\
\text { interanual }\end{array}$ & Reinscripción \\
\hline $1999 / 2000$ & $91,20 \%$ & $7,20 \%$ & $1,60 \%$ & - \\
\hline $2000 / 2001$ & $90,73 \%$ & $6,97 \%$ & 2,30 & - \\
\hline $2001 / 2002$ & $91,18 \%$ & $6,59 \%$ & $2,23 \%$ & - \\
\hline $2002 / 2003$ & $89,98 \%$ & $7,80 \%$ & $2,22 \%$ & - \\
\hline $2003 / 2004$ & $88,68 \%$ & $8,08 \%$ & $2,80 \%$ & $0,44 \%$ \\
\hline $2004 / 2005$ & $87,45 \%$ & $8,61 \%$ & $3,48 \%$ & $0,46 \%$ \\
\hline
\end{tabular}

\section{Polimodal}

\begin{tabular}{|c|c|c|c|c|}
\hline Período & Promoción & Repitencia & $\begin{array}{c}\text { Abandono } \\
\text { interanual }\end{array}$ & Reinscripción \\
\hline $1999 / 2000$ & $86,30 \%$ & $5,10 \%$ & $8,60 \%$ & - \\
\hline $2000 / 2001$ & $80,41 \%$ & $6,53 \%$ & $13,06 \%$ & - \\
\hline $2001 / 2002$ & $81,13 \%$ & $6,60 \%$ & $12,27 \%$ & - \\
\hline $2002 / 2003$ & $76,38 \%$ & $9,83 \%$ & $13,79 \%$ & - \\
\hline $2003 / 2004$ & $70,19 \%$ & $10,83 \%$ & $16,91 \%$ & $2,07 \%$ \\
\hline $2004 / 2005$ & $67,46 \%$ & $11,48 \%$ & $19,22 \%$ & $1,84 \%$ \\
\hline
\end{tabular}

Promoción, repitencia y abandono interanual / GESTIÓN PRIVADA Educación General Básica

\begin{tabular}{|l|c|c|c|c|}
\hline \multicolumn{1}{|c|}{ Período } & Promoción & Repitencia & $\begin{array}{c}\text { Abandono } \\
\text { interanual }\end{array}$ & Reinscripción \\
\hline $1999 / 2000$ & $96,30 \%$ & $1,40 \%$ & $2,30 \%$ & - \\
\hline $2000 / 2001$ & $96,05 \%$ & $1,47 \%$ & $2,48 \%$ & - \\
\hline $2001 / 2002$ & $96,00 \%$ & $1,30 \%$ & $2,71 \%$ & - \\
\hline $2002 / 2003$ & $96,65 \%$ & $1,85 \%$ & $1,50 \%$ & - \\
\hline $2003 / 2004$ & $98,22 \%$ & $2,00 \%$ & $-0,36 \%$ & $0,14 \%$ \\
\hline $2004 / 2005$ & $97,34 \%$ & $2,19 \%$ & $0,47 \%$ & $0,00 \%$ \\
\hline
\end{tabular}

\section{Polimodal}

\begin{tabular}{|c|c|c|c|c|}
\hline \multicolumn{1}{|c|}{ Período } & Promoción & Repitencia & $\begin{array}{c}\text { Abandono } \\
\text { interanual }\end{array}$ & Reinscripción \\
\hline $1999 / 2000$ & $93,60 \%$ & $2,00 \%$ & $4,40 \%$ & - \\
\hline $2000 / 2001$ & $92,89 \%$ & $2,22 \%$ & $4,90 \%$ & - \\
\hline $2001 / 2002$ & $92,83 \%$ & $1,86 \%$ & $5,31 \%$ & - \\
\hline $2002 / 2003$ & $90,92 \%$ & $3,06 \%$ & $6,02 \%$ & - \\
\hline $2003 / 2004$ & $87,94 \%$ & $3,77 \%$ & $7,79 \%$ & $0,50 \%$ \\
\hline $2004 / 2005$ & $87,04 \%$ & $4,32 \%$ & $7,95 \%$ & $0,69 \%$ \\
\hline
\end{tabular}

Fuente: Dirección Provincial de Información y Planeamiento Educativo. Dirección de Información y Estadística 
Promoción, repitencia y abandono interanual /PRIMARIA - EGB POR AÑO

DE ESTUDIO. TODOS LOS TIPOS DE GESTIÓN. 1990-2005

\begin{tabular}{|c|c|c|c|c|c|c|c|c|c|c|c|}
\hline & \multicolumn{11}{|c|}{ Período } \\
\hline & $90-91$ & $95-96$ & $96-97$ & $97-98$ & $98-99$ & $99-00$ & $00-01$ & $01-02$ & $02-03$ & 03-04 & $04-05$ \\
\hline \multirow{4}{*}{$\begin{array}{l}\text { Promoción } \\
\text { Repitencia } \\
\text { Abandono } \\
\text { interanual } \\
\text { Reinscrip- } \\
\text { ción }\end{array}$} & $95,6 \%$ & $96,4 \%$ & $96,2 \%$ & $94,6 \%$ & $94,2 \%$ & $92,6 \%$ & $92,2 \%$ & $92,5 \%$ & $91,9 \%$ & $91,4 \%$ & $90,2 \%$ \\
\hline & $2,9 \%$ & $2,8 \%$ & $2,6 \%$ & $4,0 \%$ & $3,5 \%$ & $5,6 \%$ & $5,44 \%$ & $5,12 \%$ & $6,1 \%$ & $6,35 \%$ & $6,8 \%$ \\
\hline & $1,5 \%$ & $0,8 \%$ & $1,2 \%$ & $1,4 \%$ & $2,3 \%$ & $1,8 \%$ & $2,36 \%$ & $2,38 \%$ & $2,0 \%$ & $1,90 \%$ & $2,6 \%$ \\
\hline & - & - & - & - & - & - & - & - & - & $0,35 \%$ & $0,40 \%$ \\
\hline
\end{tabular}

\begin{tabular}{|l|c|c|c|c|c|c|c|c|c|c|}
\hline \multirow{2}{*}{$\begin{array}{c}\text { Período } \\
\text { 04-05 }\end{array}$} & Total & \multicolumn{10}{|c|}{ Año de estudio } \\
\cline { 3 - 11 } & $\mathbf{1}^{\circ}$ & $\mathbf{2}^{\circ}$ & $\mathbf{3}^{\circ}$ & $\mathbf{4}^{\circ}$ & $\mathbf{5}^{\circ}$ & $\mathbf{6}^{\circ}$ & $\mathbf{7}^{\circ}$ & $\mathbf{8}^{\circ}$ & $\mathbf{9}^{\circ}$ \\
\hline $\begin{array}{l}\text { Promoción } \\
\text { Repitencia }\end{array}$ & $\mathbf{6 0 , 2 \%}$ & $91,5 \%$ & $93,9 \%$ & $94,7 \%$ & $94,8 \%$ & $94,0 \%$ & $92,8 \%$ & $83,8 \%$ & $77,7 \%$ & $88,7 \%$ \\
\hline $\begin{array}{l}\text { Abandono } \\
\text { interanual }\end{array}$ & $\mathbf{2 , 6 \%}$ & $1,3 \%$ & $0,3 \%$ & $0,2 \%$ & $0,2 \%$ & $0,7 \%$ & $1,7 \%$ & $6,0 \%$ & $9,8 \%$ & $3,1 \%$ \\
\hline $\begin{array}{l}\text { Reinscrip- } \\
\text { ción }\end{array}$ & $\mathbf{0 , 4 0 \%}$ & $0,30 \%$ & $0,30 \%$ & $0,30 \%$ & $0,30 \%$ & $0,20 \%$ & $0,30 \%$ & $0,60 \%$ & $0,70 \%$ & $0,60 \%$ \\
\hline
\end{tabular}

\begin{tabular}{|c|c|c|c|c|c|c|c|c|c|c|}
\hline \multirow{2}{*}{$\begin{array}{c}\text { Período } \\
03-04\end{array}$} & \multirow{2}{*}{ Total } & \multicolumn{9}{|c|}{ Año de estudio } \\
\hline & & $1^{\circ}$ & $2^{\circ}$ & $3^{\circ}$ & $4^{\circ}$ & $5^{\circ}$ & $6^{\circ}$ & $7^{\circ}$ & $8^{\circ}$ & $9^{\circ}$ \\
\hline Promoción & $91,4 \%$ & $91,4 \%$ & $93,9 \%$ & $94,6 \%$ & $94,8 \%$ & $94,3 \%$ & $94,6 \%$ & $88,3 \%$ & $81,1 \%$ & $89,2 \%$ \\
\hline Repitencia & $35 \%$ & $6,7 \%$ & $5,5 \%$ & $4,7 \%$ & $4,6 \%$ & $4,6 \%$ & $4,9 \%$ & $8,4 \%$ & $10,7 \%$ & $7,0 \%$ \\
\hline $\begin{array}{l}\text { Abandono } \\
\text { interanual }\end{array}$ & $1,90 \%$ & $1,6 \%$ & $0,4 \%$ & $0,4 \%$ & $0,4 \%$ & $0,8 \%$ & $0,2 \%$ & $2,9 \%$ & $7,6 \%$ & $3,2 \%$ \\
\hline Reinscrip-ción & $0,35 \%$ & $0,30 \%$ & $0,20 \%$ & $0,30 \%$ & $0,20 \%$ & $0,30 \%$ & $0,30 \%$ & $0,40 \%$ & $0,60 \%$ & $0,60 \%$ \\
\hline
\end{tabular}

\begin{tabular}{|c|c|c|c|c|c|c|c|c|c|c|}
\hline \multirow{2}{*}{$\begin{array}{c}\text { Período } \\
02-03\end{array}$} & \multirow{2}{*}{ Total } & \multicolumn{9}{|c|}{ Año de estudio } \\
\hline & & $1^{\circ}$ & $2^{\circ}$ & $3^{\circ}$ & $4^{\circ}$ & $5^{\circ}$ & $6^{\circ}$ & $7^{\circ}$ & $8^{\circ}$ & $9^{\circ}$ \\
\hline Promoción & $91,9 \%$ & $91,2 \%$ & $93,5 \%$ & $94,6 \%$ & $94,9 \%$ & $94,6 \%$ & $95 \%$ & $90 \%$ & $82,8 \%$ & $89,8 \%$ \\
\hline Repitencia & $6,1 \%$ & $6,4 \%$ & $5,5 \%$ & $4,6 \%$ & $4,2 \%$ & $4,2 \%$ & $4,3 \%$ & $7,1 \%$ & $9,6 \%$ & $6,2 \%$ \\
\hline $\begin{array}{l}\text { Abandono } \\
\text { interanual }\end{array}$ & $2 \%$ & $2,1 \%$ & $0,7 \%$ & $0,6 \%$ & $0,6 \%$ & $1 \%$ & $0,5 \%$ & $2,5 \%$ & $7 \%$ & $3,4 \%$ \\
\hline
\end{tabular}

\begin{tabular}{|c|c|c|c|c|c|c|c|c|c|c|}
\hline \multirow{2}{*}{$\begin{array}{c}\text { Período } \\
01-02\end{array}$} & \multirow{2}{*}{ Total } & \multicolumn{9}{|c|}{ Año de estudio } \\
\hline & & $1^{\circ}$ & $2^{\circ}$ & $3^{\circ}$ & $4^{\circ}$ & $5^{\circ}$ & $6^{\circ}$ & $7^{\circ}$ & $8^{\circ}$ & $9^{\circ}$ \\
\hline Promoción & $92,5 \%$ & $91,45 \%$ & $93,99 \%$ & $94,62 \%$ & $95,47 \%$ & $95,31 \%$ & $95,57 \%$ & $91,33 \%$ & $83,58 \%$ & $91,01 \%$ \\
\hline Repitencia & $5,12 \%$ & $5,99 \%$ & $5,13 \%$ & $4,33 \%$ & $3,57 \%$ & $3,46 \%$ & $3,57 \%$ & $5,98 \%$ & $8,42 \%$ & $5,69 \%$ \\
\hline $\begin{array}{l}\text { Abandono } \\
\text { interanual }\end{array}$ & $2,38 \%$ & $2,56 \%$ & $0,88 \%$ & $1,04 \%$ & $0,96 \%$ & $1,23 \%$ & $0,86 \%$ & $2,69 \%$ & $8,00 \%$ & $3,3 \%$ \\
\hline
\end{tabular}

la institución de la DGCYE, sino también para conocimiento de la opinión pública, otras áreas gubernamentales —nacionales, provinciales y/o municipales-, y la propia área de Prensa y Comunicación de la DGCYE.

El recorrido por estos diversos gráficos, elaborados precisamente por los equipos de las áreas de Información y Estadística de la Dirección Provincial de Información y Planeamiento, completa, de modo sintético, el panorama del sistema educativo, en aspectos generales.

¿Pero cómo sostener estas líneas de trabajo? ¿Cómo lograr que los docentes y directivos se apropien de ellas? Para reafirmar estas políticas, entre otras medidas, el 8 de mayo de 2006 se realizaron en la ciudad de Mar del Plata las Primeras Jornadas de Planeamiento Regional Educativo.

Curiosamente, la siguiente referencia a esas jornadas está tomada de una nota periodística publicada oportunamente en el sitio de la Dirección de Prensa y Comunicación del Portal ABC, llamado Prensa abc (hoy ABc Medios). En dicha nota, la Doctora PUIGGRós expresó, ante un auditorio conformado por los inspectores de toda la Provincia y miembros del gabinete ministerial, que 
Necesitamos hacer un esfuerzo colectivo de comprensión de la situación y las posibles perspectivas de nuestro sistema. Esto requiere conocer sus regularidades, sus núcleos duros, sus puntos de quiebre, distinguiendo entre circunstancias, externas a nuestra escuela, a nuestro distrito, a nuestra región y aquellas que están a nuestro alcance reformar mediante la acción político-educativa, de infraestructura y pedagógica", afirmó la Directora General de Cultura y Educación de la provincia de Buenos Aires, Adriana Puiggrós, al encabezar la apertura del encuentro.

Hemos pasado años difíciles, en los cuales se atendieron de manera notable las urgencias. Ahora debemos avanzar en soluciones sustentables, programadas, así como en la mejora de dispositivos permanentes que atiendan las contingencias, en una administración que, acompañada por cada vez mejores organismos de control, trabaje procesos previstos y no se vea obligada a resolver sobre el límite de los acontecimientos", puntualizó.

La unidad de la gestión que hoy se expresa aquí, donde estamos por primera vez juntos toda la conducción central y todas las conducciones regionales, es para realizar un ejercicio de articulación, de trabajo colectivo y coordinado. Habrá intervención específica de los responsables de Educación, Administración, Planeamiento, Capacitación, Infraestructura, Políticas Socioeducativas, Legislación, Auditoría, Educación y Trabajo, y las líneas que dependen de ellos, señaló. ${ }^{62}$

Respecto a algunas de las denominaciones utilizadas en los gráficos aquí incluidos, cabe aclarar que se denomina "Tasa de Promoción" al porcentaje de alumnos que se matriculan en el año de estudio siguiente al año lectivo siguiente; Tasa de Repitencia, al porcentaje de alumnos que se matriculan como alumnos repitientes en el año lectivo siguiente; "Tasa de Abandono interanual" al porcentaje de alumnos que no se matriculan en el año lectivo siguiente. La Tasa de re-inscripción expresa el porcentaje de aquellos alumnos que se registraron por segunda vez o más en un año de estudio en el que ya se habían inscripto en algún ciclo lectivo anterior, sin completar su cursada. ${ }^{63}$

Desde ya, estos datos inducen a diferentes interpretaciones en cuanto a sus causas y, también, a las propuestas para reducir los indicadores de abandono y repitencia. En tal sentido,

La situación de exclusión que sufren los sectores populares obliga a replantearse los modelos escolares propuestos y, tal como plantea PuIGgrós, "no puede describirse simplemente como un desajuste o el resultado de problemas de funcionamiento" sino que "es el proceso de agotamiento de los paradigmas educativos modernos (...) y los efectos de las políticas de ajuste desde el neofuncionalismo pedagógico".

Hacer de la escuela una institución que luche contra la inequidad, requiere revisar en primer lugar, los mecanismos que expulsan y marginan a sectores importantes de la juventud. También exige una revisión de las estrategias de gestión educativa y abordajes didácticos y pedagógicos. Las instancias de compensación económica (becas, subsidios) resultan insuficientes y sin resignar los contenidos de los aprendizajes, deberían pensarse también en estrategias compensatorias que posibiliten acompañar a los jóvenes en dificultades para que en los mismos tiempos de promoción puedan alcanzar los niveles requeridos, así como en alternativas institucionales que favorezcan el aprendizaje de la participación juvenil en la resolución de conflictos de convivencia. La institución educativa y el conjunto de actores que en ella intervienen, deberían poder visualizar a los jóvenes que ya no están en la escuela. El seguimiento del alumnado que interrumpe sus estudios requiere una atención particular y su reinserción escolar debería formar parte de las líneas de acción de las jurisdicciones educativas. La incipiente actividad conjunta entre la escuela y las organizaciones de la sociedad civil que realizan actividades de apoyo escolar, es una estrategia interesante para ser profundizada y extendida, acordando roles particulares y complementando las tareas 
educativas. Se deberían idear nuevas estrategias de articulación con otros actores sociales comprometidos con la acción educativa que posibiliten la reinserción de los jóvenes desescolarizados. ${ }^{64}$

\section{5.h) Números, datos y personas. Nancy y sus hijos}

¿Pero cómo y para qué "leer" estos datos? ¿De qué hablamos cuando hablamos de deserción escolar y de cobertura? En una oficina de la DGCYE, una tarde como cualquier otra, suena un teléfono. Por el ruido ambiente que dificulta la escucha, es fácil darse cuenta que se trata de un teléfono público. Es una mujer de Virrey del Pino, La Matanza, se llama Nancy. Su voz tiene el timbre de un cansancio resignado y cierta desesperación. Habla rápido, porque no tiene dinero ni para pagar la comunicación ni demasiadas esperanzas de resolver su problema. Para ella, quien atiende representa al Estado y es el Estado el que debe resolver la falta de vacantes en los jardines de su barrio para dos de sus seis hijos. Tiene tres en la escuela primaria, pero faltan mucho, dice, porque a veces no tiene para comprarle zapatillas y mucho menos los libros que le piden las maestras. Uno de los mayores dejó el polimodal en segundo, informa Nancy, porque le salió una changuita con el cuñado de ella, que es albañil. Para colmo, dice, mi marido está sin laburo, nada más que alguna changuita y tenemos un plan, pero no alcanza. Y la nena está en primero, pero no sé si va a poder seguir, se me embarazó la muy tonta, dice esta madre.

\begin{tabular}{|c|c|c|c|c|c|c|c|c|c|}
\hline \multirow{2}{*}{ Régimen } & \multicolumn{3}{|c|}{ Total } & \multicolumn{3}{|c|}{ Estatal } & \multicolumn{3}{|c|}{ Privado } \\
\hline & Establ. & Alumnos & secciones & Establ. & Alumnos & Secciones & Establ. & Alumnos & Secciones \\
\hline Total & 1.188 & 370.168 & 12.830 & 702 & 249.934 & 8.874 & 486 & 120.234 & 3.956 \\
\hline Dirección de Educación Inicial & 286 & 44.996 & 1.673 & 117 & 22.178 & 809 & 169 & 22.818 & 864 \\
\hline Ciclo jardín maternal & 27 & 988 & 53 & 2 & 54 & 3 & 25 & 934 & 50 \\
\hline Ciclo jardín de infantes & 286 & 44.008 & 1.620 & 117 & 22.124 & 806 & 169 & 21.884 & 814 \\
\hline Dirección de Educación Primaria Básica & 328 & 163.615 & 5.835 & 208 & 106.590 & 4.038 & 120 & 57.025 & 1.797 \\
\hline EGB $\left(1^{\circ} Y 2^{\circ}\right.$ ciclo $)$ & 328 & 156.330 & 5.554 & 208 & 103.640 & 3.910 & 120 & 52.690 & 1.644 \\
\hline $\operatorname{EGB}\left(3^{\circ}\right.$ ciclo) & 62 & 7.285 & 281 & 23 & 2.950 & 128 & 39 & 4.335 & 153 \\
\hline Dirección de Secundaria Básica & 249 & 64.020 & 2.234 & 171 & 48.020 & 1.712 & 78 & 16.000 & 522 \\
\hline Dirección de Educación Polimodal y TाP & 155 & 63.730 & 2.165 & 64 & 44.295 & 1.514 & 91 & 19.435 & 651 \\
\hline Polimodal (3 años) & 152 & 50.785 & 1.762 & 62 & 31.978 & 1.129 & 90 & 18.807 & 633 \\
\hline Polimodal ( 4 años vespertino/nocturno) & 6 & 650 & 26 & 6 & 650 & 26 & 0 & 0 & 0 \\
\hline Bachillerato y/o técnico nocturno para adultos & 42 & 8.667 & 259 & 39 & 8.324 & 250 & 3 & 343 & 9 \\
\hline Cursos de formación profesional de polimodal & 1 & 129 & 6 & 1 & 129 & 6 & 0 & 0 & 0 \\
\hline EGB 3 en escuelas Agro-Técnicas & 12 & 3.499 & 112 & 10 & 3.214 & 103 & 2 & 285 & 9 \\
\hline Dirección de Educación Superior & 23 & 8.313 & 239 & 6 & 4.793 & 125 & 17 & 3.520 & 114 \\
\hline Carreras de grado de SNU & 23 & 8.122 & 232 & 6 & 4.602 & 118 & 17 & 3.520 & 114 \\
\hline Cursos de SNU & 2 & 191 & 7 & 2 & 191 & 7 & 0 & 0 & 0 \\
\hline Dirección de Adultos y Formación Profesional & 109 & 13.090 & 327 & 108 & 12.941 & 327 & 1 & 149 & 0 \\
\hline EGB para adultos (EGBA) & 93 & 6.252 & 268 & 93 & 6.252 & 268 & 0 & 0 & 0 \\
\hline Bachillerato en CENS & 7 & 2.102 & 59 & 7 & 2.102 & 59 & 0 & 0 & 0 \\
\hline Cursos de formación profesional en centros de & 9 & 4.736 & 0 & 8 & 4.587 & 0 & 1 & 149 & 0 \\
\hline Dirección de Educación Especial & 30 & 5.018 & 0 & 21 & 3.896 & 0 & 9 & 1.122 & 0 \\
\hline Dirección de Educación Artóstica & 2 & 1.807 & 82 & 2 & 1.807 & 82 & 0 & 0 & 0 \\
\hline Dirección de Psicología y Asistencia S. E. & 3 & 595 & 27 & 2 & 430 & 19 & 1 & 165 & 8 \\
\hline Dirección de Educación Física & 3 & 4.984 & 248 & 3 & 4.984 & 248 & 0 & 0 & 0 \\
\hline
\end{tabular}

Fuente: Dirección de Información y Estadistica - Relevamiento Anual 2007 
Recurrir a los dispositivos de información como Mapa y Cédula, así como la estadística que con ellos es posible construir, permite saber, entre otras cosas, que La Matanza es el distrito más poblado de la provincia de Buenos Aires, con 1.255.288 de acuerdos a los datos del Censo Nacional de Población 2001, supera en población a la mayoría de las provincias argentinas y con indicadores de pobreza de los más altos del país.

En el Conurbano Bonaerense la población bajo la línea de pobreza se incrementó en más de seis (6) puntos porcentuales entre octubre de 1995 y mayo de 2000. Cabe resaltar que el crecimiento más pronunciado (aproximadamente cuatro puntos porcentuales) se produce entre octubre de 1999 y mayo de 2000 [...]

Si se observan las cifras correspondientes al total de aglomerados urbanos del país, incluidos en la Encuesta Permanente de Hogares, se advierte que la población por debajo de la línea de pobreza pasó del 34,0\%, en octubre de 1995 al 35,0\% en mayo de 2000, lo que arroja una diferencia de un (1) punto porcentual.

En síntesis, si bien el incremento de la pobreza constituye un proceso generalizado, ha tenido mayor impacto en el Conurbano Bonaerense, siendo este el aglomerado que muestra las mayores diferencias en el período considerado. ${ }^{65}$

Si se observa el gráfico "Establecimientos, alumnos y secciones de La Matanza", los 27 Jardines Maternales y los 286 Jardines de Infantes de los que se da cuenta en La Matanza, pueden parecer muchos. Ahora bien, esta información por sí misma no es significativa, si no es posible cruzarla con datos de la ubicación geográfica de esos establecimientos, así como considerar otros indicadores socio-demográficos. Sabiendo que Nancy vive en Virrey del Pino, el Mapa Escolar resulta revelador en cuanto al déficit de Jardines en esa zona, tal como se puede apreciar en el gráfico realizado mediante la herramienta del dispositivo de acercamiento para ampliar un área en particular, en este caso el partido de La Matanza.

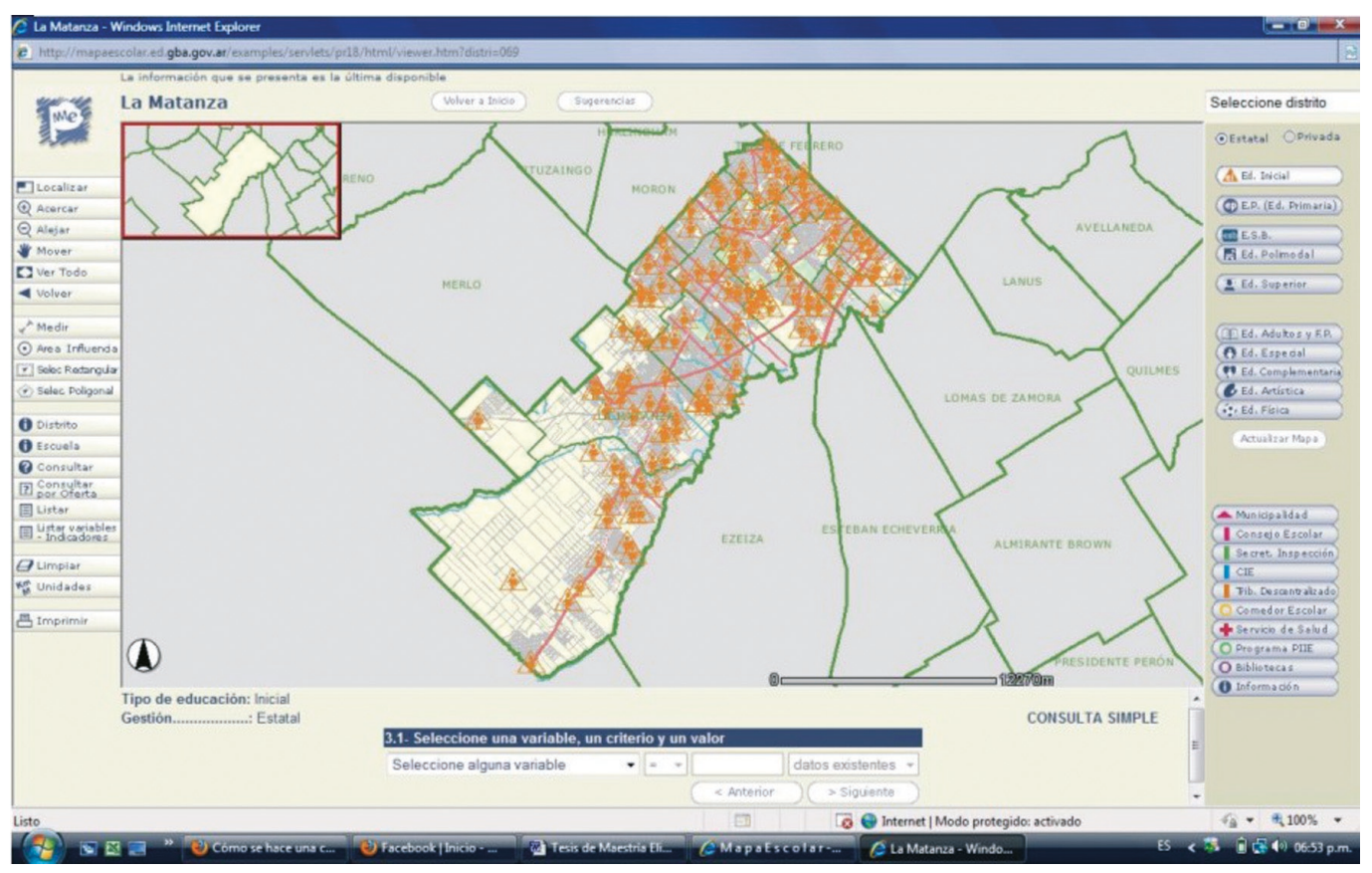

65 Educación y Pobreza. Informe sobre la situación social y educativa de la población. Estudio N 1, Dirección de Información y Estadística, Área Proyectos, mayo 2000, en http://abc.gov.ar/lainstitucion/organismos/informacionyestadistica/otraspublicaciones/ documentosdescarga/informe04.pdf. 
Del relato que hace esta madre respecto a la situación de sus hijos mayores y la situación laboral de la pareja, surgen las implicaciones concretas en la vida de una familia bonaerense de lo que se lee en el siguiente cuadro, en cuanto a la vinculación entre la asistencia escolar y la actividad. ${ }^{66}$

¿Pero qué se hace con toda esta información para dar una respuesta a esta y a todas las familias a las que el Estado no les está garantizando sus derechos? Durante la gestión de PuIGGRós se inauguraron 35 jardines en ese municipio.

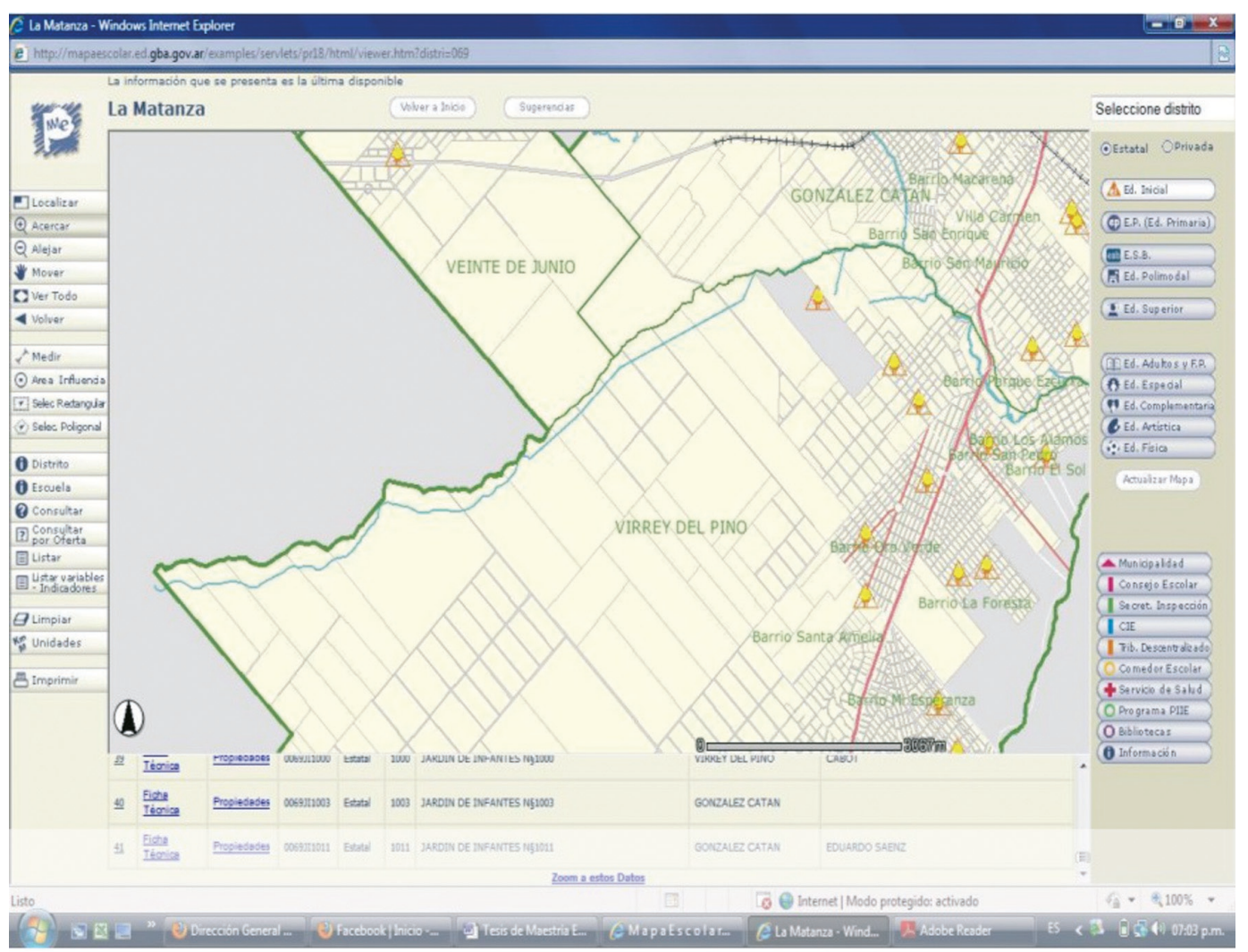

Ampliación área Virrey del Pino, La Matanza, efectuada con la herramienta Mapa Escolar

En tal sentido, como ilustra la siguiente nota, la política comunicacional no sólo implicó el uso de las TIC y los dispositivos informáticos para relevar la información y tomar, en ese caso, las decisiones en materia de inclusión, sino también para darlas a conocer a la opinión pública. La opinión pública, categoría abstracta en cierta forma, es también esta madre y esta familia concreta de La Matanza que además de la necesidad de satisfacer una demanda justa y de derecho, necesita conocer qué se hizo (o no se hizo) para dar respuesta a su problema.

\section{La provincia de Buenos Aires cuenta con 35 nuevos jardines de infantes}

La directora general de Cultura y Educación de la provincia de Buenos Aires, Adriana Puiggrós, inauguró días atrás unos 35 edificios de ese nivel escolar distribuidos en gran parte del conurbano bonaerense. La Matanza, Florencio Varela, Moreno, Lomas de Zamora y Lanús son algunos de los lugares que cuentan con nuevos jardines de infantes. "Es una responsabilidad del Estado atender a los niños pequeños, y no sólo cuidarlos, sino 
también posibilitarles el acceso a los libros, a los juegos, a las herramientas de aprendizaje, enseñarles y socializarlos en un clima de diálogo y cariño, y eso es justamente lo que brindan las instituciones educativas de nivel inicial", explicó Puiggrós.

En La Matanza se inauguraron 7 edificios; 2 en Almirante Brown; 1 en Berazategui; 1 en Escobar, 2 en Florencio Varela; 4 en José C. Paz; 1 en Lanús; 1 en Lomas de Zamora; 2 en Malvinas Argentinas; 4 en Merlo; 3 en Moreno; 3 en Pilar; 2 en Presidente Perón; 1 en Quilmes y 1 en San Nicolás.

"Más de la mitad de la educación preescolar está a cargo del Estado provincial y ya se alcanzó una cobertura de más del 90 por ciento de las salas de cinco años", señaló la funcionaria quien agregó que "además de la presencia del Estado, en todos los distritos hay establecimientos de educación privada y otros muchos creados por los propios vecinos y organizaciones sociales". ${ }^{67}$

2003 - Población de 14 a 18 años. Asistencia Escolar y condición de actividad. Total aglomerados Provincia de Buenos Aires. EPH, 2003

\begin{tabular}{|l|c|c|c|c|c|c|}
\hline \multirow{2}{*}{ Ocupación } & \multicolumn{4}{|c|}{ Asistencia } & \multicolumn{2}{c|}{ Total 2003} \\
\cline { 2 - 7 } & \multicolumn{2}{|c|}{ Asiste } & No asiste pero asistió & \multicolumn{2}{c|}{} \\
\cline { 2 - 7 } & Abs. & $\%$ & Abs. & $\%$ & Abs. & $\%$ \\
\hline Ocupado & 30.093 & $2,6 \%$ & 30.216 & $2,7 \%$ & 60.309 & $5,3 \%$ \\
\hline Desocupado & 10.507 & $0,9 \%$ & 64.857 & $5,7 \%$ & 75.364 & $6,6 \%$ \\
\hline Inactivo & 937.326 & $82,3 \%$ & 65.961 & $5,8 \%$ & 1.003 .287 & $88,1 \%$ \\
\hline Total & $\mathbf{9 7 7 . 9 2 6}$ & $\mathbf{8 5 , 9} \%$ & $\mathbf{1 6 1 . 0 3 4}$ & $\mathbf{1 4 , 1 \%}$ & $\mathbf{1 . 1 3 8 . 9 6 0}$ & $\mathbf{1 0 0 \%}$ \\
\hline
\end{tabular}

Los porcentajes se calculan sobre el total de la muestra.

\begin{tabular}{|l|c|c|c|c|c|c|}
\hline \multirow{2}{*}{ Ocupación } & \multicolumn{4}{|c|}{ Asistencia } & \multicolumn{2}{c|}{ Total 2003} \\
\cline { 2 - 6 } & \multicolumn{2}{|c}{ Asiste } & No asiste pero asistió & \multicolumn{2}{c|}{} \\
\cline { 2 - 6 } & Abs. & $\%$ & Abs. & $\%$ & Abs. & $\%$ \\
\hline Ocupado & 30.093 & $3,1 \%$ & 30.216 & $18,8 \%$ & 60.309 & $5,3 \%$ \\
\hline Desocupado & 10.507 & $1,1 \%$ & 64.857 & $40,3 \%$ & 75.364 & $6,6 \%$ \\
\hline Inactivo & 937.326 & $95,8 \%$ & 65.961 & $41,0 \%$ & 1.003 .287 & $88,1 \%$ \\
\hline Total & $\mathbf{9 7 7 . 9 2 6}$ & $\mathbf{1 0 0 , 0} \%$ & $\mathbf{1 6 1 . 0 3 4}$ & $\mathbf{1 0 0 , 0} \%$ & $\mathbf{1 . 1 3 8 . 9 6 0}$ & $\mathbf{1 0 0 \%}$ \\
\hline
\end{tabular}

Los porcentajes se calculan en función a la asistencia escolar.

\section{Promoción, repitencia y abandono en los totales provinciales}

En la presentación ante los legisladores en 2006, otra de las cuestiones significativas que mencionó PuIgGrós fue que

La inclusión comprende el acceso a los saberes y a los valores que la sociedad prescribe y selecciona en su currículum histórico, social y futuro. Desde el 2005 se dispuso que se permita la matriculación a todos los niños aunque no tuvieran la documentación requerida. Para responder a este mandato de inclusión, apuntamos a que la escuela sea un lugar amigable para los alumnos, donde tengan la oportunidad de experimentar su dignidad sintiéndose valiosos, valorados y útiles. En este contexto de bienestar y de cuidado, el interés por educarse se irá consolidando y tornando habitual. ${ }^{68}$

También planteó como tema de interés jerarquizar la formación y capacitación de los docentes, y destacó en ese sentido la capacitación gratuita, en servicio y con puntaje de 98.000 docentes

67 Esta noticia, además de aparecer en los medios privados, se incorporó, al igual que muchas otras, en el sitio de la Dirección de Prensa y Comunicación de la DGCyE, en http://abc.gov.ar. En este caso, se la toma del Portal Educ.ar, que, a su vez, la reprodujo de su fuente original. Cfr. http://portal.educ.ar/noticias/educacion-y-sociedad/la-provincia-de-buenos-aires-c-1.php.

68 http://abc.gov.ar/lainstitucion/noticiasdeladgcye/ 
mediante diversos programas; la prolongación a cuatro años en la formación de grado y el proyecto, de creación de una Universidad Pedagógica Provincial (plasmada luego en la sanción de Ley 13.511/06), que es la primera experiencia de universidad exclusivamente para los docentes del país.

En cuanto a los destinatarios del proyecto político-pedagógico, PuIGGRós afirmó que "Este proyecto responde a necesidades fuertemente sentidas por una comunidad de 4.500 .000 de alumnos, 260.000 trabajadores de la educación y cerca de 150.000 estudiantes terciarios." En síntesis, en su informe anual de gestión para los legisladores, la Directora General de Cultura y Educación detalló, entre otros lineamientos generales y cambios que se pretendían producir en el sistema en base a las prioridades del sistema educativo provincial, los siguientes puntos:

- Planeamiento estratégico y prospectivo, vinculado con el desarrollo de la Provincia.

- Justicia social como eje de las políticas sociales en educación y acciones de apoyo a la escolaridad.

- Mejorar la comunicación entre los niveles centrales y las escuelas.

- Producción editorial. Por ejemplo: Textos escolares, revistas Anales de la educación común y Portal Educativo.

En el siguiente Informe de gestión 2006- 2007, presentado ante la Legislatura, se da cuenta de una propuesta de trabajo basada en objetivos tendientes a "fortalecer el lugar de la enseñanza en todas las instituciones dependientes de la misma, lo que incluyó, entre muchas otras acciones, la reforma de la educación secundaria (que se plasmó más adelante en la sanción de la Ley de Educación provincial 13.688/07). Asimismo, tal como estaba previsto en la legislación pero no se había concretado, se comenzó con el proceso de cobertura de cargos directivos mediante pruebas de selección de aspirantes. Así, se activaron los concursos para directores que estaban en etapas diversas de realización en los distintos distritos.

No es competencia de este trabajo desarrollar todas las líneas de acción que en materia de reforma curricular, pedagógica y administrativa se fueron ejecutando. ${ }^{69} \mathrm{En}$ tal sentido, el interés se centra en lo referido a los procesos de comunicación y de producción de información para la toma de decisiones. De todas maneras, vamos a desarrollar algunos aspectos en los que la vinculación entre la decisión político-pedagógica hacia determinados objetivos, y la disposición de los datos adecuados, nos permiten demostrar la vinculación entre uno y otro aspecto. Tal es el caso, por ejemplo, de la Educación Secundaria. A fin de conocer las opiniones de los principales destinatarios y rescatar el valor de la palabra de los sujetos, se realizaron más de diez encuentros durante el transcurso de 2007, que reunieron a más de 5.000 chicos bajo el lema "¿Qué secundaria querés?" y que sirvieron para hacerlos partícipes también del cambio. 


\section{3 - POBLACIÓN DE 14 A 18 AÑOS ASISTENCIA ESCOLAR Y CONDICIÓN DE ACTIVIDAD}

\begin{tabular}{|l|c|c|c|c|c|c|}
\hline \multirow{2}{*}{ Ocupación } & \multicolumn{4}{|c|}{ Asistencia } & \multicolumn{2}{c|}{ Total 2003} \\
\cline { 2 - 5 } & \multicolumn{2}{|c|}{ Asiste } & \multicolumn{2}{c|}{ No asiste pero asistió } & \multicolumn{2}{|c|}{} \\
\cline { 2 - 5 } & Abs. & $\%$ & Abs. & $\%$ & Abs. & $\%$ \\
\hline Ocupado & 30.093 & $49,9 \%$ & 30.216 & $50,1 \%$ & 60.309 & $100 \%$ \\
\hline Desocupado & 10.507 & $13,9 \%$ & 64.857 & $86,1 \%$ & 75.364 & $100 \%$ \\
\hline Inactivo & 937.326 & $93,4 \%$ & 65.961 & $6,6 \%$ & 1.003 .287 & $100 \%$ \\
\hline Total & $\mathbf{9 7 7 . 9 2 6}$ & $\mathbf{8 5 , 9} \%$ & $\mathbf{1 6 1 . 0 3 4}$ & $\mathbf{1 4 , 1 \%}$ & $\mathbf{1 . 1 3 8 . 9 6 0}$ & $\mathbf{1 0 0 \%}$ \\
\hline
\end{tabular}

Todos porcentajes se calculan en función a la condición de actividad.

Nota: Estos datos se obtienen por muestra, por lo tanto en su lectura no debe olvidarse la existencia de intervalos de confianza para cada una de las estimaciones.

Para conocer la realidad de la Provincia y compararla con el total país y otros países, ${ }^{70}$ la Dirección de Información y Estadística responsable de Cédula y Mapa Escolar, realiza un cálculo de las tasas de escolarización ${ }^{71}$ con base en la Encuesta Permanente de Hogares (EPH) del INDEC, en mayo de 2003 y se utiliza este año para que sea coincidente con el año de relevamiento del total país. Así; los porcentajes de alumnos con extraedad (o sobreedad $)^{72}$ en dos o más años (población urbana) están calculados con base en el Relevamiento Censal 2003 de la Dirección de Información y Estadística de la Provincia de Buenos Aires.

No se efectuó el cálculo de la tasa de escolarización para la población urbana de 5 años de la Provincia, dado que el tamaño de la muestra utilizada por la EPH del INDEC no permite una estimación confiable para ese nivel de desagregación (edad individual). Para el total de aglomerados de la población urbana de 6 a 11 años de la Provincia de Buenos Aires, la tasa de escolarización es del 100\%. Para el total país la tasa de escolarización es de 99,5\%; para la población de 6 a 8 y $99,7 \%$ para el grupo de 9 a 11 años. Con ello, podemos afirmar que la Provincia se encuentra en una situación similar al total país.

Si se compara el porcentaje de alumnos con extraedad en 2 o más años, la situación varía, siendo más favorable la de la Provincia, principalmente en la edad de 9 a 11 donde disminuye cerca de 2 puntos respecto del total país. Para el grupo de edad de 12 a 14 años, la tasa de escolarización provincial es del $99,5 \%$ y la del total país es del $99 \%$. Como puede observarse, aquí tampoco encontramos fuertes variaciones. Nuevamente se observan diferencias en la extraedad, la Provincia tiene un porcentaje de extraedad de $7,1 \%$ mientras que para el total país este indicador asciende a 9,8\%. Por último, en la población urbana de 15 a 17 años, se ve que la situación de los jóvenes y adolescentes bonaerenses es más favorable que la sintetizada en las tasas de escolarización

70 Indicadores educativos, comparación de 13 países latinoamericanos y Provincia de Buenos Aires. Dirección de Información y Estadística. Dirección Provincial de Planeamiento. Dirección de Información y Estadística. Dirección General de Cultura y Educación. Provincia de Buenos Aires.

71 Tasa de escolarización: es la cantidad de matriculados en un nivel de educación, pertenezcan o no al grupo de edad correspondiente a ese nivel, expresada como porcentaje del total de la población del grupo de edades correspondientes a ese nivel. Fuente: PNUD. 1997

72 Sobreedad: son los alumnos que tienen más edad que la considerada técnicamente ideal* según las normas legales de acceso al sistema educativo con respecto al año que cursa. *Años cumplidos al 30 de junio del calendario. Fuente: Definiciones Básicas para la producción de Estadísticas Educativas; Dirección Nacional de Información y Evaluación de la Calidad Educativa. Ministerio de Educación, Ciencia y Tecnología - Dirección de Información y Estadística. Dirección Provincial de Planeamiento. DGCyE. Provincia de Buenos Aires. 
de total país. En el total país, la tasa es de $87,4 \%$, mientras que el total de aglomerados urbanos de la Provincia asciende a $89,8 \%$ de jóvenes que asisten a un establecimiento de educación formal. Las diferencias encontradas respecto de la escolaridad, también se observan dentro del sistema educativo; el porcentaje de alumnos con extraedad en 2 o más años es, para el país, de $26 \%$, mientras que para la Provincia decrece más de la mitad, llegando al 12,4\%. El Plan de Educación de la Provincia abarca el conjunto que fue destinado a guiar las dos gestiones que lo abordaron.

[...] La política educativa que llevamos adelante [...] parte de reconocer que los niños, los adolescentes, los jóvenes, los adultos y los adultos mayores, sujetos que le dan sentido a la educación, registraron en sus cuerpos y en sus saberes, en sus sentimientos y en sus valores, el daño producido por las políticas neoliberales y se dispersaron, y perdieron saberes de sobrevivencia, olvidaron o no alcanzaron a conocer los signos de la Patria que los excluía." 73

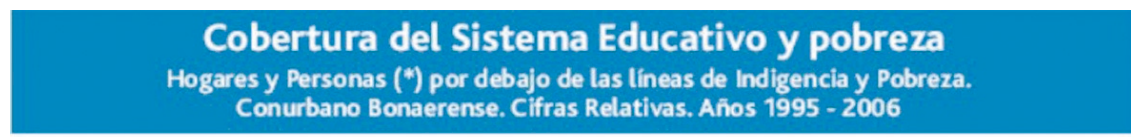

\begin{tabular}{|l|c|c|c|c|}
\hline \multirow{2}{*}{ Año } & \multicolumn{2}{|c|}{ Indigencia } & \multicolumn{2}{c|}{ Pobreza } \\
\cline { 2 - 5 } $\mathbf{1 9 9 5}$ & Hogares & Personas & Hogares & Personas \\
\hline $\mathbf{1 9 9 6}$ & 6,3 & 6,9 & 21,0 & 27,0 \\
$\mathbf{1 9 9 7}$ & 5,4 & 8,8 & 25,3 & 32,7 \\
$\mathbf{1 9 9 8}$ & 5,2 & 6,2 & 24,8 & 32,7 \\
$\mathbf{1 9 9 9}$ & 7,3 & 9,6 & 23,7 & 30,3 \\
\hline $\mathbf{2 0 0 0}$ & 6,6 & 9,0 & 26,1 & 33,0 \\
\hline $\mathbf{2 0 0 1}$ & 9,7 & 13,0 & 29,9 & 35,7 \\
$\mathbf{2 0 0 2}$ & 21,2 & 27,9 & 48,1 & 39,4 \\
\hline $\mathbf{2 0 0 3}$ & 21,4 & 30,4 & 50,5 & 61,3 \\
$\mathbf{2 0 0 4}$ & 13,9 & 12,8 & 39,0 & 40,2 \\
\hline $\mathbf{2 0 0 5}$ & 9,4 & 13,9 & 28,2 & 36,9 \\
$\mathbf{2 0 0 6}$ & 8,3 & 11,4 & 23,5 & 29,7 \\
\hline
\end{tabular}

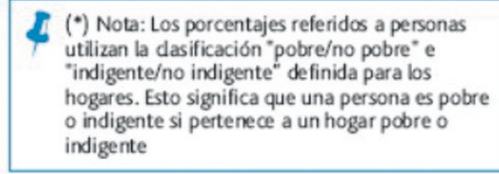

Fuente: Sistematización propia en base a datos def INDEC; EPH, Primer Semestre $1995-2005$

Nota: los porcentajes de personas y hogares bajo la linea de pobreza incluyen la indigencia

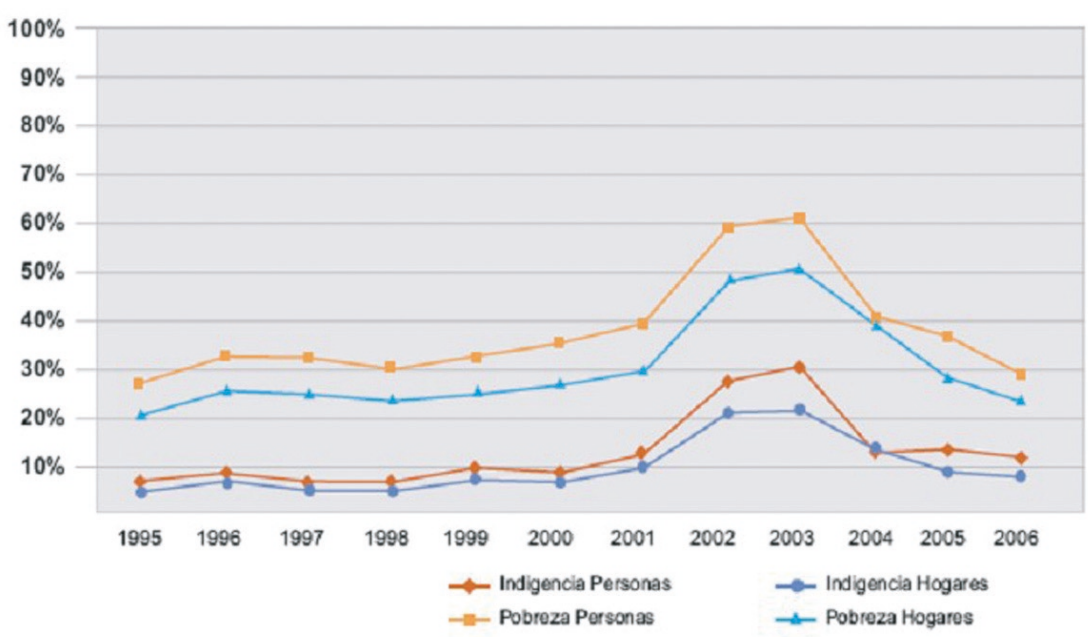

El abrupto incremento de la pobreza e indigencia en 20002003 continúa siendo un enorme desaffo para las

instituciones educativas y los educadores.
Este escenario social demanda una profunda adecuación de las estrategias pedagógicas y de la organización institucional que respondan a estos nuevos problemas. 
En tal sentido, resultaba estratégico disponer de información que diera cuenta de la realidad de estos sujetos destinatarios de nuestra política. ¿Cuál era entonces el mapa de la pobreza en nuestro país? ${ }^{74}$
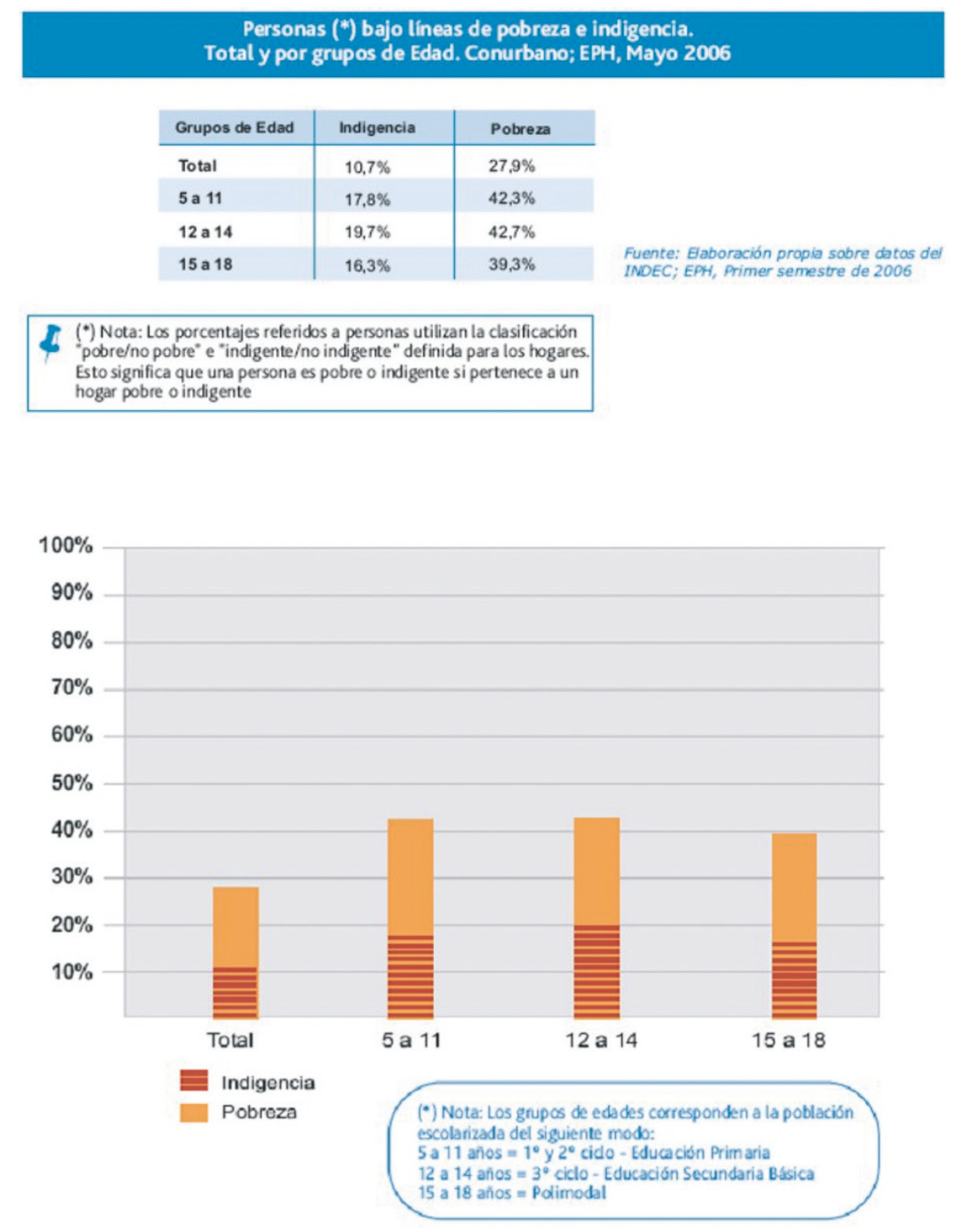

Alarmante: Si bien el porcentaje total de personas baja la linea de pobreza e indigencia ha disminuido en los dos últimos años notablemente, 4 de cada 10 niños que están en edad de asistir al sistema de educación formal son pobres o indigentes.

Como fácilmente se puede deducir de los gráficos que ilustran este capítulo, la inclusión no sólo es una categoría ordenadora del conjunto de la política educativa actual, en particular en los criterios nacionales y provinciales de educación, sino una verdadera urgencia que se constituyó, como dijimos, en uno de los objetivos primordiales de la política educativa de esa etapa. 


\begin{tabular}{|c|c|c|c|c|c|}
\hline \multicolumn{6}{|c|}{$\begin{array}{l}\text { Tasas de escolarizació } \\
\text { Total Aglomerados } \mathrm{Pr}\end{array}$} \\
\hline Año & Total & 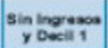 & $\begin{array}{l}\text { Decclles } \\
2 y^{3}\end{array}$ & Doclles & $\begin{array}{l}\text { Docillos } \\
9 \times 10\end{array}$ \\
\hline 1995 & $99,3 \%$ & $98,5 \%$ & $99,9 \%$ & $99,2 \%$ & $100,0 \%$ \\
\hline 1996 & $99,8 \%$ & $99,6 \%$ & $99,9 \%$ & $100,0 \%$ & \\
\hline 1997 & $99,3 \%$ & $.1 \%$ & $99,4 \%$ & $99,4 \%$ & \\
\hline 1998 & $99,5 \%$ & $99.1 \%$ & $99,7 \%$ & $99,7 \%$ & \\
\hline 1999 & $99,4 \%$ & $99,0 \%$ & $99,0 \%$ & $99.8 \%$ & $100,0 \%$ \\
\hline 2000 & $99,2 \%$ & $98,2 \%$ & $99,7 \%$ & $99,4 \%$ & $100,0 \%$ \\
\hline 2001 & $99,2 \%$ & $98,6 \%$ & $99,2 \%$ & $99.7 \%$ & $100,0 \%$ \\
\hline 2002 & $99,7 \%$ & $99,7 \%$ & $100,0 \%$ & $99,7 \%$ & $100,0 \%$ \\
\hline 2003 & $100,0 \%$ & $100,0 \%$ & $100,0 \%$ & $99,8 \%$ & $100,0 \%$ \\
\hline 2004 & $98,9 \%$ & $99,4 \%$ & $98,6 \%$ & $99,0 \%$ & $100,0 \%$ \\
\hline 2005 & $98,3 \%$ & $96,4 \%$ & $98,9 \%$ & $98,6 \%$ & $100,0 \%$ \\
\hline 2006 & $99,4 \%$ & $100 \%$ & $99,5 \%$ & $99,3 \%$ & $100,0 \%$ \\
\hline
\end{tabular}

Escolarización

Tasas de escolarización, según deciles de ingreso familiar per cápita.

\begin{tabular}{|c|c|c|c|c|c|}
\hline \multicolumn{6}{|c|}{ Población de 5 a 11 affos } \\
\hline Año & Total & 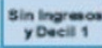 & $\begin{array}{c}\text { Decllos } \\
2 y^{2}\end{array}$ & $\begin{array}{l}\text { Decllos } \\
4: 8\end{array}$ & $\begin{array}{l}\text { Docellos } \\
9 \text { y } 10\end{array}$ \\
\hline 1995 & $96,8 \%$ & $93,1 \%$ & $99,0 \%$ & $98,6 \%$ & $100,0 \%$ \\
\hline 1996 & $96,5 \%$ & $92,1 \%$ & $97,8 \%$ & $98,4 \%$ & $100,0 \%$ \\
\hline 1997 & $96,4 \%$ & $93,0 \%$ & $97,9 \%$ & $97,6 \%$ & $100,0 \%$ \\
\hline 1998 & $98,0 \%$ & $96,5 \%$ & $99,2 \%$ & $98,6 \%$ & $99,6 \%$ \\
\hline 1999 & $98.2 \%$ & $97,2 \%$ & $97,9 \%$ & $99,4 \%$ & $100,0 \%$ \\
\hline 2000 & $97,5 \%$ & $95,5 \%$ & $97,4 \%$ & $98.7 \%$ & $100,0 \%$ \\
\hline 2001 & $98.1 \%$ & $97,0 \%$ & $98,0 \%$ & $99,0 \%$ & $100,0 \%$ \\
\hline 2002 & $99,0 \%$ & $99.0 \%$ & $99,1 \%$ & $99,0 \%$ & $100,0 \%$ \\
\hline 2003 & $98.8 \%$ & $97,0 \%$ & $98,6 \%$ & $99,8 \%$ & $100,0 \%$ \\
\hline 2004 & $97,5 \%$ & $95,3 \%$ & $97,9 \%$ & $98,5 \%$ & $100,0 \%$ \\
\hline 2005 & $97,0 \%$ & $93,5 \%$ & $97,2 \%$ & $98,3 \%$ & $97,1 \%$ \\
\hline 2006 & $98,5 \%$ & $97,8 \%$ & $99,6 \%$ & $99,3 \%$ & $98,1 \%$ \\
\hline
\end{tabular}

(Nota: la diferencia de este cuadro con el anterior muestra la evoludón de la incorporación de la sala de dinco años)

\section{Población de 12 a 14 afios}

\begin{tabular}{|c|c|c|c|c|c|}
\hline Año & Total & 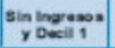 & $\begin{array}{c}\text { Declles } \\
2 \text { y } 3\end{array}$ & $\begin{array}{l}\text { Decilles } \\
4 \text { a } 8\end{array}$ & $\begin{array}{l}\text { Decillos } \\
9 \text { y } 10\end{array}$ \\
\hline 1995 & $90,2 \%$ & $82,9 \%$ & $90,4 \%$ & $94,8 \%$ & $95,2 \%$ \\
\hline 1996 & $89,2 \%$ & $84,9 \%$ & $92,0 \%$ & $92,4 \%$ & $100,0 \%$ \\
\hline 1997 & $95,4 \%$ & $89,9 \%$ & $95.5 \%$ & $98,4 \%$ & $100,0 \%$ \\
\hline 1998 & $98,8 \%$ & $98,4 \%$ & $98,0 \%$ & $99,3 \%$ & $100,0 \%$ \\
\hline 1999 & $97,7 \%$ & $95,4 \%$ & $97,3 \%$ & $98,7 \%$ & $100,0 \%$ \\
\hline 2000 & $98,3 \%$ & $95,4 \%$ & $99,5 \%$ & $100,0 \%$ & $100,0 \%$ \\
\hline 2001 & $97,6 \%$ & $98,2 \%$ & $97.5 \%$ & $97,9 \%$ & $99,1 \%$ \\
\hline 2002 & $98.7 \%$ & $99,1 \%$ & $97.9 \%$ & $98,7 \%$ & $100,0 \%$ \\
\hline 2003 & $99.5 \%$ & $98.0 \%$ & $99,7 \%$ & $100,0 \%$ & $100,0 \%$ \\
\hline 2004 & $97,2 \%$ & $94,8 \%$ & $97.1 \%$ & $98,7 \%$ & $100,0 \%$ \\
\hline 2005 & $96,4 \%$ & $93,8 \%$ & $98,3 \%$ & $97,4 \%$ & $93,4 \%$ \\
\hline 2006 & $99,3 \%$ & $98,6 \%$ & $99,1 \%$ & $100,0 \%$ & $100,0 \%$ \\
\hline
\end{tabular}

\section{Población de 15 a 18 affos}

\begin{tabular}{|c|c|c|c|c|c|}
\hline An̂̃o & Total & $\begin{array}{c}\text { Sn ingevas } \\
\text { youell } 1\end{array}$ & $\begin{array}{c}\text { Deelles } \\
2 y^{3}\end{array}$ & $\begin{array}{l}\text { Decelles } \\
4 \text { as }\end{array}$ & $\begin{array}{l}\text { Deelles } \\
\text { ox } 10\end{array}$ \\
\hline 1995 & $60,7 \%$ & $40,3 \%$ & $48,5 \%$ & $68,7 \%$ & $97,1 \%$ \\
\hline 1996 & $59,8 \%$ & $37,1 \%$ & $58,2 \%$ & $69.7 \%$ & $97,6 \%$ \\
\hline 1997 & $64,9 \%$ & $43,0 \%$ & $57,9 \%$ & $75,5 \%$ & $85,9 \%$ \\
\hline 1998 & $69,7 \%$ & $61,2 \%$ & $66,3 \%$ & $74,7 \%$ & $91,4 \%$ \\
\hline 1999 & $75.7 \%$ & $69,2 \%$ & $72,8 \%$ & $82,3 \%$ & $96,2 \%$ \\
\hline 2000 & $73.8 \%$ & $64,0 \%$ & $75,4 \%$ & $75,2 \%$ & $94,1 \%$ \\
\hline 2001 & $74.7 \%$ & $65,6 \%$ & $73,1 \%$ & $76,5 \%$ & $91,6 \%$ \\
\hline 2002 & $80,8 \%$ & $72,5 \%$ & $78,9 \%$ & $84,2 \%$ & $93,8 \%$ \\
\hline 2003 & $80,0 \%$ & $72.0 \%$ & $76,9 \%$ & $82,0 \%$ & $98,6 \%$ \\
\hline 2004 & $79,3 \%$ & $67,6 \%$ & $74,8 \%$ & $86,9 \%$ & $98,0 \%$ \\
\hline 2005 & $78,7 \%$ & $75.2 \%$ & $73.7 \%$ & $80,9 \%$ & $98,7 \%$ \\
\hline 2006 & $79,8 \%$ & $76,0 \%$ & $75,5 \%$ & $84,5 \%$ & $89,2 \%$ \\
\hline
\end{tabular}

(*) Fuente: Elaboración propia sobre datos del INDEC; EPH, Primer Semestre 2006. Induye los agiomerados de Conurbano, Gran La Pata, Bahía Blanca, Mar del Plata

Nota: Estas tasas de escolarizadón se obtienen por muestra, por lo tanto, en su lectura no debe olvidarse la existencia de intervalos de confiarza para cada una de las estimaciones.

Pese al alarmante incremento de niños y jóvenes en situación de pobreza se han mantenido las tasas de escolarización, lo que denota la permanencia de los sectores más desfavorecidos en el sistema educativo.

Esto nos permite afirmar que el sisterna educativo provindial está sosteniendo con mucho esfuerzo la cobertura lograda en los últimos años. Esto puede verse especialmente en el incremento de las tasas de escolarización en 2006, y en especial de los más pobres (sin ingreso y decil 1).

Un incremento significativo en la escolaridad se observa en el grupo de 12 a 14 años, que venía desde 2003 disminuyendo la tasa de escolarización, alcanzando en 2006 valores superiores a lo histórico. A pesar de esto, continúa siendo señal de alerta el grupo de edad de 15 a 18 años. 


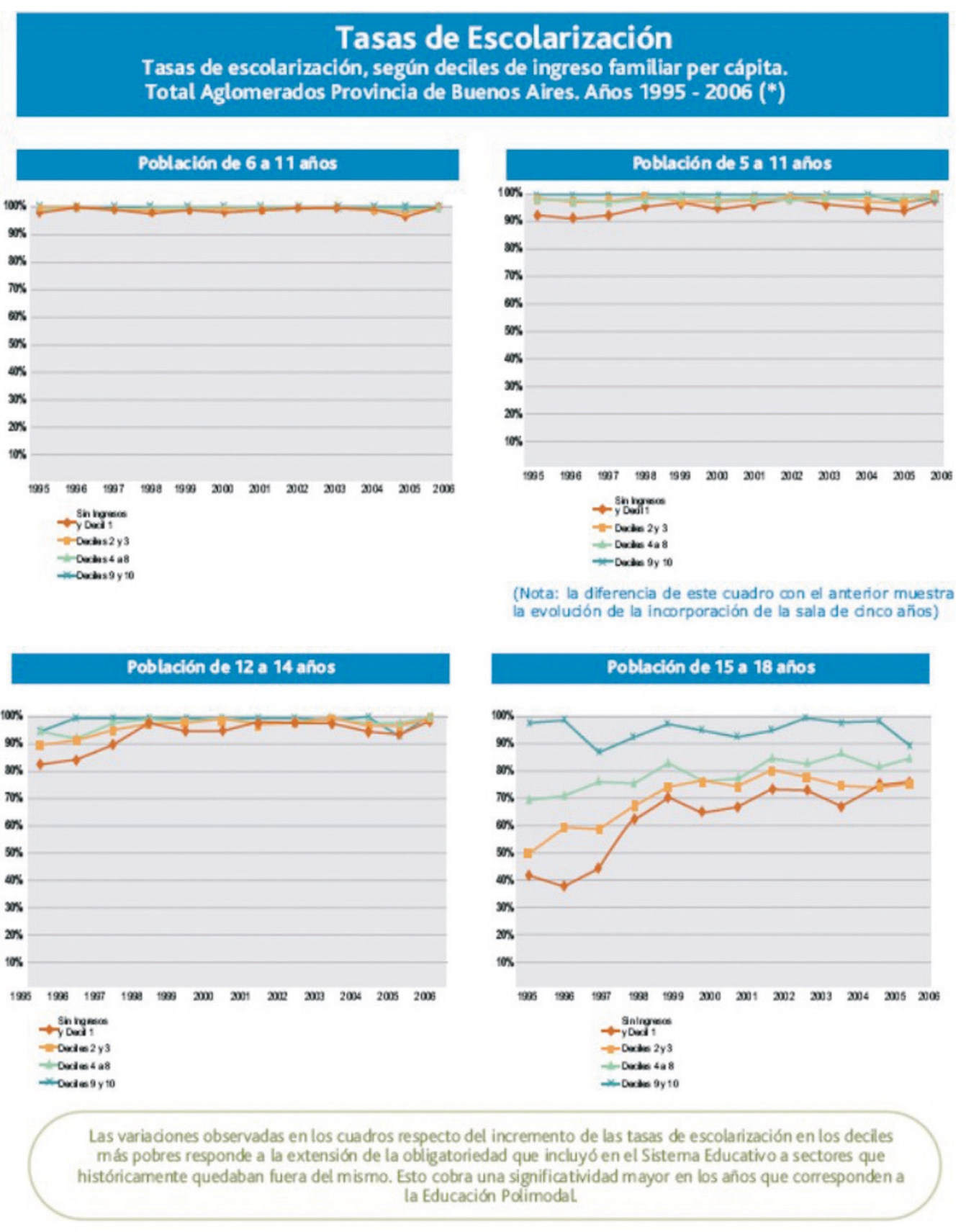

En el mencionado Informe ante los legisladores se destaca que

Sin embargo, la estrategia más vigorosa para la inclusión es, precisamente [...] la reforma del sistema educativo, que hemos comenzado de acuerdo a las nuevas leyes [...]: la extensión de la obligatoriedad escolar desde los 4 años de edad hasta el término de la escuela secundaria, que establece la Ley de Educación Provincial (LEP); la reconstrucción de la escuela secundaria de seis años y de la educación técnica, profesional y agraria; la aplicación de los nuevos diseños curriculares en los que están inscriptas las Modalidades; la capacitación docente gratuita, en servicio, con puntaje.

Estas son algunas de las tareas que hemos emprendido y que constituyen políticas de Estado cuya continuidad es indispensable, ya que de desestimarlas estaríamos provocando un doloroso e injusto retroceso que ya fue rechazado por la comunidad educativa cuando expresó su apoyo a las políticas que ha puesto en marcha el Gobierno.

Desde ya que tanto la reforma pedagógica, como la reforma administrativa y de la gestión que la acompañan, están aún en pleno desarrollo y se requiere de algunos años más para alcanzar su plena expansión.

En tal sentido, por dar un ejemplo, la transparencia y consolidación de la planta de 
personal docente, administrativa y auxiliar, es muy significativa, así como la mejora en la intervención de los organismos de control. Este modo de funcionamiento ha permitido mejorar el uso de los fondos públicos. Lograr la difícil relación entre democracia y eficiencia en una gestión es un proceso que requiere invertir mucha creatividad y capacidad políticotécnica.

Quiero destacar la participación activa de los docentes en las comisiones de cogestión y en las convenciones colectivas de trabajo y de los trabajadores de la Ley $N^{\circ} 10.430$ (administrativos y auxiliares) con sus permanentes demandas y sugerencias; de los distintos sectores de trabajadores organizados en las centrales obreras (CGT y CTA), y de las organizaciones sociales de trabajadores desocupados y subocupados, que cooperan con los organismos de gestión de la DGCYE. Así como también la participación de las organizaciones empresariales en el Consejo Provincial de Educación y Trabajo. Falta recorrer un largo camino que no podrá carecer de conflictos pero que cuenta con instrumentos legales y culturales para encaminarse democráticamente.

Otra medida tendiente a la inclusión, estuvo dada por la

La posibilidad de continuidad de los estudios, sin que existan circuitos terminales, garantizando el tránsito vertical y horizontal por el sistema de educación escolar, al cumplir con los requisitos que se fijen para la aprobación de cada segmento formativo, al mismo tiempo que estableciendo estrategias de reconocimiento de los saberes adquiridos en otras prácticas no escolarizadas;

Así como una definición de la calidad "entendida como el cumplimiento de los anteriores enunciados y de la transmisión de los principios científicos y tecnológicos y de lenguajes que presiden la producción cultural en el más alto nivel contemporáneo." A lo que se agrega la consideración del acceso irrestricto a la información pública "en tanto derecho consagrado constitucionalmente, inalienable y necesario para el libre ejercicio de la ciudadanía, la transmisión social de la cultura y el cumplimiento de los principios anteriores." 75

\section{5.i) Institucionalización del Mapa Escolar y la Cédula Escolar ${ }^{76}$}

Durante el período abril 2002-abril 2003 los proyectos de Cédula Escolar y Mapa Escolar, inicialmente diseñados e implementados en el marco de la Unidad Ejecutora Provincial (UEP), se institucionalizaron en la Dirección de Información y Planeamiento Educativo (DIPE).

Con este fin el personal de planta de la DIPE y los consultores de la UEP se integraron en un único equipo. El trabajo conjunto permitió insertar el uso de nuevas tecnologías de la información a los procesos tradicionales, capacitar y reconfigurar los roles del personal de planta permanente, integrar los datos provenientes de distintos relevamientos en un solo modelo de datos, mejorar los procedimientos para la consistencia de los datos, acortar los tiempos entre el relevamiento de datos y la publicación de información y redefinir las relaciones con los productores y usuarios de información. En síntesis, la institucionalización de los programas Cédula Escolar y Mapa Escolar produjo una reingeniería de la Dirección de Información y Planeamiento Educativo que redundó 
en una mejora sustantiva de los procesos relacionados con la gestión de información.

Para modernizar y adaptar los procedimientos internos de la DIPE al nuevo diseño conceptual y base de datos únicos se renovaron los programas de carga, clasificación, consistencia y anexado de datos. El funcionamiento de la Mesa de Ayuda, de acuerdo al informe 2003,"está totalmente institucionalizado ya que es atendida por personal de la planta permanente de la DIPE. El personal responsable de la atención de la mesa de ayuda no sólo incorporó las tareas originales sino que desarrolló nuevos procedimientos innovadores que perfeccionaron su funcionamiento." 77

En cuanto a la incorporación de la mesa de ayuda, en el mismo Informe y tal como lo recuerda la Lic. Jorgelina SEMINARIO en la entrevista que se le efectuó para esta tesis, se sostiene que ésta "permitió establecer una relación directa con los actores escolares que era inédita en la DIPE. El secretario o director de algún establecimiento que tiene dudas o inconvenientes con el uso del software escolar se comunica con la mesa de ayuda que lo escucha, lo contiene y lo asiste en la solución de sus problemas." Otras variantes de asistencia a los usuarios que consigna el Informe 2002-2003, refieren a:

\section{Soporte telefónico}

Recibe llamadas gratuitas para el usuario (a través de dos líneas 0-800) atendidas de lunes a viernes de 8:00 a 20:00 horas.

Se responden en promedio 477 llamadas por mes referidas a la operatividad del software de Cédula Escolar y otras consultas (certificados de cursos, pedidos de PC, denuncias de robos de PC, fechas de entrega de relevamientos, sugerencias, etc.).

Aquellos problemas que no pueden ser resueltos vía telefónica generan el envío de instructivos especiales, vía e-mail o correo, (reportes corregidos, programa de cambio de clave, envío de bases extraviadas, copias del programa, etc.). Todos los procedimientos se registran en la base de datos de la Mesa de Ayuda.

A las fallas del programa u otros problemas que no tienen una solución estandarizada se los deriva al equipo técnico correspondiente para su solución.

\section{Recepción de notas}

Se reciben un promedio de 367 notas por mes que son clasificadas por problema y registras en la base de datos de la Mesa de Ayuda.

\section{Atención on-line}

Los usuarios del software tienen además la opción del correo electrónico para resolver inquietudes y realizar consultas. Por esta vía también se reciben bases de datos. Se reciben y contestan un promedio de 2033 e-mail por mes.

Sistematización de los requerimientos de nuevas funcionalidades del software y control de calidad de las nuevas versiones

La información obtenida a través de la base de datos de la Mesa de Ayuda, organizada en gráficos, estadísticas e informes, permite analizar las necesidades de los usuarios para desarrollar actualizaciones del software que se adecuen a los requerimientos de los mismos.

A través del trabajo conjunto de los integrantes de la Mesa de Ayuda y especialistas se desarrollan nuevas versiones del software a las que se les aplica un control de calidad (beta test) y se analiza su posterior implementación.

Se amplió la capacitación en el uso de nuevas herramientas de información destinada a los usuarios del sistema Cédula Escolar.

Continuando las tareas y la metodología de capacitación de la etapa de implementación del software de cédula escolar 5 se diseñó un programa de "Herramientas Básicas de Informática y Uso de Información para la Gestión" en el marco de la Red Federal de 
Capacitación. Desde septiembre a diciembre de 2002 se realizaron encuentros de capacitación y asistencia técnica destinados a los secretarios de las escuelas. Los mismos se desarrollaron en cada uno de los distritos y estuvieron a cargo de capacitadores especialmente contratados y entrenados.
Algunos obstáculos a ser subsanados en instancias futuras:
a. Escasa concientización de los Inspectores en cuanto a la Utilidad e importancia de Cédula / Mapa Escolar.
b. Escasa conectividad para la enseñanza de Nivel II (Internet y correo electrónico).
c. Carencia de equipamiento informático y conectividad en los Centros de Investigación
Educativa (CIES), que fueron las unidades operativas de cada distrito.
d. Dificultad para imprimir los certificados por falta de insumos básicos.
e. Problemas administrativos en la contratación y el pago de los capacitadores.
Línea de acción Lugar Fecha Destinatarios Cantidad de destinatarios
Capacitación de capacitadores.

En cuanto a la institucionalización del Mapa dentro de un sistema de información en la Dirección de Información y Planeamiento, el Informe de 2003 destaca que

Tradicionalmente la DIPE sólo manejaba información agrupada al nivel provincial y/o distrital por tipo de educación. Esta información era poco eficiente a la hora de focalizar políticas. El equipo técnico profesional de la Dirección asumió la tarea como un enorme desafío, comprometiéndose y modificando sustancialmente la visión de la gestión de información y conocimiento para la toma de decisiones al tener que pasar del análisis de datos agrupados al análisis por escuela e inclusive por alumno cuando existe la posibilidad de ubicarlo espacialmente, seguir su trayectoria escolar y asociar información pertinente proveniente de otras fuentes.

La modificación del enfoque en la publicación, al pasar del dato agrupado a la información por escuela, repercutió en una redefinición de procedimientos en todos los niveles de la DIPE. Exigió perfeccionar los procesos de carga de datos aumentando las pruebas de consistencia al nivel de cada uno de los establecimientos.

Se definió la circulación de información destinada al GIS y se volcaron los procedimientos a un Manual de Procedimientos.

3- Se trabajó permanentemente con los potenciales usuarios del sistema en la validación de la información existente.

El Mapa Escolar y su aplicativo en Internet están diseñados para atender demandas de información de distintos actores, al nivel escolar, local, regional y provincial: Director General, Consejeros Generales, Subsecretarios, Asesores, Personal Administrativo, Inspectores, Directores de Establecimientos, Consejos Escolares y otros usuarios internos y externos que requieran información educativa de la Provincia, con distintos niveles de agregación.

Para asegurar la sustentabilidad del sistema en la DGCyE se implementaron programas de capacitación para el personal de planta en los procesos de mantenimiento, programación, actualización y manejo integrado de sistemas de información geográfica.

Se capacitó al equipo técnico profesional de la Dirección de Información y Planeamiento Educativo en manejo de sofware Arcview 3.1.

A su vez, el equipo técnico profesional de la Dirección capacitó a asesores, a personal administrativo de distintos organismos centrales de la DGCyE, a inspectores, a personal de los Consejos Escolares y Secretarías de Inspección en el uso de Mapa Escolar en Internet. Este proceso recién se inicia y debe ser profundizado y diseñado como sistema de capacitación permanente debido al dinamismo del sistema educativo. [...].

\section{"Club de Usuarios"}

El "club de usuarios" de información territorial había surgido, al comienzo del proyecto, a partir de la necesidad de contar con información cartográfica digital actualizada al nivel urbano y rural de toda la provincia de Buenos Aires. La existencia de múltiples usuarios de Sistemas de 
costos de dicha información impulsaron el diseño de una estrategia de cooperación que evitase la superposición de tareas y gastos. Oportunamente, el club de usuarios que se rige por los principios básicos de cooperación, integración, excelencia y transparencia en el manejo de información pública, estuvo compuesto por los siguientes organismos:

- Ministerio de Seguridad;

- Ministerio de Desarrollo Humano;

- Ministerio de Asuntos Agrarios y Producción;

- Ministerio de Salud;

- Dirección General de Cultura y Educación;

- Dirección Provincial de Estadísticas y Censos;

- Dirección Provincial de Catastro;

- Dirección Provincial de Geodesia.

\section{Las personas o los actores institucionales involucrados en el circuito de información administrado por la DIPE:}

\section{En el nivel de la institución escolar:}

Los Secretarios y/o Directores como personal responsable de la información de la escuela han tenido oportunidad de capacitación en herramientas básicas de informática y software de Cédula Escolar durante los años 2001 y 2002. Sin embrago, ya en 2003 se daba cuenta de la necesidad de la permanente actualización, el soporte técnico y nuevas capacitaciones debido a los movimientos de personal.

\section{Mónica GonzÁLEZ Gaviola explica que para la capacitación}

El operativo lo armamos con gente que había trabajado en el Censo y que se había ido del INDEC, gente muy capaz: 1 geógrafo, 1 historiador, 1 estadístico, que trabajó en el operativo de campo que fue "palabras mayores". No les pagábamos mucho, a los docentes, les pagábamos sueldo de docentes provinciales, que nos abarataba mucho, porque hacer convenios con las universidades, al menos en ese tiempo, salía muy caro para capacitar. Pero lo de menos es que la Universidad te cobra más, el tema es que no había raport entre los docentes de la provincia y los alumnos en la Universidad....a mi me sorprendió. Yo con eso aprendí un montón, que para capacitación es un mundo, que tenés que ver quién capacita a quien. No hay normas porque no pensás que los pibes de 22 años iban a ser los que mejor interpretaran el dispositivo tecnológico necesario y los objetivos...y los encontramos en los institutos superiores. Todos esos habían sido alumnos de los docentes a los que capacitaron. ${ }^{78}$

\section{En el nivel del distrito:}

Deben ser los Inspectores Jefes e Inspectores de Área, en su rol de supervisión de la gestión escolar, los actores fundamentales para la universalización del programa Cédula Escolar. Si bien se han realizado reiteradas reuniones informativas con los mismos hace falta una capacitación intensiva en el uso de la herramienta y en la importancia del uso de la información para la toma de decisiones para lograr un compromiso más importante en la implementación del programa. Uno de los puntos débiles de la implementación del Programa fue la imposibilidad de realizar esta concientización en las primeras etapas. Esta 
misma concientización en la importancia del uso de la información, que se planteaba en el Informe de 2003, sigue siendo hoy vigente. También se sugería entonces que "Los Institutos Superiores con ofertas curriculares vinculadas a informática, en coordinación con los CIE, deben tener un rol central no sólo en la capacitación sino también en el soporte técnico a los secretarios de establecimientos."79

\section{5.j) ¿Cómo utilizar el Mapa Escolar?}

El Mapa Escolar ubica establecimientos educativos en cartografía digital y los vincula a distintas bases de datos a fin de generar información múltiple y contextualizada geográficamente. Se puede visualizar información del sistema educativo en su contexto geográfico, trabajar con información de distintos tipos de educación y/o gestión, en distintos niveles de agregación (escuela, área, distrito, región, provincia, país), realizar consultas de información simples y complejas, guardar los resultados en archivos de planillas de cálculo e imprimir las tablas y los mapas.

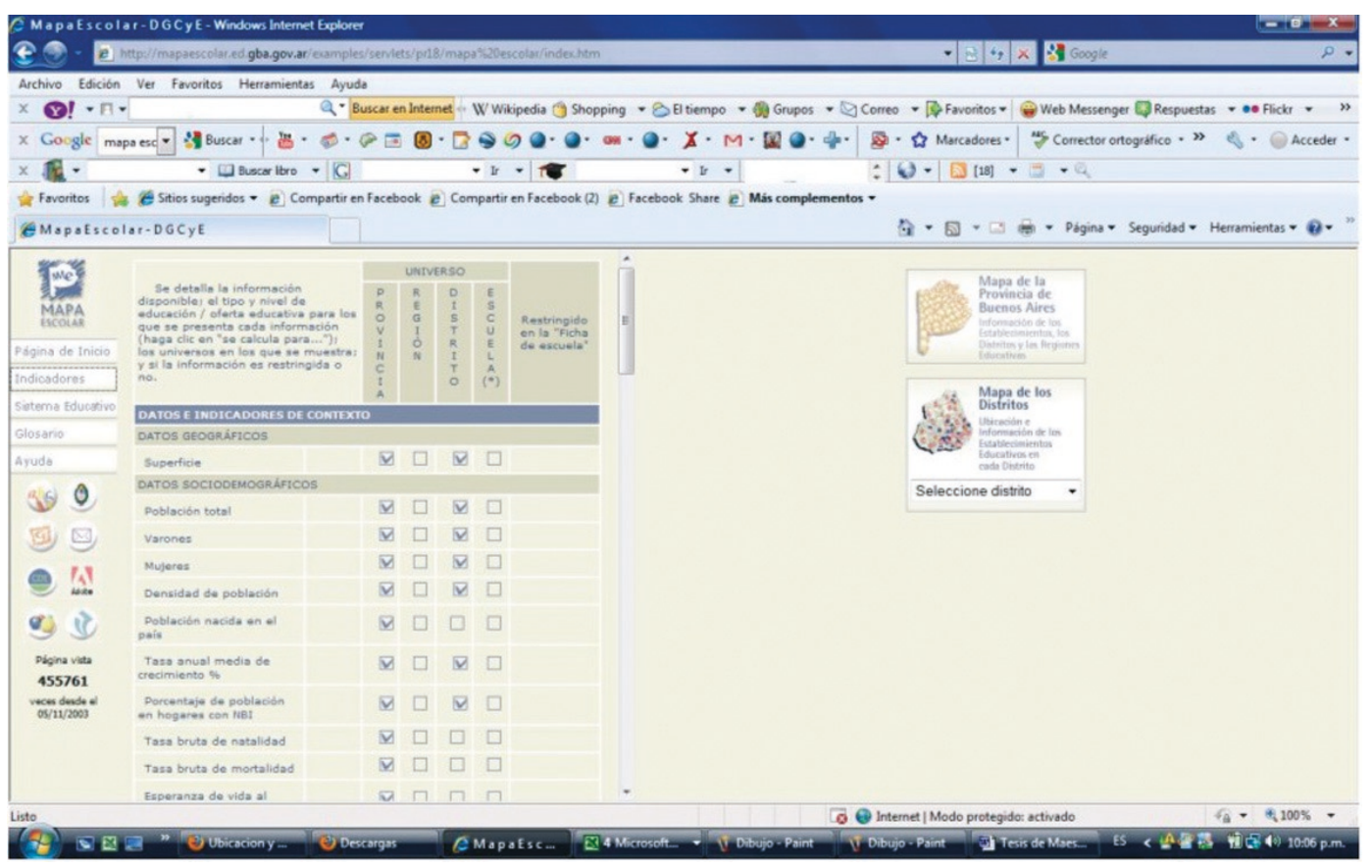

Las operaciones de consulta tienen el mismo grado de complejidad que las de cualquier administrador de bases de datos, con la diferencia de que las respuestas son espaciales y se presentan en formato gráfico. Esto facilita notablemente la comprensión de los análisis de variables múltiples tan importantes para dar cuenta de los complejos procesos que intervienen en el logro de la calidad y la equidad educativas. En cuanto a la información disponible, se destacan:

\section{Datos e indicadores de contexto:}

Se organizan en datos geográficos, sociodemográficos, socioeducativos y socioeconómicos: Superficie, Población total, Varones, Mujeres, Densidad de población, Población nacida en el país, 
Tasa anual media de crecimiento, Porcentaje de población en hogares con NBI, Tasa bruta de natalidad, Tasa bruta de mortalidad, Tasa de analfabetismo, Porcentaje de población que no tiene cobertura por obra social y/o plan de salud privado o mutual, Población ocupada de 14 años y más.

\section{Datos e Indicadores de Educación:}

Se clasifican en organizacionales y de proceso y presenta datos del Servicio Alimentario Escolar a nivel establecimiento: Total de establecimientos, Total de establecimientos con ubicación urbana/rural/sin caracterizar, Total de establecimientos con/sin desfavorabilidad, Total de alumnos, Total de alumnos por año de estudio, Total de secciones/divisiones/grupos, Promedio de alumnos por servicio educativo, Promedio de alumnos por sección/grupo/disciplina, Porcentaje de secciones múltiples, Porcentaje de matrícula estatal, Porcentaje de matrícula privada, Tasa de variación de matrícula, Porcentaje de alumnos extranjeros, Porcentaje de tutores de determinado nivel educativo, Ubicación, Desfavorabilidad, Tasa de promoción efectiva, Tasa de promoción efectiva por año de estudio, Tasa de repitencia, Tasa de repitencia por año de estudio, Tasa de abandono interanual, Tasa de abandono interanual por año de estudio, Tasa de reinscripción, Tasa de reinscripción por año de estudio, Tasa de abandono anual, Tasa de abandono anual por año de estudio, Tasa de pasaje, Tasa de sobreedad. Del Servicio de Alimentario Escolar (SAE): Raciones comedor, Raciones copa de leche, Raciones copa de leche reforzada, Raciones comedor doble, Raciones copa de leche doble, Raciones copa de leche reforzada doble.

¿Cómo se traduce esta información en acciones concretas de gobierno? Un ejemplo ilustrativo se da con los comedores de verano. Todos los años, cuando termina el ciclo lectivo, la DGCYE desarrolla programas y actividades de verano, muchas de las cuales incluyen el Servicio Alimentario Escolar (SAE). Por lo tanto, es indispensable para planificar desde el presupuesto hasta la distribución en el territorio, disponer de esos datos, en distintos niveles: desde cada institución escolar que requiere este servicio, los consejos escolares —en el nivel municipal_; los Inspectores Regionales, responsables de alguna de las 25 regiones en las que se divide la administración del sistema; diversas áreas del gobierno provincial, no sólo la DGCYE, sino el propio Gobernador, el Jefe de Gabinete, los ministerios de Desarrollo Humano y Salud, entre otros, necesitan conocer estos datos para articular políticas y acciones.

Por otra parte, el aspecto de auditoría y control que es fundamental en toda acción de gobierno, también necesita disponer de información precisa y detallada, para evitar un mal uso de los recursos humanos (por ejemplo, la designación del personal auxiliar para la atención de los comedores de verano y del personal docente para la atención de las actividades recreativas de de enseñanza) y de los recursos materiales.

\section{Mapas temáticos:}

Población, Analfabetismo, NBI, Establecimientos, Matrícula, Escuelas de Islas y Detalle de Esc. de Islas, Tasas de promoción efectiva, repitencia, abandono interanual y sobreedad para $1^{\circ}$ y 2 ciclo de educación Primaria (EP) -hoy la educación primaria comprende 6 años-, $3^{\circ}$ ciclo Educación Secundaria Básica (ESB)—hoy Educación Secundaria de 6 años, que incluye el ex Polimodal-y Polimodal (secundario orientado). 


\section{Otra información:}

Municipalidades, Consejos Escolares, Secretarías de Inspección, Centros de Investigación Educativa (CIES), Tribunales descentralizados, Comedores Escolares, Servicios de Salud, Programa Integral para la Igualdad Educativa (PIIE), Programa Aguapey (bibliotecas).

En el nivel del establecimiento:

Ficha técnica del establecimiento educativo seleccionado con información de Clave del establecimiento, Nombre, Gestión, Nivel de educación, Domicilio, Teléfono, Correo Electrónico, RPV, Desfavorabilidad, Ubicación (urbana/rural), Docentes-POF, Relevamientos presentados, Datos e indicadores Educativos, Gráficos de indicadores (Distrito/región/provincia)

\section{Datos de Propiedades:}

en el cual se reiteran datos de denominación del establecimiento que constan en la ficha técnica y se detalla Información de Propiedad del inmueble en el que funciona el establecimiento.

\section{5.k) La aplicación en los cambios de los diseños curriculares}

Con el nuevo marco normativo propuesto por la gestión PUIGGRós, se hizo necesaria la adecuación curricular a la nueva estructura del sistema educativo. Para ello, el aporte de la información provista por estos dispositivos de la información, amén de otros factores, hizo posible un conocimiento más preciso del sistema y la situación socio-demográfica de sus protagonistas.

La diversidad de la Provincia se manifiesta mediante diferentes paisajes y poblaciones, en tanto que sus características y problemáticas han dado lugar a distintos desarrollos locales. En este sentido, los datos cuantitativos nos permiten visualizar su magnitud y complejidad. Es así que, al elaborarse el Marco General para los diferentes Diseños Curriculares, se consideró esa compleja realidad provincial en la que se inscribe el sistema y la reforma, así como también se recurrió a otros insumos estadísticos del orden nacional.

La Provincia tiene una superficie que excede los trescientos mil kilómetros cuadrados, lo que representa el $11 \%$ del territorio nacional. Según los datos del Censo Nacional 2001, se asienta en ella una población de casi catorce millones de habitantes, que constituyen el $38,61 \%$ de la población total del país. Estos habitantes se distribuyen en 134 partidos, de los cuales 24 forman el Gran Buenos Aires también denominado conurbano bonaerense. Esta zona alberga a poco menos de nueve millones de habitantes en 3.627 kilómetros cuadrados. El entramado demográfico del conurbano bonaerense comprende menos del $2 \%$ del territorio provincial, concentra el $60 \%$ de la población y el $70 \%$ de la producción industrial.

Es interesante considerar que el Conurbano forma parte de la denominada Región Metropolitana de Buenos Aires (RMBA), que ofrece la variante de considerar al Conurbano como espacio articulado con la Ciudad Autónoma de Buenos Aires. Así, la RMBA incluye el Área Metropolitana de Buenos Aires (AMBA) -que comprende la Ciudad Autónoma y los 24 partidos del Gran Buenos Aires- y otros partidos ubicados fuera del AMBA pero que tienen fuertes interrelaciones con el resto de la metrópoli. Esta región se caracteriza por las vinculaciones laborales, de servicios, de transporte y de problemáticas sociales específicas. Su urbanización tiende a configurarse en forma de tentáculos, que van del centro hacia fuera, presentando áreas de diversa densidad de población, infraestructura urbana, servicios públicos, que aparecen más consolidados en el centro y más precarios en las periferias.

Para comprender más acabadamente la complejidad del territorio provincial, resulta valioso prestar atención a su producción económica primaria, secundaria y terciaria. En cuanto a la producción primaria -que representa, según datos del año 2006 , el $5 \%$ del total de 
su economía-, se trata de la principal productora agrícola del país: cereales como trigo y maíz, oleaginosas como soja y girasol, hortalizas, además de la ganadería bovina, la pesca, la explotación forestal y la minería; ésta última relacionada, fundamentalmente, con la extracción de insumos para la industria de la construcción. El sector secundario, vinculado con las actividades industriales, representa el $34 \%$ de su economía, concentra el $40 \%$ del total de locales manufactureros de la República Argentina y el $47,9 \%$ del valor bruto industrial nacional. Las principales actividades industriales de la Provincia son: la producción de alimentos y bebidas; la industria siderúrgica y petroquímica; la producción metalmecánica para la elaboración de automóviles, autopartes y maquinaria agrícola; la fabricación de productos plásticos y resinas sintéticas; la producción de químicos y equipamiento hospitalario y la fabricación de textiles e indumentaria.

Por último, el sector terciario -que representa el $61 \%$ del total de su economía- cuenta con actividades relacionadas con la provisión de servicios empresariales, inmobiliarios, de transporte, de almacenamiento, de comunicaciones, de comercio y de turismo.

En cuanto al desarrollo de la infraestructura que da apoyo a sus actividades económicas, Buenos Aires se abastece de energía térmica de generación propia, hidroeléctrica -que llega de otras provincias por el sistema interconectado nacional- y nuclear, procedente de la central de Atucha. Cuenta además con una densa red de carreteras -aproximadamente quince mil kilómetros de ruta pavimentada-, vías férreas que presentan un dispositivo radial convergente hacia el puerto de Buenos Aires y una importante infraestructura portuaria en sus costas atlánticas, además de puertos fluviales en el Río de la Plata y el Paraná.

Para finalizar, resulta oportuno mencionar la relevancia de las exportaciones de nuestra Provincia.

Según datos del año 2006, las colocaciones en el exterior alcanzaron los 18.000 millones de dólares, que suponen el $39 \%$ de las ventas externas totales del país. Las exportaciones bonaerenses se distribuyen en un grupo amplio de destinos que incluye a más de 140 países, aunque con un grado considerable de concentración en América Latina. Quienes tienen mayor participación son Brasil, Estados Unidos, Chile, México, China, Uruguay, Países Bajos y España (en ese orden) que representan en conjunto el destino del $64 \%$ de la exportación provincial.

Los principales productos exportados se vinculan con los siguientes rubros: transporte, industria química, petroquímica, minería -ya sea de producción primaria o secundaria-, materiales plásticos, cereales, carnes, grasas y aceites vegetales. En un segundo plano, productos como miel, lácteos, pescados, medicamentos y cueros curtidos y fundas para tapicería, entre otros.

Esta somera descripción de las características sociales y económicas de la provincia, permite dotar de sentido histórico-contextual a los documentos curriculares que enmarcan la enseñanza en el sistema educativo. ${ }^{80}$

\section{I) La articulación con otros dispositivos de comunicación}

Como se ha podido verificar a lo largo de la investigación, las diversas aplicaciones de los dispositivos Mapa y Cédula se potenciaron al articularse en un contexto de gestión que impulsó la participación democrática de los sujetos en la elaboración de la estrategia comunicacional, a lo que se agrega la articulación con otros dispositivos comunicacionales que se utilizaron en la DGCYE, en un contexto social muy diferente al que existía en el momento de la creación de estas herramientas, y en el cual

Si hay algo que caracteriza a la información que se produce diariamente, es la rapidez y la simultaneidad. En consecuencia, los tiempos de procesamiento, selección y jerarquización de la información se acortan cada día más, como los plazos para la comprobación, verificación y la búsqueda de las distintas miradas que hay al respecto. Pareciera ser que es preferible tener una primicia errónea que perderse la posibilidad de decir: "Fue primicia de...". 
[...] En esta dinámica informativa, mucho más compleja de lo que podemos contar aquí, se juega la relación entre sociedad, medios e instituciones. Uno de los temas más delicados que nos tocó abordar desde el área de Comunicación y Prensa de la DGcye fue el de preservar y recuperar, entonces, la credibilidad, que es el valor simbólico más preciado que pueden tener las instituciones y quienes tienen la responsabilidad de conducirlas, aunque no faltan las oportunidades en las que nos tentamos, cuando hay que enfrentar temas álgidos, controvertidos, dificultosos, de esconder información o tergiversarla. [...] En lo que refiere a la educación, casi siempre se repiten de acuerdo a la temporada. A principio del año lectivo lo más probable es que los títulos se concentren en la falta de docentes, carencias edilicias, falta de agua, etc.; temporada otoño-invierno: falta de gas, techos que se llueven [...] Entre éstos también surgirá, por algún caso aislado, el tema de la violencia escolar y sus derivaciones. Hacia fin de año, si es que no hay reclamos de aumento salarial docente, serán las colas en las puertas de los establecimientos modelos para inscribir a los chicos para el ciclo lectivo siguiente.

Si bien nosotros decidimos no esquivar las informaciones de problemas que no son de fácil resolución, y muy por el contrario, hacerles frente algunas veces implica guardar silencio, cuando existe un sentido y una motivación justificada -de protección de una investigación judicial que así lo requiera o de salvaguarda de la identidad de menores, por ejemplo- por los cuales la institución prefiere no dar estado público, en un determinado momento, a algún hecho. El silencio, en estos casos, también marca postura.

¿Dónde radica el equilibrio? Como Dirección de Comunicación y Prensa de un organismo oficial (público y no debe interpretarse como oficialista), tenemos la obligación de informar siempre. El equilibrio radica, precisamente, en asumir con responsabilidad que son las situaciones concretas (que involucran a personas tangibles con sus dolores y sus expectativas) las que determinan qué es información pública y qué es información mediática. De ahí la importancia de mantener una fluida comunicación entre institución, medios y comunidad. La mejor receta que hemos encontrado desde la Dirección de Prensa es hablar con la verdad, no esconder datos y afrontar las situaciones de crisis. ${ }^{81}$

Frente a este panorama, se tomó la decisión de implementar nuevas herramientas de comunicación, en particular en el Área de Comunicación y Prensa de la DGcyE, no sólo con el fin de satisfacer las demandas de información de los propios medios de prensa, sino también para sostener un buen tratamiento de los temas y de la información de la estadística educativa surgida del área de Planeamiento, en particular de Cédula escolar, a fin de evitar, por ejemplo, que se le diera un tratamiento superficial a determinadas cuestiones. Por supuesto esta posición no debe ser interpretada como un mecanismo de control, censura o prohibición. Muy por el contrario, tiene que ver con la jerarquización y legitimación de la información que deja de ser personal para convertirse en una cuestión del ámbito público en la que tanto la comunicación externa como la interna constituyen un proceso dinámico que se retroalimenta. ${ }^{82}$

Cuando existe una relación coherente entre el discurso institucional y su puesta en práctica, las tareas de comunicación tienen una gran parte de la batalla ganada al no tener que dedicarse a formular respuestas congruentes a situaciones incoherentes. Con seguridad falta mucho por hacer, pero ya en el camino se avizoran carteles de ruta que indican hacia dónde dirigirse. Las señales advierten que no se puede pensar sólo en una buena imagen institucional construida para los medios, si ella no contiene las voces de quienes son los verdaderos multiplicadores del mensaje: docentes, padres, alumnos, empleados y comunidad educativa en su conjunto.

Llegados a este punto y antes de finalizar este capítulo, es necesario detenerse para hacer

81 Cfr.Ghea, María Elisa, Rogovsky, Cintia, "Capítulo xxii Comunicación y prensa para la educación" en Puiggrós, Adriana, et al, Cartas a los educadores de siglo XXI, Galerna, Buenos Aires, 2007. 
algunas reflexiones. Hasta aquí se ha realizado un relato de cómo y para qué se construyeron estos dispositivos así como del contexto histórico, político e institucional en que intervinieron. Se ha dado cuenta de una serie de categorías que se utilizan para nombrar, designar, los nuevos modos de comunicación con los que la sociedad de la información ha ido modificando las "maneras de informarnos, de educarnos, de gobernarnos."83

Sin embargo, hay que considerar que los objetivos de planificación y transformación del sistema a partir de contar con información sistematizada, confiable y completa que portaron Mapa y Cédula Escolar como herramientas pueden disponer, y seguramente lo harán, de nuevos dispositivos de comunicación más adecuados de los que probablemente no podamos hoy formarnos una idea, puesto que la velocidad y la variedad de ámbitos en los que impacta la tecnología hacen que tanto nuestras categorías conceptuales cuanto las formulaciones teóricas que sobre éstas efectuamos resulten insuficientes, como plantea Ester Kaufman. En tal sentido

Contrariamente a lo que se pensó en las hipótesis iniciales sobre las TIC, no es necesaria y obligatoriamente la computadora el soporte de la información necesaria para todos los ciudadano. En efecto, hace algún tiempo se empezó a trabajar en los modos en que, por ejemplo, los dispositivos de comunicación móviles (o teléfonos celulares, aunque teléfono es una denominación muy empobrecedora para el conjunto de prestaciones de estos aparatos) pueden satisfacer necesidades de una menor complejidad y exigencia de conocimiento. ${ }^{84}$

Ya en ocasión de realizar la entrevista a la Lic. González Gaviola para esta tesis ella había destacado, con referencia a su actividad actual en ámbitos internacionales, el impacto del uso de los teléfonos como soporte comunicacional masivo para el uso de Internet, lo que permitió reflexionar acerca de las dificultades iniciales, que originaron no pocas resistencias para llevar adelante estos programas de relevamiento de información y los cambios ocurridos desde entonces. En el periodo de los pocos años analizados desde la puesta en marcha de Mapa y Cédula Escolar se pasó de un contexto en el que muchas escuelas no contaban siquiera con teléfono de línea ni computadoras conectadas a la red, a una etapa en la que un gran número de docentes y alumnos disponen de teléfonos celulares conectados a la red y forman parte de una cultura que ha hecho del intercambio comunicativo mediante estos dispositivos un hábito cotidiano.

A la vez, la llegada de la televisión digital e interactiva a nuestro país, inimaginable hace apenas diez años cuando se comenzaron a idear Mapa y Cédula Escolar y los nuevos soportes que vayan surgiendo para la producción y distribución de información, nos obligarán sin duda a repensar las categorías de inclusión digital — vinculada en principio con el hecho de contar con una computadora-que hasta aquí hemos problematizado. Esto no significa desde ya que la brecha digital haya dejado de ser un problema, en particular en los países de América latina, pero sin duda introduce variantes y complejidades a la definición de esa misma brecha digital. 



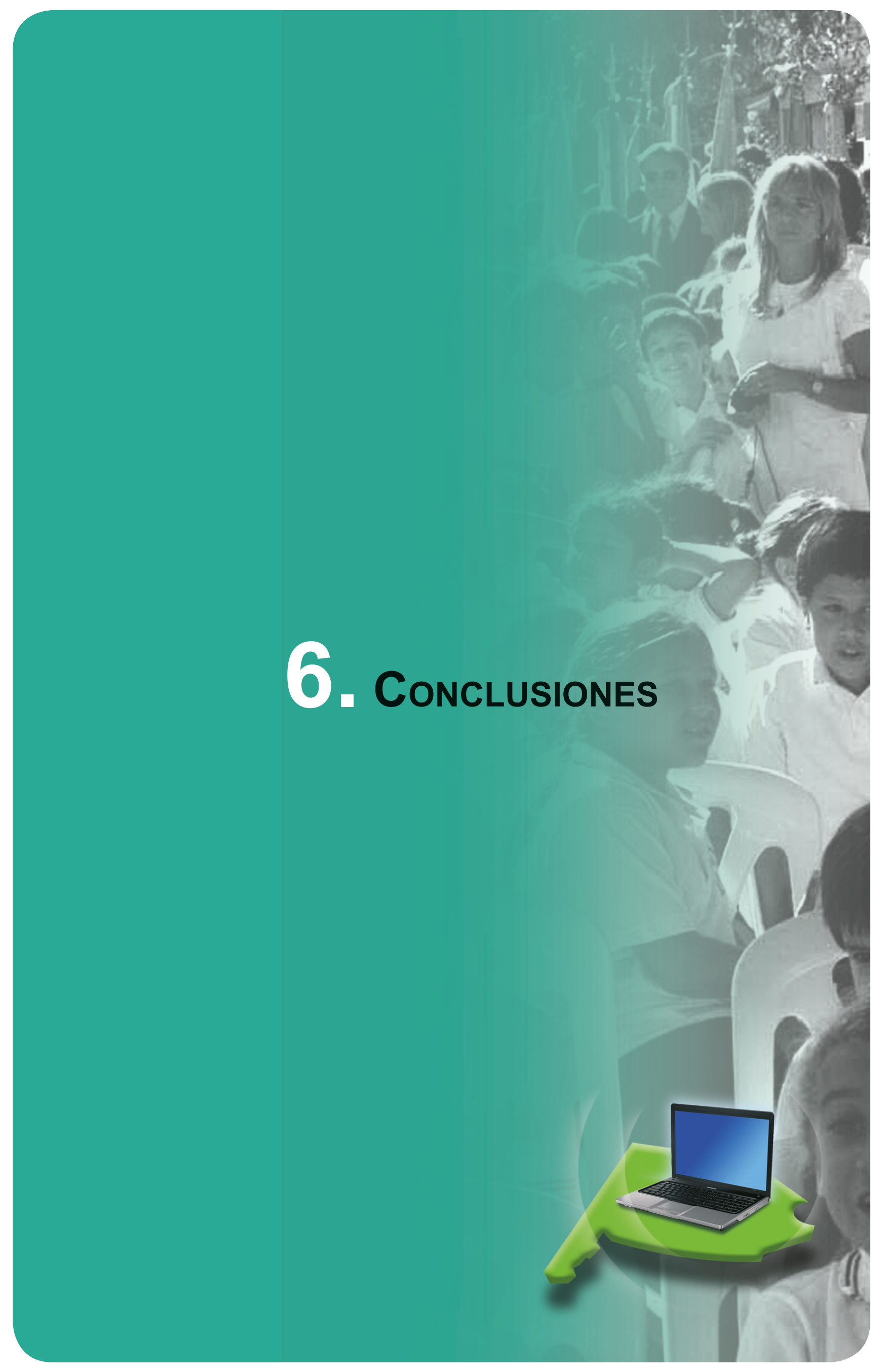



Al comienzo del trabajo se plantearon algunos interrogantes acerca de la vinculación entre la sociedad de la información con los procesos educativos, vinculados a la aplicación de los dispositivos Mapa y Cédula aquí analizados que vale la pena repasar: ¿Es posible pensar la transformación pedagógica y política sin considerar "los saberes técnicos" y el uso de las tecnologías digitales?; ¿Se puede sostener en el tiempo herramientas tecnológicas que permitan la construcción, acceso, y distribución de esa información sin capacitación?; ¿Se pueden generar nuevos espacios en ese sentido sin inversión acorde?; ¿La democracia en la información es darle a los sujetos lo que estos demandan?; ¿Y acaso es posible demandar algo diferente a lo que se está en condiciones de demandar?

Al mismo tiempo, se propuso indagar si los dispositivos diseñados en un determinado contexto socio-político, para relevar, procesar y distribuir información para la toma de decisiones en el sistema educativo bonaerense, Cédula y Mapa Escolar, han sido efectivos a lo largo de casi una década. Por otra parte, surgieron las preguntas en torno a cómo estos dispositivos tecnológicos se inscribieron en el marco del proyecto de transformación pedagógica y política que llevó adelante la gestión de la doctora PuIGGrós entre 2005 y 2007. Asimismo se ha intentado evaluar si el uso de las TIC en ámbitos gubernamentales como la DGCYE realmente han contribuido para mejorar el acceso y la interacción a la información pública del sistema educativo a la ciudadanía.

\section{Una primera conclusión que podemos enunciar, se refiere a que estos dispositivos han impactado, aunque de manera desigual, y junto con otras medidas y procesos, en la transformación de los sujetos pedagógicos y del sistema, la gestión y las instituciones educativas provinciales.}

A lo largo de esta investigación se ha podido comprobar que en la actualidad no es posible hablar de los sujetos sin considerar el impacto de las tecnologías y los medios de comunicación masivos, tanto en la construcción de sus subjetividades como en sus modos de relacionarse y de producir e intercambiar saberes.

En el caso de las instituciones educativas estos procesos adquieren particular relevancia, dado que hacen visibles las transformaciones socioculturales que experimentan todos los actores 
del proceso de enseñanza-aprendizaje en los distintos niveles de la organización institucional. Al mismo tiempo, estas transformaciones han impactado, e impactan, en la organización y la administración del sistema educativo, y afectan a las estructuras orgánicas y funcionales y los roles $-\mathrm{y}$ relaciones - de los distintos actores que conforman estas instituciones. De todas maneras, aún queda por verse en qué grado este impacto ha modificado a los sujetos como tales, a las prácticas comunicacionales y al funcionamiento del sistema como conjunto.

Es posible afirmar que los dispositivos han afectado de manera heterogénea, ya que no todos los sujetos ni las instituciones los han incorporado del mismo modo, aunque sí se han instalado y sistematizado de manera parcial. Por su parte, no se ha podido verificar si los beneficios de la aplicación de éstas, tanto en las instituciones educativas cuanto en los demás niveles de conducción del sistema —pedagógicos y políticos_ - y el aprovechamiento de estos se da en los niveles máximos que los propios dispositivos poseen.

Esta última conclusión obedece a varias razones. La principal, duda es que el Estado —ni el nivel nacional ni en el provincial que aquí se abordó—no ha podido aún resolver la accesibilidad, tanto en materia de software como de hardware, a la totalidad de los actores implicados. La extensión de la conectividad, uno de los pilares de la política de comunicación fundada en derechos, está todavía pendiente. $\mathrm{Y}$ este es un punto neurálgico que debe ser abordado de manera urgente por el Estado y el conjunto de la sociedad. Como se ha analizado a lo largo de la investigación, las tensiones entre mercado y Estado han atravesado no sólo a la sociedad sino también a los gobiernos. Los intereses en pugna de grandes grupos económicos transnacionales por convertirse en proveedores del servicio de Internet en todo el mundo, y especialmente por apropiarse como lo vienen haciendo en esta geografía, del rico campo educativo, encontraron también en el caso particular del estado bonaerense y la DGCYE un escenario propicio para presionar e intentar negociar beneficios y privilegios en función de sus intereses comerciales. ${ }^{1}$

No es necesario recordar que, por sus dimensiones, la DGCYE constituye un "cliente" preferencial y sumamente apetecible para cualquier empresa de comunicaciones (telefonía, Internet, editoriales, etcétera). Esta disputa de intereses financieros, que quedó quizá como nunca antes, desnuda en ocasión del debate de la nueva Ley de Servicios de comunicación Audiovisual impulsada por el gobierno de Cristina FERNÁNDEZ DE KIRCHNER en 2009 — que ha sido objeto de mención en esta investigación-es una disputa por el modelo de construcción nacional y el rol del Estado frente a la

\footnotetext{
1 Cabe destacar que en el momento de terminar esta tesis, el 6 de abril de 2010, la Presidenta de la Nación, Cristina Fernández de Kirchner, anunció la puesta en marcha del programa "Conectar Igualdad.com.ar", financiado con fondos de la ANSES. En primer término se repartirán 250.000 netbooks para alumnos de nivel medio de escuelas técnicas. El objetivo del Gobierno es que en tres años todos los alumnos y docentes de la escuela secundaria tengan una de estas computadoras portátiles. En esa oportunidad la mandataria afirmó que "Estamos ante un nuevo mundo, un mundo de conectividad, de conocimiento", remarcó Cristina, e insistió en la necesidad de adaptar el sistema educativo a esta nueva realidad así como de salvar la "brecha digital [..] Creo que el signo distintivo del Bicentenario tiene que ser la igualdad, contra algunos intereses que precisan las desigualdades para seguir teniendo poder", agregó la Jefa de Estado y aseguró que el plan lanzado hoy es "un absoluto instrumento de igualdad" . En igual sentido, el gobernador de la provincia de Buenos Aires, Daniel Scioli, y el Director General de Cultura y Educación, Mario Oporto, comenzaron un plan de distribución de netbook de este programa, a fines del mes de abril, en la Escuela de Educación Técnica № 4 de Mar del Plata. Según se prevé, a lo largo de 2010 se repartirán en la Provincia de Buenos Aires unas 100.000 computadoras, que beneficiarán a estudiantes de 352 escuelas de Educación Técnica y de Educación Agrarias, Centros Educativos para la Producción Total (CEPT) y Centros de Educación Agraria (CEA). Fuente: Dirección General de Cultura y Educación - Portal ABC. Va de suyo que no estamos en condiciones de evaluar los efectos que estas medidas tendrán en el corto, mediano y largo plazo, aunque es posible anticipar un 
hegemonía del mercado. Es necesario recordar que dentro de las instituciones gubernamentales existen y han existido sectores, muchas veces con niveles de decisión, que son funcionales a intereses corporativos y no es sencillo, no lo ha sido para la administración PUIGGRós ni para las anteriores, avanzar en este sentido si esta decisión no forma parte de una política pública macro, en los más altos niveles, sostenida con firmeza en el tiempo. En tal sentido, cabe mencionar que la decisión de concursar, editar y distribuir textos escolares para los alumnos de la educación secundaria asumida en 2007, de mucho menor impacto económico pero de fuerte carga simbólica por cuanto avanzaba en recuperar para el Estado su rol de garante principal del derecho a educarse, se enfrentó con fuertes obstáculos por parte de grupos editoriales multinacionales, ${ }^{2}$ que encuentran siempre aliados dentro de las propias estructuras gubernamentales.

La conectividad no sólo es imperativa para el adecuado funcionamiento de los dispositivos aquí abordados - Mapa y Cédula - que son fundamentales para la toma de decisiones políticas en la conducción y planificación del sistema, sino también para la producción y difusión de contenidos educativos, el enriquecimiento de las prácticas pedagógicas y la alfabetización digital de todos los habitantes.

Aunque se pudiera pensar en el mediano y largo plazo en grandes inversiones por parte del Estado para la provisión, por ejemplo, de computadoras para los alumnos de la educación obligatoria, lo cual sería un gran paso en este sentido, e incluso, en la capacitación permanente de los recursos humanos -ya sea docentes, alumnos o personal técnicoadministrativo- resolver la conectividad total es un aspecto central que no podrá darse sin enfrentar estos intereses.

Es así que resulta posible concluir, en este punto, que pese a las diversas condiciones en que llevaron adelante sus gestiones, con objetivos comunes y otros diferenciados, ni la administración de BORDÓN—que diseñó y comenzó a implementar los dispositivos y una fuerte impronta en materia de renovación tecnológica— ; ni la de OPORTO — que priorizó las medidas que permitieran pilotear la crisis del 2001 y hubo de realizar un fuerte ajuste económico—ni la de PuIGGRós — que impulsó una fuerte transformación pedagógica, normativa y de producción de contenidos educativos-, por distintas razones, pudieron resolver la conectividad total en el periodo 2000-2007 que aquí se aborda. Aunque no haya sido materia de este trabajo, la situación actual no parece verificar novedades en este sentido.

\section{Una segunda conclusión es que gran parte de la información provista por Mapa y Cédula Escolar desde su implementación ha sido de fundamental relevancia para la aplicación de las reformas educativas propuestas en la Ley 13.688/06.}

En el interior de las escuelas, es posible reconocer las tensiones que se establecen entre los discursos, saberes y prácticas culturales, que circulan "a través de los medios masivos y las lógicas, concepciones y dinámicas propias de los espacios escolares, viviendo en muchas

2 Cfr. Giordano, Carlos, Romera, Elvira, Cap. XX "Publicar para todos, conectar a todos”, en Puiggrós, Adriana, et al, Cartas a los educadores de siglo XXI. Op. cit. 
oportunidades esta tensión como obstáculo insalvable en los procesos de enseñanza y de aprendizaje." 3

Como se ha desarrollado en este trabajo, las tecnologías de la información y la comunicación no son meros dispositivos tecnológicos cuyos efectos positivos o negativos dependen de su uso. Constituyen una dimensión importante de las culturas contemporáneas, en tanto tienen la capacidad de configurar y transformar un conjunto de prácticas, saberes y representaciones sociales, extendiendo este proceso a todas las formas de la vida cotidiana y no sólo a situaciones específicas en las que los sujetos se exponen a la recepción de productos mediáticos. ${ }^{4}$

Por otra parte, el uso de las tecnologías de la información y la comunicación transformaron las nociones de tiempo y espacio y, al quebrar la lógica del espacio, permitió acercar lugares distantes geográficamente y generó la necesidad de conocer anticipadamente. Asimismo, se han potenciado nuevos modos de producción y circulación del saber.

En tal sentido, una tercera conclusión hace evidente que estas mismas tensiones acompañaron el proceso de institucionalización de Cédula y Mapa y que ese proceso aún no está completo ni ha tenido las suficientes adecuaciones a los cambios y necesidades del propio sistema.

Por otra parte, han sido útiles a los fines de establecer la elaboración de los nuevos diseños curriculares que surgieron tras la modificación de la Ley, ya que contribuyeron para delinear las características sociales y económicas de la Provincia, que nos permitan comprender las múltiples realidades que la habitan.

Una última conclusión, por cierto auspiciosa, permite afirmar que los dispositivos de Mapa y Cédula escolar fueron y son de suma importancia para generar espacios no sólo de producción de información del sistema educativo, sino, además, de información que debe ser distribuida entre la comunidad educativa y el resto de la sociedad que es, en definitiva la sostenedora y destinataria de los esfuerzos que estas áreas puedan realizar. En sociedades de la información y en instituciones como la Dirección General de Cultural y Educación, proveen de la información crítica y sensible para la planificación estratégica de la educación, teniendo en cuenta a sus actores en todos los niveles de responsabilidad.

Es fundamental que los responsables de la administración y gestión de las políticas públicas, en este caso educativas, pongan todos los esfuerzos en sostenerlos, invirtiendo recursos económicos y capacitando en forma permanente al personal para tal fin. Como se sabe desde hace siglos, la información es poder. Hoy en la Argentina, como en el resto de América Latina, existen numerosas consultoras privadas que sugieren, con base a los datos que obtienen del

3 Marco General de Política Curricular, DGCYE, aprobado por Resolución №3655/07 de la Directora General de Cultura y Educación de la provincia de Buenos Aires, Adriana Puiggrós, en 2007, pág. 26. 
propio sistema estadístico oficial, cuáles deberían ser las políticas a aplicar. Cientos de miles de dólares son destinados a abonar estos diagnósticos, sin tener en cuenta quiénes son y de dónde provienen los técnicos y profesionales encargados de su elaboración. Es decir, sin considerar a los sujetos y sus saberes más que en términos del discurso que le reclama al Estado más "eficiencia y eficacia", entendiéndolas como reclamo hacia los trabajadores. ${ }^{5}$

No caben dudas de que en la administración estatal existen cientos de profesionales con capacidades para diagnosticar y planificar políticas públicas acordes al modelo nacional y popular. Sólo es necesario brindarles herramientas tecnológicas, recursos y por sobre todas las cosas confiar en que es posible. De lo contrario, la información como insumo que se necesite para la planificación y gestión de, en este caso, políticas públicas educativas, siempre serán provistas por los mismos tecnócratas que fueron y siguen siendo funcionales al proyecto neoliberal. Conviene repetir que

\begin{abstract}
La comunicación no es lineal, es reticular, y en esta linealidad este movimiento no está contemplado. Por más horizontal que se presente la relación, el poder está puesto en el emisor porque así está constituida la creencia en el sistema. De tal modo que el emisor ejerce su poder alimentando su incapacidad adiestrada de no escuchar y su capacidad desmedida de informar el pensamiento único que piensa imponer. Del otro lado de la supuesta linealidad, el emisor se encuentra con la obturación de su capacidad de diálogo ya sea porque no es escuchado, ya sea porque no encuentra canales concretos de participación y comunicación.

Generalmente las políticas Públicas van hacia "los otros" desde el modelo informacional o desde el modelo de los efectos buscando resultados a partir de metas físicas. ${ }^{6}$
\end{abstract}

En este sentido desde la concepción de las políticas públicas llevadas a cabo en la gestión de Adriana PUIGGrós y su equipo de trabajo, se intentó llevar a la práctica políticas transformadoras profundas, para lo cual, como se explicó, la comunicación interna y externa, los puentes tendidos entre la comunidad del sistema educativo y el mundo exterior, fue esencial. Para ello la palabra, la información, los dispositivos comunicacionales con los que se continuó en la gestión y que provenían de otras gestiones y los que se crearon, tuvieron como objetivos romper los silencios, abrir los espacios de participación, ser parte de los que hacen circular esa información, en las que se respetaron, también los tiempos propios de la gestión pública y los tiempos propios de los distintos actores que hacen al sistema educativo en general. Para que esto sucediera, fue necesario reconstruir espacios de participación y espacios para la palabra acallada de sus miembros.

Son muchos los desafíos que tiene la educación de cara a futuro. Pero también están los desafíos que los propios comunicadores encargados de la gestión y procesos comunicacionales institucionales de gestión estatal tienen. Es importante y fundamental sentirnos parte y actores de las políticas públicas que impactarán en la vida de cientos de personas. Algunas de esas políticas los atravesarán para bien o para mal, sumergiéndolos en el olvido, convirtiéndoles en ciudadanos sin derechos, sin sueños, descreídos en que la política es la herramienta que puede transformar la realidad.

5 Cfr. Puiggrós (Dir.) Saberes: reflexiones, experiencias y debates, Op. cit, pág. 9.

6 Ceraso, Cecilia, apartado "Modelos de Comunicación / Educación", en Redes de desarrollo local y colectivos de comunicación en el territorio, en http://www.scribd.com/doc/9381194/Tesis-Completa, sitio consultado marzo 2010, pág. 45 y pág. 161. 
Ser un buen comunicador, planificador y gestor de procesos comunicacionales implica considerarse un eslabón fundamental para el incentivo del encuentro que debe existir entre el Estado y su comunidad. Sin esta comunión, sin ese construir en forma conjunta el bien común, es imposible que exista comunicación emancipadora. Para ello es vital que el comunicador descubra y respete las identidades propias de las personas de la comunidad, sus matrices culturales, sus sueños, sus expectativas, que se ofrezca como un colaborador para hacerlas realidad. En palabras de Aura Patricia Orozco

[...] la comunicación pedagógicamente ayuda a producir, a fortalecer competencias organizativas, competencias argumentales, expresivas axiológicas, porque cuando los niños se organizan porque saben que ellos solos no pueden, que tienen que colaborar con el otro, ahí van dando valores, tengo que ser responsable, tengo que ser puntual porque mi trabajo depende también del otro y el otro también depende de mí.

[...] Yo creo que los comunicadores y planificadores estamos llamados a ser, a generar alianzas entre la institucionalidad pública, las comunidades, la academia...Yo creo que nosotros tenemos un gran llamado a ser conectores, a ser traductores de lo imaginarios y concepciones que tienen cada una de las instancias sociales. ${ }^{7}$

Decíamos que la experiencia de lo vivido, del transcurrir de la historia, no sólo en la Argentina, sino en América Latina, ha dado muestras más que suficientes para tener en cuenta los saberes y prácticas culturales propias de nuestra cultura. Reconocernos y reconocerlas es un primer paso para la construcción de la educación que nuestra nación necesita.

Los dispositivos de Mapa y Cédula escolar son parte de la gestión de procesos comunicacionales que las políticas públicas pueden llevar a la práctica como herramientas no sólo de la democratización de la palabra y como usina de información necesaria para la planificación educativa, sino, además, como una herramienta para la producción y gestión de procesos comunicacionales destinados a la construcción de redes intra y extra comunicacionales institucionales que colaboren en la producción de sentidos colectivos tendientes al sosteniendo de la educación que todos queremos y que con seguridad tiene mucho más que ver con lo que soñaba Paulo FreIRE que con la que planificaron los tecnócratas de los 90. 


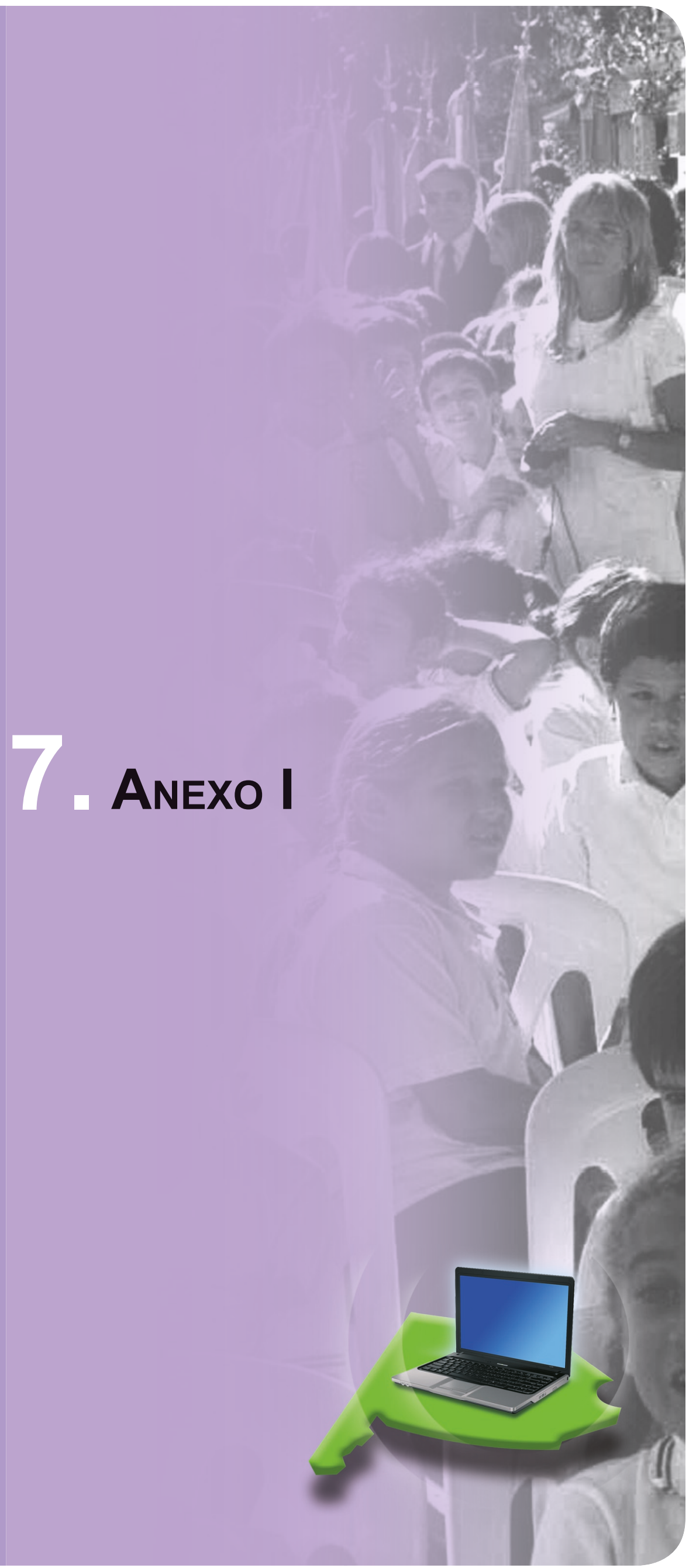





\section{Plan de Trabajo -Dirección de Comunicación y Prensa- Dirección General de Cultura y Educación de la provincia de Buenos Aires e Informe de la gestión en el área (2005-2007)}

En el presente no se puede pensar en una estructura de Estado moderno sin tener en cuenta en cómo la gestión comunica sus acciones de Gobierno. Mantener una fluida comunicación entre Gobierno y ciudadanos requiere del uso de herramientas técnicas y conceptuales que deben ser claramente definidas.

Para implementar cualquier estrategia de comunicación institucional de prensa es necesario identificar los inconvenientes, las expectativas, los deseos y las acciones del organismo que cree poder llevar a cabo la tarea. Este análisis previo, permite identificar también las oportunidades reales y los posibles conflictos a futuro tanto externos como internos. No hay que olvidar que toda institución está conformada por personas que poseen distintas ideologías, prioridades y participación en el construir de la institución.

Pero este análisis previo sirve, además, para algo que es de consideración: crear, organizar y poner en marcha "alternativas" que pueden construir, siempre que se cuente con decisión política, el cambio de lo establecido y que merezca ser modificado. Pero aún hay algo más importante. El análisis de situación ayuda a tener una descripción del campo de acción real y evita el divague de aquellos que pretenden poner en marcha soluciones románticas, utópicas y de poca eficiencia y eficacia a la hora de recoger los frutos.

Los resultados de comenzar por el principio de ese proceso de cambio que se pretende poner en marcha y no por el final, posibilita encontrar, dentro de cada institución, las limitaciones, necesidades, riquezas y potencialidades de los recursos humanos con los que cuenta.

En otra instancia, pero en igual sentido, se plantea la necesidad, como en todo organismo público o privado, de coordinar y difundir las distintas actividades que dependen de él y que se llevan a cabo tanto adentro de su ámbito como en sus lugares de influencia. Esto permitirá construir 
una imagen clara de Gobierno y centralizar la información para su difusión en medios gráficos, radiales, televisivos y digitales, no sólo en la provincia de Buenos Aires, sino, también, en aquellos medios de circulación nacional y regional del país.

Existe una enorme demanda, por parte de la sociedad y de los medios masivos, de información sobre educación, teniendo en cuenta el lugar que ocupa la misma en la vida cotidiana de los ciudadanos y cuántas circunstancias y actividades se vinculan directa e indirectamente a ella. Por esto, la producción de información en este campo requiere una elaboración permanente y continua, cuyos contenidos sean producidos con un alto grado de especialización, rigurosidad, precisión y claridad.

Hay tres cuestiones que caracterizan el tratamiento de las informaciones referentes a lo educativo y son las siguientes: por un lado, existen medios que dedican amplios espacios a la información educativa; pero también caen en errores conceptuales, de liviandad en su tratamiento, y de interpretación. Por otro, están aquellos medios en los que el lugar destinado a estos temas es casi nulo. En tercer lugar están aquellos medios especializados o interesados en la problemática educativa, en los cuales se hace necesario abrir una vía de comunicación entre la Dirección General y el medio y ocupar un lugar en ellos con calidad informativa y conocimiento especializado de la temática. Por estas razones, una institución como la Dirección General necesita producir el equilibrio generando, por un lado, sus propios espacios, y por el otro, teniendo un cuidado riguroso con lo que comunica.

En lo que respecta a la difusión de actividades, es necesario, debido al espíritu de trabajo, que la Dirección de Comunicación y Prensa no sólo sea el área de difusión que centralice toda aquella información de actividades que se desarrollan, no sólo como una forma de dar a conocer las actividades hacia adentro de la Dirección General e informar a sus miembros, sino, que tiene como tarea el pensar la forma adecuada de hacer que la comunidad en general conozca las actividades que se realizan en el cronograma de gestión y ejecución de las políticas educativas.

\section{De las tareas de Difusión de la Dirección de Comunicación y Prensa}

- Es una estructura que tiene a su cargo todo lo referente a las políticas de comunicación no sólo de las actividades de la Directora General de Cultura y Educación, sino, además tiene la función de diseñar, crear y poner en marcha los mecanismos necesarios de difusión y distribución de aquellos hechos políticos que merezcan ser atendidos y difundidos interna y externamente en lo referente a las acciones de planificación, gestión y ejecución de proyectos educativos y decisiones políticas de la institución.

- Tiene una relación de jerarquía sobre un espacio transversal que enlaza a las estructuras internas de la Dirección General, direcciones provinciales y en general, teniendo en cuenta las prioridades y necesidades de difusión de las tareas que éstas llevan a cabo.

- La Dirección de Comunicación y Prensa tiene áreas de acción específicas para definir 
las tareas de difusión. Un área de Prensa y Difusión, un área de Multimedia y un área de Fotografía. Todas estas áreas se encuadran en lo que hemos definido como Programa de Políticas Comunicacionales.

\section{De las misiones y funciones}

\section{Misiones}

- Generar, gestionar y coordinar información sobre las acciones de la Dirección General de Cultura y Educación.

- Coordinar y gestionar los mecanismos comunicacionales necesarios para garantizar el acceso y distribución de información, hacia fuera y hacia adentro sobre las acciones de gestión.

- Coordinar acciones en conjunto con otras dependencias gubernamentales, ONGs, Asociaciones intermedias, medios de comunicación, entre otros, con el fin de poder establecer una fluida comunicación y difusión de las acciones de la Dirección General de Cultural y Educación.

- Transformar las informaciones que así lo merezcan, en hechos políticos de gestión.

\section{Función}

- Difusión de proyectos, servicios, actividades que realice la Dirección General de Cultura y Educación, mediante charlas, conferencias, cursos, gacetillas de prensa, informes especiales, cobertura periodística, creación de medios propios de difusión, entre otras posibilidades.

- Realización de la producción periodística y edición de boletines de difusión e información por correo electrónico y en soporte papel. El boletín puede ser semanal, quincenal o mensual, dependiendo de la necesidad de ubicación de información y a la generación de acciones que merezcan ser informadas.

- Redacción de las gacetillas de prensa para la difusión de actividades.

- Investigación y seguimiento periodístico sobre aquellos temas de interés, legislativo, gubernamental provincial, judicial y educativo, entre otras. Esta información será volcada en el $A B C$, en el programa de radio y en la revista que editará.

- Diseño y actualización de la página electrónica y/o sitio del link prensa.

- Construcción de la agenda de temas para los medios gráficos, televisivos, radiales y digitales. 
- Redacción de los comunicados de prensa de toda aquella información de importancia referente a las actividades que lleva a cabo la Directora General y su gabinete, u otros, a través de sus distintas áreas de gestión que merezcan ser difundidas en los medios de comunicación radiales, gráficos y televisivos, tanto locales, regionales como nacionales.

- Cobertura periodística de aquellos eventos de interés político y/o de gestión de la Directora General que merezcan ser difundidos en los medios de comunicación. Por ejemplo: eventos, entrevistas, programas, charlas, conferencias, reuniones, entre otros.

- Realización de una síntesis periodística diaria que contemple aquellas informaciones relevantes de interés gubernamental, para información de la Directora General, directores provinciales y funcionarios.

- Atender al pedido de información por parte de los medios de comunicación, entidades intermedias, otros ministerios pertenecientes al Gobierno provincial, entre otros, sobre actividades, en general, que lleve a cabo el ministerio.

\section{Programa de política Comunicación}

\section{Función}

- Coordinación del envío e intercambio de información de interés político-gubernamental y periodístico con otros organismos (públicos y privados), como por ejemplo: oNGs, ministerios provinciales y nacionales, sindicatos, empresas, fundaciones, cooperativas, entre otros, no sólo provinciales, sino, además, municipales, regionales y nacionales.

- Actualización y mantenimiento de un archivo periodístico de aquellas informaciones relacionadas a la gestión de la Dirección General.

- Confección de una base de datos de entidades públicas y privadas no sólo de la provincia de Buenos Aires, sino, también, del ámbito municipal, regional y nacional para intercambiar información de interés político gubernamental.

- Coordinación y seguimiento del flujo de información con estas instituciones, como forma de coordinar y distribuir las inquietudes que surjan.

- Creación de vínculos, y a requerimiento del gobierno, tendientes a la organización y realización de cursos, charlas, seminarios, conferencias y talleres destinados a la formación del personal que desarrolle tareas en áreas de comunicación.

- Crear las herramientas de difusión como medio para recuperar el espacio de consulta y de referencia por parte de la comunidad en todo aquello que hace a la gestión, administración y ejecución de programas de la Dirección General de Cultura y Educación. 
- Crear el espacio de sugerencias, como herramienta de intercambio entre La Dirección General y la comunidad educativa.

- Crear espacios de rediseño y creación de espacios de campañas de Estado, como por ejemplo, el mes del medio ambiente en la escuela, de la seguridad, de la salud, de la Constitución. Se emplearán para ello los recursos disponibles de prensa y difusión y todos los espacios que haya construido el área a tal fin.

- Diseñar y elaborar los proyectos de sondeo de opinión ciudadana. 



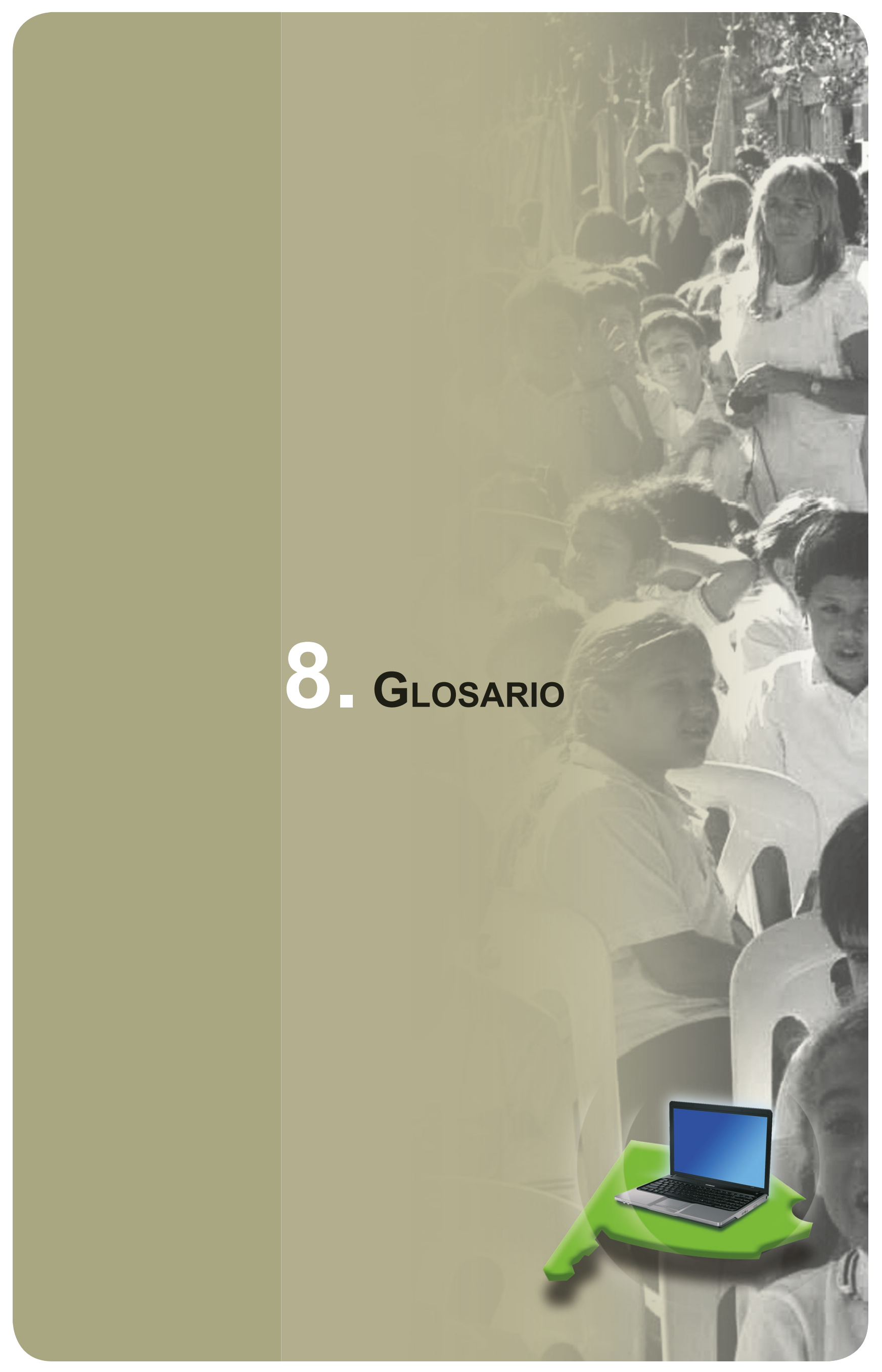





\section{Taller}

Es un servicio orientado a canalizar aptitudes, o intereses, desarrollar habilidades o destrezas , tendientes al conocimiento y preparación de la formación laboral, a través de distintas orientaciones tanto de la educación especial como de la educación artística. Fuente: Definiciones Básicas para la producción de Estadísticas Educativas Dirección Nacional de Información y Evaluación de la Calidad Educativa. Red Federal de Información Educativa. Ministerio de Educación, Ciencia y Tecnología - Dirección de Información y Planeamiento Educativo. Dirección General de Escuelas y Cultura .Provincia de Buenos Aires.

\section{Tasa}

Es una relación expresada como porcentaje.

Fuente: Instituto Internacional de Planeamiento Educativo, "Planificación y Formulación de Políticas Educativas", Módulo III UNESCO, 1998.

\section{Tasa bruta de mortalidad}

Es el cociente entre el número de defunciones ocurridas durante un período determinado, generalmente un año calendario, y la población media del período.

Fuente: Situación y evolución social Síntesis $N^{\circ} 4$; INDEC.

\section{Tasa bruta de natalidad}

Es el cociente entre el número de nacimientos ocurridos durante un período determinado, generalmente un año calendario, y la población media del período.

Fuente: Situación y evolución social Síntesis $N^{\circ} 4$; INDEC.

\section{Tasa de abandono anual}

Expresa el porcentaje de alumnos que abandonan un año de estudio durante el ciclo lectivo. Es posible calcular una tasa total y/o por año de estudio. La tasa de abandono anual es el cociente de la cantidad de alumnos matriculados (i) al comienzo del año lectivo ( $t$ ) menos la cantidad de alumnos matriculados (i) al finalizar el mismo año lectivo ( $\mathrm{t}$ ) y la cantidad de alumnos matriculados (i) al comienzo del año lectivo (t) por 100. Nota: -(i) corresponde al año de estudio en cuestión por ejemplo: $1^{\circ}$ año de EGB. -(t) corresponde al año lectivo en cuestión por ejemplo: 2002. 
Fuente: Dirección Provincial de Planeamiento-Dirección de Información y Estadística. Dirección General de Cultura y Educación. Provincia de Buenos Aires.

\section{Tasa de abandono interanual}

Expresa el porcentaje de alumnos que no se matriculan en el año lectivo siguiente en ningún año de estudio. Es posible calcular una tasa total y/o por año de estudio. Es el cociente entre la cantidad de alumnos que terminaron el año de estudio (i) en el año lectivo (t) que no están matriculados en el año lectivo ( $\mathrm{t}+1)$ y la cantidad de alumnos que terminaron el año de estudio (i) en el año lectivo (t) por 100.

Nota:

- (i) corresponde al año de estudio en cuestión por ejemplo: $1^{\circ}$ año de EGB, mientras que $(i+1)$ es el año de estudio siguiente al año de estudio tomado como base.

- (t) corresponde al año lectivo en cuestión por ejemplo: 2002 y (t+1) al año lectivo siguiente.

Fuente: Dirección Nacional de Información y Evaluación de la Calidad Educativa. Ministerio de Educación, Ciencia y Tecnología - Dirección Provincial de Planeamiento-Dirección de Información y Estadística. Dirección General de Cultura y Educación. Provincia de Buenos Aires.

\section{Tasa de Analfabetismo}

Es el cociente entre el número de personas analfabetas de 10 años y más y el total de la población de 10 años y más por cien.

Fuente: Situación y evolución social Síntesis N 4; INDEC.

\section{Tasa de crecimiento medio anual 0/00}

Expresa el ritmo de crecimiento de una población es decir, cuanto aumenta o disminuye en promedio anual por cada 1000 (mil) habitantes, durante un determinado período. Es la suma algebraica de la tasa de crecimiento natural y la tasa de crecimiento migratoria correspondiente a un determinado período.

Fuente: Situación y evolución social Síntesis $N^{\circ} 4$; INDEC.

\section{Tasa de Mortalidad}

Expresa el número de defunciones totales en relación con el tamaño de la población en que se han producido las mismas. Se calcula teniendo en cuenta el número de defunciones ocurridas en un año, en una región determinada, y la población de dicha región a mitad de ese año. Se expresa el número de defunciones cada 1.000 habitantes.

Fuente: Dirección Provincial de Estadística. Provincia de Buenos Aires.

\section{Tasa de Natalidad}

Mide la relación del número de nacimientos con el tamaño de la población en la que han ocurrido los mismos. Se calcula teniendo en cuenta los nacidos vivos durante un año en una región determinada y la población existente a la mitad del año en dicha región. Se expresa en número de nacimientos cada 1.000 habitantes.

Fuente: Dirección Provincial de Estadística. Provincia de Buenos Aires. 


\section{Tasa de Pasaje}

Es el porcentaje de alumnos promovidos de un nivel que se matriculan como alumnos nuevos en el nivel siguiente. Es el cociente entre la cantidad de alumnos matriculados en $1^{\circ}$ año de cada nivel (sin repitientes) y la cantidad de alumnos en la matrícula final del último año del nivel anterior por 100. Fuente: Dirección Provincial de Planeamiento-Dirección de Información y Estadística. Dirección General de Cultura y Educación. Provincia de Buenos Aires.

\section{Tasa de Promoción Efectiva}

Expresa el porcentaje de alumnos que se matriculan en el año de estudio inmediato superior en el año lectivo siguiente. Es posible calcular una tasa total y/o por año de estudio. Es el cociente entre la cantidad de alumnos en el año estudio $(i+1)$ del año lectivo $(t+1)$ menos la cantidad de alumnos repitientes en el año de estudio $(i+1)$ del año lectivo $(t+1)$ y la cantidad de alumnos en el año de estudio i en el año lectivo t por 100.

Nota:

- (i) corresponde al año de estudio en cuestión por ejemplo: $1^{\circ}$ año de EGB, mientras que $(i+1)$ es el año de estudio siguiente al año de estudio tomado como base.

- (t) corresponde al año lectivo en cuestión por ejemplo: 2002 y ( $\mathrm{t}+1)$ al año lectivo siguiente.

Fuente: Dirección Nacional de Información y Evaluación de la Calidad Educativa. Ministerio de Educación, Ciencia y Tecnología - Dirección Provincial de Planeamiento-Dirección de Información y Estadística. Dirección General de Cultura y Educación. Provincia de Buenos Aires.

\section{Tasa de re-inscripción}

Expresa el porcentaje de aquellos alumnos que se registraron por segunda vez o más en un año de estudio en el que ya se habían inscripto en algún ciclo lectivo anterior, sin completar su cursada. Fuente: Dirección Provincial de Planeamiento-Dirección de Información y Estadística DGCYE.

\section{Tasa de Repitencia}

Es el porcentaje de alumnos que se matriculan en el mismo año de estudio en el año lectivo siguiente. Es posible calcular una tasa total y/o por año de estudio. La tasa de repitencia (total) es el cociente entre la cantidad de alumnos repitientes en el año lectivo $(t+1)$ y la cantidad de alumnos matriculados en el año lectivo t por 100. La tasa de repitencia (por año de estudio) es el cociente entre la cantidad de alumnos repitientes matriculados en el año de estudio i en el ciclo lectivo ( $t+1)$ y la cantidad de alumnos matriculados en el año de estudio i en el año lectivo t por 100. Nota:

- (i) corresponde al año de estudio en cuestión por ejemplo: $1^{\circ}$ año de EGB, mientras que $(i+1)$ es el año de estudio siguiente al año de estudio tomado como base. - (t) corresponde al año lectivo en cuestión por ejemplo: 2002 y $(\mathrm{t}+1)$ al año lectivo siguiente.

Fuente: Dirección Nacional de Información y Evaluación de la Calidad Educativa. Ministerio de Educación, Ciencia y Tecnología - Dirección Provincial de Planeamiento-Dirección de Información y Estadística. Dirección General de Cultura y Educación. Provincia de Buenos Aires. 


\section{Tasa de sobreedad}

Expresa el porcentaje de alumnos con edad mayor a la edad teórica o ideal correspondiente al grado/año de estudio en elcual están matriculados. Es el cociente entre la cantidad de alumnos con sobreedad y la cantidad de alumnos por 100 Fuente: Dirección Nacional de información y Evaluación de la Calidad Educativa. Ministerio de Educación, Ciencia y Tecnología. Dirección Provincial de Planeamiento-Dirección de Información y Estadística DGCYE.

\section{Tasa de Variación de matrícula}

Expresa el incremento o decremento porcentual de la matrícula de un año lectivo a otro para el mismo año de estudio. Es el cociente entre la cantidad de alumnos en el año lectivo $(t+1)$ menos la cantidad de alumnos en el año lectivo $t$ y la cantidad de alumnos en el año lectivo t por 100. Nota:

- (i) corresponde al año de estudio en cuestión por ejemplo: $1^{\circ}$ año de EGB, mientras que $(i+1)$ es el año de estudio siguiente al año de estudio tomado como base. - (t) corresponde al año lectivo en cuestión por ejemplo: 2002 y ( $t+1)$ al año lectivo siguiente. Fuente: Dirección Nacional de Información y Evaluación de la Calidad Educativa. Ministerio de Educación, Ciencia y Tecnología - Dirección Provincial de Planeamiento-Dirección de Información y Estadística. Dirección General de Cultura y Educación. Provincia de Buenos Aires.

\section{Tipos de Educación}

Son las diferentes formas en que se organiza la educación en función de la población a la que se dirigen, definida a partir de la edad de los alumnos, de sus necesidades educativas o de sus inquietudes y motivaciones. Cada uno de los tipos de educación cuenta con una organización curricular específicamente diseñada, con modalidades pedagógicas particulares y una articulación interna en niveles de complejidad creciente. Los tipos de educación son: Común, Especial, Adultos, Artística y Otras Modalidades Especiales. Cabe aclarar que en cada tipo de educación pueden existir ofertas educativas formales o no formales. El tipo de Educación Común constituye el Régimen común; Educación Especial, Adultos y Artística constituyen los Regímenes específicos; Educación Estética, Educación Complementaria, Educación Física y Formación Profesional, Otras Modalidades Especiales. (Ver Sistema Educativo Provincial).

Fuente: Dirección Nacional de Información y Evaluación de la Calidad Educativa. Red Federal de Información Educativa. Ministerio de Educación, Ciencia y Tecnología - Dirección Provincial de Planeamiento-Dirección de Información y Estadística. Dirección General de Cultura y Educación. Ley de Educación Nº 11612. Provincia de Buenos Aires.

\section{Total de población en hogares particulares y población en hogares con NBI}

Porciento de población en hogares con NBI sobre el total de población en hogares de cada provincia. La Necesidades Basicas Insatisfechas fueron definidas de acuerdo con la metodología utilizada por INDEC en "La pobreza en Argentina", Serie Estudios INDEC N 1, Bs. As. 1984. Se define a los indicadores de privación de la siguiente manera: Hacinamiento: Hogares que tuvieran mas de 3 personas por cuarto. Vivienda: Hogares que habitaran en una vivienda de tipo inconveniente (pieza de inquilinato, vivienda precaria u otro tipo). Condiciones Sanitarias: Hogares que no tuvieran ningun tipo de retrete. Asistencia Escolar: Hogares que tuvieran algún niño en edad 
escolar que no asista a la escuela. Capacidad de subsistencia: Hogares que tuvieran 4 o más personas por miembro ocupado y, además, cuyo jefe tuviera baja educación.

Fuente: INDEC, Anuario Estadístico de la República Argentina 2002 - 2003

\section{Trayectos de Artes Profesionales}

Los TAP se implementan en los Polimodales de Comunicación, Arte y Diseño y se formulan sobre la base de acuerdos para la formación básica de capacidades previas al ingreso a carreras docentes y técnicas profesionales de Arte en: Música, Danza, Teatro y Artes Visuales de Institutos Terciarios de la Dirección de Educación Artística. Garantizan a su vez, la salida laboral desde el nivel medio. La carga horaria es de horas-reloj semanales. Al igual que los TTP, la estructura modular presenta dos clases de módulos: Módulos Polimodalizados: insertos en espacios institucionales de la estructura curricular del Nivel Polimodal, con el que articula el TTP a cargo de un solo docente. Módulo fuera de la estructura curricular del Nivel Polimodal, se organizan en áreas modulares y se articulan con el Nivel Polimodal, definiendo el recorrido formativo del técnico en el Nivel Medio, logrado esto con los contenidos específicos de la modalidad, la incorporación de módulos del trayecto en espacios institucionales y el desarrollo de módulos trimestrales caracterizados por prácticas intensas extendidas a lo largo de todo el recorrido formativo.

Fuente: Resolución N 4625/98 y 1238 del 25 de marzo de 1999, Dirección de Información y Planeamiento Educativo Dirección General de Cultura y Educación. Provincia de Buenos Aires.

\section{Trayectos Preprofesionales}

Son propuestas pedagógicas a desarrollarse en el $8^{\circ}$ y $9^{\circ}$ años de la EGB y se definen como propuestas de formación que brindan al alumno saberes instrumentales para promover condiciones de empleabilidad y orienten en la elaboración de criterios adecuados para enfrentar las opciones del nivel de estudios siguiente. Se trata de una formación no específica de saberes prácticos para actuar en contextos concretos, no de aprendizajes de oficios. Los proyectos de éstas ofertas formarán parte de los Proyectos Educativos Institucionales (PEI) de cada unidad educativa articulada. Los TTP serán obligatorios para las escuelas de la EGB que articulan el $8^{\circ}$ y $9^{\circ}$ año con las Escuelas Técnicas, Agrarias y Polimodales de Arte.

Fuente: Resoluciones $N^{\circ} 5682, N^{\circ} 5683, N^{\circ} 5684$ del 31/10/96, Dirección Nacional de Información y Evaluación de la Calidad Educativa .Dirección General de Cultura y Educación. Provincia de Buenos Aires.

\section{Trayectos Técnicos Profesionales (TTP)}

Son ofertas educativas complementarias dirigidas a un campo profesional determinado, para lo cual se requiere la dominación de competencias profesionales que se aplicarán en el desempeño del trabajo real. Junto con la Educación Polimodal los TTP constituyen una unidad pedagógicodidáctica, integrada en tres años de duración y de carácter obligatorio para aquellos estudiantes que opten por cursar el Nivel Medio/ Polimodal en instituciones que tengan dicha oferta. En ellas, los alumnos reciben, además del título de base de la orientación polimodal cursada, una o más certificaciones técnicas.Con la Resolución N 4625/98 se inició su implementación en forma gradual y progresiva en la Provincia de Bs.As. Los mismos tienen el objetivo de formar Técnicos de nivel medio. La Resolución №1237 del 25 de marzo de 1999 propone el diseño curricular que articula la Educación Polimodal y los TTP. El perfil profesional que se considera 
surge de las necesidades y demandas del sector productivo. Se busca formar técnicos con capacidades polivalentes y adaptabilidad a distintas situaciones laborales y posibles cambios, con inserción laboral en el sistema productivo de su zona de referencia, real o potencial; para ello las instituciones educativas orientan la formación hacia sectores productivos específicos que posean relevancia en el entorno de la comunidad regional o local. La estructura curricular de los TTP es modular, la cual constituye una unidad que organiza el proceso de enseñanzaaprendizaje con objetivos formativos evaluables. Los contenidos y estrategias de enseñanzaaprendizaje están seleccionados y organizados para la formación de determinadas competencias profesionales, integrando la formación teórica y práctica. Es una unidad autónoma de acreditación de aprendizajes. Se desarrolla en distintos entornos y de diferentes modalidades: aula, laboratorio, aula-taller, pasantías, visitas, etc., involucrando diversas actividades formativas como son: resolución de situaciones problemáticas, estudio de casos, proyectos productivos, simulaciones, trabajos de campo, etc. Esta estructura modular presenta dos clases de módulos: Módulos Polimodalizados: insertos en espacios institucionales de la estructura curricular del Nivel Polimodal, con el que articula el TTP, a cargo de un solo docente. Módulos fuera de la estructura curricular del Nivel Polimodal: posibilitan el trabajo por equipos docentes; no tienen correlación horizontal. Tanto los Módulos Polimodalizados como los Módulos fuera de la estructura curricular del Nivel Polimodal, se organizan en áreas modulares y se articulan con el Nivel Polimodal, definiendo el recorrido formativo del Técnico en el Nivel Medio, logrado esto con los contenidos específicos de la modalidad, la incorporación de módulos del Trayecto en espacios institucionales y el desarrollo de módulos trimestrales caracterizados por prácticas intensas extendidas a lo largo de todo el recorrido formativo.

Fuente: Resoluciones N 4625/98 y 1237/99. Dirección de Información y Planeamiento Educativo Dirección General de Cultura y Educación. Provincia de Buenos Aires.

\section{Turno de funcionamiento}

Es la parte del día en la cual funciona una sección de un establecimiento. Los turnos pueden ser: mañana, tarde, intermedio, vespertino, noche o doble. Los establecimientos desarrollan sus actividades en uno o más turnos. En el caso en que un establecimiento desarrolle actividades para un mismo grupo escolar en el turno mañana y en el turno tarde.

Fuente: Dirección Nacional de Información y Evaluación de la Calidad Educativa. Red Federal de Información Educativa. Ministerio de Educación, Ciencia y Tecnología-Dirección Provincial de Planeamiento-Dirección de Información y Estadística. Dirección General de Cultura y Educación. Provincia de Buenos Aires.

\section{Tutor}

Representante legítimo, es decir con autoridad conferida por la ley, que se encarga de cuidar de la persona y bienes del menor, cuando ambos padres sean incapaces, estén privados de la patria potestad o suspendidos en su ejercicio.

Fuente: Código Civil- Art. 377, 264, 411. Dirección Provincial de Planeamiento-Dirección de Información y Estadística. Dirección General de Cultura y Educación. Provincia de Buenos Aires. 


\section{REFERENCIAS BIBLIOGRÁFICAS}

\section{Libros y artículos}

-Ander-Egg, Ezequiel, La planificación educativa. Conceptos, métodos, estrategias y técnicas para educadores. Magisterio del Río de La Plata. Argentina.1996.

- Aproximaciones a la planificación de procesos comunicacionales, Buenos Aires, Mimeo, abril de 2001.

- Aquilano, Roberto, “Jóvenes, ciencia y tecnología”, en revista Anales de la Educación común, Tercer siglo, año 1, números 1-2 "Adolescencia y juventud”. Publicación de la DGcyE, septiembre de 2005.

- Arteton, Perina, Estrategias de comunicación para gobiernos, La crujía. Buenos Aires, 2009.

- Bávaro, Punta Cana, República Dominicana, 29 al 31 de enero de 2003, en http://www.itu.int/ wsis/docs/rc/bavaro/eclac-es.pdf, sitio consultado octubre 2009.

- Bevilacqua, Liliana, "Planificación y formulación de políticas educativas", Monografía Acerca del Sistema Educativo de la Provincia de Buenos Aires. Argentina, 2001, en http://abc.gov.ar/ lainstitucion/organismos/planeamiento/pdf\%20documentos/monografia.PDF.

- Bolívar, A. (1999), La educación no es un mercado. Crítica de la "Gestión de Calidad Total". Aula deinnovación educativa.

- Borsotti, Carlos A. Temas de metodología de la investigación en ciencias empíricas. Moño y Dávila Editores. Buenos Aires. 2007.

- Botero Montoya, luis Horacio, "Comunicación política y democracia: un cruce de caminos. Comunicación pública, revista Cuartillas, Publicación del Círculo de Periodistas y Comunicadores Sociales de Antioquia -CIPA, № 15, diciembre 2007, pag. 36.

- Cassin, Bárbara, Googléame. La segunda misión de los Estados Unidos, Fondo de Cultura Económica, Buenos Aires, 2008.

- Castells, Manuel, "Internet y la Sociedad Red", revista La Factoría, Febrero - Septiembre de $2001 \cdot n^{\circ} 14$ - 15, en http://www.revistalafactoria.eu/articulo.php?id=185, sitio consultado octubre 2009.

- Castells, Manuel, La era de la información. Tomo I, Economía, Sociedad y Cultura, en http: //aquevedo.wordpress.com/manuel-castells-la-era-de-la-informacion-tomo-i-economia-sociedady-cultura/, sitio consultado en octubre 2009.

- Ceraso, Cecilia, Redes de Desarrollo Local y Colectivos de Comunicación en el Territorio, Tesis de Maestría en Planificación y Gestión de Procesos Comunicacionales, Dir. Larrañaga, Nancy, La Plata, octubre de 2008. 
- Couffignal, Georges, "El papel del Estado en un mundo globalizado: el caso de América Latina. Democracia y Neoliberalismo." Vol 13. $\mathrm{N}^{\mathrm{a}}$ 1- Institut des Hautes Études de l'Amérique Latine - Paris. 2002.

- De Diego, José Luis, "Políticas editoriales y políticas de lectura", revista Anales de la educación común, Tercer siglo, año 3, número 6, Educación y lenguajes, julio de 2007, Publicación de la Dirección General de Cultura y Educación de la Provincia de Buenos Aires.

- Decibe, Susana, "Editorial” y "Informática y educación” en Zona educativa Nª 20, Ministerio de Educación, Buenos Aires, marzo de 1998.

- Delleuze, Pilles, "Posdata sobre las sociedades de control", en http://www.uam.es/ra/sin/ pensamiento/deleuze/postdata.htm, sitio consultado octubre 2009.

Dirección de Información y Planeamiento Educativo." Dirección General de Cultura y Educación. Provincia de Buenos Aires, en Informe Ejecutivo de la Institucionalización de los Programas Cédula / Mapa Escolar. Dirección de Información y Planeamiento Educativo. Dirección General de Cultura y Educación. Provincia de Buenos Aires.

- Durán Barba, Jaime, "Estrategias de comunicación política", en Izurieta, Arteton, Perina, Estrategias de comunicación para gobiernos, La crujía, Buenos Aires, 2009.

- Eco, Umberto. Cómo se hace una tesis, Gedisa. Barcelona. 2002.

- Elíades, Analía, "Hacia una Ley de Servicios de Comunicación Audiovisual. Una batalla política y cultural", Ponencia en Proyecto de Ley de Servicios de Comunicación Audiovisual. Audiencia pública. En www.diputados.gov.ar.

- Empson, L. (1999, October 8). The challenge of managing knowledge. The Financial Times Mastering Series: Mastering Strategy.

- Filmus, Daniel, "Breves reflexiones sobre la escuela del futuro y presentación de la experiencia 'Aulas en red' de la Ciudad de Buenos Aires.", en Filmus et al, Educación y nuevas tecnologías. Experiencias en América latna, IIPE-UNESCO, Buenos Aires, 2003.

- Focault, Michelle, Las palabras y las cosas, Siglo XXI, Buenos Aires, 1968.

- Freire, Paulo, Pedagogía del oprimido, Siglo xxI, Uruguay, 2005.

- Fulcanelli, El misterio de las catedrales, Debolsillo, Barcelona, 2002.

- García Canclini, Néstor, Consumidores y ciudadanos, Conflictos multiculturales de la globalización, Grijalbo, México, 1995.

- Ghea, María Elisa, Documento Plan de trabajo - Dirección de Comunicación y Prensa (DGCyE), 2005-2007, s/e.

- Ghea, María Elisa, Rogovsky, Cintia, “Capítulo xxiI Comunicación y prensa para la educación” en Puiggrós, Adriana, et al, Cartas a los educadores de siglo XXI. Galerna. Buenos Aires, 2007.

- Giordano, Carlos, Romera, Elvira, Cap. XX “Publicar para todos, conectar a todos", en Puiggrós, Adriana, et al, Cartas a los educadores de siglo XXI, Galerna. Buenos Aires, 2007.

- Giroux, Henry, "El neoliberalismo y la crisis de la democracia”, revista Anales de la educación común, Tercer siglo, Año 1, números 1-2, septiembre 2005, publicación de la DGcyE de la provincia de Buenos Aires.

- Giroux, Henry, "Más allá del sentido común neoliberal: políticas culturales y pedagogía pública en tiempos oscuros", en http://www.adrianapuiggros.com.ar/ver_recomendados.php?id=67, sitio consultado octubre 2009.

- GonzÁlez Gaviola Mónica, (Directora), “Informe Final 2001. Programa De Relevamiento de Matrícula para La Cédula Escolar" Dirección de Información y Estadística Enero 2002, en http:// abc.gov.ar/escuelas/consultas/cedulaescolar/informes/i_final.PDF, sitio consultado octubre 2009.

- HIEKKILA, ERIC J.: GIS is dead, Long live GIS, APA journal, Summer 1998. 
- Hirschiein, R. y Klein, H., "Paradigmatic Influences of Information Systems Development Methodologies : Evolution and Conceptual Advances", en Advances in Computers \# 34, 1992.

- Izurieta Cánova, Roberto, "La comunicación política en la era del entretenimiento", en IzURIeta, Arteton, Perina. Estrategias de comunicación para gobiernos, La crujía. Buenos Aires, 2009.

- Kaufman, Ester (Coord.), Políticas públicas y tecnologías. Líneas de acción para América Latina, La Crujía, Buenos Aires, 2007.

- Kossoy, Alicia, "La escolaridad de los jóvenes de sectores populares: tiempos de desafío", en www.crisolps.org.ar/.../11La_escolaridad_sectores_populares.doc, consultado en octubre 2009.

- LASH, ScotT, "De las representaciones a los medios. La contradicción de la representación", conferencia, en http://www.exargentina.org/_txt/krise_slash_representationmedia_es.html.

- LASH, Scott, Crítica de la Información, Amorrortu, Buenos Aires, 2005.

- "Los caminos hacia una sociedad de la información en América Latina y el Caribe", Conferencia Ministerial Regional Preparatoria de América Latina y el Caribe para la Cumbre Mundial sobre la Sociedad de la Información.

- Martín Barbero, Jesús, De los medios a las mediaciones, Bogotá, Convenio Andrés Bello, 2003, $351 \mathrm{p}$.

- Martin, María Victoria, Planificación en Comunicación: Tres Aproximaciones a su Finalidad en las Organizaciones, en Razón y Palabra. Revista Electrónica. www.razonypalabra.org.mx/.../n55/ mmartin.html

- Morley, David, "Pertenencias, lugar, espacio e identidad" en Arfuch, Leonor (compiladora) Pensar este tiempo. Espacios, afectos, pertenencias, Paidós, Buenos Aires, 2005.

- Mouffe, Chantal, En torno a lo político, Fondo de cultura económica, Buenos Aires, 2007.

- Noguera, Felipe, la campaña permanente, en Izurieta, Arteton, Perina, Ibidem.

- Orozco Gómez, Guillermo, La Investigación en Comunicación desde la Perspectiva Cualitativa., Ediciones de Periodismo y Comunicación. FPyCS.UNLP, La Plata, Mayo 1996.

- Ortiz, Renato, Mundialización y Cultura, Alianza Editorial, Buenos Aires, 1997.

- Palamidessi, Mariano (comp.) Galarza, Daniel, Landau, Mariana, Schneider, Débora "La escuela en la sociedad de Redes. Una introducción a las TIC en la educación, s/d.

- Pérez Serrano, G., Elaboración de proyectos sociales. Casos prácticos, Madrid, Ed. Narcea, 1993.

- Piñuel Raigada, José Luís, Teoría de la comunicación y gestión de las organizaciones, Ed. Síntesis, Madrid, 1997.

- Piovani, Verónica, Eliades, Analia, "Internet y Sociedad de la Información. La concepción política-social y económica de Internet en Argentina y su expresión jurídico institucional", en http: //s3.amazonaws.com/lcp/alaic-internet/myfiles/Veronica\%20Piovani\%20y\%20Aanalia\%20Eliades \%20\%28Argentina\%29.pdf, sitio consultado en octubre 2009 .

- Porat, Marc, The Information Economy: Definition and Measurement, Washington. DC, Departamento de Comercio de Estados Unidos, Oficina de Telecomunicaciones, 1977.

- Prieto Castillo, D., Planificación de la comunicación institucional, San Salvador, mimeo, Universidad Centroamericana José Simeón Cañas, 1993.

- Puiggrós, Adriana y Gagliano, Rafael (Dirección): La fábrica del conocimiento. Los saberes socialmente productivos en América Latina, Ediciones Homo Sapiens, Rosario, 2004.

- Puiggrós, Adriana, "Liberar la comunicación" en diario Página/12, 09 de setiembre de 2009, http: //www.pagina12.com.ar/diario/elpais/subnotas/131460-42342-2009-09-09.html, en http://www.adri anapuiggros.com.ar/ver_noticias.php?id=518.

- Puiggrós, Adriana, "Principales cambios curriculares en el sistema educativo provincial", Editorial 
revista Anales de la educación común, Filosofía política del currículum, Publicación de la Dirección General de Cultura y Educación de la provincia de Buenos Aires, Tercer siglo, año 2, número 4, agosto 2006, en http://abc.gov.ar/lainstitucion/revistacomponents/revista/default.cfm?ldP=5\&page $=$ Editorial\&IdArticulo=193, sitio consultado en octubre 2009.

- Puiggrós, Adriana, et al, Cartas a los educadores de siglo XXI. Galerna. Buenos Aires. 2007.

- Puiggrós, Adriana, Fundamentación del proyecto de Ley de Educación provincial. s/publicar.

- Puiggrós, Adriana,(Dir.), Rodríguez, Lidia (Coord.) Saberes: reflexiones, experiencias y debates, Galerna, Buenos Aires, 2009.

- Puiggrós, Adriana, La tremenda sugestión de pensar que no es posible. Luchas por una democracia educativa (1995-2010), Galerna, Buenos Aires, 2010.

-S. GVIRTZ. y L. MAnolakis, (inédito) Algunas propuestas para mejorar la calidad y equidad en el Sistema Educativo de América Latina a partir del uso de las NTICs.

- SAintout, Florencia, "Descubrir una comunicación: En búsqueda de las huellas", en Esteinon, Javier, revista Espacios de comunicación, Nro. 3, 1999, México.

- Sanguinetti, Luciano, "Sociedad de la Información: las Políticas Públicas en el ámbito educativo de la provincia de Buenos Aires.", Programa "Comunicación y Sociedad de la Información".FPy CS., UNLP-Facultad de Periodismo y Comunicación Social.

- Scheinsohn, Daniel. Comunicación estratégica. Granica. Buenos Aires. 2009.

- Schmucler, Héctor, "Apuntes sobre el tecnologismo y la voluntad de no querer", en revista Artefacto. Pensamiento sobre la técnica, Artículo publicado en Artefacto/1, 1996, www.revistaartefacto.com.ar, sitio consultado en octubre 2009.

- Shiefelbein, Ernesto: En Busca del Eslabón más Débil: Mejorar la Estadística Educativa, en: Boletín 46, OREALC, Santiago, 1998.

- Slagle, Mike, "GIS in Community based School Planning: A Tool to Enhace Decision Making Cooperation, and Democratization in the Planning Processs", en: Stein \& Schools Lecture Series, Policy, Planning and Design for a 21 st Public education System, Ithaca, NY, March 2, 2000.

- Svampa, Maristella, La sociedad excluyente, la Argentina bajo el signo del neoliberalismo, Taurus, Buenos Aires, 2005.

- Tedesco, Juan Carlos, "Las TICs y la desigualdad educativa en América Latina", en http: //www.ritla.net/index.php?option=com_docman\&task=doc_view\&gid=96, sitio consultado octubre 2009.

- Thorn, Christopher A.,"Knowledge Management for Educational Information Systems: What Is the State of the Field?", EDUCATION POLICY ANALYSIS ARCHIVES. Volume 9, Number 47, November 19, 2001.

- URAnga, W. y BRUno, D., Itinerarios, razones e incertidumbres en la planificación de la comunicación.

- Vega, Hannia, "La comunicación de gobierno e Internet", en IzUrieta, Arteton, Perina, Ibidem.

- Velazco, Alicia, La gestión de las organizaciones educativas. Universidad Jesuita de Guadalajara. portal.iteso.mx/portal/page/.../20\%20Alicia\%20Velasco.pdf, sitio consultado octubre 2009.

- Velazco, Alicia. La gestión de las organizaciones educativas. Portal.iteso.mx/portal/page/.../20 \%20Alicia\%20Velasco.pdf, www.crefal.edu.mx/Biblioteca/.../tiv4.htm, sitio consultado en octubre 2009.

\section{Informes y documentos}


http://www.scribd.com/doc/21140111/1er-Jornada-de-Debate-MENyP-24-8-09, sitio consultado en octubre 2009.

- "Estadística educativa" en Revista Anales de la educación común, publicación de la DGCyE, Tercer siglo, año 1, números 1-2, septiembre 2005.

- "Indicadores educativos, comparación de 13 países latinoamericanos y Provincia de Buenos Aires.", Dirección de Información y Estadística, Dirección Provincial de Planeamiento, Dirección General de Cultura y Educación, provincia de Buenos Aires. Período 2006/2007.

- "Informe Ejecutivo de la Institucionalización de los Programas Cédula / Mapa Escolar." Dirección de Información y Planeamiento Educativo. Dirección General de Cultura y Educación, provincia de Buenos Aires.

- "Informe Legislatura 2005/2006, DGCyE", en http://abc.gov.ar/lainstitucion/noticiasdeladgcye/ v072/default2.cfm?id=591

- "Institucionalización de Cédula Escolar y Mapa Escolar en el Sistema de Información

- "La escuela en la sociedad en red, Internet en el ámbito educativo no universitario", investigación de la Universidad Abierta de Cataluña, en http://www.uoc.edu/in3/pic/esp/pdf/PIC_Escoles_ esp.pdf, sitio consultado octubre 2009.

- "La formación de recursos humanos para la gestión educativa en América Latina." Informe del foro realizado en el IIPE- Instituto Internacional de Planeamiento de la Educación, Unesco, 1999.

- "La sociedad de la información en América Latina y el Caribe: Desarrollo de las tecnologías y tecnologías para el desarrollo", Santiago de Chile, CEPAL, 2008.

- Ley 26.206/06, de Educación Nacional.

- Ley de Educación Provincial N¹3.688/07.

- "Los caminos hacia una sociedad de la información en América Latina y el Caribe.", CEPAL, documento elaborado en el marco de la Conferencia Ministerial Regional Preparatoria de América Latina y el Caribe (Bávaro, Punta Cana, República Dominicana, 29 al 31 de enero de 2003), 78 páginas.

- "Marco General de Política Curricular, DGCYE", aprobado por Resolución N³655/07 de la Directora General de Cultura y Educación de la provincia de Buenos Aires, Adriana Puiggrós, en 2007.

- "MEMORIA/BALANCE GESTION 2006-07, DIRECCIÓN GENERAL DE CULTURA Y EDUCACIÓN.

- "Relevamiento Anual 2004", Dirección Nacional de Información y Evaluación de la Calidad Educativa (DiNIECE ).

\section{Sitios en Internet}

- Sitio de Mapa Escolar en el portal de la DGCyE de la provincia de Buenos Aires, en http://mapa escolar.ed.gba.gov.ar/examples/servlets/pr18/mapa\%20escolar/instructivos/introduccion.htm.

- Dirección Provincial de Planeamiento-Dirección de Información y Estadística DGCyE. http: //abc.gov.ar/. 


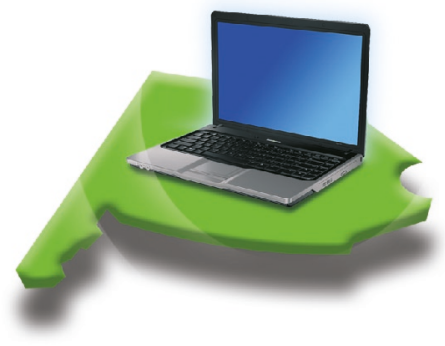

